\title{
Interactions Between Sponges and Macroalgae on Temperate Rocky Reefs
}

\author{
by
}

César A. Cárdenas

\author{
A thesis submitted to \\ Victoria University of Wellington \\ in fulfilment of the requirements for the degree of \\ Doctor of Philosophy in Marine Biology
}

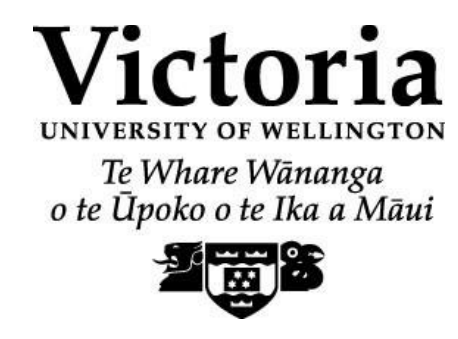



This thesis was conducted under the supervision of:

\author{
Dr. James J. Bell (Primary Supervisor) \\ Victoria University of Wellington \\ Wellington, New Zealand \\ and \\ Dr. Simon K. Davy (Co-Supervisor) \\ Victoria University of Wellington \\ Wellington, New Zealand
}


This thesis is dedicated to the memory of my sister Pamela (1974-2009) 


\section{Acknowledgments}

I would like to express my most sincere gratitude to all those people who helped and supported me throughout the duration of this journey called $\mathrm{PhD}$. First, I would like to thank my primary supervisor Dr James Bell, for his advise and guidance during this long trip $(\mathrm{PhD})$. Thanks for your patience, support and encouragement, especially when things were looking more and more difficult due to the constant challenging conditions of the Cook Strait. I am also thankful to my co-supervisor Dr Simon Davy for his constant support and critical comments with writing and lab-related matters. I also express my gratitude to Dr Mike Taylor (UoA) for his support and help with the microbial-related analyses and also for his help on the interpretation of my data. I had a great time working at Auckland Uni. Thanks to the Taylor Lab, especial thanks to Mike Hoggard, Anna Lau, David Waite and Georg Steinert for their patience with this newby.

This thesis was possible with the financial support from CONICYT-VUW PhD Scholarship, VUW Submission Scholarship, the Tertiary Education Council (TEC) and a VUW Faculty Research Grant (202305). Research within the Taputeranga Marine Reserve (Chapter 5) was conducted under the permit DocDM816684 granted by The Department of Conservation. Many thanks to the First Overseas Conference Travel Fund by the New Zealand Marine Sciences Society.

I would like to thank to all the skippers and divers for the immense help and support during diving activities during these years. Fieldwork would have been impossible without your help battling the challenging conditions of the Wellington south coast. I am also grateful to John van der Sman and Daniel McNaughtan (Snout), Stephen Journee and Don Nelson for their help with lab and field related aspects of my projects. Thanks also to Patricia Stein, Mary, Sandra and Paul for the great advice throughout this time.

Special thanks to all the amazing people who have been part of the great VUCEL, Jeff Shima, Nicole Phillips, John van der Sman, Daniel McNaugthan, Shane Geange, Danelle Lekan, Paul Mensink, Tim Jones, Daniela Diaz-Guisado, Sergio 
Carrasco, Jenny Oliver, Sonja Miller, Alejandra Perea, Abi Powell, Jade Berman, Jamie Tam, Ian Geeson, Alix LaFerriere, Ale Perez Matus, Tyler Eddy, Phil Neubauer, Bionda Morelissen, Erasmo Macaya, Gareth Williams, Ingrid Knapp, Rachel Clausing, Tracey Bates, Agnes Rouchon, Fernanda Piraud, Ursula Rojas, Mauricio Cifuentes, Jeannine Fischer, Dana Morton, Mark Kaemingk and Steve Journee. Thank you all for your friendship, you guys made this experience even greater that it was supposed to be. Gracias de el Presidente!!! Thanks also to VUW and especially to VUCEL for providing such and amazing place to work, the absolutely awesome view from my desk was very important inspiring me throughout this long journey!

I am grateful to my great friends and partners in crime at VUCEL, Shane, Danelle and Paul. Thanks for your support, help, friendship, smiles, etc. Without you guys everything would have been difficult, and for sure, it wouldnâ have been fun. Shane, thanks bro for you massive help with fieldwork and stats, and for those tons of rock and roll, rugby and of course, science. Danelle, thanks for your help ( \& chocolates), those trips to Pukerua Bay in all sorts of conditions really helped us to create such a great and lasting friendship. This one is for you too!, D. Paul, thanks for being Paul, such a great character, man we got this, I think we made it! I would also like to thank Tim Jones for always been keen to provide assistance with stats, and all sorts of informatics issues, Brain you are a legend! Thanks to Emma and Carlos (and the Newcombe family) for their friendship and support, especially during the early stages of the NZ chapter. Gracias poh!.

I wish to thank my parents Tirzo and Irma for their never-ending support and encouragement. Thanks for believing in me! Thanks also to my mother in law Jacqueline and the Ojeda-Rabanal-Primo family for their support. Gracias familia en Chile.

Finally, special thanks to the love of my life, my wife Anita. Thanks for your tremendous and invaluable support throughout the years. We knew this adventure was not going to be easy and without your support it would have been impossible to finish my $\mathrm{PhD}$. Your never-ending support was vital, especially during those tough days 
were everything was going wrong at the lab. Gracias mi amor and I hope you are ready for our next adventure, which I think it is going to be even more challenging. 



\begin{abstract}
Changes in the distributions of organisms not only alter community composition and food web structure, but also can initiate important changes at the ecosystem level. Understanding the interactions between biotic and abiotic factors affecting speciesô distribution patterns in temperate habitats is important for predicting responses to future environmental change. Sponges are important members of temperate rocky reefs assemblages that are influenced by a number of abiotic factors including water movement, light regime, inclination and stability of the substratum, as well as complex ecological interactions.
\end{abstract}

The aim of this thesis was to investigate the interactions between sponges and macroalgae on shallow-water rocky reefs of Wellington, New Zealand, assessing if the distribution patterns of sponges are independent of algal populations. I used a combination of surveys, and manipulative field and laboratory experiments to explore the existence of interactions (positive or negative) between sponges and macroalgae and also to explore the effect of environmental factors on the distribution and abundance of temperate sponges. My first objective was to determine if the spatial distribution patterns of sponges are independent of macroalgae distribution and abundance at different sites on the Wellington south coast (Chapter 2). The results showed that abundance of most sponge species were strongly correlated with inclination, which supports previous studies in the northern hemisphere suggesting that sponge abundance and algal abundance are negatively correlated. In contrast, only a few sponge species were positively correlated with algal abundance. I then explored the positive interactions occurring between some sponges species and the presence of canopy-forming algae (Chapter 3). Results from this chapter suggest the canopy of Ecklonia radiata facilitates the existence of some sponge species such as Crella incrustans on vertical rocky walls. The removal of Ecklonia canopy led to a community dominated by turf algae, which corresponded with a decrease in sponge abundance and richness. My results suggest that the Ecklonia canopy facilitates the presence of some sponge species and allows their coexistence with turf algae underneath the canopy and also by altering immediate physical factors that may be detrimental for some sponge species. To further explore the existence of sponges and 
understory algae, I used an experimental approach (Chapter 4) to investigate the effect of the brown alga Zonaria turneriana on Leucetta sp. and also mechanisms involved in the interactions. However results from this chapter provided no evidence to support previous hypotheses that understory algae negatively affect sponges. In the last data chapter (Chapter 5), I studied sponges inhabiting different habitats in order to test if environmental variation affects the abundance and diversity of microorganisms, hence having the potential to affect the distribution and abundance of these species The stability observed in bacterial communities among specimens occupying different habitats suggests that environmental variation occurring in those habitats does not affect the stability of the community, and hence most likely does not radically alter the metabolism of these sponges. Although environmental factors such as light and sediment may have an effect on early sponge stages, other environmental (e.g. nutrients, temperature, wave action) and biotic factors, are more likely to influence the growth, survival and distribution of sponges on temperate rocky reefs.

In summary, temperate sponge assemblages are strongly influenced by interactions between a number of abiotic and biotic factors. The outcomes of the ecological interactions are controlled by environment (e.g. influence of inclination on competition between sponges and understory algae) and at the same time, biological interactions (e.g. facilitation) can moderate the influence of abiotic factors such as light, sedimentation and wave action, thus facilitating the coexistence between sponge and macroalgae underneath the Ecklonia canopy. My thesis makes a significant contribution to our knowledge of temperate subtidal ecology, in terms of the effects of biotic and abiotic factors on sponge assemblages and also improves our knowledge of temperate patterns of sponge and macroalgal interactions. Finally, my thesis highlights the importance of small-scale environmental variation in influencing the structure and diversity of sponge assemblages and also increase our understanding of temperate rocky reefs sponges, especially on the less studied sponge assemblages occurring in Ecklonia stands on vertical rocky walls. 
Table of Contents

Acknowledgments............................................................................................ vii

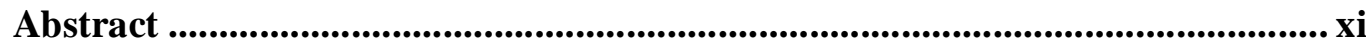

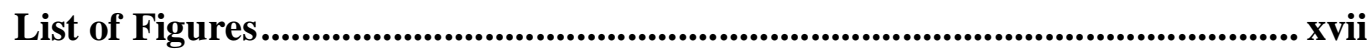

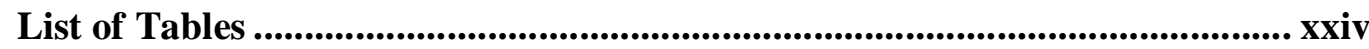

Contributions and Publications .................................................................... 27

Chapter 1. General introduction................................................................. 29

1.1. Factors affecting sponge distribution patterns .......................................... 29

1.2. Sponge interactions with other organisms .......................................................... 33

1.3. Sponge-microbe associations .................................................................................... 34

1.4. Associations between sponges and macroalgae ................................................. 35

1.5. Interactions between sponges and macroalgae............................................. 37

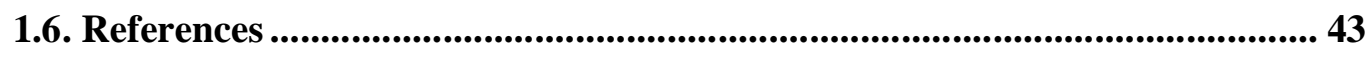

Chapter 2: Distribution patterns and spatial associations between sponges and

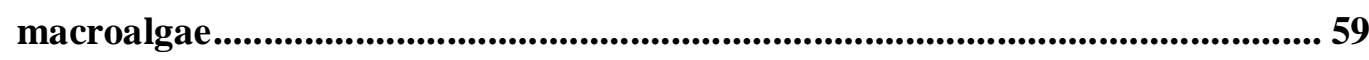

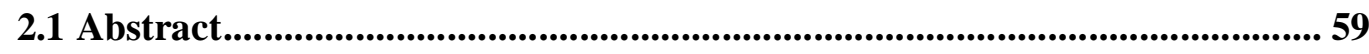

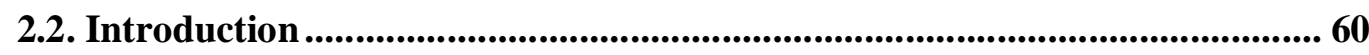

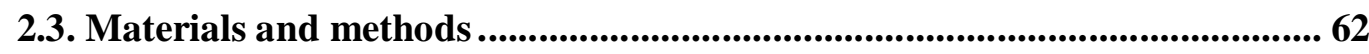

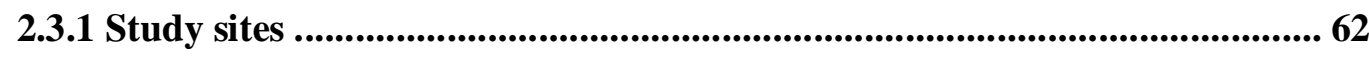

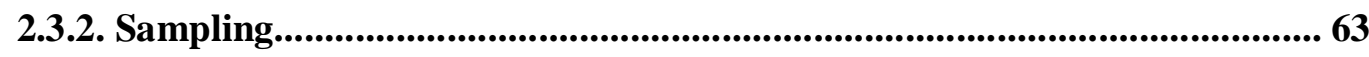

2.3.3. Data analysis .........................................................................................65 65

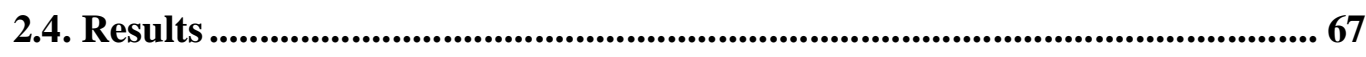

2.4.1. Species richness of sponge assemblages ............................................ 67

2.4.2. Distribution patterns of benthic organisms ................................................... 70

2.4.3. Relationship between algal abundance, environmental variables and benthic assemblages at different taxonomic levels ........................................... 77 
2.5.1. Interactions between sponges and macroalgae ........................................... 80

2.5.2. Effect of surface inclination and its associated factors on sponge assemblages......................................................................................................................... 81

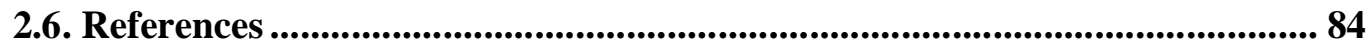

Chapter 3. Positive interactions between canopy-forming algae and sponges.... 91

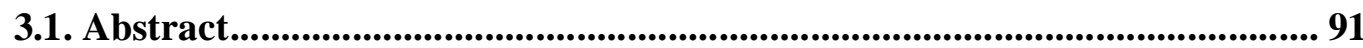

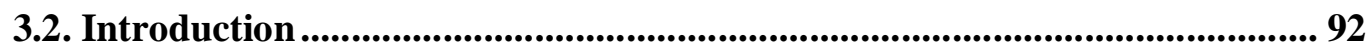

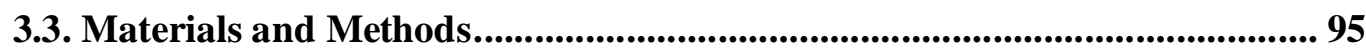

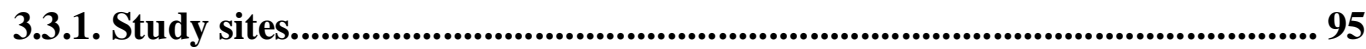

3.3.2. Experimental design and data analysis ................................................. 96

3.3.3. Effect of canopy removal on the structure of subcanopy assemblages...... 97

3.3.4. Factors driving changes in sponge assemblages after canopy removal ..... 99

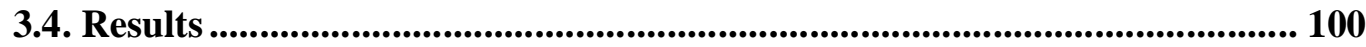

3.4.1. Effect of canopy removal on the structure of subcanopy assemblages.... 100

3.4.2. Effect of canopy removal on the structure of sponge assemblages ........... 100

3.4.3. Taxon specific responses to Ecklonia removal...................................... 111

3.4.4. Factors driving changes in sponge assemblages after canopy removal ... 117

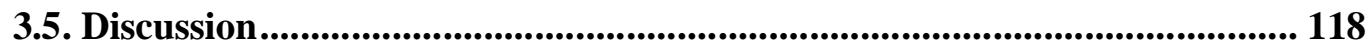

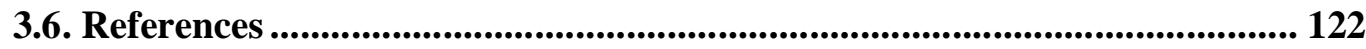

Chapter 4. Effect of the brown alga Zonaria turneriana on the growth and survival of the calcareous sponge Leucetta sp................................................. 131

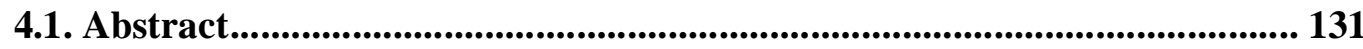

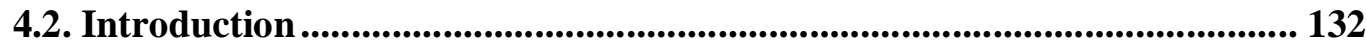

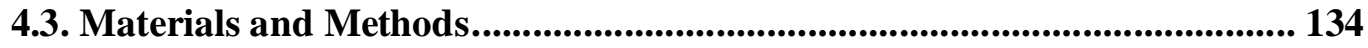

4.3.1. Collection and experimental design ................................................... 134

4.3.2. Data analysis ......................................................................................... 136 
4.4. Results

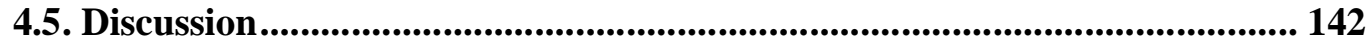

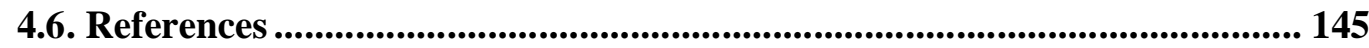

Chapter 5. Effect of environmental irradiance on sponges inhabiting shallowwater rocky reefs and its effect on microbial communities associated with sponges .......................................................................................................................... 151

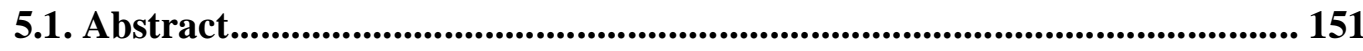

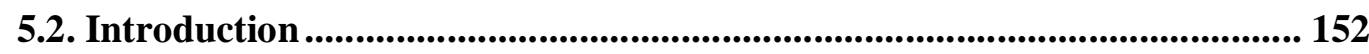

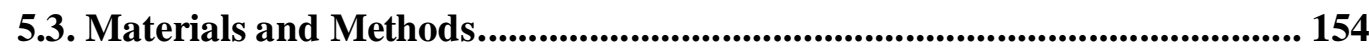

5.3.1. Sampling and experimental design .................................................... 154

5.3.2. DNA extraction ................................................................................ 155

5.3.3. PCR and pyrosequencing of $16 \mathrm{~S}$ rRNA genes ............................................ 156

5.3.4. Processing of raw sequence data ................................................................ 156

5.3.5. Analysis of high quality sequence data .................................................... 157

5.3.6. Sponge growth ............................................................................................ 158

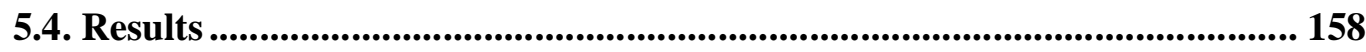

5.4.1.Sponge growth ............................................................................................. 158

5.4.2. Effect of experimental treatment on bacterial community structure ...... 160

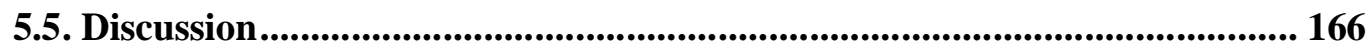

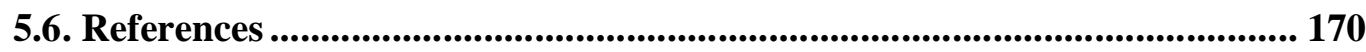

Chapter 6. General discussion ......................................................................... 177

6.1. Factors affecting diversity and abundance of sponge assemblages............. 178

6.1.1. Abiotic factors ................................................................................ 178

6.1.2. Biotic factors: interactions with macroalgae .............................................. 179

6.2. The role of grazers ................................................................................................ 181

6.3. Influence of abiotic factors on sponge-associated bacteria and their role on temperate rocky reefs.......................................................................................................... 183 
6.4. Conceptual model of sponge ecology on temperate rocky reefs................... 184

6.5. Further research of sponge assemblages on temperate rocky reefs............. 188

6.6. Concluding remarks ........................................................................................ 189

6.7. References ............................................................................................................. 189

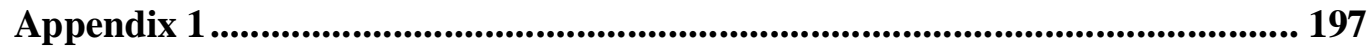

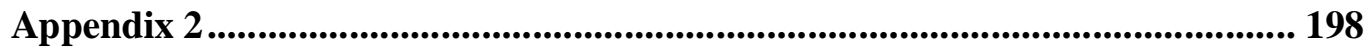

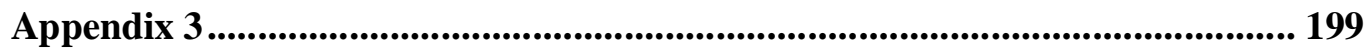

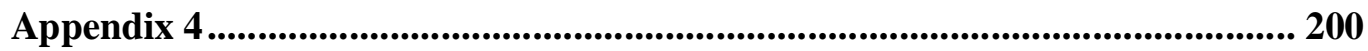

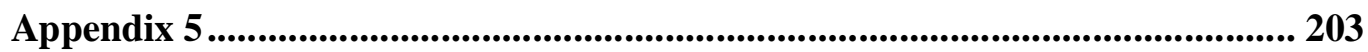

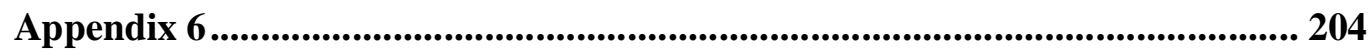

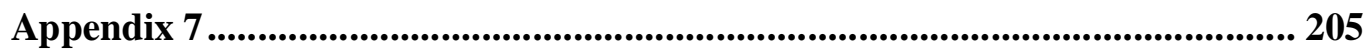

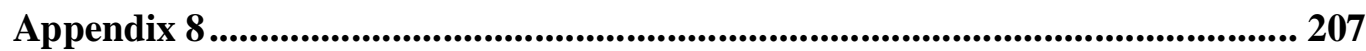

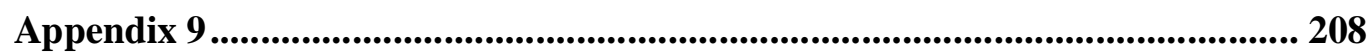

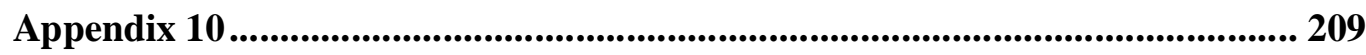

Appendix 11 ...................................................................................................................... 212

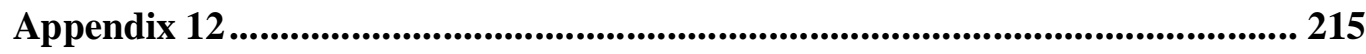

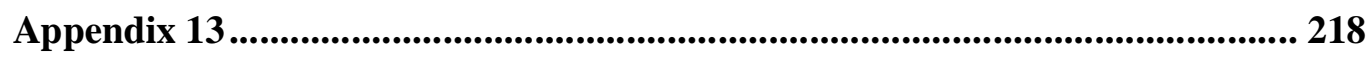

Appendix 14 .................................................................................................... 230 


\section{List of Figures}

Figure 2.1. A) Location of study sites on the south coast of Wellington; B) Locations of study sites at Kapiti Island, New Zealand. 1. Breaker Bay; 2. Barrett Reef; 3. Palmer Head; 4. Princess Bay; 5. The Sirens Rocks; 6. Trig Point; 7. Kaiwharawhara Point

Figure 2.2. a) Mean species richness of sponges recorded at different sites; b) Mean species richness recorded for surface inclinations. $\mathrm{BB}=$ Breaker $\mathrm{Bay} ; \mathrm{BR}=$ Barrett Reef; PH = Palmer Head; PB = Princess Bay; SR = The Sirens Rocks; $\mathrm{KP}=$ Kaiwharawhara Point; TP $=$ Trig Point. Percentage cover values of each sample were pooled for each site and surface inclination (Error bars represent S.E.). 69

Figure 2.3. Differences in mean species richness of sponges recorded for different sites (a) and inclinations (b). Pairwise comparisons for sites showed significant differences between BR-BB, KP-BB, PB-BB, PH-PB, SR-BB, KP-BR, TP-BR, PB-KP, TP-PB $(P<0.05)$. For abbreviations see figure 2.2. $\mathrm{H}=$ horizontal; $\mathrm{I}=$ inclined; $\mathrm{V}=$ vertical; $\mathrm{O}=$ overhanging. Significant differences were found in all comparisons between inclinations, except for vertical vs inclined $(P>0.05) \ldots 69$

Figure 2.4. Mean percentage cover of sponges and macroalgae across sites studied on the south coast of Wellington and at Kapiti Island. PB = Princess Bay; SR = The Sirens Rocks; BR = Barrett Reef; PH = Palmer Head; BB = Breaker Bay; KP = Kaiwharawhara Point; TP $=$ Trig Point. 71

Figure 2.5. Mean percentage cover of sponges across sites studied on the south coast of Wellington and at Kapiti Island. PB = Princess Bay; SR = The Sirens Rocks; $\mathrm{BR}=$ Barrett Reef PH = Palmer Head; $\mathrm{BB}=$ Breaker Bay; $\mathrm{KP}=$ Kaiwharawhara Point; TP $=$ Trig Point. Percentage cover values for each sample were pooled for each surface inclination (Error bars represent S.E.). 71

Figure 2.6. Relationship between mean percentage cover of sponges and macroalgae for different surface inclinations. Percentage cover values for each sample were pooled for each surface inclination (Error bars represent S.E.) 74 
Figure 2.7. Mean percentage cover of canopy across sites studied on the south coast of Wellington and at Kapiti Island. For abbreviations see figure 2.2. Percent cover values for each sample were pooled for each surface inclination (Error bars

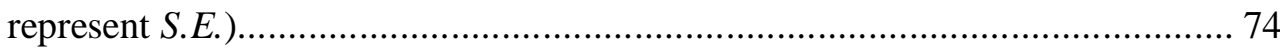

Figure 2.8. Examples of photoquadrats showing the different assemblages on different surface inclinations A) horizontal; B) inclined; C) vertical; D) overhanging.... 75

Figure 2.9. a) Relationship between percentage cover of sponges and canopy $(y=$ $\left.35.2678 * \exp ^{-0.0296 x}, \mathrm{r}^{2}=0.546, P<0.001\right)$; b) Relationship between percentage cover of sponges and macroalgae per quadrat $\left(\mathrm{y}=35.3829 * \exp ^{-0.0799 x}, \mathrm{r}^{2}=0.387\right.$, $P<0.001)$. c). Relationship between percentage cover of sponges and crustose coralline algae $(\mathrm{CCA})$ per quadrat $\left(\mathrm{y}=\exp ^{0.0415 \mathrm{x}}, \mathrm{r}^{2}=0.004, P<0.001\right)$. Scale for $\mathrm{X}$-axis differs between panels. 76

Figure 2.10. a) Ordination plot of the overall community and variables based on a redundancy analysis (RDA-biplot); b) Ordination plot of sponge assemblages, and variables based on a redundancy analysis (RDA-biplot). Vectors represent the environmental variables and species are represented as circles. Inclinat $=$ inclination. See Appendix 3 for taxon names. 79

Figure 3.1. Ordination plots (nMDS) showing the effect of Ecklonia radiata on the understory at Breaker Bay. Lines represent trajectory of understory change at an individual plot though time. Ordination based on Bray-Curtis similarity matrices fourth root-transformed percentage cover data of species, with centroids as treatment averages. $\mathrm{P}=$ removal plot, $\mathrm{C}=$ control. 101

Figure 3.2. Ordination plots (nMDS) showing the effect of Ecklonia radiata on the understory at Palmer Head. Lines represent trajectory of understory change at an individual plot though time. Ordination based on Bray-Curtis similarity matrices fourth root-transformed percentage cover data of species, with centroids as treatment averages. $\mathrm{P}=$ removal plot, $\mathrm{C}=$ control. 102

Figure 3.3. Ordination plots (nMDS) showing the effect of Ecklonia radiata on sponge assemblages at Breaker Bay. Lines represent trajectory of understory change at an individual plot though time. Ordination based on Bray-Curtis 
similarity matrices fourth root-transformed percentage cover data of species, with centroids as treatment averages. $\mathrm{P}=$ removal plot, $\mathrm{C}=$ control. 103

Figure 3.4. Ordination plots (nMDS) showing the effect of Ecklonia radiata on sponge assemblages at Palmer Head. Lines represent trajectory of understory change at an individual plot though time. Ordination based on Bray-Curtis similarity matrices fourth root-transformed percentage cover data of species, with centroids as treatment averages. $\mathrm{P}=$ removal plot, $\mathrm{C}=$ control. 104

Figure 3.5. Differences in mean sponge species richness between control and removal treatments through time in response to canopy removal, at (left) Breaker Bay and (right) Palmer Head. Each panel shows the effect of canopy removal at an individual plot. Error bars represent $95 \%$ confidence intervals. Dotted lines indicate initial differences $(t=0)$ between control and removal. See methods for further explanation. 105

Figure 3.6. Effect of removal of Ecklonia radiata on: (a, b) mean sponge species richness; and (c, d) mean percentage cover of sponges, at Breaker Bay and Palmer Head. Values are means $( \pm$ S.E.) of five quadrats on each experimental plot. $* P<0.05, * * P<0.001$ 106

Figure 3.7. Differences in mean sponge abundance between control and removal treatments through time in response to canopy removal, at (left) Breaker Bay and (right) Palmer Head. Each panel shows the effect of canopy removal at an individual plot. Error bars represent $95 \%$ confidence intervals. Dotted lines indicate initial differences $(t=0)$ between control and removal. See methods for further explanation 107

Figure 3.8. Responses of: (a, b) Crella incrustans; (c, d) Cliona sp; (e) Haliclona sp; and (f) Strongylacidon conulosa, to removal of Ecklonia radiata at Breaker Bay and Palmer Head. Values are means ( \pm S.E.) of five quadrats on each experimental plot. $* P<0.05$, $* * P<0.001$. Note: scale for $\mathrm{Y}$-axis differs between panels 110

Figure 3.9. Responses of: (a, b) red algae; (c, d) ECA; (e, f) Zonaria turneriana; and $(\mathrm{g}, \mathrm{h})$ other brown algae, to removal of Ecklonia radiata at Breaker Bay and 
Palmer Head. Values are means $( \pm$ S.E.) of five quadrats on each experimental plot. $* P<0.05, * * P<0.001$ 114

Figure 3.10. Mean percentage cover of sediment at: (a) Breaker Bay and (b) Palmer Head in response to removal of Ecklonia radiata. Values are means ( \pm S.E.) of five quadrats on each experimental plot. $* P<0.05$, $* * P<0.001$. 116

Figure 4.1. Schematic diagram of the experimental treatments showing manipulation control (Leucetta sp. without algae and mimics); algal mimic (clear; Leucetta sp. with clear mimics); algal mimic (black; Leucetta sp. with black mimics), and algal (Zonaria) treatment (Leucetta sp. with Zonaria). 137

Figure 4.2. Relative light intensity levels recorded in each treatment. $\mathrm{C}=$ control; $\mathrm{MB}$ $=$ algal mimic (black); MT = algal mimic (clear); Algae = algal treatment (Zonaria). Error bars indicate $1 \mathrm{SE}$. 138

Figure 4.3. Relative changes in growth of Leucetta sp. after four weeks. C= control; A $=$ algal treatment $($ Zonaria $) ; \mathrm{MB}=$ algal mimic (black) MT = algal mimic (clear). The horizontal line in the box interior represents the median and the doted line represents the mean.

Figure 4.4. Relative changes in (a) length, (b) width, and (c) height of Leucetta sp. after four weeks. $\mathrm{C}=$ control; $\mathrm{A}=$ algal treatment $($ Zonaria $) ; \mathrm{MB}=$ algal mimic (black); MT = algal mimic (clear). The horizontal line in the box interior represents the median and the doted line represents the mean 141

Figure 4.5. Mean values $( \pm$ SE) of directional growth of Leucetta sp. for treatments after four weeks. $\mathrm{C}=$ control; $\mathrm{A}=$ algal treatment $($ Zonaria $) ; \mathrm{MB}=$ algal mimic (black); MT = algal mimic (clear).

Figure 5.1. a) Ecionemia alata and b) Tethya bergquistae explants at the beginning (left) and end (right) of the experiment after 6 weeks. In both cases photos correspond to explants transplanted from low- to high-light habitats. 159

Figure 5.2. Bacterial diversity observed in (a) Ecionemia alata and (b) Tethya bergquistae samples, when transplanted between different habitats. $\mathrm{CH}=$ control high-light, $\mathrm{CL}=$ control low-light, $\mathrm{HL}=$ high- to low-light transplantation, $\mathrm{LH}=$ 
low- to highï light transplantation. Note: scale for Y-axis differs between panels. 160

Figure 5.3. Relative abundance of bacterial phyla in (a) Ecionemia alata and (b) Tethya bergquistae samples, when transplanted between different habitats. ECH $=E$. alata control high-light, $\mathrm{ECL}=E$. alata control low-light, $\mathrm{ETHL}=E$. alata samples transplanted from high- to low-light, ETLH $=E$. alata samples transplanted from low- to high-light, $\mathrm{TCH}=T$. bergquistae control high-light, $\mathrm{CL}$ $=T$. bergquistae control low-light, $\mathrm{TTHL}=T$. bergquistae samples transplanted from high- to low-light, TTLH $=T$. bergquistae samples transplanted from lowto high-light. Number (1-6) in sample code refers to replicate number of samples recovered at the end of the experiment. SAUL $=$ sponge-associated unidentified lineage. 162

Figure 5.4. Heat map representing the abundance of the 25 most abundant OTUs in Ecionemia alata and Tethya bergquistae, when transplanted between different habitats. Values represent the percentage of all sequence reads for a given sample. See Figure 5.3 for abbreviations. 164

Figure 5.5. Non-metric multidimensional scaling (nMDS) to examine differences in bacterial community structure between species and experimental treatments. (a) Relative abundance of OTUs based on Yue and Clayton distance matrix and (b) presence-absence data based on a Jaccard-based distance matrix. $\mathrm{R} \mathrm{sq}(\mathrm{a})=0.985$, $R \mathrm{sq}_{(\mathrm{b})}=0.829$. See Figure 5.3 for abbreviations 166

Figure 6.1. Schematic of the effects of Ecklonia canopy on sponge assemblages on open reefs habitats (vertical walls). Solid lines are direct interactions and dashed lines are indirect interactions. (+) Indicates positive effect; (ï) indicates a negative effect; (?) = effect unknown or unstudied. Canopy indirectly affects sponges (a) by reducing algal abundance (b) and allows the coexistence of both groups (c). In contrast when canopy is absent, the abundance of understory algae (d), due to increased irradiance, may result in sponges being outcompeted by algae (e). Direct negative interactions (e.g. effects of sweeping fronds) between canopy and sponges were not addressed in this study and remain unclear (f). Algal canopies limit algal recruitment (g). In contrast, when absent, increased light levels positively affect recruitment and growth of understory algae (h). 
Urchins, even at low densities, can modify the structure of the understory as they are capable of removing sponges, algae and other organisms, thus creating free space available for other species. However, their role seems to be highly variable in space and time being driven by factors that remain unknown. Wave action also influences the interactions occurring between canopy and sponge assemblages. Ecklonia canopy is also important as it limits its own recruitment. Depending on its growth and density it will have a direct effect on light availability for the understory, thus affecting algal and sponge recruitment and growth as well as the structure of the assemblage. Furthermore, wave action is responsible of plant removal, which creates gaps that can be used for new recruits that will take advantage of these new gaps. 182

Figure 6.2. Schematic showing the relationships between abiotic and biotic factors influencing temperate sponge assemblages. Grey lines represent effects of abiotic factors (associated with gradients). Solid lines are direct effects and dashed lines are indirect effects. (+) Indicates positive effect; (ï ) indicates a negative effect; $(?)=$ unclear. Inclination is probably the most important factor affecting sponge assemblages on temperate rocky reefs. Factors such as sediment and light are directly influenced by inclination and depth (a,b,c,d) and thus, they indirectly affect sponge and algal abundance by altering abiotic factors (light and sediment) $(\mathrm{e}, \mathrm{f}, \mathrm{g}, \mathrm{h})$. Inclination also affects settlement of sponges by affecting the amount of light and sediment reaching the substrate. While sediment is detrimental for most sponge species (i), the direct role of light on adult sponges remain unclear (j), however, it may have a negative effect on sponge recruits. The effect of macroalgae is variable and is highly dependent on abiotic factors (e.g. inclination, light) (h, k). Understory algae negatively affect most sponge species in habitats with high irradiance (1). Algal canopy positively affects only some sponge species (m), and when present indirectly facilitates sponge abundance, by reducing algal abundance (n). Grazing by urchins can also play an important role structuring sponge assemblages by removing sponges and other organisms thus creating free space available for other species. The effect of grazing by urchins is heavily influence by inclination (q). Storms (wave action) can influence the structure of sponge assemblages and also the interactions occurring between canopy and sponges (o, p). Storms (wave action) are responsible of plant 
removal, which creates gaps that can be used for new recruits that will take advantage of these new gaps (p). Biological disturbance produced by urchin grazing and therefore the defensive strategies of sponge species (e.g. physical or chemical) may also play a key role on open reefs (r), however the effect of grazing and the strategies of prey sponges was not studied on this thesis....... 185

Figure 6.3. Conceptual model showing the relationships between abiotic and biotic factors influencing temperate sponge assemblages. Panels show different scenarios influenced by surface inclination $($ top $=$ horizontal/inclined, middle $=$ vertical, bottom $=$ overhanging). Grey lines represent effects of abiotic factors (associated with gradients). Solid lines are direct effects and dashed lines are indirect effects. (+) Indicates positive effect; (ï) indicates a negative effect; (?) = unclear. Line thickness represent the strength of the interaction. Note that in the bottom panel white arrows represent the absence of an effect produced by urchins and sediment. See Figure 6.2 for further explanation on interactions described by letters 187 


\section{List of Tables}

Table 2.1. Mean values ( \pm SE) for the physical parameters of the water column measured at each study site on south coast of Wellington and at Kapiti Island. 68

Table 2.2. Permutational analysis of variance (PERMANOVA) based on a BrayCurtis similarity matrix, testing the effect of region ( 2 levels, random), site (5 levels, random), depth (2 levels, fixed) and inclination (4 levels, fixed) on species/taxa richness. Statistical differences were tested using 9,999 permutations under a reduced model. Significance is indicated by asterisks: $* P<$ 0.05 .

Table 2.3. PERMANOVA to test for differences between sites, depths and inclinations in the percentage cover of dominant benthic groups. Statistical differences were tested using 9,999 permutations of raw dada. Significance is indicated by asterisks: $* P<0.05, * * P<0.001$

Table 2.4. Permutational analysis of variance (PERMANOVA) based on a BrayCurtis similarity matrix, testing the effect of region ( 2 levels, random), site (5 levels, random), depth (2 levels, fixed) and inclination (4 levels, fixed) on the overall community. Statistical differences were tested using 9,999 permutations under a reduced model. Significance is indicated by asterisks: $* P<0.05$, $* * P<$ 0.001 . 73

Table 2.5. Summary results of the redundancy analysis for the overall community on the south coast of Wellington and at Kapiti Island 78

Table 2.6. Summary results of the redundancy analysis for sponge assemblages on the south coast of Wellington and at Kapiti Island. 78

Table 3.1. Sponge taxa contributing to $50 \%$ of the observed differences in sponge assemblages between treatments, as determined by SIMPER. $P$-values correspond to PERMANOVA results testing the effect of treatment on the percentage cover of dominant sponge taxa $(\mathrm{Tr}=$ treatment, $\mathrm{Ti}=$ time, $\mathrm{Tr} \times \mathrm{Ti}=$ interaction). Statistical differences were tested using 9,999 permutations of raw data. Significant $P$-values are in bold $(P<0.05)$ 109 
Table 3.2. Sponge taxa contributing to $50 \%$ of the observed differences in sponge assemblages between treatments, as determined by SIMPER. PERMANOVA analyses to test the effect of canopy removal were based on Euclidean distances using 9,999 permutations of the raw data. ${ }^{*} P<0.05$, $* * P<0.001$, NS $=$ non significant.

Table 3.3. Subcanopy taxa contributing to $50 \%$ of observed differences in subcanopy assemblage structure between treatments, as determined by SIMPER. $P$-values correspond to PERMANOVA results testing the effect of treatment on the percentage cover of dominant taxa $(\operatorname{Tr}=$ treatment, $\mathrm{Ti}=$ time, $\operatorname{Tr} \times \mathrm{Ti}=$ interaction). Statistical differences were tested using 9,999 permutations of raw data. Significant $P$-values are in bold $(P<0.05)$.

Table 3.4. Subcanopy taxa contributing to $50 \%$ of observed differences in subcanopy assemblage structure between treatments, as determined by SIMPER. PERMANOVA analyses to test the effect of canopy removal were based on Euclidean distances using 9,999 permutations of raw data. $* P<0.05$, ** $P<$ $0.001, \mathrm{NS}=$ non significant 115

Table 3.5. Results of distance-based permutational multivariate multiple regression analyses (DistLM) for associations between the decrease in sponge abundance after canopy removal and predictor variables. Model selection was based on models with lowest modified Akaikeôs Information Criterion (AICc) for each response variable. All tests were based on 9,999 permutations. 117

Table 4.1. Mean values ( \pm S.E.) for the morphological parameters (length, width and height) of Leucetta sp. measured at the beginning $\left(\mathrm{T}_{0}\right)$ and at the end $\left(\mathrm{T}_{\mathrm{F}}\right)$ of the experiment. $\mathrm{Tr}=$ treatment; $\mathrm{C}=$ control; $\mathrm{A}=$ algal treatment $($ Zonaria $) ; \mathrm{MB}=$ algal mimic (black); MT = algal mimic (clear). 140

Table 4.2. PERMANOVA results testing the effect of time (Ti) and treatment (Tr) on the shape (length, width and height) of Leucetta sp. Statistical differences were tested using 9,999 permutations. Significance is indicated by asterisk: $* P<0.05$. 140

Table 5.1. Bacterial diversity (Sobs) and Chao1 estimates based on 16S rRNA gene pyrosequencing derived from Ecionemia alata and Tethya bergquistae samples. 
$\mathrm{ECH}=E$. alata control high-light, $\mathrm{ECL}=E$. alata control low-light, $\mathrm{ETHL}=E$. alata samples transplanted from high- to low-light, ETLH $=E$. alata samples transplanted from low- to high-light, $\mathrm{TCH}=T$. bergquistae control high-light, $\mathrm{TCL}=T$. bergquistae control low-light, TTHL $=T$. bergquistae samples transplanted from high- to low-light, TTLH $=T$. bergquistae samples transplanted from low- to high-light..................................................... 161 


\section{Contributions and Publications}

The data chapters that make up this thesis are based on a series of manuscripts that are in the review process or shortly to be submitted for publication.

\section{Chapter 2}

Study design: C.A.C with guidance from Dr. James Bell and Dr. Simon K. Davy

Data collection: C.A.C

Analyses: C.A.C

Writing and editing: C.A.C with editing by Dr. James Bell and Dr. Simon K. Davy

Publication: Cárdenas CA, Davy SK \& Bell JJ (2012) Correlations between algal abundance, environmental variables and sponge distribution patterns on southern hemisphere temperate rocky reefs. Aquatic Biology 16: 229-239.

\section{Chapter 3}

Study design: C.A.C with guidance from Dr. James Bell and Dr. Simon K. Davy

Data collection: C.A.C

Analyses: Analyses were carried out by the author except for the R code that was written in R by Timothy Jones

Writing and editing: Author with editing by Dr. James Bell

Publication: Cárdenas CA, Davy SK \& Bell JJ (submitted) Influence of canopyforming algae on temperate sponge assemblages Submitted to the Journal of the Marine Biological Association of the United Kingdom

\section{Chapter 4}

Study design: C.A.C with guidance from Dr. James Bell and Dr. Simon K. Davy

Data collection: C.A.C

Analyses: C.A.C

Writing and editing: C.A.C with editing by Dr. James Bell 


\section{Chapter 5}

Study design: C.A.C with guidance from Dr. James Bell, Dr. Simon K. Davy and Dr. Michael Taylor. The University of Auckland (UoA).

Data collection: C.A.C

Laboratory analyses: C.A.C with Michael Hoggard

Analyses: C.A.C with the guidance of Dr. Michael Taylor (UoA)

Writing and editing: C.A.C and Dr. M. Taylor with editing by Dr. James Bell and Dr. S. Davy

Publication: Influence of environmental variation on symbiotic bacterial communities of two temperate sponges. FEMS Microbiology Ecology 88: 516-527. 


\section{Chapter 1. General introduction}

Subtidal rocky reefs are important and productive marine environments. They usually support complex and highly diverse communities as a result of habitat diversity and complexity (Dayton 1985a, Sebens 1985, Schiel \& Hickford 2001). Sponges are ubiquitous components on rocky reef communities throughout the world (Dayton et al. 1974, Ayling 1983a, Barthel et al. 1991, Bell \& Barnes 2000e, Teixidó 2003, Bell 2008). Although sponges represent the most simple and primitive multicellular animals, their ecological success and efficiency in nutrient assimilation are quite remarkable (De Vos et al. 1991).

Bell (2008) reviewed all identified functional roles of sponges throughout tropical, temperate and polar ecosystems. Functional roles of sponges include: impacts on substrate resulting in bioerosion, reef creation, stabilization, consolidation and regeneration; bentho-pelagic coupling and their importance in carbon, silicon and nitrogen cycling and oxygen depletion; and their high diversity of associations with other organisms. Furthermore, recent studies have shown the importance of sponges at ecosystem level and their impact in the availability of compounds they take, transform and release (Maldonado et al. 2011, 2012, de Goeij et al. 2013).

\subsection{Factors affecting sponge distribution patterns}

Sponge distribution patterns are thought to be influenced by a number of physical and biological factors (Wilkinson \& Evans 1989). Physical factors include depth, light/shade, Ultra Violet (UV) radiation, temperature, salinity, sedimentation, and water flow rate (Battershill 1987, Wilkinson \& Evans 1989, Riisgard et al. 1993, Witman \& Grange 1998, Glasby 1999, Ginn et al. 2000, Bell 2002, Duckworth et al. 2004, Konar \& Iken 2005).

\section{Light}

Although depth is an important factor influencing sponge distribution (Wilkinson \& Trott 1985, Diaz et al. 1990a, Witman \& Sebens 1990, Duckworth et al. 2004, Cleary et al. 2005, Knapp \& Bell 2010b), its influence is more likely to be related to other 
physical factors associated with increased in depth such as light and the degree of disturbance (from wave action) (Wilkinson \& Evans 1989). Light intensity is considered to be an important factor structuring shallow-water benthic communities across different latitudes. A number of studies have considered the effect of light on sponge assemblages with respect to light reduction with depth, reduced light in cryptic habitats (Wilkinson \& Vacelet 1979, Uriz et al. 1992), the presence of the algal canopy (Kennelly 1989), and artificial structures (Glasby 1999). For example, Wilkinson and Vacelet (1979) found that sponge assemblages were negatively correlated with light, where reduced light levels occurred at deeper depths and in cryptic habitats (e.g. walls and ceilings). Furthermore, Uriz et al. (1992) suggested that light indirectly influences sponge diversity in a Mediterranean sublittoral community, as light affected algal growth, and the algae competed with sponges for space. Turon et al. (1998) reported differential growth and mortality rates among the same sponge species (Crambe crambe) living in well-illuminated, compared to shaded vertical walls. These authors found that sponge survival was greater in shaded habitats, but they grew more slowly than specimens living in well-illuminated habitats. Based on these results they suggested the existence of a trade-off between defence and growth rate. Thus, sponges living in shaded habitats (where space is a limiting resource) might grow slower than those living in high light habitats, because of the greater investment in defence. In contrast, sponge specimens living in highlight habitats might show an opportunistic strategy, investing more energy in regeneration and growth, since the habitat is dominated by fast-growing algae, with patches of bare substratum becoming available frequently. Glasby (1999) studied the effect of artificial structures on sessile organisms and found a tendency of increasing sponge cover in shaded areas. However, in other sponge species, an increase in shade has been considered detrimental to growth and has a negative effect on the reproductive status and concentration of symbiotic algae (Roberts et al. 2006a).

High light intensity and UV radiation can affect growth and have dramatic effects on sponges that are not protected by cyanobacteria in very shallow waters, resulting in death or tissue damage (Jokiel 1980). Cyanobacteria are effective at screening out UV radiation, and as symbionts they may protect sponges by providing a sunscreen, allowing them to grow in shallow water where irradiance is high (Usher 2008). Wilkinson and Vacelet (1979) demonstrated that the growth of sponges 
containing symbiotic cyanobacteria was enhanced by light, whereas species without cyanobacteria were inhibited by light and grew preferentially in shaded habitats. More recently, Thacker (2005) experimentally demonstrated that some cyanobacteriacontaining sponges are more heavily impacted by shade than others. His results showed that species containing cyanobacterial symbionts lost over $30 \%$ of their dry mass after being shaded for two weeks, while other species did not lose weight, suggesting the existence of more specialized symbionts in some sponge species.

\section{Salinity}

Sponges are well known to have low tolerance to reduced salinity (Leamon \& Fell 1990, Fell 1993), however, they can be exposed to salinity changes in intertidal zones or where populations are located near estuaries or fjords, where there is freshwater input from run off or ice melting (see Witman \& Grange 1998, Barnes 1999). Witman and Grange (1998) found that sponge diversity and abundance decreased with reduced salinity, and recorded higher sponge abundance at depths below the shallow lowsalinity layer in New Zealand fjords. However, salinity decreases have also been shown to result in sponge mortality, for example, for the boring sponge Cliona celata (Hopkins 1962). Some experimental studies have demonstrated that decreased salinity is detrimental for the growth and reproductive activity of some species (Francis et al. 1982, Roberts et al. 2006c). Recently, Miller et al. (2010) did not find any significant losses in pigment concentrations in Cliona celata, suggesting that some sponge species are highly adapted to a wide range of salinities, however, further research on the effects of salinity on sponges is needed.

\section{Water flow and disturbance}

Water flow is known to affect sponge distribution in shallow waters (e.g. Leichter \& Witman 1997). Barnes (1999) suggested that increased water flow positively influences tropical sponge diversity and abundance in subtidal habitats, while Ginn et al. (2000) reported that current velocity influenced only the coverage of massive sponges. These authors recorded increased sponge cover with increasing current velocity, probably as a result of the lower sedimentation rates that result from increased current. However, Bell and Barnes (2000e) found that sponge diversity and richness decreased with higher flow rates due to an increase in disturbance, which enabled more delicate branching species with less basal area to become more 
abundant (Bell \& Barnes 2000e, Bell 2004). Furthermore, Duckworth et al. (2004) found that even though high water flow promoted sponge growth in individuals transplanted to sites with different water-flow levels, in other cases, individuals of Latrunculia wellingtonesis grew better at medium- and low-flow sites. A similar pattern was described previously by Leichter and Witman (1997). These authors found that increased water flow affected the distribution and growth of Haliclona panicea, suggesting that sponges may feed more efficiently at lower flow rates.

Shading and grazer-exclusion experiments have revealed that light, grazing, and topographic complexity are also important determinants of sponge distribution patterns and assemblage composition (Wilkinson \& Vacelet 1979, Jokiel 1980, Baynes 1999, Preciado \& Maldonado 2005). Wilkinson \& Evans (1989) explained the low abundance of sponges in the first $10 \mathrm{~m}$ of an Australian reef through waveinduced turbulence occurring in exposed, shallow-water habitats. However, some sponge species have physical adaptations, such as having sufficiently rigid or tough skeletons, to withstand strong water turbulence (Palumbi 1986).

\section{Sedimentation}

Sedimentation is another important factor affecting the spatial distribution patterns of sponges (Sarà \& Vacelet 1973, Wilkinson \& Vacelet 1979, Zea 1994b, Ilan \& Abelson 1995, Wulff 1997, Roberts et al. 1998, Bell \& Barnes 2000c, Roberts et al. 2006c), which may also explain the restriction of sponges to the undersides of boulders and to vertical or overhanging cliff surfaces, because these environments enable sponges to avoid high levels of silt accumulation (Konar \& Iken 2005, Preciado \& Maldonado 2005). Increased sedimentation has been shown to be detrimental to some sponge species (Gerrodette \& Flechsig 1979, Wulff 1997, Roberts et al. 2006c), for example by affecting pumping activity (Gerrodette \& Flechsig 1979), while other species may be sensitive to burial beneath sediment (Wulff 1997). Eckman and Duggins (1991) found that higher sedimentation rates existed beneath kelp canopies, but this did not result in higher mortality of Myxilla sp., however, they found that sediment deposition negatively affected its growth. Roberts et al. (1998) reported that the abundance of several sponge species decreased in response to increased siltation produced by sewage outfalls. The abundance of the sponge Cymbastela concentrica, a phototrophic species (Roberts et al. 1999), 
decreased three-fold after the installation of an outfall. Furthermore, Roberts et al. (2006c) experimentally demonstrated for the same species that increased siltation resulted in a reduction in growth and lower reproductive activity and it also affected the photosynthetic activity of its symbiotic microalgae. An increase in sedimentation may alter the symbiotic relationships by reducing the photosynthetic activity due to burial or by reducing the flow of water and nutrients. In contrast, other studies have reported sponge species that are well adapted to habitats with high sedimentation. Some species, such as Biemna ehrenbergi, is adapted to live sedimented habitats, being able to survive in these conditions due to its morphology and adaptive feeding behaviour (which include eventual consumption of its symbiotic bacteria) (Ilan \& Abelson 1995). Roberts et al. (1998) studied the effects of sedimentation produced by sewage discharges and found no significant differences in species richness and percentage cover of species. Bell and Barnes (2000e) reported higher sponge diversity in areas that experience higher rates of sedimentation, compared with areas experiencing lower sedimentation rates, and Bell et al. (2006) and Bell \& Smith (2004) also found rich sponge assemblages in shallow sedimented waters in Wales and Indonesia, respectively. Bell (2007) suggested that the general conception that sedimentation is a detrimental factor affecting sponges may be incorrect, since many species appear to be adapted to sedimented conditions (e.g. Bell 2004).

\subsection{Sponge interactions with other organisms}

Sponges interact in a variety of ways with other organisms including: being a food source; through symbiotic associations; and through inter and intraphyletic competition (Aerts 1998, Fagerstrom et al. 2000, Wulff 2000, Wulff 2006, Taylor et al. 2007, Wulff 2012). Sponges provide a microhabitat for many organisms, and can enhance predation protection and survival success, help with range expansions and camouflage, and providing substrate for settlement. They are also releasers of chemicals involved in spatial competition and defence mechanisms against other organisms (Bell 2008).

Sponges play an important role in providing microhabitat and refuge against predators for a high number of taxa (Wright et al. 1997, Bejarano-Chavarro et al. 2004, Huang et al. 2008, DôAloia et al. 2011). Several authors have described the 
macrofauna associated with different sponge species from tropical and temperate waters (Peattie \& Hoare 1981, Wendt et al. 1985, Voultsiadou-Koukoura et al. 1987, Duarte \& Nalesso 1996, Koukouras et al. 1996, Ribeiro et al. 2003, Abdo 2007, Fiore \& Cox-Jutte 2010, Hultgren \& Duffy 2010, Padua et al. 2013). In contrast, few papers have considered these relationships at high latitudes, with those available particularly focusing on the amphipod fauna associated with deep (Broyer et al. 2001, Lörz 2001) and shallow water sponges in Antarctica (Amsler et al. 2009). Recently, Schejter et al. (2012) described more than 23 taxa associated with the sponge Mycale (Aegogropila) magellanica in the south-western Atlantic Ocean.

\subsection{Sponge-microbe associations}

In recent years there has been considerable focus on the associations between sponges and microorganisms as sponges can host diverse and abundant microbial communities (Taylor et al. 2007, Hentschel et al. 2012, Thacker \& Freeman 2012, Webster \& Taylor 2012). In some cases symbionts can comprise up to $35 \%$ of the sponge volume (Taylor et al. 2007). Sponges are associated with a wide range of microorganisms including Acidobacteria, Bacteroidates, Chloroflexi, Cyanobacteria, Firmicutes, Proteobacteria (alpha-, beta-, gamma- and deltaproteobacteria) and Poribacteria (Webster \& Taylor 2012). Sponge hosts can benefit from microbial symbionts as the latter can provide supplemental nutrition (Wilkinson \& Fay 1979, Sarà et al. 1998) and secondary metabolites (Flatt et al. 2005, Schmidt 2008). Microbes can also enhance structural rigidity (Wilkinson et al. 1981), provide protection from UV radiation (Regoli et al. 2000, Usher 2008) and protection from, or deterrence of, predators (Pawlik et al. 1995, Thacker et al. 1998, Engel \& Pawlik 2000).

Experimental research on sponges containing photosymbionts has shown the complexity of sponge-microbe associations (reviewed by Thacker \& Freeman 2012). In fact, is still unclear whether the majority of sponge-microbe associations are commensal, mutualistic or parasitic (Simister et al. 2013). While in some cases sponge species appear to be extremely dependent on photosymbionts (obligate mutualism), others species seem to form obligate commensalism (Thacker 2005), commensalism (Thacker 2005, Erwin \& Thacker 2008, Freeman \& Thacker 2011) or facultative mutualisms (Wilkinson \& Vacelet 1979, Erwin \& Thacker 2008) with their photosymbionts. However, most of this research has been carried out in tropical 
latitudes, with far less knowledge on sponges occurring in temperate rocky reefs. In fact, much remains unknown about their relationships with the symbiotic communities they harbour, and specifically the role that these symbionts play in sponge physiology, feeding and adaptation to local environmental conditions.

Understanding the variability of microbial communities is a fundamental goal when examining any microbe-host association (Simister et al. 2013). However, the dynamics and stability of sponge-microbe interactions are still not well understood and considering the high degree of specificity and complexity of these associations, it is likely that the stability of microbial communities may be affected by changes in environmental conditions (Hentschel et al. 2006, Webster 2007, Simister et al. 2012a, Simister et al. 2013). Experimental research has tested the effect of different factors such as nutrients (Friedrich et al. 2001, Gerçe et al. 2009, Gochfeld et al. 2012), irradiance (Thoms et al. 2003, Thacker 2005, Gerçe et al. 2009), and temperature (Friedrich et al. 2001, Lemoine et al. 2007, Webster et al. 2008, Gerçe et al. 2009), as well as the effect of antibiotics (Friedrich et al. 2001) and heavy metals (Webster et al. 2001). However, results from these previous sponge studies have yielded contrasting results on the effect of environmental variability on microbial communities, perhaps because some sponges harbour more stable bacterial communities than others (Friedrich et al. 2001, Thoms et al. 2003, Lemoine et al. 2007, Webster et al. 2008, White et al. 2012, Simister et al. 2013).

\subsection{Associations between sponges and macroalgae}

Positive associations between sponges and macroalgae have been widely reported in the literature, however, the majority of these associations occur in tropical regions (e.g. Davy et al. 2002, Trautman et al. 2003) with only in few reports from temperate waters (Carballo \& Ávila 2004). Most commonly these associations represent symbiotic associations between sponges and red algae (Vacelet 1981, Scott et al. 1984, Palumbi 1985, Rützler 1990, Davy et al. 2002, Trautman et al. 2003, Carballo \& Ávila 2004, Enríquez et al. 2009). In most cases the relationship corresponds to a mutualistic association where the sponge provides resources to the algae (e.g. supplies of nitrogen via excretion) (see Davy et al. 2002), and the sponge benefits from being able to persist and colonize harsher habitats and being able to resist abrasion and 
water turbulence (Davy et al. 2002, Carballo \& Ávila 2004). In most cases, the mutualistic association is very specific and in many cases it is an obligatory relationship, where neither the sponge nor the algae occur independently or in association with other species (Trautman et al. 2003). In the case of Haliclona panicea and Corallina vancouveriensis, the sponge benefits from coralline algae as the latter provides protection from desiccation in the intertidal (Palumbi 1985). Other well-known positive associations described in the literature include those between sponges and brown algae, where the latter provides secondary substrate for settlement. However, most previous research has focused on the sponges that live associated mainly with algal holdfasts (Norton \& Benson 1983, but see Wright et al. 1997). Avila et al. (2010) explained the occurrence of sponges on holdfasts as a result of selective settlement by sponge larvae, which is based on results obtained by Maldonado and Uriz (1998), who demonstrated that sponge larvae are able to locate microhabitats to settle. Therefore, sponge larvae may prefer the increased level of complexity provided by the holdfast structure, providing habitat and shelter from predators and physical stress. However, it is possible that larvae have to deal with other factors, such as high sedimentation occurring beneath algal canopies and sediment entrapment produced by the structural complexity of holdfasts (Maldonado \& Uriz 1998); this increased sediment accumulation could be detrimental for the larval settlement of some sponge species (Kennelly 1989).

Sponges also have negative interactions with other organisms, since sponges are effective spatial competitors in most sublittoral and bathyl hard bottom communities (Maldonado \& Young 1998, Maldonado \& Uriz 1999, Barnes \& Kuklinski 2004). As an important member of rocky reef communities, sponges are often involved in competition for space and they are considered to be one of the top competitors in temperate reefs, mainly because of the absence of hermatypic (stony) corals (Maughan \& Barnes 2000b, Bell \& Barnes 2003b), which are the main sponge competitors on coral reefs. Competition between sponges and other organisms can be mediated by different mechanisms such as chemical defenses (Uriz et al. 1996, Pawlik 1997, McClintock et al. 2005, Ruzicka \& Gleason 2009) or other physiological and morphological adaptations, such as growth rates and morphologies (Jackson \& Buss 1975, Thoms \& Schupp 2007). 
Interactions between sponges and other organisms, especially corals, have been relatively well-documented in the literature (Jackson \& Buss 1975, Fell \& Lewandrowski 1981, Aerts \& van Soest 1997, Aerts 1998, Aerts 2000, River \& Edmunds 2001, Rützler 2002, de Voogd et al. 2004, López-Victoria et al. 2006, McLean \& Yoshioka 2008, Vermeij et al. 2010) and the coral community structure can have important effects on sponge diversity (de Voogd \& Cleary 2008). Sponges are considered successful competitors for space against corals (Aerts \& van Soest 1997). Some sponge species can overgrow neighbour corals or cause necrosis by releasing allelopathic chemicals (de Voogd et al. 2004). Aerts (2000) suggested that competition between both groups is complex, being highly dynamic where both competitors alternately lose and gain space and tissue depending on changes in local environmental conditions. Competitive ability also depends on the growth strategy (including growth rate, directional growth and form) displayed by sponge species (Becerro et al. 1994, Uriz et al. 1995, Aerts 2000, de Voogd \& Cleary 2008). For example, some encrusting sponges show fast area changes, while others form thick cushions on the substratum and can therefore increase their height, overgrowing neighbours (Aerts 2000).

\subsection{Interactions between sponges and macroalgae}

Although sponges are dominant in many habitats, under some circumstances they can be restricted to cryptic habitats, such as the undersides of boulders or shaded surfaces, when the boulder tops or areas of high light intensity are dominated by macroalgae (Baynes 1999, Irving \& Connell 2002, Konar \& Iken 2005). Macroalgae are an important group of benthic organisms competing for space with sponges in shallow temperate waters. Although, algae have been considered successful spatial competitors over sponges (see Wulff 2006, 2012), interactions and spatial competition between both groups are not clearly understood, and the reason why sponges are restricted to cryptic habitats in the presence of macroalgae and the nature of interactions between sponges and algae remains undetermined. Sponges, together with other encrusting invertebrates, such as ascidians, have been found to be competitively inferior to algae in high-light habitats, but competitively superior in shaded habitats (Baynes 1999, Konar \& Iken 2005). In fact, several authors have suggested that algae are able to out-compete sponges (Kaandorp \& de Kluijver 1992, 
Kennelly \& Underwood 1993, Turon et al. 1998, Bell \& Barnes 2000c, b, Ginn et al. 2000), although the mechanism remains unclear. Several authors have reported the existence of negative interactions or sponges being outcompeted by macroalgae. For example, Kaandorp and Kluijver (1992) reported the partial death of sponges due to the high occurrence of algae on their surface during spring and summer, whereas Turon et al. (1998) explained the high mortality of sponges observed in high-light habitats due to overgrowth by fast-growing algal species. Nevertheless, there is a paucity of experimental data to support hypotheses explaining the interactions between sponges and algae.

There have been numerous attempts to clarify the spatial relationships between sponges and algae. Bell and Barnes $(2000 \mathrm{e}, \mathrm{c})$ explained the higher diversity of sponges on vertical surfaces through reduced light intensity, compared with inclined surfaces, resulting in decreased algal populations. Bell $(2002,2007)$ explained the existence of such negative associations between sponges and algae by sponges only being able to persist in areas that are unsuitable or less suitable for algae or that sponges have adapted to these habitats that are less favourable for algae (i.e. low light). In this sense, Uriz et al. (1992) suggested that light was the main factor affecting sponge diversity in a Mediterranean community by affecting algal growth, resulting in competition with sponges for space. Konar and Iken (2005) identified the existence of micro-habitat differences among surface orientations with respect to differences in sediment and light, on different substrate inclinations.

Preciado and Maldonado (2005) studied negative association patterns between sponges and algae and suggested that other environmental factors, such as substratum inclination was the main force structuring sponge assemblages in shallow waters. Importantly, these authors suggested that sponge abundance and diversity is independent of algae and they probably occupy different habitats. Preciado and Maldonado based their conclusions on the absence of sponge species particularly associated with the presence/absence of macroalgae and the apparent absence of clear patterns in sponge distribution and abundance between suitable (high light) habitats and unsuitable algal habitats (walls and caves). They found sponges are mostly restricted to overhangs, where factors considered detrimental for sponges are reduced. In the south-east coast of Australia, Knott et al. (2004) found similar results, where no 
correlation was found between the abundance of macroalgae and sponges. However, results from these two studies appear to contrast with most other studies. For example, the high sponge diversity reported by Bell and Barnes (2000e) in areas of high sedimentation, supposedly unsuitable habitats for sponges, appears to contradict Maldonado and Preciadoôs conclusions. Recent research, however, suggests that the structure of sponge assemblages cannot be attributed solely to inclination (Knott et al. 2006, Laudien \& Orchard 2012); it may be affected by other associated factors such as light and sedimentation, which also affect algal assemblages. All these contrasting results illustrate the need for more research in order to clarify the interactions between sponges and macroalgae.

Studies on the relationship between sponges and invasive species belonging to the genus Caulerpa have recorded a decrease in diversity and coverage of sponges relative to an increase in the percentage cover of Caulerpa spp. (Davis et al. 1997, Baldacconi \& Corriero 2009, Guljevil et al. 2011). These macroalgae may cause changes in sponge assemblages by overgrowing species and causing sediment accumulation, generating a shift to a less diverse and more silt-tolerant assemblage (Knott et al. 2006). Recently, de Caralt and Cebrian (2013) reported how overgrowth by the invasive read alga Womersleyella setacea negatively affected gamete production of several sponge species in the northwestern Mediterranean. Nevertheless, there are some exceptions; according to Baldacconi and Corriero (2009) the Mediterranean species C. crambe is able to produce an anti-fouling toxin (Davis et al. 1997), which inhibits overgrowth by Caulerpa. Other exceptions reported in the literature include sponges that are able to outcompete macroalgae in eutrophic waters in the presence of high turbidity (Baldacconi \& Corriero 2009). Furthermore, Duckworth and Battershill (2001) found increased bioactivity in Latrunculia wellingtonensis during spring in New Zealand rocky reefs, suggesting that the increased bioactivity might prevent the settlement of algae and other organisms on its surface.

Studies examining the effect of the kelp canopy on sessile assemblages have reported contrasting results. For example, Kennelly (1987b, 1989) did not find any effect of shade or scour produced by Ecklonia radiata on the sponge Myxilla sp. in Australia. Eckman and Duggins (1991) found a similar trend with no effect on the 
growth of Myxilla sp. between kelp and non-kelp treatments on the coast of Washington State (U.S.). However, they reported an indirect effect from the canopy that negatively affected the growth of Myxilla. In contrast, Kennelly and Underwood (1993) suggested that understory algae prevented settlement and affected the abundance of some sponge species after removal of the E. radiata in temperate Australia. Furthermore, Fowler-Walker et al. (2005) reported the existence of negative correlations between sponge abundance and morphology of E. radiata.

Despite negative associations between sponges and filamentous or foliose algae having been commonly suggested (e.g. Kaandorp \& de Kluijver 1992, Turon et al. 1998), direct interactions have been rarely reported (Bell 2007). In fact, in the few cases where negative interactions have been explicitly recorded, it has been due to the presence of rapid-invasive species (Davis et al. 1997, Baldacconi \& Corriero 2009, Guljevil et al. 2011). Furthermore, Palumbi (1985) experimentally demonstrated that a coralline alga was able to out-compete the sponge Halichondria panicea in the absence of a common herbivorous chiton. Increased abundance of coralline and other algae eliminated sponges within the macroalgal canopy, while in the presence of chitons, a commensalism relationship was found between the sponge and the algae. These contrasting studies highlight the need for more research to clarify the existence of positive or negative associations and interactions between sponges and algae, testing potential factors that may be affecting the observed patterns.

Competition between algae and other organisms such as corals as been relatively well studied (Jenkins et al. 1999, Leonard 1999, River \& Edmunds 2001, Nugues \& Roberts 2003, Márquez \& Diaz 2005, Titlyanov et al. 2007). Nugues and Roberts (2003) suggested that macroalgae may out-compete corals, preventing coral recovery by their rapid colonization of the space newly opened due to sediment accumulation, and by suppressing settlement and growth of corals. Box and Mumby (2007), studying Caribbean corals, found a decrease in coral growth and a reduction of juvenile coral survivorship through interference competition with algae. Furthermore, the sweeping action of algal fronds over the substratum can affect recruitment of other organisms such as barnacles (Leonard 1999) and it is also considered to be a major source of mortality to settling cyprids (Jenkins et al. 1999). In contrast, Connell (2003b) suggested that sponges can tolerate physical abrasion 
under canopies due to their capacity to feed without projecting their filter feeding appendages outside their bodies. Nevertheless, these complex relationships have not been explicitly examined in sponges and further research is needed in order to understand the interactions existing between sponges and macroalgae and how these interactions influence sponge abundance and distribution patterns on temperate rocky reefs.

The aim of this thesis is to investigate the interactions between sponges and macroalgae in shallow-water rocky reefs of Wellington, New Zealand, assessing if the distribution patterns of sponges are independent of algal populations. I used a combination of surveys, and manipulative field and laboratory experiments to explore the existence of interactions (positive or negative) between sponges and macroalgae and also to explore the effect of environmental factors on the distribution and abundance of temperate sponges. The specific aims and objectives of my thesis were:

\section{Chapter 2: Distribution patterns and spatial associations between sponges and macroalgae}

1. Aim: To determine if the spatial distribution patterns of sponges are independent of macroalgae distribution and abundance at different sites on the Wellington south coast.

Objective 1: To examine the distribution patterns and spatial relationships between sponges and algae I examined the existence of negative and positive correlations between sponges and algae following the methodology described by Preciado and Maldonado (2005). I also tested for correlations between sponge abundance and distribution and other environmental variables.

\section{Chapter 3: Positive interactions between canopy-forming algae and sponges}

2. Aim: To identify the existence of positive interactions between canopy forming-algae and sponges. 
Objective 2: To conduct experimental manipulations in the field to determine the effect of canopy removal on sponge distribution and abundance in shallow waters assessing the potential for some sponge species to benefit from the presence of macroalgae through facilitation as a result of habitat modification.

\section{Chapter 4: Effect of filamentous and foliose algae on sponges}

3. Aim: To determine the existence of negative interactions between turfing algae (filamentous, foliose and corticated macrophytes) on sponges.

Objective 3: To conduct experimental field and laboratory manipulations to determine the effect of the presence of the understory alga Zonaria turneriana on the growth and survival of the sponge Leucetta sp. I tested if the low abundance of sponges in areas of high algal richness were the result of competitive displacement by turfing algae.

\section{Chapter 5: Effect of environmental irradiance on sponges inhabiting shallow-water rocky reefs and its effect on microbial communities associated with sponges}

4 Aim: To experimentally determine the effect of irradiance on sponges inhabiting shaded habitats by examining if changes in irradiance affect the abundance and diversity of sponge-associated microorganisms.

Objective 4: To conduct field experiments to test the effect of irradiance on sponges containing microorganisms, specifically examining its effect on the composition and abundance of microorganisms and therefore having potential role in determining the abundance and distribution patterns of sponges.

\section{Chapter 5: General discussion}

I discuss and summarize the main findings of this thesis and the contribution of this thesis to sponge ecology in temperate reefs. 
Chapter 1. General introduction

\subsection{References}

Abdo DA (2007) Endofauna differences between two temperate marine sponges (Demospongiae; Haplosclerida; Chalinidae) from southwest Australia. Marine Biology 152:845-854

Aerts LAM (1998) Sponge/coral interactions in Caribbean reefs: analysis of overgrowth patterns in relation to species identity and cover. Marine Ecology Progress Series 175:241-249

Aerts LAM (2000) Dynamics behind standoff interactions in three reef sponge species and the coral Montastraea cavernosa. Marine Ecology 21:191-204

Aerts LAM, van Soest RWM (1997) Quantification of sponge/coral interactions in a physically stressed reef community, NE Colombia. Marine Ecology Progress Series 148:125-134

Amsler MO, Mcclintock JB, Amsler CD, Angus RA, Baker BJ (2009) An evaluation of sponge-associated amphipods from the Antarctic Peninsula. Antarctic Science 21:579-589

Ávila E, Blancas-Gallangos NI, Riosmena-Rodríguez R, Paul-Chávez L (2010) Sponges associated with Sargassum spp. (Phaeophyceae: Fucales) from the south-western Gulf of California. Journal of The Marine Biological Association of the United Kingdom 90:193-202

Ayling AL (1983) Growth and regeneration rates in thinly encrusting demospongiae from temperate waters. Biological Bulletin 165:343-352

Baldacconi R, Corriero G (2009) Effects of the spread of the alga Caulerpa racemosa var. cylindracea on the sponge assemblage from coralligenous concretions of the Apulian coast (Ionian Sea, Italy). Marine Ecology 30:337-345

Barnes DKA (1999) High diversity of tropical intertidal zone sponges in temperature, salinity and current extremes. African Journal of Ecology 37:424-434

Barnes DKA, Kuklinski P (2004) Scale-dependent variation in competitive ability among encrusting Arctic species. Marine Ecology Progress Series 275:21-32

Barthel D, Gutt J, Tendal OS (1991) New information on the biology of Antarctic deep-water sponges derived from underwater photography. Marine Ecology Progress Series 69:303-307 
Battershill CN (1987) Factors affecting the structure and dynamics of subtidal communities characterised by sponges. Ph.D. Thesis, The University of Auckland

Baynes TW (1999) Factors structuring a subtidal encrusting community in the southern Gulf of California. Bulletin of Marine Science 64:419-450

Becerro MA, Uriz MJ, Turon X (1994) Trends in space occupation by the encrusting sponge Crambe crambe: variation in shape as a function of size and environment. Marine Biology 121:301-307

Bejarano-Chavarro S, Zea S, Diaz JM (2004) Esponjas y otros mocrohabitats de ofiuros (Ophiuroidea: Echinodermata) en ambientes arrecifales del archipielago de San Bernardo (Caribe Colombiano). Boletin de Investigaciones Marinas y Costeras - INVEMAR 33:29-47

Bell JJ (2002) The sponge community in a semi-submerged temperate sea cave: density, diversity and richness. Marine Ecology 23:297-311

Bell JJ (2004) Evidence for morphology-induced sediment settlement prevention on the tubular sponge Haliclona urceolus. Marine Biology 146:29-38

Bell JJ (2007) The ecology of sponges in Lough Hyne Marine Nature Reserve (southwest Ireland): past, present and future perspectives. Journal of the Marine Biological Association of the United Kingdom 87:1655-1668

Bell JJ (2008) The functional roles of marine sponges. Estuarine, Coastal and Shelf Science 79:341-353

Bell JJ, Barnes DKA (2000a) The distribution and prevalence of sponges in relation to environmental gradients within a temperate sea lough: inclined cliff surfaces. Diversity and Distributions 6:305-323

Bell JJ, Barnes DKA (2000b) The distribution and prevalence of sponges in relation to environmental gradients within a temperate sea lough: vertical cliff surfaces. Diversity and Distributions 6:282-303

Bell JJ, Barnes DKA (2000c) A sponge diversity centre within a marine ôslandô Hydrobiologia 440:55-64

Bell JJ, Barnes DKA (2003) The importance of competitor identity, morphology and ranking methodology to outcomes in interference competition between sponges. Marine Biology 143:415-426 
Chapter 1. General introduction

Bell JJ, Burton M, Bullimore B, Newman PB, Lock K (2006) Morphological monitoring of subtidal sponge assemblages. Marine Ecology Progress Series 311:79-91

Bell JJ, Smith D (2004) Ecology of sponge assemblages (Porifera) in the Wakatobi region, south-east Sulawesi, Indonesia: richness and abundance. Journal of The Marine Biological Association of the United Kingdom 84:581-591

Box SJ, Mumby PJ (2007) Effect of macroalgal competition on growth and survival of juvenile Caribbean corals. Marine Ecology Progress Series 342:139-149

Broyer CD, Scailteur Y, Chapelle G, Rauschert M (2001) Diversity of epibenthic habitats of gammaridean amphipods in the eastern Weddell Sea. Polar Biology 24:744-753

Carballo JL, Ávila E (2004) Population dynamics of a mutualistic interaction between the sponge Haliclona caerulea and the red alga Jania adherens. Marine Ecology Progress Series 279:93-104

Cleary DFR, Becking LE, de Voogd NJ, Renema W, de Beer M, van Soest RWM, Hoeksema BW (2005) Variation in the diversity and composition of benthic taxa as a function of distance o $\square$ shore, depth and exposure in the Spermonde Archipelago, Indonesia. Estuarine, Coastal and Shelf Science 65:557-570

Connell SD (2003) Negative effects overpower the positive of kelp to exclude invertebrates from the understorey community. Oecologia 137:97-103

DôAloia CC, Majoris JE, Buston PM (2011) Predictors of the distribution and abundance of a tube sponge and its resident goby. Coral Reefs 30:777-786

Davis AR, Roberts DE, Cummins SP (1997) Rapid invasion of a sponge-dominated deep-reef by Caulerpa scalpelliformis (Chlorophyta) in Botany Bay, New South Wales. Australian Journal of Ecology 22:146-150

Davy SK, Trautman DA, Borowitzka MA, Hinde R (2002) Ammonium excretion by a symbiotic sponge supplies the nitrogen requirements of its rhodophyte partner. Journal of Experimental Biology 205:3505-3511

Dayton PK (1985) Ecology of kelp communities. Annual Review of Ecology and Systematics 16:215-245

Dayton PK, Robilliard GA, Paine RT, Dayton LB (1974) Biological accommodation in the benthic community at McMurdo Sound, Antarctica. Ecological Monographs 44:105-128 
de Caralt S, Cebrian E (2013) Impact of an invasive alga (Womersleyella setacea) on sponge assemblages: compromising the viability of future populations. Biological Invasions 15:1591-1600

de Goeij JM, van Oevelen D, Vermeij MJA, Osinga R, Middelburg JJ, de Goeij AFPM, Admiraal W (2013) Surviving in a marine desert: the sponge loop retains resources within coral reefs. Science 342: 108-110

de Voogd NJ, Becking LE, Noor A, Hoeksema BW, van Soest RWM (2004) Sponge interactions with spatial competitors in the Spermonde Archipelago. Bollettino dei Musei Instituti Biologici dellôUniversita di Genova 68:253-261

de Voogd NJ, Cleary DFR (2008) An analysis of sponge diversity and distribution at three taxonomic levels in the Thousand Islands/Jakarta Bay reef complex, West-Java, Indonesia. Marine Ecology 29:205-215

De Vos L, Rutzler K, Boury-Esnault N, Donadey C, Vacelet J (1991) Atlas of sponge morphology. Smithsonian Institution Press, Washington

Diaz MC, Alvarez B, Laughlin RA (1990) The sponge fauna on a fringing coral reef in Venezuela, II: community structure. In: New perspectives in sponge biology. Smithsonian Institution Press, London, p 367-375

Duarte LFL, Nalesso RC (1996) The sponge Zygomycale parishii (Bowerbank) and its endobiotic fauna. Estuarine, Coastal and Shelf Science 42:139-151

Duckworth AR, Battershill CN (2001) Population dynamics and chemical ecology of New Zealand Demospongiae Latrunculia sp. nov. and Polymastia croceus (Poecilosclerida: Latrunculiidae: Polymastiidae). New Zealand Journal of Marine and Freshwater Research 35:935-949

Duckworth AR, Battershill CN, Schiel DR (2004) Effects of depth and water flow on growth, survival and bioactivity of two temperate sponges cultured in different seasons. Aquaculture 242:237-250

Eckman JE, Duggins DO (1991) Life and death beneath macrophyte canopies: effects of understory kelps on growth rates and survival of marine, benthic suspension feeders. Oecologia 87:473-487

Engel S, Pawlik JR (2000) Allelopathic activities of sponge extracts. Marine Ecology Progress Series 207:273-281

Enríquez S, Ávila E, Carballo JL (2009) Phenotypic plasticity induced in transplant experiments in a mutualistic association between the red algae Jania adhaerens (Rhodophyta, Corallinales) and the sponge Haliclona caerulea 
(Porifera: Haplosclerida): morphological responses of the algae. Journal of Phycology 45:81-90

Erwin PM, Thacker RW (2008) Phototrophic nutrition and symbiont diversity of two Caribbean spongeï cyanobacteria symbioses. Marine Ecology Progress Series 362:139-147

Fagerstrom JA, West RR, Kershaw S, Cossey PJ (2000) Spatial competition among clonal organisms in extant and selected Paleozoic reef communities. Facies 42:1-24

Fell P (1993) Porifera. In: Adiyodi KG, Adiyodi RG (eds) Reprodutive Biology of Invertebrates. Oxford \& IBH Publishing Co., New Dehli, p 1-44

Fell PE, Lewandrowski KB (1981) Population dynamics of the estuarine sponge, Halichondria sp., within a New England eelgrass community. Journal of Experimental Marine Biology and Ecology 55:49-63

Fiore CL, Cox-Jutte P (2010) Characterization of macrofaunal assemblages associated with sponges and tunicates collected off the southeastern United States. Invertebrate Biology 129:105-120

Flatt PM, Gautschi JT, Thacker RW, Musafija-Girt M, Crews P, Gerwick WH (2005) Identification of the cellular site of polychlorinated peptide biosynthesis in the marine sponge Dysidea (Lamellodysidea) herbacea and symbiotic cyanobacterium Oscillatoria spongeliae by CARD-FISH analysis. Marine Biology 147:761-774

Fowler-Walker MJ, Gillanders BM, Connell SD, Irving AD (2005) Patterns of association between canopy-morphology and understorey assemblages across temperate Australia. Journal of Experimental Marine Biology and Ecology 63:133-141

Francis JC, Poirrier MA, LaBiche RA (1982) Effects of calcium and salinity on the growth rate of Ephydatia fluviatilis (Porifera: Spongillidae). Hydrobiologia 89:225-229

Freeman CJ, Thacker RW (2011) Complex interactions between marine sponges and their symbiotic microbial communities. Limnology and Oceanography 56:1577-1586

Friedrich AB, Fischer I, Proksch P, Hacker J, Hentschel U (2001) Temporal variation of the microbial community associated with the mediterranean sponge Aplysina aerophoba. FEMS Microbiology Ecology 38:105-113 
Gerçe B, Schwartz T, Voigt M, Rühle S, Kirchen S, Putz A, Proksch P, Obst U, Syldatk C, Hausmann R (2009) Morphological, bacterial, and secondary metabolite changes of Aplysina aerophoba upon long-term maintenance under artificial conditions. Microbial Ecology 58:865-878

Gerrodette T, Flechsig AO (1979) Sediment-induced reduction in the pumping rate of the tropical sponge Verongia lacunosa. Marine Biology 55:103-110

Ginn BK, Logan A, Thomas MLH (2000) Sponge ecology on sublittoral hard substrates in a high current velocity area. Estuarine, Coastal and Shelf Science 50:403-414

Glasby TM (1999) Effects of shading on subtidal epibiotic assemblages. Journal of Experimental Marine Biology and Ecology 234:275-290

Gochfeld DJ, Easson CG, Freeman CJ, Thacker RW, Olso JB (2012) Disease and nutrient enrichment as potential stressors on the Caribbean sponge Aplysina cauliformis and its bacterial symbionts. Marine Ecology Progress Series 456:101-111

Hentschel U, Piel J, Degnan SM, Taylor MW (2012) Genomic insights into the marine sponge microbiome. Nat Rev Microbiol 10:641-654

Hentschel U, Usher KM, Taylor MW (2006) Marine sponges as microbial fermenters. FEMS Microbiology Ecology 55:167-177

Hopkins SH (1962) Distribution of species of Cliona (boring sponge) on the Eastern Shore of Virginia in relation to salinity. Chesapeake Science 3:121-124

Huang JP, McClintock JB, Amsler CD, Huang YM (2008) Mesofauna associated with the marine sponge Amphimedon viridis. Do its physical or chemical attributes provide a prospective refuge from fish predation? Journal of Experimental Marine Biology and Ecology 362:95-100

Hultgren KM, Duffy JE (2010) Sponge host characteristics shape the community structure of their shrimp associates. Marine Ecology Progress Series 407:1-12

Ilan M, Abelson A (1995) The life of a sponge in a sandy lagoon. Biological Bulletin 189:363-369

Irving AD, Connell SD (2002) Sedimentation and light penetration interact to maintain heterogeneity of subtidal habitats: algal versus invertebrate dominated assemblages. Marine Ecology Progress Series 245:83-91 
Jackson JBC, Buss L (1975) Allelopathy and spatial competition among coral reef invertebrates (species interactions/community structure). Proceedings of the National Academy of Sciences of the United States of America 72:5160-5163

Jenkins SR, Norton TA, Hawkins SJ (1999) Settlement and post-settlement interactions between Semibalanus balanoides (L.) (Crustacea: Cirripedia) and three species of fucoid canopy algae. Journal of Experimental Marine Biology and Ecology 236:49-67

Jokiel PL (1980) Solar ultraviolet radiation and coral reef epifauna. Science 207:1069-1071

Kaandorp JA, de Kluijver MJ (1992) Verification of fractal growth models of the sponge Haliclona oculata (Porifera) with transplantation experiments. Marine Biology 113:133-143

Kennelly SJ (1987) Physical disturbances in an Australian kelp community. II. Effects on understorey species due to differences in kelp cover. Marine Ecology Progress Series 40:155-165

Kennelly SJ (1989) Effects of kelp canopies on understorey species due to shade and scour. Marine Ecology Progress Series 50:215-224

Kennelly SJ, Underwood AJ (1993) Geographic consistencies of effects of experimental physical disturbance on understorey species in sublittoral kelp forests in central New South Wales. Journal of Experimental Marine Biology and Ecology 168:35-58

Knapp ISS, Bell JJ (2010) Effect of depth on sponge assemblage structure at Palmyra Atoll, Central Pacific. The Open Journal of Marine Biology 4:26-30

Knott NA, Underwood AJ, Chapman MG, Glasby TM (2004) Epibiota on vertical and on horizontal surfaces on natural reefs and on artificial structures. Journal of the Marine Biological Association of the United Kingdom 84:1117-1130

Knott NA, Underwood AJ, Chapman MG, Glasby TM (2006) Growth of the encrusting sponge Tedania anhelans (Lieberkuhn) on vertical and on horizontal surfaces of temperate subtidal reefs. Marine and Freshwater Research 57:95-104

Konar B, Iken K (2005) Competitive dominance among sessile marine organisms in a high Arctic boulder community. Polar Biology 29:61-64 
Chapter 1. General introduction

Koukouras A, Russo A, Voultsiadou-Koukoura E, Arvanitidis C, Stefanidou D (1996) Macrofauna associated with sponge species of different morphology. Marine Ecology 17:569-582

Laudien J, Orchard J-B (2012) The significance of depth and substratum incline for the structure of a hard bottom sublittoral community in glacial Kongsfjorden (Svalbard, Arctic)ð an underwater imagery approach. Polar Biology 35:10571072

Leamon J, Fell PE (1990) Upper salinity tolerance of and salinity-induced tissue regression in the estuarine sponge Microciona prolifera. Transactions of the American Microscopical Society 109:265-272

Leichter JJ, Witman JD (1997) Water flow over subtidal rock walls: relation to distributions and growth rates of sessile suspension feeders in the Gulf of Maine Water flow and growth rates. Journal of Experimental Marine Biology and Ecology 209:293-307

Lemoine N, Buell N, Hill A, Hill M (2007) Assessing the utility of sponge microbial symbiont communities as models to study global climate change: a case study with Halichondria bowerbanki. In: Custodio MR, Lobo-Hajdu G, Hajdu E, Muricy G (eds) Porifera research: biodiversity, innovation and sustainability. Museu Nacional, Rio de Janeiro, Brazil, p 419-425

Leonard GH (1999) Positive and negative effects of intertidal algal canopies on recruitment and survival of barnacles. Marine Ecology Progress Series 178:241-249

López-Victoria M, Zea S, Weil E (2006) Competition for space between encrusting excavating Caribbean sponges and other coral reef organisms. Marine Ecology Progress Series 312:113-121

Lörz A-N (2001) Low diversity of spongicolous Amphipoda (Crustacea) observed in the Antarctic autumn. Organisms, Diversity and Evolution 1:133-138

Maldonado M, Uriz MJ (1998) Microrefuge exploitation by subtidal encrusting sponges: patterns of settlement and post settlement survival. Marine Ecology Progress Series 174:141-150

Maldonado M, Uriz MJ (1999) An experimental approach to the ecological significance of microhabitat-scale movement in an encrusting sponge. Marine Ecology Progress Series 185:239-255 
Chapter 1. General introduction

Maldonado M, Young C (1998) Limits on the bathymetric distribution of keratose sponges: a field test in deep-water. Marine Ecology Progress Series 174:123139

Maldonado M, Navarro L, Grasa A, Gonzalez A, Vaquerizo I (2011) Silicon uptake by sponges: a twist to understanding nutrient cycling on continental margins. Scientific Reports 1: 30

Maldonado M, Ribes M, van Duyl FC (2012) Nutrient fluxes through sponges: biology, budgets, and ecological implications. Advances in Marine Biology 62: $113-182$

Márquez JC, Diaz JM (2005) Interacciones entre corales y macroalgas: dependencia de las especies involucradas. Boletin de Investigaciones Marinas y Costeras $34: 227-242$

Maughan BC, Barnes DKA (2000) A óminimum stress inflexionô in relation to environmental and biotic influences on the dynamics of subtidal encrusting communities? Hydrobiologia 440:101-109

McClintock JB, Amsler CD, Baker BJ, van Soest RWM (2005) Ecology of Antarctic marine sponges: an overview. Integrative and Comparative Biology 45:359368

McLean EL, Yoshioka P (2008) Substratum effects on the growth and survivorship of the sponge Desmapsamma anchorata. Caribbean Journal of Science 44:83-89

Miller AN, Strycha KB, Shirley TC, Rützler K (2010) Effects of heat and salinity stress on the sponge Cliona celata. International Journal of Biology 2:3-16

Norton TA, Benson MR (1983) Ecological interactions between the brown seaweed Sargassum muticum and its associated fauna. Marine Biology 75:169-177

Nugues MM, Roberts CM (2003) Coral mortality and interaction with algae in relation to sedimentation. Coral Reefs 22:507-516

Padua A, Lanna E, Klautau M (2013) Macrofauna inhabiting the sponge Paraleucilla magna (Porifera: Calcarea) in Rio de Janeiro, Brazil. Journal of the Marine Biological Association of the United Kingdom 93:889-898

Palumbi SR (1985) Spatial variation in an algal-sponge commensalism and the evolution of ecological interactions. American Naturalist 126:267-275

Palumbi SR (1986) How body plans limit acclimation: responses of a demosponge to wave force. Ecology 67:208-214 
Pawlik JR (1997) Fish predation on Caribbean reef sponges: an emerging perspective of chemical defenses. Proceedings of the 8th International Coral Reefs Symposium 2:1255-1258

Pawlik JR, Chanas B, Toonen RJ, Fenical W (1995) Defenses of Caribbean sponges against predatory reef fish. I. Chemical deterrency. Marine Ecology Progress Series 127:183-194

Peattie ME, Hoare R (1981) The sublittoral ecology of the Menai Strait. II. The sponge Halichondria panicea (Pallas) and its associated fauna. Estuarine, Coastal and Shelf Science 13:621-635

Preciado I, Maldonado M (2005) Reassessing the spatial relationship between sponges and macroalgae in sublittoral rocky bottoms: a descriptive approach. Helgoland Marine Research 59:141-150

Regoli F, Cerrano C, Chierici E, Bompadre S, Bavestrello G (2000) Susceptibility to the oxidative stress of the Mediterranean demosponge Petrosia ficiformis: role of endosymbionts and solar irradiance. Marine Biology 137:453-461

Ribeiro SM, Omena EP, Muricy G (2003) Macrofauna associated to Mycale microsigmatosa (Porifera, Demospongiae) in Rio de Janeiro State, SE Brazil. Estuarine, Coastal and Shelf Science 57:951-959

Riisgard HU, Thomassen S, Jakobsen H, Weeks JM, Larsen PS (1993) Suspension feeding in marine sponges Halichondria panicea and Haliclona urceolus: effects of temperature on filtration rate and energy cost of pumping. Marine Ecology Progress Series 96:177-188

River GF, Edmunds PJ (2001) Mechanisms of interaction between macroalgae and scleractinians on a coral reef in Jamaica. Journal of Experimental Marine Biology and Ecology 261:159-172

Roberts D, Cummins S, Davis A, Pangway C (1999) Evidence for symbiotic algae in sponges from temperate coastal reefs in New South Wales, Australia. Memoirs of the Queensland Museum 44:493-497

Roberts DE, Cummins SP, Davis AR, Chapman MG (2006a) Structure and dynamics of sponge-dominated assemblages on exposed and sheltered temperate reefs. Marine Ecology Progress Series 321:19-30

Roberts DE, Davis AR, Cummins SP (2006b) Experimental manipulation of shade, silt, nutrients and salinity on the temperate reef sponge Cymbastela concentrica. Marine Ecology Progress Series 307:143-154 
Roberts DE, Smith A, Ajani P, Davis AR (1998) Rapid changes in encrusting marine assemblages exposed to anthropogenic point-source pollution: a 'Beyond BACI' approach. Marine Ecology Progress Series 163:213-224

Rützler K (1990) Associations between Caribben sponges and photosynthetic organisms. In: Rützler $\mathrm{K}$ (ed) New perspectives in sponge biology. Smithsonian Institution Press, London, p 455-466

Rützler K (2002) Impact of crustose clionid sponges on Caribbean reef corals. Acta Geologica Hispanica 37:61-72

Ruzicka R, Gleason DF (2009) Sponge community structure and anti-predator defenses on temperate reefs of the South Atlantic Bight. Journal of Experimental Marine Biology and Ecology 380:36-46

Sarà M, Bavestrello G, Cattaneo-Vietti R, Cerrano C (1998) Endosymbiosis in sponges: Relevance for epigenesis and evolution. Symbiosis 25:57-70

Sarà M, Vacelet J (1973) Ecologie des Démosponges. In: Grass PP (ed) Spongiaires Traité de Zoologie. Masson, Paris, p 462-576

Schejter L, Chiesa IL, Doti BL, Bremec C (2012) Mycale (Aegogropila) magellanica (Porifera: Demospongiae) in the southwestern Atlantic Ocean: endobiotic fauna and new distributional information. Scientia Marina 76:753-761

Schiel DR, Hickford MJH (2001) Biological structure if nearshore rocky subtidal habitats in southern New Zealand. Science for Conservation 182:1-54

Schmidt EW (2008) Trading molecules and tracking targets in symbiotic interactions. Nat Chem Biol 4:466-473

Scott F, Wetherbee R, Kraft G (1984) The morphology and development of some prominently stalked southern Australian Halymeniaceae (Cryptoneniales, Rhodophyta). II. The sponge-associated genera Thamnoclonium Kuetzing and Codiophyllum Gray. Journal of Phycology 20:286-295

Sebens KP (1985) Community ecology of vertical rock walls in the Gulf of Maine, U.S.A.: Small-scale processes and alternative States. In: Moore PG, Seed R (eds) The ecology of rocky coasts. Columbia University Press, New York, p 346-371

Simister R, Taylor MW, Rogers KM, Schupp PJ, Deines P (2013) Temporal molecular and isotopic analysis of active bacterial communities in two New Zealand sponges. FEMS Microbiology Ecology 85:195-205 
Simister R, Taylor MW, Tsai P, Fan L, Bruxner TJ, Crowe ML, Webster N (2012) Thermal stress responses in the bacterial biosphere of the Great Barrier Reef sponge, Rhopaloeides odorabile. Environ Microbiol 14:3232-3246

Taylor MW, Radax R, Steger D, Wagner M (2007) Sponge-associated microorganisms: evolution, ecology, and biotechnological potential. Microbiology and Molecular Biology Reviews 71:295-347

Teixidó N (2003) Analysing benthic communities in the Weddell Sea (Antarctica): a landscape approach. Ph.D. Thesis, University of Bremen

Thacker RW (2005) Impacts of shading on sponge-cyanobacteria symbioses: a comparison between host-speciýc and generalist associations. Integrative and Comparative Biology 45:369-376

Thacker RW, Becerro MA, Lumbang WA, Paul VJ (1998) Allelopathic interactions between sponges on a tropical reef. Ecology 79:1740-1750

Thacker RW, Freeman CJ (2012) Spongeï microbe symbioses: recent advances and new directions. Advances in Marine Biology 62:57-111

Thoms C, Horn M, Wagner M, Hentschel U, Proksch P (2003) Monitoring microbial diversity and natural product proýles of the sponge Aplysina cavernicola following transplantation. Marine Biology 142:685-692

Thoms C, Schupp PJ (2007) Chemical defense strategies in sponges: a review. In: Custodio MR, Lobo-Hajdu G, Hajdu E, Muricy G (eds) Porifera research: biodiversity, innovation and sustainability. Museu Nacional, Rio de Janeiro, Brazil, p 627-637

Titlyanov EA, Yakovleva IM, Titlyanova TV (2007) Interaction between benthic algae (Lyngbya boullonii, Dyctiota dichotoma) and scleratinian coral Porites lutea in direct contact. Journal of Experimental Marine Biology and Ecology 342:282-291

Trautman DA, Hinde R, Borowitzka MA (2003) The role of habitat in determining the distribution of a sponge-red alga symbiosis on a coral reef. Journal of Experimental Marine Biology and Ecology 283:1-20

Turon X, Tarjuelo I, Uriz MJ (1998) Growth dynamics and mortality of the encrusting sponge Crambe crambe (Poecilosclerida) in contrasting habitats: correlation with population structure and investment in defence. Functional Ecology 12:631-639 
Uriz MJ, Becerro MA, Tur JM, Turon X (1996) Location of toxicity within the Mediterranean sponge Crambe crambe (Demospongiae: Poecilosclerida). Marine Biology 124:583-590

Uriz MJ, Rosell D, Martin D (1992) The sponge population of the Cabrera Archipelago (Balearic Islands): characteristics, distribution and abundance of the most representative species. Marine Ecology 13:101-117

Uriz MJ, Turon X, Becerro MA, Galera J, Lozano J (1995) Patterns of resource allocation to somatic, defensive, and reproductive functions in the Mediterranean encrusting sponge Crambe crambe (Demospongiae, Poecilosclerida). Marine Ecology Progress Series 124:159-170

Usher KM (2008) The ecology and phylogeny of cyanobacterial symbionts in sponges. Marine Ecology 29:178-192

Vacelet J (1981) Algal-sponge symbiosis in the coral reefs of New Caledonia: a morphological study. Proceedings of the 4th International Coral Reef Symposium 2:713-719

Vermeij MJA, Dailer ML, Walsh SM, Donovan MK, Smith CM (2010) The effect of trophic interactions and spatial competition on algal composition on Hawaiian coral reefs. Marine Ecology 31:291-299

Voultsiadou-Koukoura HE, Koukouras A, Eleftheriou A (1987) Macrofauna associated with the sponge Verongia aerophoba in the north Aegean Sea. Estuarine, Coastal and Shelf Science 24:2

Webster N, Taylor M (2012) Marine sponges and their microbial symbionts: love and other relationships. Environmental Microbiology 14:335-346

Webster NS (2007) Sponge disease: a global threat? Environmental Microbiology 9:1363-1375

Webster NS, Cobb RE, Negri AP (2008) Temperature thresholds for bacterial symbiosis with a sponge. The ISME Journal 2:830-842

Webster NS, Webb RI, Ridd MJ, Hill RT, Negri AP (2001) The effects of copper on the microbial community of a coral reef sponge. Environmental Microbiology $3: 19-31$

Wendt PH, van Dolah RF, O'Rourke C (1985) A comparative study of the invertebrate macrofauna associated with seven sponge and coral species collected from the south Atlantic Bight. Journal of the Elisha Mitchell Scientific Society 101:187-203 
Chapter 1. General introduction

White JR, Patel J, Ottesen A, Arce G, Blackwelder P, Lopez JV (2012) Pyrosequencing of bacterial symbionts within Axinella corrugata sponges: diversity and seasonal variability. PloS ONE 7:e38204

Wilkinson C, Trott L (1985) Light as a factor determining the distribution of sponges across the central Great Barrier Reef. Proceedings of the 5th International Coral Reef Symposium 5:125-130

Wilkinson CR, Evans E (1989) Sponge distribution across Davies Reel Great Barrier Reef relative to location, depth, and water movement. Coral Reefs 8:1-7

Wilkinson CR, Fay P (1979) Nitrogen fixation in coral reef sponges with symbiotic cyanobacteria. Nature 279:527-529

Wilkinson CR, Nowak M, Austin B, Colwell RR (1981) Specificity of bacterial symbionts in Mediterranean and Great Barrier Reef sponges. Microbial Ecology 7:13-21

Wilkinson CR, Vacelet J (1979) Transplantation of marine sponges to different conditions of light and current. Journal of Experimental Marine Biology and Ecology 37:91-104

Witman JD, Grange KR (1998) Links between rain, salinity, and predation in a rocky subtidal community. Ecology 79:2429-2447

Witman JD, Sebens KP (1990) Distribution and ecology of sponges at a subtidal rock ledge in the Central Gulf of Maine. In: Rützler K (ed) New perspectives in sponge biology. Smithsonian Institution Press, London, p 391-396

Wright JT, Benkendorff K, Davis AR (1997) Habitat associated differences in temperate sponge assemblages: the importance of chemical defence. Journal of Experimental Marine Biology and Ecology 213:199-213

Wulff J (2012) Ecological interactions and the distribution, abundance, and diversity of sponges. Advances in Marine Biology 61:273-344

Wulff JL (1997) Mutualisms among species of coral reef sponges. Ecology 78:146159

Wulff JL (2000) Sponge predators may determine differences in sponge fauna between two sets of mangrove cays, Belize Barrier Reef. Atoll Res Bull 477:251-263

Wulff JL (2006) Ecological interactions of marine sponges. Canadian Journal of Zoology 84:146-166 
Zea S (1994) Patterns of coral and sponge abundance in stressed coral reefs at Santa Marta, Columbian Caribbean. In: van Soest RWM, van Kempen T, Braekman JC (eds) Sponges in time and space. Balkema, Rotterdam, p 257-264

G̣uljeviĺ A, Thibaut T, Despalatoviĺ M, Cottalorda J-M, Nikolil V, Cvitkoviĺ I, Antolic B (2011) Invasive alga Caulerpa racemosa var. cylindracea makes a strong impact on the Mediterranean sponge Sarcotragus spinosulus. Biological Invasions 13:2303-2308 
Chapter 2. Correlations between sponges and macroalgae

\section{Chapter 2: Distribution patterns and spatial associations between sponges and macroalgae}

\subsection{Abstract}

Sponges are important components of temperate rocky reefs and although a range of biological and physical factors influences their abundance and diversity, previous studies have highlighted the importance of algal interactions in shallow water. In high light environments that are dominated by macroalgae, sponges are generally lessabundant and are often restricted to shaded habitats. However, this generalisation is from research conducted in the northern hemisphere, with the comparatively limited information from the southern hemisphere contradicting this pattern. The aim of this chapter was to examine the correlations between sponge abundance and assemblage composition with algal abundance and environmental variables. I measured the distribution patterns of sponges relative to macroalgal abundance, physical factors (including depth, surface inclination, turbidity, rugosity and temperature) and the abundance of other phyletic groups at multiple sites in New Zealand. A negative correlation was found between sponge abundance and algal abundance, with surface inclination strongly affecting the distribution patterns of both groups. My results confirm previous studies in the northern hemisphere that show negative correlations between sponge and algal abundance. 
Chapter 2. Correlations between sponges and macroalgae

\subsection{Introduction}

Sponges are abundant components of rocky benthic communities in temperate (Ayling 1983b, Bell \& Barnes 2000b), tropical (Diaz et al. 1990b, Diaz \& Rützler 2001, Bell \& Smith 2004, de Voogd et al. 2009) and polar regions (Dayton et al. 1974, Barthel et al. 1991, Sarà et al. 1992, Teixidó 2003) whose abundance patterns are strongly influenced by a range of biological and physical factors. For example, the distribution and abundance patterns of sponges are strongly influenced by depth (Knapp \& Bell 2010a), water flow (Bell \& Barnes 2003a), sedimentation (Carballo 2006, de Voogd \& Cleary 2007b), predation (Dunlap \& Pawlik 1996), salinity (Roberts et al. 2006b), nutrient concentrations (Wilkinson \& Cheshire 1989), substrate type and angle (Bell \& Barnes 2000a, Powell et al. 2010), and turbidity (Zea 1994a). In addition, a number of these studies suggest that these factors can indirectly influence sponges through their effects on other organisms, for example; light influences algal abundance, a potential sponge competitor. Separating the relative importance of these different factors remains challenging and far less is known about how biological factors influence sponges compared to physical factors.

Although sponges are dominant in many habitats, they are often restricted to the undersides of boulders or shaded surfaces in high light areas, with such environments being dominated by macroalgae (Baynes 1999, Irving \& Connell 2002, Konar \& Iken 2005). Macroalgae have been considered successful spatial competitors over sponges (Wulff 2006) and sponge abundance in shallow water, may, therefore, be strongly influenced by competitive interactions with algae (Witman \& Sebens 1990, Turon et al. 1998, Baynes 1999, Bell \& Barnes 2000b, c, d, Bell 2002). For example, a negative interaction from the shading-interference produced by macroalgae over photosymbionts-containing Cliona spp. in the Mediterranean (Cebrian 2010). Several authors have reported negative interactions between sponges and algae, with sponge mortality resulting from overgrowth by native and non-native faster-growing algae (Kaandorp \& de Kluijver 1992, Davis et al. 1997, Turon et al. 1998, Baldacconi \& Corriero 2009, G̦uljevil et al. 2011). Furthermore, sponges have

been found to be competitively inferior to algae in high-light habitats, but competitively superior in shaded habitats (Baynes 1999). However, these suggestions 
are based largely on research from the northern hemisphere and the generality of such interactions remains unknown.

Several authors have tried to clarify the spatial relationships between sponges and algae and examine correlations between these two groups. For example, Bell \& Barnes $(2000 \mathrm{~b}, \mathrm{e})$ proposed that the higher diversity of sponges on vertical surfaces, compared to horizontal surfaces, was a result of reduced light intensity, resulting in reduced algal populations. Furthermore, these authors also found strong correlations between depth and sponge abundance, where algal abundance declined, sponge abundance increased. Bell $(2002,2007)$ suggested that such negative correlations between sponges and algae might be explained by sponges only being able to persist in areas that are unsuitable or less suitable for algae or by sponges preferring habitats that are less favourable for algae (i.e. low light). Similarly light was the main factor affecting sponge diversity in a Mediterranean community as it affects algal growth, and results in competition with sponges for space (Uriz et al. 1992). Konar \& Iken (2005) proposed that the dominance of algae over sponges on the tops of boulders was the result of micro-habitat differences among surface orientations, including differences in sediment load and light intensity, preventing sponges from occurring on horizontal surfaces (Wilkinson \& Vacelet 1979, Maldonado et al. 2008). Preciado \& Maldonado (2005) found that substratum inclination strongly correlated with sponge and algal distribution patterns, suggesting that substratum inclination was the main factor structuring sponge assemblages in the shallow waters of the Mediterranean. These authors found that sponges were mostly restricted to overhangs, where factors considered to be detrimental to sponges (e.g. high light and high sedimentation) are reduced (Wilkinson \& Vacelet 1979, Jokiel 1980, Ginn et al. 2000, Roberts et al. 2006a). However, in contrast to these results from northern hemisphere locations, no correlation was found between sponges and macroalgae in rocky reefs on the southeast coast of Australia (Knott et al. 2004).

While there is comparatively less study of the correlations between sponges and biological and physical factors in the southern hemisphere, the information that is available seems to contrast with that from the better studied northern hemisphere. Therefore the aims of this study were to: 1) re-examine the correlations between sponge abundance and distribution patterns with algae and environmental variables at 
study sites in the southern hemisphere; and 2) consider the specific influence of depth and surface inclination on sponge diversity, abundance and assemblage structure since these two variables are also likely to correlated with algal abundance.

\subsection{Materials and methods}

\subsubsection{Study sites}

Subtidal surveys were carried out at seven sites along the south coast of Wellington ( $41^{\circ} 21$ ô02ò S; $174^{\circ} 47$ ô01ò E) and at Kapiti Island (40 51 ô17ò S; $174^{\circ}$ 54ô32ò E) on the west coast of the North Island in New Zealand. Study sites on the coast of Wellington included Breaker Bay, Barrett Reef, Palmer Head, Princess Bay and The Sirens Rocks, the two sites studied at Kapiti Island were Trig Point and Kaiwharawhara Point (Fig. 2.1).

The sites selected on the Wellington coast were chosen to represent a wide range of habitats with different environmental and biological characteristics; this enabled me to determine which factor or combination of factors best explain sponge spatial distribution patterns. Sites were characterised by the presence of relatively continuous bedrock and steep walls. The Wellington coast is an energetic environment that is subjected to regular southerly swells that move onto the Wellington shelf for more than $80 \%$ of the time (Carter \& Lewis 1995). The algal assemblage is mainly dominated by Ecklonia radiata and by a mixture of Carpophyllum spp., Lessonia variegata and Landsburgia quercifolia (Shears \& Babcock 2007a). The understory is dominated by crustose coralline algae and the overall abundance of sessile invertebrates has been reported to be low (Shears \& Babcock 2007a). Nevertheless, Berman \& Bell (2010) reported a diverse sponge assemblage in this region, where sponge cover exceeds $50 \%$ of the substratum at some sites.

Kapiti Island is located off the west coast of the North Island, approximately $50 \mathrm{~km}$ north of Wellington. My study sites were located on the west coast of the island, and are exposed to relatively strong tidal currents and regular strong northwesterly or south-westerly winds (Chiswell \& Stevens 2010). The area is characterised by an extensive boulder reef and larger blocks of bedrock (Baxter 
1987). The habitats are dominated by a mixed E. radiata/Carpophyllum spp. forest in the shallow zone and forest consisting of only E. radiata in the deeper zone (below 10 $\mathrm{m})$. The understory contains a rich assemblage of turf algae, bryozoans, sponges and ascidians (Battershill et al. 1993, Shears \& Babcock 2007a).

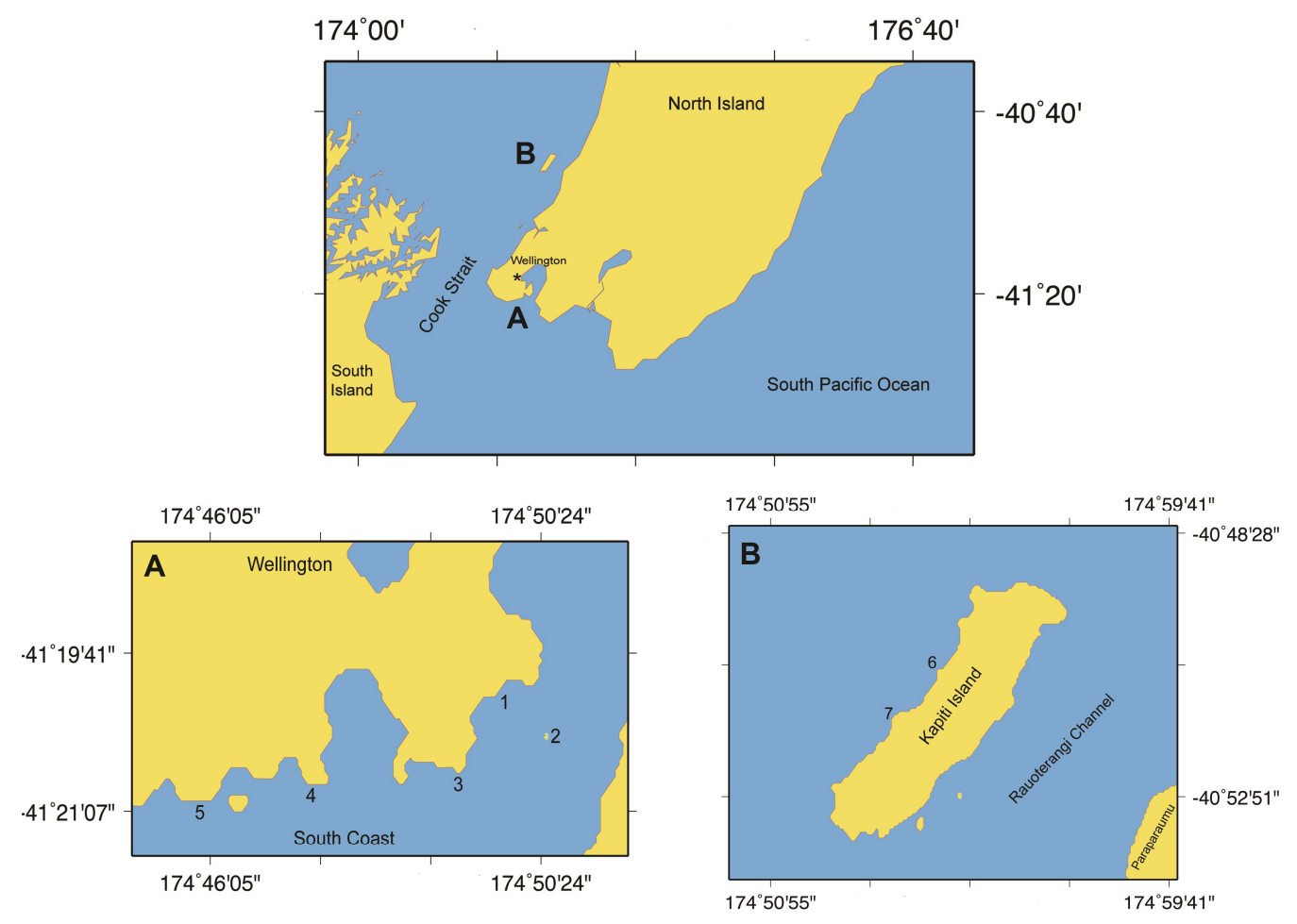

Figure 2.1. A) Location of study sites on the south coast of Wellington; B) Locations of study sites at Kapiti Island, New Zealand. 1. Breaker Bay; 2. Barrett Reef; 3. Palmer Head; 4. Princess Bay; 5. The Sirens Rocks; 6. Trig Point; 7. Kaiwharawhara Point.

\subsubsection{Sampling}

Surveys were conducted by SCUBA at two depths $(5 \mathrm{~m}$ and $15 \mathrm{~m})$ at each site. Breaker Bay and The Sirens Rocks were only surveyed at $5 \mathrm{~m}$ because of the absence of rocky reefs below $10 \mathrm{~m}$. At each depth, five $0.25 \mathrm{~m}^{2}$ quadrats were haphazardly placed on the benthos and photographed with a digital camera (all sites had similar levels of available vertical, horizontal, inclined and overhanging surfaces). Quadrats were photographed in two layers: canopy (first layer) and understory (second layer). 
Quadrats were subdivided into four smaller sections to improve the level of resolution for the different groups of organisms. Each quarter was photographed after the canopy was moved aside and picture quality enabled even the smallest sponge patches to be identified. Depth was measured using a dive computer (UWATEC Smart Pro). Additional information was collected for each quadrat including inclination, rugosity, and orientation with respect to the dominant swells (as a surrogate of exposure). The inclination angle was categorised into horizontal $\left(\mathrm{a}^{\circ}\right)$, inclined $\left(\mathrm{a}^{\circ} 45^{\circ}\right)$, vertical $(\stackrel{\circ}{\mathrm{a}}$ $90^{\circ}$ ) and overhanging surfaces (å $125^{\circ}$ ). The rugosity was estimated in situ by measuring the bottom contour distance between the corners of the quadrat. Subsequently, a rugosity index was estimated based on the ratio of the measured bottom contour distance and the straight-line distance between the extremes of the quadrat $(70 \mathrm{~cm})$. Orientation of each quadrat (with respect to dominant swells) was included as an ordinal categorical variable: sheltered (for quadrats facing $\mathrm{W}-\mathrm{NE}$ ) $=0$; semi-exposed $(E N E-E)=1$; exposed $(\mathrm{SE}-\mathrm{SW})=2$. At each site, physical variables of the water column were recorded at both depths with a CTD (RBR XR-420). Variables included turbidity, temperature, salinity, conductivity and chlorophyll.

Each photo-quadrat was analysed with CPCe v3.5 (Coral Point Count with Excel extensions) (Kohler \& Gill 2006) by superimposing a grid of points onto each picture (Appendix 1). The percentage cover of the first layer (canopy) was measured, and then the coverage of the second layer containing the sponges, macroalgae (erect non-calcareous algae), coralline algae (erect and encrusting algae), other encrusting organisms, bare rock and settled sediment was estimated in each quadrat. Settled sediment was estimated as the area of the quadrat covered in sediment in each picture. Organisms were placed in the following categories: Porifera, Hydrozoa, Anthozoa, Polychaeta, Bryozoa, Ascidiacea, Rhodophyta (erect non-calcareous algae), Chlorophyta, Phaeophyta, and crustose coralline algae. Abiotic categories included bare rock and sediment. Percentage cover estimates were made for each category/taxon. All taxa discernible in the photo-quadrats were identified to the lowest taxonomic level possible. A grid of 100 points was superimposed over each photo-quadrat in order to estimate canopy cover and 100 points were used for each section of the quadrat ( 4 for each quadrat) to estimate the percentage cover of the understory (400 points in total)(Appendix 1). 


\subsubsection{Data analysis}

The number of sponge taxa was estimated for each quadrat, and mean values were obtained for each site. To estimate the mean number of sponge species for the different surface inclinations, the number of species per quadrat for each inclination was combined to obtain a mean value for each surface inclination across all sites for each depth. Differences in the mean number of species between regions ( 2 levels, random), sites (7 levels, random), depths (2 levels, fixed) and surface inclinations (4 levels, fixed) were tested using a Permutational analysis of variance (PERMANOVA) (Anderson 2001). Tukeyôs HSD tests were performed for pairwise comparisons among sites and inclinations.

The percentage cover estimate of organisms, bare rock and settled sediment were averaged across quadrats for comparison between sites. The same routine was undertaken for comparisons between depths $(\mathrm{n}=5$ per depth) and surface inclinations $\left(\mathrm{n}_{\text {horizontal }}=19 ; \mathrm{n}_{\text {inclined }}=12 ; \mathrm{n}_{\text {vertical }}=22 ; \mathrm{n}_{\text {overhanging }}=12\right.$ as data was combined across all sites). Percentage cover data were double square root transformed in order to downweight the influence of extreme values (i.e. rare and very abundant species); this enabled us to test for differences in the percentage coverage between sites, depths and inclinations. Permutational analysis of variance (PERMANOVA) (Anderson 2001) based on a Bray-Curtis similarity matrix (Bray \& Curtis 1957) was performed in order to test for differences in assemblage structure among the assumed a priori factors. This test was used as the data did not meet the assumptions of normality and equal variance, even after transformation. Factors considered in the analysis were region (2 levels, random), site (5 levels, random), depth (2 levels, fixed) and inclination (4 levels, fixed). Statistical differences were tested using 9,999 permutations under a reduced model. PERMANOVA tests were applied to the full dataset to examine multivariate patterns at the category level. PERMANOVA was also used to test for differences in the percentage cover of the dominant benthic groups (treated as univariate measures) between sites, depths and inclinations. All procedures were conducted in the PRIMER v6 statistical package (Clarke \& Gorley 2006, Anderson et al. 2007). 
Relationships between sponge abundance, crustose coralline algae and algal abundance (separated into canopy and understory) were plotted as scatter plots and the curve fitter option was then applied using the software Slide-Write v5 (Advanced Graphics Software 1999). Linear and non-linear functions were fitted to plots to determine the best fit to the data. The curve fitter function fits 40 different linear functions and 60 different non-linear functions (10 exponential, 25 power and 25 polynomial) to the scatter plot. For the non-linear functions, the method employs the Levenbergï Marquardt algorithm in an unconstrained optimisation approach to estimate the coefficients of the equation (Advanced Graphics Software 1999).

In order to analyse the relationships between the percentage cover of benthic organisms relative to different environmental factors and biological groups, an ordination method was applied using CANOCO v4.5 (ter Braak \& Smilauer 2002). Two ordination analyses were performed in order to test the relationship between organisms and environmental variables. The first analysis was run for the whole data set to analyse the overall community at the category level, and the second analysis included sponges at species level. In order to downweight the influence of rare species, percentage cover data were double square root transformed. Environmental and biological variables used in the analysis were depth, inclination, orientation, turbidity, rugosity, water temperature, salinity, conductivity, percentage cover of crustose coralline algae, percentage cover of canopy algae (first layer), algal understory (erect algae-second layer) and percentage of settled sediment on the substrate. Detrended canonical correspondence analysis (DCCA) was conducted to calculate the gradient length. DCCA yielded a short gradient $(>3)$ for both cases and a redundancy analysis (RDA) was then applied (ter Braak \& Smilauer 2002, Leps \& Smilauer 2003). A Monte-Carlo test was used to determine the statistical significance of the first axis and all canonical axes combined using 9,999 permutations under the reduced model. Automatic selections of variables were used to identify the five most significant variables. The variance inflation factors (VIF) were used to assess linear dependencies among variables. Variables with a VIF less than five were maintained in the analysis. RDA results were represented graphically in a scaling bi-plot (two bidimensional ordinations), focusing on inter-species distances. Categories/species were graphically represented as circles and variables as vectors. The vectors show the direction in which the value of the variable of interest increases and the length shows 
its relative importance in explaining speciesô distributions. The category/species symbols can be projected onto the vectors (variables) in order to approximate the optimal individual category/species with respect to values of the variable.

\subsection{Results}

Physical parameters of the water column recorded at each study sites on the south coast of Wellington and Kapiti Island are shown in Table 2.1

\subsubsection{Species richness of sponge assemblages}

The mean number of taxa per quadrat varied between sites nested within region (PERMANOVA $P<0.05$, Table 2.2) but not between the two regions (Table 2.2). The lowest value was observed at Princess Bay $(3.6 \pm 1.00$ S.E. $)$ and the highest at Breaker Bay (13.50 \pm 1.32 S.E.); the latter site was significantly different from the majority of the other sites (Fig. 2.2a). Although the area sampled by each quadrat was small $\left(0.25 \mathrm{~m}^{2}\right)$, the high values obtained for species richness suggests that quadrat size did not significantly bias my sampling. No differences were found in the number of taxa per quadrat between depths (PERMANOVA P > 0.05). The number of taxa per quadrat ranged between $6.9( \pm 0.92$ S.E. $)$ at $15 \mathrm{~m}$ and $7.9( \pm 0.92$ S.E. $)$ at $5 \mathrm{~m}$. The mean number of taxa per quadrat varied significantly between surface inclinations (PERMANOVA $P<0.05$, Table 2.2), ranging from $2.92( \pm 0.57)$ on horizontal surfaces to 13.3 ( \pm 0.92 S.E.) on overhanging surfaces (Fig. 2.2b). In most cases the species richness differed between inclination types (Fig. 2.2-2.3). 
Chapter 2. Correlations between sponges and macroalgae

Table 2.1. Mean values ( \pm SE) for the physical parameters of the water column measured at each study site on south coast of Wellington and at Kapiti Island.

\begin{tabular}{|c|c|c|c|c|c|c|}
\hline \multirow[t]{2}{*}{ Site } & Depth & Temperature & Salinity & Turbidity & Chlorophyll & Conductivity \\
\hline & (m) & $\left({ }^{\circ} \mathrm{C}\right)$ & (PSU) & (NTU) & $(\mu \mathrm{g} / \mathrm{l})$ & $(\mathrm{mS} / \mathrm{cm})$ \\
\hline Breaker Bay & 5 & $13.99 \pm 0.04$ & $34.76 \pm 0.02$ & $4.65 \pm 0.75$ & $0.39 \pm 0.06$ & $41.68 \pm 0.01$ \\
\hline \multirow[t]{2}{*}{ Barrett Reef } & 5 & $15.25 \pm 0.01$ & $35.17 \pm 0.02$ & $3.00 \pm 0.78$ & $0.65 \pm 0.05$ & $43.34 \pm 0.03$ \\
\hline & 15 & $15.24 \pm 0.01$ & $35.10 \pm 0.07$ & $5.33 \pm 0.65$ & $1.00 \pm 0.08$ & $43.17 \pm 0.08$ \\
\hline \multirow[t]{2}{*}{ Palmer Head } & 5 & $16.66 \pm 0.01$ & $34.91 \pm 0.01$ & $1.35 \pm 0.24$ & $0.45 \pm 0.07$ & $44.47 \pm 0.01$ \\
\hline & 15 & $16.53 \pm 0.01$ & $34.90 \pm 0.01$ & $3.35 \pm 0.41$ & $0.40 \pm 0.06$ & $44.71 \pm 0.04$ \\
\hline \multirow[t]{2}{*}{ Princess Bay } & 5 & $15.22 \pm 0.01$ & $35.18 \pm 0.01$ & $0.73 \pm 0.01$ & $0.69 \pm 0.01$ & $43.34 \pm 0.01$ \\
\hline & 10 & $14.99 \pm 0.04$ & $35.16 \pm 0.02$ & $8.67 \pm 1.24$ & $0.47 \pm 0.01$ & $43.11 \pm 0.04$ \\
\hline Sirens Rocks & 5 & $14.56 \pm 0.01$ & $34.73 \pm 0.01$ & $13.03 \pm 0.01$ & $0.39 \pm 0.01$ & $42.19 \pm 0.01$ \\
\hline \multirow[t]{2}{*}{ Kaiwharawhara Point } & 5 & $18.14 \pm 0.02$ & $35.10 \pm 0.01$ & $1.88 \pm 0.35$ & $2.2 \pm 0.51$ & $46.17 \pm 0.02$ \\
\hline & 15 & $17.75 \pm 0.01$ & $35.11 \pm 0.02$ & $2.53 \pm 0.42$ & $0.71 \pm 0.01$ & $45.78 \pm 0.01$ \\
\hline \multirow[t]{2}{*}{ Trig Point } & 5 & $15.80 \pm 0.01$ & $35.11 \pm 0.01$ & $0.35 \pm 0.01$ & $0.55 \pm 0.01$ & $43.83 \pm 0.01$ \\
\hline & 15 & $15.72 \pm 0.01$ & $35.01 \pm 0.01$ & $11.7 \pm 0.97$ & $0.59 \pm 0.01$ & $43.64 \pm 0.01$ \\
\hline
\end{tabular}


Chapter 2. Correlations between sponges and macroalgae

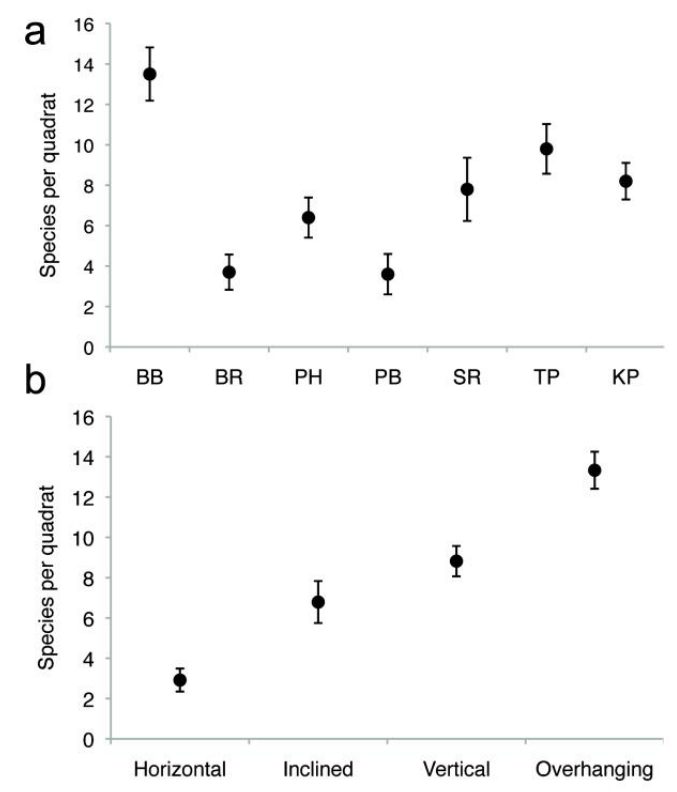

Figure 2.2. a) Mean species richness of sponges recorded at different sites; b) Mean species richness recorded for surface inclinations. $\mathrm{BB}=$ Breaker Bay; $\mathrm{BR}=$ Barrett Reef; $\mathrm{PH}=$ Palmer Head; $\mathrm{PB}=$ Princess Bay; $\mathrm{SR}=$ The Sirens Rocks; $\mathrm{KP}=$ Kaiwharawhara Point; TP $=$ Trig Point. Percentage cover values of each sample were pooled for each site and surface inclination (Error bars represent S.E.).

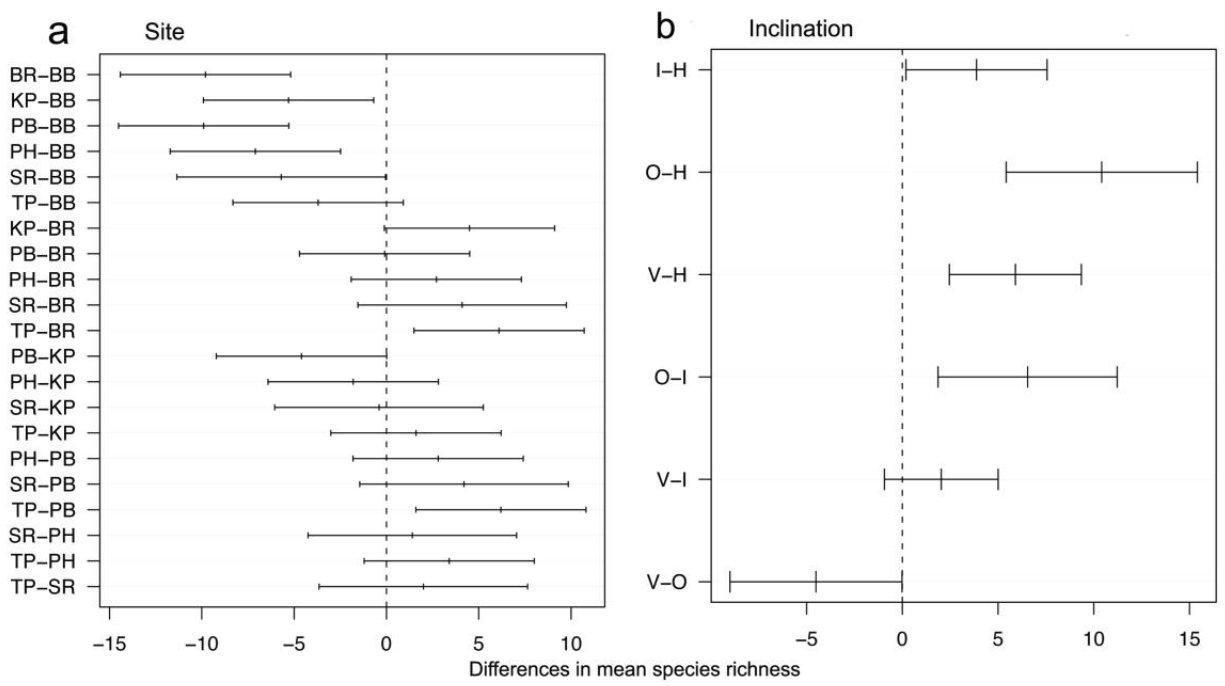

Figure 2.3. Differences in mean species richness of sponges recorded for different sites (a) and inclinations (b). Pairwise comparisons for sites showed significant differences between BR-BB, KP-BB, PB-BB, PH-PB, SR-BB, KP-BR, TP-BR, PBKP, TP-PB $(P<0.05)$. For abbreviations see figure $2.2 . \mathrm{H}=$ horizontal; $\mathrm{I}=$ inclined; $\mathrm{V}=$ vertical; $\mathrm{O}=$ overhanging. Significant differences were found in all comparisons between inclinations, except for vertical vs inclined $(P>0.05)$. 
Table 2.2. Permutational analysis of variance (PERMANOVA) based on a BrayCurtis similarity matrix, testing the effect of region (2 levels, random), site (5 levels, random), depth (2 levels, fixed) and inclination (4 levels, fixed) on species/taxa richness. Statistical differences were tested using 9,999 permutations under a reduced model. Significance is indicated by asterisks: $* P<0.05$.

\begin{tabular}{lrrrc}
\hline Factor & $d f$ & MS & $F$ & $P$ \\
\hline Region & 1 & 23.196 & 0.392 & 0.557 \\
Depth & 1 & 6.8100 & 0.419 & 0.546 \\
Inclination & 3 & 78.235 & 6.800 & $0.048^{*}$ \\
Site(Region) & 5 & 70.443 & 1.657 & $0.021^{*}$ \\
Region x Depth & 1 & 3.8815 & 0.113 & 0.775 \\
Region x Inclination & 3 & 11.304 & 0.374 & 0.774 \\
DexInclination & 3 & 34.384 & 1.367 & 0.415 \\
Site(Region) x Depth & 3 & 89.007 & 2.094 & 0.169 \\
Site(Region) x Inclination & 9 & 25.054 & 0.589 & 0.658 \\
Region x Depth x Inclination & 2 & 23.135 & 0.614 & 0.676 \\
Site(Region) x Depth x Inclination & 1 & 37.036 & 0.871 & 0.312 \\
Residual & 32 & 42.506 & & \\
Total & 64 & & & \\
\hline
\end{tabular}

\subsubsection{Distribution patterns of benthic organisms}

The percentage coverage of CCA differed among sites (PERMANOVA $P<0.05$ ) and was greater at Palmer Head $(53.7 \% \pm 4.4$ S.E. $)$ and lowest at Trig Point $(21.4 \% \pm 4.5$ S.E.) (Appendix 2). Red erect algae (Rhodophyta) were most abundant at Barrett Reef with a mean percentage cover of $17 \%$, while Phaeophyta was most conspicuous at Kapiti Island sites, with approximately $14 \%$ coverage (PERMANOVA $P<0.001$ ), differences among sites were significant (Table 2.3). The presence of Chlorophyta was generally low, and was only abundant at Princess Bay and The Sirens Rocks (Fig. 2.4). Sponges were the most conspicuous sessile invertebrates; their mean percentage cover was significant different across sites (PERMANOVA $P<0.001$ ), being highest at Trig Point $(20.6 \% \pm 3.0$ S.E. $)$ and lowest at Princess Bay $(3.9 \% \pm 1.4$ S.E.). Sponge coverage was also high at the Sirens Rock and Breaker Bay in Wellington (Figs. 2.42.5), where both sites were characterised by the presence of steep-walled channels. 
Other important invertebrates were ascidians, hydroids and bryozoans, however their mean coverage was less than $6 \%$ coverage (Appendix 2).

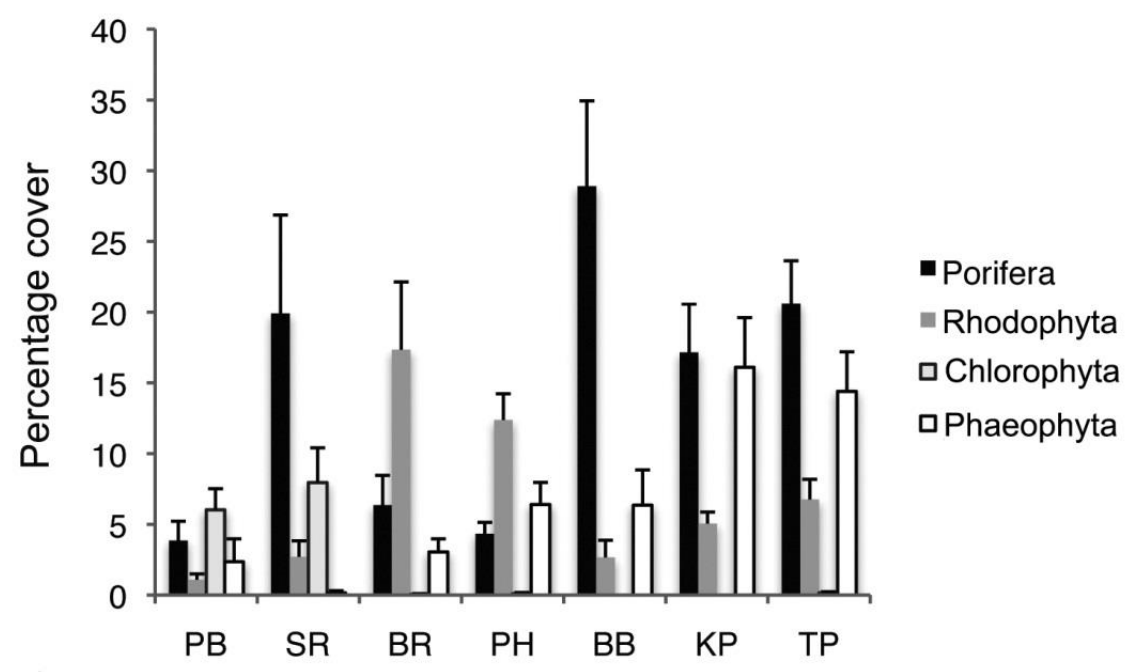

Figure 2.4. Mean percentage cover of sponges and macroalgae across sites studied on the south coast of Wellington and at Kapiti Island. PB = Princess Bay; SR = The Sirens Rocks; BR = Barrett Reef; $\mathrm{PH}=$ Palmer Head; $\mathrm{BB}=$ Breaker Bay; $\mathrm{KP}=$ Kaiwharawhara Point; TP = Trig Point.

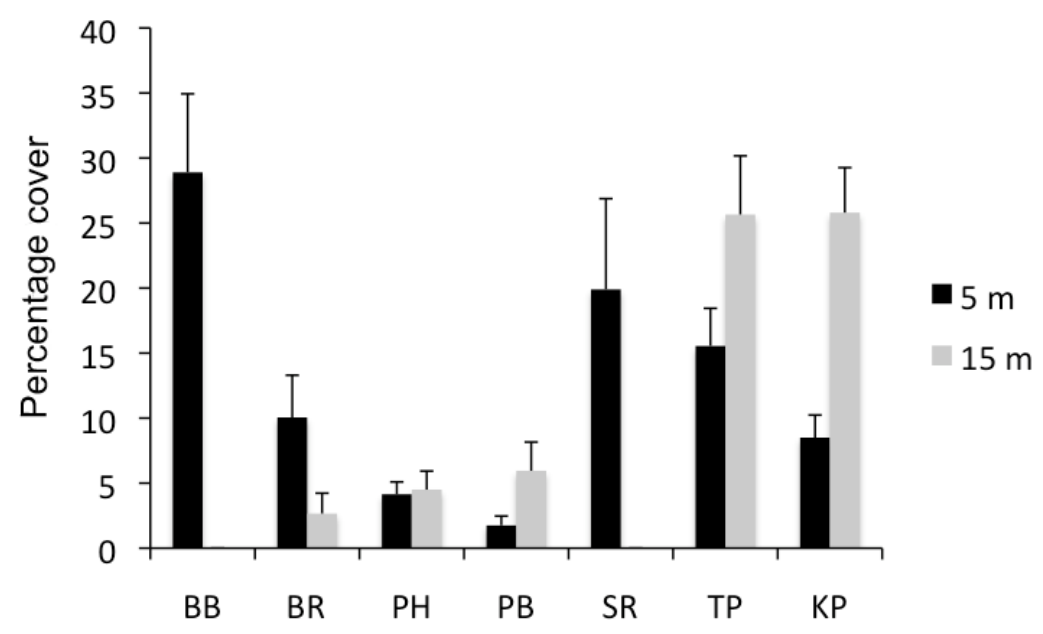

Figure 2.5. Mean percentage cover of sponges across sites studied on the south coast of Wellington and at Kapiti Island. PB = Princess Bay; SR = The Sirens Rocks; BR = Barrett Reef; PH = Palmer Head; BB = Breaker Bay; KP = Kaiwharawhara Point; TP $=$ Trig Point. Percentage cover values for each sample were pooled for each surface inclination (Error bars represent S.E.). 
Differences in community structure were found between sites nested in region (PERMANOVA $P<0.001$, Table 2.4) but not between regions (PERMANOVA $P>$ 0.05). I found significant differences in community structure between surface inclinations; there was also a significant interaction between site nested in region and depth (PERMANOVA $P<0.05$, Table 2.4), meaning the effect of depth varied between sites. The effect of depth was different among sites as there was a significant effect of depth at Barrett Reef, Princess Bay and Kaiwharawhara Point $(P<0.05)$, but not at Palmer Head and Trig Point $(P>0.05)$. The greatest differences in community structure were observed between Trig Point at Kapiti Island and most of the sites on the Wellington south coast, except Breaker Bay, which was more similar to the sites studied at Kapiti Island rather than the sites located in Wellington. The percentage cover of sponges, crustose coralline algae and red erect algae varied between depths (PERMANOVA $P<0.001$ ). In contrast, no differences were found in coverage of Phaeophyta and Chlorophyta (PERMANOVA $P>0.05$, Table 2.3).

Table 2.3. PERMANOVA to test for differences between sites, depths and inclinations in the percentage cover of dominant benthic groups. Statistical differences were tested using 9,999 permutations of raw dada. Significance is indicated by asterisks: $* P<0.05, * * P<0.001$.

\begin{tabular}{|c|c|c|c|c|c|c|}
\hline & Site & & Depth & & Inclination & \\
\hline Taxa & $\mathrm{F}$ & $P$ & $\mathrm{~F}$ & $P$ & $\mathrm{~F}$ & $P$ \\
\hline Porifera & $4.9068(6,64)$ & $0.0001 * *$ & $4.733(1,64)$ & 0.057 & $5.342(3,64)$ & $0.0002 * *$ \\
\hline Rhodophyta & $10.664(6,64)$ & $0.001 * *$ & $6.1242(1,64)$ & $0.014 *$ & $4.723(3,64)$ & $0.002 * *$ \\
\hline Chlorophyta & $27.983(6,64)$ & $0.0001 * *$ & $0.20802(1,64)$ & 0.669 & $0.5095(3,64)$ & 0.6936 \\
\hline Phaeophyta & $4.796(6,64)$ & $0.0001 * *$ & $1.9618(1,64)$ & 0.139 & $1.584(3,64)$ & 0.1665 \\
\hline CCA & $2.4961(6,64)$ & $0.0227 *$ & $7.2963(1,64)$ & $0.005^{* *}$ & $6.970(6,64)$ & $0.0004 * *$ \\
\hline
\end{tabular}

Differences in sponge percentage cover were found on different surface inclinations, ranging from $5.5 \%( \pm 2.0$ S.E. $)$ on horizontal surfaces to $38.8 \%( \pm 5.8$ S.E.) on overhanging surfaces (PERMANOVA $P<0.001$, Table 2.3). In contrast, the coverage of erect algae decreased with increasing inclination, having the lowest 
abundance on overhangs (Fig. 2.6; PERMANOVA $P<0.001$ ). The abundance of crustose coralline algae decreased their percentage cover from inclined surfaces $(42.8 \% \pm 6.44$ S.E. $)$ to overhangs $(13.7 \% \pm 7.67$ S.E.; PERMANOVA $P<0.05)$. Canopy cover showed the highest values at Palmer Head, with near to $90 \%( \pm 12.1$ S.E), at $5 \mathrm{~m}$ and $39 \%( \pm 11.2$ S.E.) at $15 \mathrm{~m}$ (Fig. 2.7). Sites at Kapiti Island showed the same pattern of decreased canopy cover with depth. The most important canopyforming species were Ecklonia radiata, Lessonia variegata and Carpophyllum maschalocarpum.

Table 2.4. Permutational analysis of variance (PERMANOVA) based on a BrayCurtis similarity matrix, testing the effect of region ( 2 levels, random), site (5 levels, random), depth (2 levels, fixed) and inclination (4 levels, fixed) on the overall community. Statistical differences were tested using 9,999 permutations under a reduced model. Significance is indicated by asterisks: $* P<0.05$, $* * P<0.001$.

\begin{tabular}{lrrrc}
\hline Factor & $d f$ & \multicolumn{1}{c}{ MS } & $F$ & $P$ \\
\hline Region & 1 & 4597.8 & 1.268 & 0.304 \\
Depth & 1 & 2336.9 & 1.105 & 0.414 \\
Inclination & 3 & 2785.8 & 1.820 & $0.050^{*}$ \\
Site(Region) & 5 & 4798.4 & 2.584 & $0.001^{* *}$ \\
Region x Depth & 1 & 2233.5 & 0.581 & 0.629 \\
Region x Inclination & 3 & 1526.1 & 0.605 & 0.863 \\
DexInclination & 3 & 2616.9 & 1.009 & 0.509 \\
Site(Region) x Depth & 3 & 3740.4 & 2.015 & $0.013 *$ \\
Site(Region) x Inclination & 9 & 2789 & 1.502 & 0.069 \\
Region x Depth x Inclination & 2 & 2718.3 & 1.963 & 0.338 \\
Site(Region) x Depth x Inclination & 1 & 1335.5 & 0.719 & 0.649 \\
Residual & 30 & 1856.8 & & \\
Total & 62 & & & \\
\hline
\end{tabular}




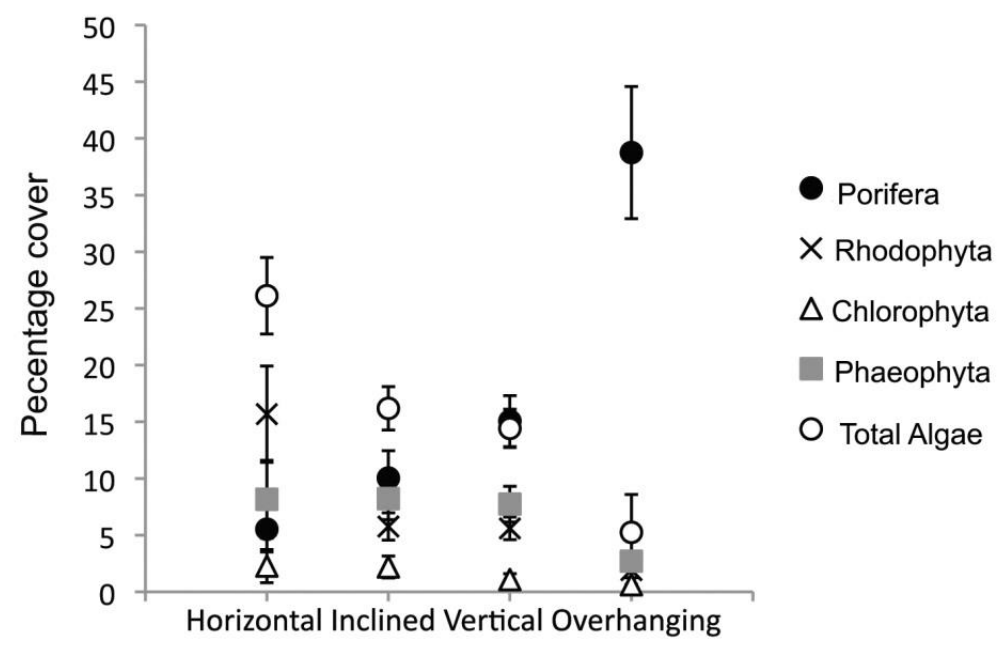

Figure 2.6. Relationship between mean percentage cover of sponges and macroalgae for different surface inclinations. Percentage cover values for each sample were pooled for each surface inclination (Error bars represent S.E.).

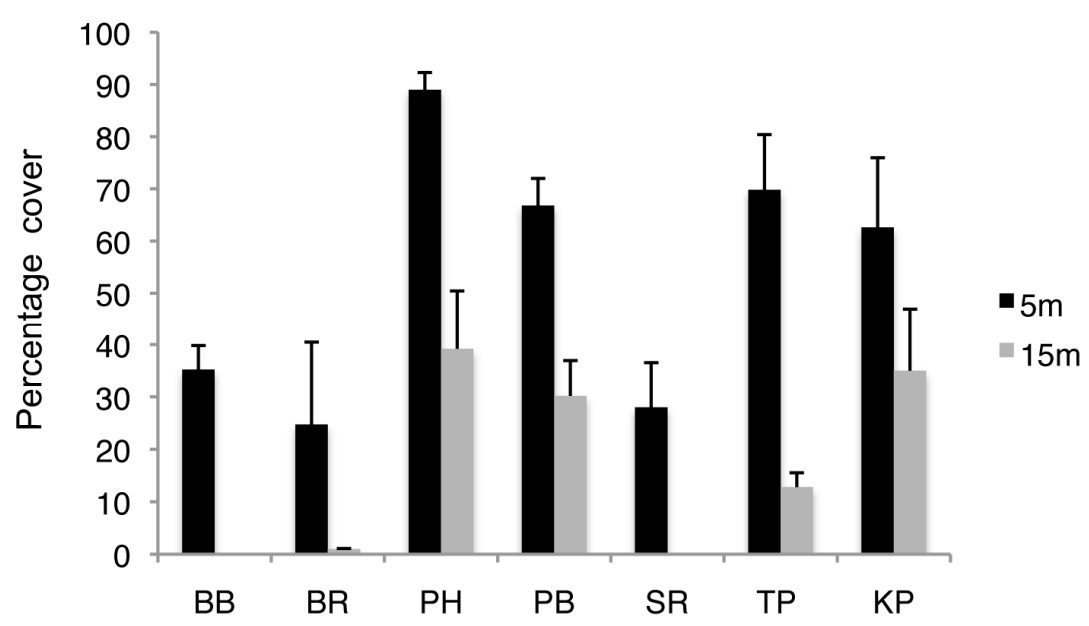

Figure 2.7. Mean percentage cover of canopy across sites studied on the south coast of Wellington and at Kapiti Island. For abbreviations see figure 2.2. Percent cover values for each sample were pooled for each surface inclination (Error bars represent S.E.).

Figure 2.8 shows examples of assemblages found on different surface inclinations, where the dominance of macroalgae decreased from inclined to 
overhanging surfaces. In contrast, sponges were significantly more abundant in vertical and overhanging surfaces.

When sponge abundance was correlated with algal coverage and canopy cover, an exponential relationship was observed in both cases (Fig. 2.9). However, the latter correlation was weak $\left(\mathrm{r}^{2}=0.387, P<0.001\right)$. Nonetheless, when sponge coverage was correlated against canopy cover (first layer), a significant negative correlation was found $\left(\mathrm{r}^{2}=0.546, P<0.001\right)$. Linear relationships fitted to both data sets were much weaker than those for the exponential relationships $(0.1$ and 0.3 , respectively). A weak but significant relationship between percentage cover of sponges and crustose coralline algae was found $\left(r^{2}=0.004, P<0.001\right.$; Fig 2.9c). When sponge coverage was plotted against canopy, algal abundance and CCA for each inclination type, no significant correlations were found in most cases, except for sponge coverage versus canopy cover and algal abundance on inclined surfaces $\left(\mathrm{r}^{2}=\right.$ 0.9286 and $0.9283, P<0.001$ respectively).

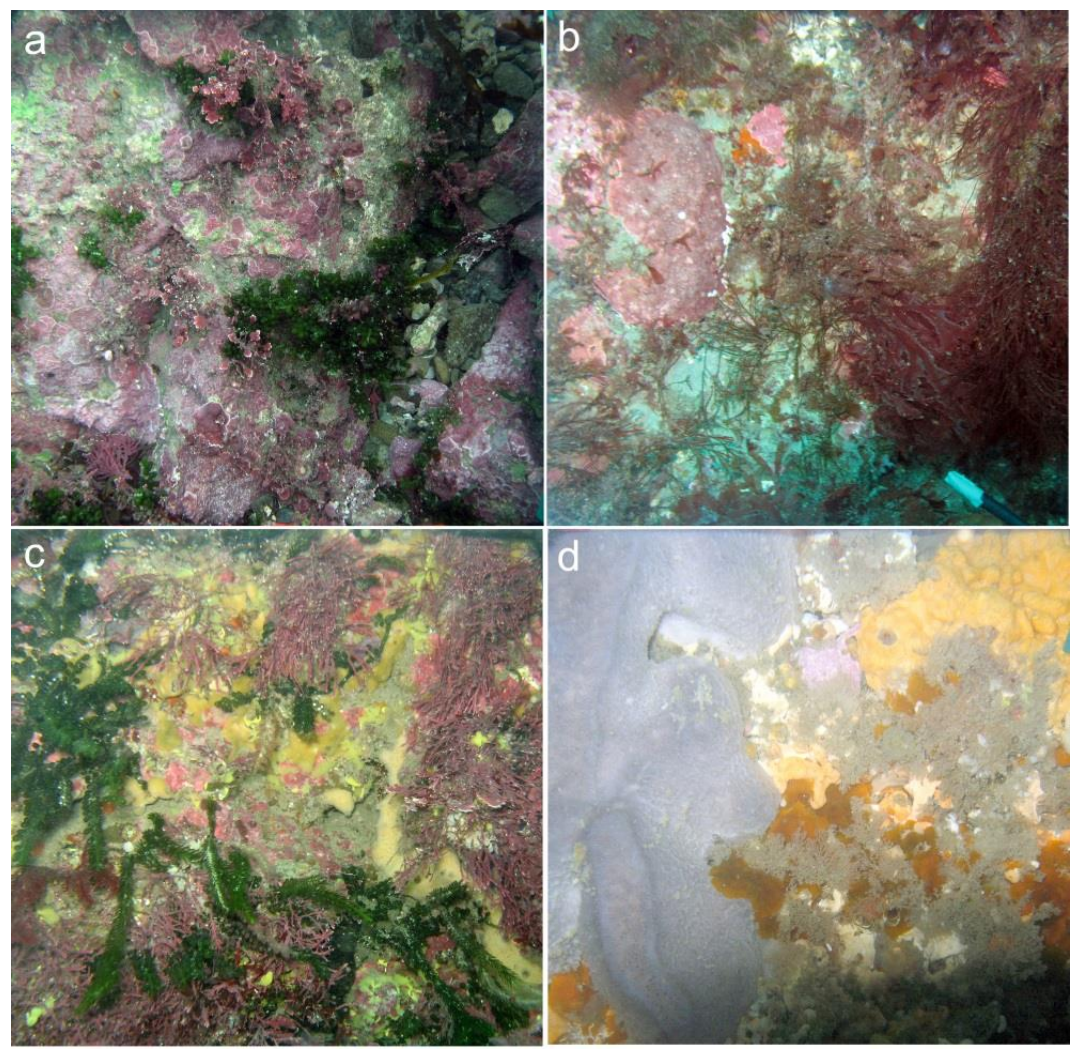

Figure 2.8. Examples of photoquadrats showing the different assemblages on different surface inclinations A) horizontal; B) inclined; C) vertical; D) overhanging. 
Chapter 2. Correlations between sponges and macroalgae
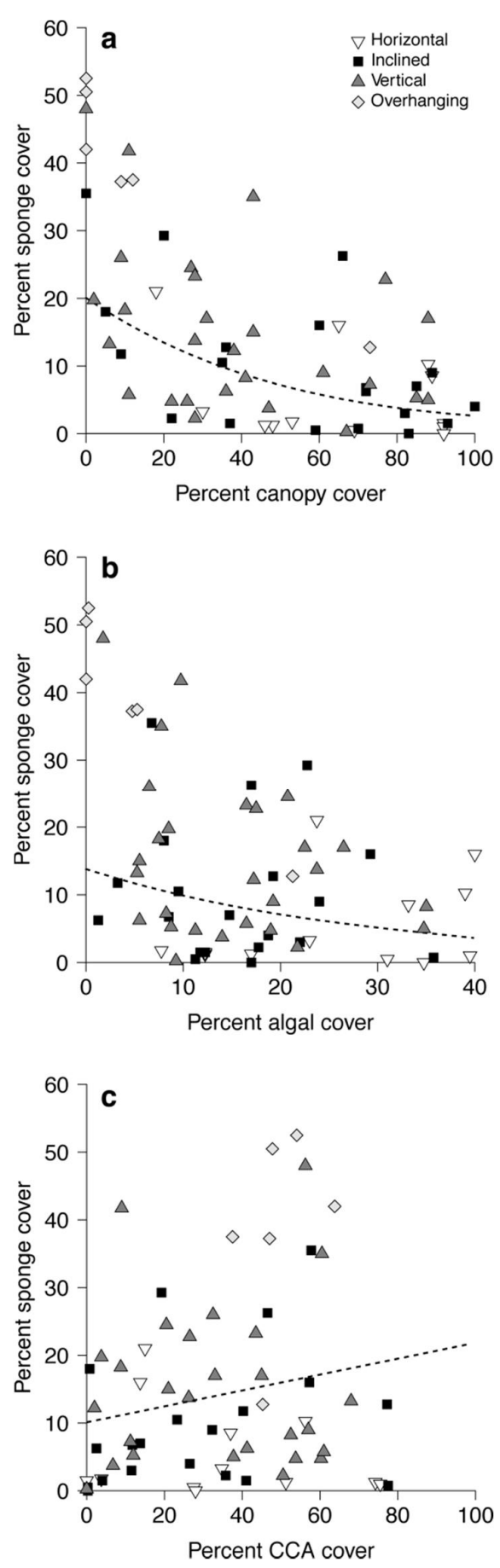

Figure 2.9. a) Relationship between percentage cover of sponges and canopy ( $y=$ $\left.35.2678 * \exp ^{-0.0296 x}, \mathrm{r}^{2}=0.546, P<0.001\right)$; b) Relationship between percentage cover of sponges and macroalgae per quadrat $\left(\mathrm{y}=35.3829 * \exp ^{-0.0799 x}, \mathrm{r}^{2}=0.387, P<\right.$ 0.001). c). Relationship between percentage cover of sponges and crustose coralline algae $(\mathrm{CCA})$ per quadrat $\left(\mathrm{y}=\exp ^{0.0415 \mathrm{x}}, \mathrm{r}^{2}=0.004, P<0.001\right)$. Scale for $\mathrm{x}$-axis differs between panels. 
Chapter 2. Correlations between sponges and macroalgae

\subsubsection{Relationship between algal abundance, environmental variables and benthic assemblages at different taxonomic levels}

The variation in community composition relative to the different environmental variables is shown in Fig. 2.10a. The first two axes explained $64.4 \%$ of the variation in the community structure (Table 2.5). The Monte-Carlo test results showed that the first and all canonical axes were significant $(P=0.001)$. The most important variables were inclination, percentage cover of crustose coralline algae, canopy cover, percentage cover of settled sediment and algal abundance. The redundancy analysis showed that the community composition of encrusting invertebrates was positively correlated with surface inclination and not with the other variables. Sponges were positively correlated with inclination, especially with vertical and overhanging surfaces. The redundancy analysis confirmed the results of the correlation analysis in that it identified a significant negative association between sponges and algal canopy and crustose coralline algae.

A detailed analysis of the sponge assemblages showed how sponge taxa correlated with the different environmental and biological variables (Fig. 2.10b). According to the Monte-Carlo tests, the first and all canonical axes were significant $(P=0.001)$. The first two axes explained $19.0 \%$ and $22.8 \%$ of the variation in the species data, respectively, and both axes explained $84.5 \%$ of the variance of the species-environment relationships (Table 2.6). The first axis was determined mainly by canopy cover $(r=-0.61)$, inclination $(r=0.56)$ and crustose coralline algae $(r=-$ $0.49)$ and the second axis by algal abundance $(\mathrm{r}=-0.43)$. The RDA showed that most taxa were highly correlated with inclination. The majority of sponge taxa were negatively correlated with algal canopy cover (first layer) and algal understory abundance and crustose coralline algae, whereas a few species, such as Polymastia crocea and Haliclona sp. 2, were positively correlated with these variables. The settled sediment cover on the substratum negatively correlated with the abundance of the majority of the sponge species, with most being associated with low levels of settled sediment. Species such as the calcareous sponges, Clathrina spp. and Leucosolenia echinata, Tedania sp., Oscarella lobularis were more abundant on vertical and overhanging surfaces. 
Chapter 2. Correlations between sponges and macroalgae

Table 2.5. Summary results of the redundancy analysis for the overall community on the south coast of Wellington and at Kapiti Island.

\begin{tabular}{lrrrrr}
\hline Axes & 1 & 2 & 3 & 4 & Total variance \\
\hline Eigenvalues & 0.61 & 0.034 & 0.01 & 0.001 & 1 \\
Species-environment correlations & 0.957 & 0.558 & 0.344 & 0.15 & \\
Cumulative percentage variance & & & & & \\
$\quad$ of species data & 61 & 64.4 & 65.3 & 65.5 & 1 \\
$\quad$ of species-environment relation: & 93.1 & 98.3 & 99.7 & 99.9 & 0.655 \\
$\quad$ Sum of all eigenvalues & & & & & \\
Sum of all canonical eigenvalues & & & & & \\
\hline
\end{tabular}

Table 2.6. Summary results of the redundancy analysis for sponge assemblages on the south coast of Wellington and at Kapiti Island.

\begin{tabular}{lrrrrr}
\hline Axes & 1 & 2 & 3 & 4 & Total variance \\
\hline Eigenvalues & 0.19 & 0.038 & 0.022 & 0.012 & 1 \\
Species-environment correlations & 0.899 & 0.64 & 0.618 & 0.444 & \\
Cumulative percentage variance & & & & & \\
$\quad$ of species data & 19 & 22.8 & 24.9 & 26.1 & 1 \\
$\quad$ of species-environment relation & 70.5 & 84.5 & 92.5 & 97 & 0.27 \\
Sum of all eigenvalues & & & & & \\
Sum of all canonical eigenvalues & & & & & \\
\hline
\end{tabular}


Chapter 2. Correlations between sponges and macroalgae
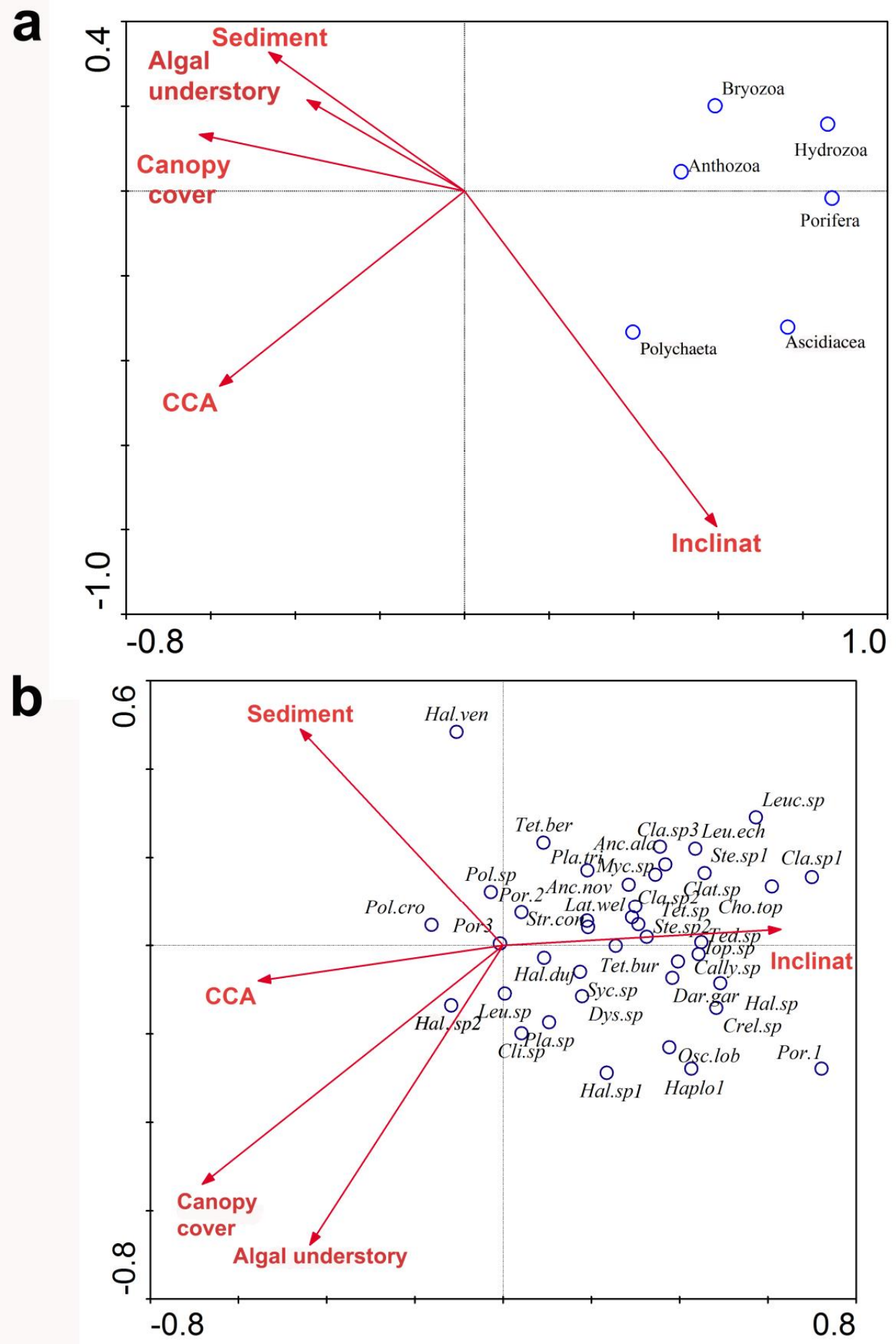

Figure 2.10. a) Ordination plot of the overall community and variables based on a redundancy analysis (RDA-biplot); b) Ordination plot of sponge assemblages, and variables based on a redundancy analysis (RDA-biplot). Vectors represent the environmental variables and species are represented as circles. Inclinat $=$ inclination. See Appendix 3 for taxon names. 


\subsection{Discussion}

\subsubsection{Interactions between sponges and macroalgae}

Supporting previous studies from the northern hemisphere, I found that sponge distribution and abundance were negatively correlated with erect algae and algal canopy cover. Despite sponge abundance and richness being strongly correlated with surface inclination, my results also show a negative correlation between sponges and the abundance of erect algae, crustose coralline algae and, especially algal canopy cover. A considerable number of sponge species (more than $80 \%$ ) were strongly positively associated with the degree of surface inclination and turbidity, and also negatively correlated with the percentage of canopy cover and crustose coralline and erect algae. In contrast, only a few sponge species were positively correlated with algae, which is in contrast to what was reported for the Mediterranean by Preciado and Maldonado (2005) where several species were strongly correlated to some algal communities.

Despite the overall negative correlation between sponge and algal abundance that I observed, it is possible that some sponge species, such as Polymastia spp. and Haliclona sp. 2, might be adapted to high-light habitats that are generally dominated by fast-growing algae. Turon et al. (1998) found that the growth rates were higher for sponges inhabiting high-light habitats compared to shaded habitats in the western Mediterranean. These authors argued that these sponge species show an opportunistic strategy in response to this type of habitat, which is dominated by fast-growing algae that might out-compete them, and where patches of bare substratum frequently become available (as algae tend to be short lived).

The low explanatory value obtained when sponge cover was correlated with algal cover and crustose coralline algae is most likely a result of the high variability recorded in the sponge coverage, as I considered sponges as a single group, rather than constituent species. This problem could explain why other authors have not found a negative relationship between both groups, as it is difficult to show a clear pattern as different sponge species show different responses to algal abundance and other environmental factors. My analysis at the species level showed variable 
responses by different sponge species to algal abundance, however negative correlations were much more common. Previous studies have reported contrasting results regarding the effects of algal canopies on sponge species. For example, Kennelly (1987b, 1989) did not find any relationship between shade or scour produced by Ecklonia radiata on the growth and abundance of the sponge Myxilla sp. in Australia. In another study, carried out in Washington State (U.S.), Eckman \& Duggins (1991) found that higher sedimentation rates existed beneath kelp canopies, but this did not result in higher mortality of Myxilla sp.; however, these authors also found that sediment deposition negatively affected the spongeôs growth (although their study organisms had been collected from a sediment-free environment). Thus, the probability of finding a negative effect of light and sedimentation were highly likely, as it has been demonstrated that both factors may be detrimental for some species (Jokiel 1980, Maldonado et al. 2008). In contrast, some sponge species appear to be influenced by conditions (e.g. shade and sedimentation) that occur underneath the canopy (Smith 1996, Bulleri et al. 2002). For example, Wright et al. (1997) found a higher percentage of inorganic material in sponges living beneath Ecklonia forests, suggesting that sponges living beneath the canopy may be better adapted to sedimented conditions and respond by incorporating it into their skeletal matrix rather than shedding it. Interestingly, these authors also suggested that sand incorporated into the matrix might help sponges to tolerate scouring from algal fronds, although there is no experimental data to support such an hypothesis.

\subsubsection{Effect of surface inclination and its associated factors on sponge assemblages}

The effect of surface inclination on sessile organisms has been considered extensively (Barnes 1995, Turon et al. 1998, Baynes 1999, Bell \& Barnes 2000b, c, Maughan \& Barnes 2000a, Bell 2001, Irving \& Connell 2002, Knott et al. 2006, Walker et al. 2007). Generally, sessile invertebrates are more abundant on vertical and overhanging surfaces, compared to inclined and horizontal surfaces (Witman \& Sebens 1990, Baynes 1999, Irving \& Connell 2002, Konar \& Iken 2005). Surface inclination affects the composition and diversity of sponge assemblages (Bell \& Barnes 2000b, c, Bell \& Smith 2004) as well as the growth of some species (Knott et al. 2006). My results support these previous studies and highlight the importance of small-scale 
environmental variability in influencing sponge assemblage structure. I found that surface inclination also affected sponge species richness. These differences between surface inclinations may be explained by the different levels of disturbance occurring on horizontal compared to vertical or overhanging surfaces, which affect sponge species and especially competition between sponges and algae (Bell \& Barnes 2000b). The effect of irradiance and sediment on horizontal surfaces might affect sponge diversity, as fewer species are adapted to tolerate sediment accumulation on their surface, while others might be affected by the higher levels of irradiance in these habitats. In contrast, such conditions might be favourable for algal colonisation, reducing the space available for sponges and other sessile invertebrates (Bell \& Barnes 2000e). Other possible sources of disturbance variability include differing algal whiplash effects across different surface inclination (see Konar \& Estes 2003), which could affect the settlement of sponges. However, further experimental work is needed to test the magnitude of the effect of algal abrasion on sponges. I also found clear differences between surface inclinations for both sponges and algae, with sponges dominating vertical surfaces and overhangs, while macroalgae dominated horizontal and inclined surfaces. It has been suggested that the dominance of sponges on vertical and overhanging surfaces at bathyal depths (Maldonado \& Young 1996), where light and macroalgae do not occur, demonstrate that factors, other than competition with macroalgae, are responsible for these patterns. However, I believe that in shallow water competition with macroalgae cannot be discarded as an important interaction influencing the distribution of sponges. Furthermore, my analysis at the species-level suggests that the distribution of sponge species cannot be attributed to a single factor (e.g. inclination), as I found species associated with one or more factors. For example, several sponge species (e.g. Tedania sp. and Oscarella lobularis) were positively associated with surface inclination and turbidity, and negatively associated with settled sediment and algal presence (canopy cover and abundance of turf algae). In contrast, other taxa (Polymastia spp. Haliclona sp. 2 and Haliclona venustina) were positively correlated with high levels of settled sediment and canopy/algal understory abundance.

Depth has been considered to be an important factor influencing sponge distribution patterns (Wilkinson \& Evans 1989, Diaz et al. 1990b, Witman \& Sebens 1990), through its effect on physical factors, such as light and the degree of 
disturbance from wave action or sedimentation (Wilkinson \& Evans 1989). My results showed a significant interaction between site and depth, with depth being important to explain differences in community structure at three sites. However, the effect of depth was less important than other physical variables measured at my study sites. It seems that the level of disturbance produced by sediment and light was more related to changes associated with surface inclination. It is likely that disturbance produced by sedimentation with increasing depth is less important than other factors at my study sites, as they are highly dynamic due to the presence of regular southerly swells that may re-suspend the sediment. The level of exposure was measured with a surrogate of the orientation of the sites with respect to the main swells, however, previous studies (Leichter \& Witman 1997) have found no significant effect produced by wall orientation to flow and tidal currents. They suggested that interaction between smallscale variations in substrate (e.g. shape or inclination) with local flow fields were important factors, rather than wall orientation, influencing the distribution and growth of sponges.

In conclusion, I found that sponge abundance was negatively correlated with algal abundance. My results confirm the results of a number of previous studies carried out in northern latitudes, but contradicting findings from an earlier study in the southern hemisphere. Nevertheless, I acknowledge that I have only demonstrated a correlation between these groups and further manipulative experimental approaches are needed to critically identify the factors and mechanisms explaining the interactions occurring between sponges and the algal canopy. I also found that the distribution and abundance of sponges cannot be attributed to substratum inclination alone, as this factor is also affecting algae. In fact, several physical factors including inclination, and settled sediment, as well as biological factors including the abundance of canopy forming species, erect algae and crustose coralline algae, seem to correlate with the spatial distribution and abundance of sponge assemblages at my study sites on the south coast of New Zealandôs North Island. 
Chapter 2. Correlations between sponges and macroalgae

\subsection{References}

Advanced Graphics Software (1999) SlideWrite Plus Userô Guide. Advanced Graphics Software, Inc, Encinitas, CA

Anderson MJ (2001) A new method for non-parametric multivariate analysis of variance. Austral Ecology 26:32-46

Anderson MJ, Gorley RN, Clarke KR (2007) Permanova for Primer: Guide to Software and Statistical Methods, PRIMER-E, Plymouth

Ayling AM (1983) Factors affecting the spatial distributions of thinly encrusting sponges from temperate waters. Oecologia 60:412-418

Baldacconi R, Corriero G (2009) Effects of the spread of the alga Caulerpa racemosa var. cylindracea on the sponge assemblage from coralligenous concretions of the Apulian coast (Ionian Sea, Italy). Marine Ecology 30:337-345

Barnes DKA (1995) Sublittoral epifaunal communities at Signy Island, Antarctica. II. Below the ice foot zone. Marine Biology 121:565-572

Barthel D, Gutt J, Tendal OS (1991) New information on the biology of Antarctic deep-water sponges derived from underwater photography. Marine Ecology Progress Series 69:303-307

Battershill CN, Murdoch RC, Grange KR, Singleton RJ, Arron ES, Page MJ, Oliver MD (1993) A survey of the marine habitats and communities of Kapiti Island. In. Depatment of Conservation, Wellington

Baxter A (1987) Kapiti Island: subtidal ecology survey. In, Book 87/2. MAF Central Fisheries Area Internal report, Napier, New Zealand

Baynes TW (1999) Factors structuring a subtidal encrusting community in the southern Gulf of California. Bulletin of Marine Science 64:419-450

Bell JJ (2001) The influence of water flow rate, depth and surface inclination on the density and the distribution of five species of temperate anthozoa at Lough Hyne, Ireland. Journal of the Marine Biological Association of the United Kingdom 81:883-884

Bell JJ (2002) The sponge community in a semi-submerged temperate sea cave: density, diversity and richness. Marine Ecology 23:297-311

Bell JJ (2007) The ecology of sponges in Lough Hyne Marine Nature Reserve (southwest Ireland): past, present and future perspectives. Journal of the Marine Biological Association of the United Kingdom 87:1655-1668 
Chapter 2. Correlations between sponges and macroalgae

Bell JJ, Barnes DKA (2000a) A sponge diversity centre within a marine óslandô Hydrobiologia 440:55-64

Bell JJ, Barnes DKA (2000b) The distribution and prevalence of sponges in relation to environmental gradients within a temperate sea lough: Inclined cliff surfaces. Diversity and Distributions 6:305-323

Bell JJ, Barnes DKA (2000c) The distribution and prevalence of sponges in relation to environmental gradients within a temperate sea lough: inclined cliff surfaces. Diversity and Distributions 6:305-323

Bell JJ, Barnes DKA (2000d) The distribution and prevalence of sponges in relation to environmental gradients within a temperate sea lough: vertical cliff surfaces. Diversity and Distributions 6:282-303

Bell JJ, Barnes DKA (2000e) The influences of bathymetry and flow regime upon the morphology of sublittoral sponge communities. Journal of the Marine Biological Association of the United Kingdom 80:707-718

Bell JJ, Barnes DKA (2003) Effect of disturbance on assemblages: an example using porifera. Biological Bulletin 205:144-159

Bell JJ, Smith D (2004) Ecology of sponge assemblages (Porifera) in the Wakatobi region, south-east Sulawesi, Indonesia: richness and abundance. Journal of The Marine Biological Association of the United Kingdom 84:581-591

Berman J, Bell JJ (2010) Spatial variability of sponge assemblages on the Wellington South Coast, New Zealand. The Open Journal of Marine Biology 4:12-25

Bray JR, Curtis JT (1957) An ordination of the upland forest communities of southern Wisconsin. Ecological Monographs 27:325-349

Bulleri F, Benedetti-Cecchi L, Acunto S, Cinelli F, Hawkins SJ (2002) The influence of canopy algae on vertical patterns of distribution of low-shore assemblages on rocky coasts in the northwest Mediterranean. Journal of Experimental Marine Biology and Ecology 89-106

Carballo JL (2006) Effect of natural sedimentation on the structure of tropical rocky sponge assemblages. Ecoscience 13:119-130

Carter L, Lewis K (1995) Variability of the modern sand cover on a tide and storm driven inner shelf, south Wellington, New Zealand. New Zealand Journal of Geology and Geophysics 38:451-470

Cebrian E (2010) Grazing on coral reefs facilitates growth of the excavating sponge Cliona orientalis (Clionaidae, Hadromerida). Marine Ecology 31:533-538 
Chiswell SM, Stevens CL (2010) Lagrangian and Eulerian estimates of circulation in the lee of Kapiti Island, New Zealand. Continental Shelf Research 30:515-532

Clarke KR, Gorley RN (2006) Primer v6: user manual/tutorial, Vol 1

Davis AR, Roberts DE, Cummins SP (1997) Rapid invasion of a sponge-dominated deep-reef by Caulerpa scalpelliformis (Chlorophyta) in Botany Bay, New South Wales. Australian Journal of Ecology 22:146-150

Dayton PK, Robilliard GA, Paine RT, Dayton LB (1974) Biological accommodation in the benthic community at McMurdo Sound, Antarctica. Ecological Monographs 44:105-128

de Voogd NJ, Becking LE, Cleary DFR (2009) Sponge community composition in the Derawan Islands, NE Kalimantan, Indonesia. Marine Ecology Progress Series 396:216-230

de Voogd NJ, Cleary DFR (2007) Relating species traits to environmental variables in Indonesian coral reef sponge assemblages. Marine and Freshwater Research 58:240-249

Diaz MC, Alvarez B, Laughlin RA (1990) The sponge fauna on a fringing coral reef in Venezuela: community structure. In: Rützler K (ed) New perspectives in sponge biology. Smithsonian Institution Press, London

Diaz MC, Rützler K (2001) Sponges: as essential component of Caribbean coral reefs. Bulletin of Marine Science 69:535-546

Dunlap M, Pawlik JR (1996) Video-monitored predation by Caribbean reef fishes on an array of mangrove and reef sponges. Marine Biology 126:117-123

Eckman JE, Duggins DO (1991) Life and death beneath macrophyte canopies: effects of understory kelps on growth rates and survival of marine, benthic suspension feeders. Oecologia 87:473-487

Ginn BK, Logan A, Thomas MLH (2000) Sponge ecology on sublittoral hard substrates in a high current velocity area. Estuarine, Coastal and Shelf Science 50:403-414

Irving AD, Connell SD (2002) Sedimentation and light penetration interact to maintain heterogeneity of subtidal habitats: algal versus invertebrate dominated assemblages. Marine Ecology Progress Series 245:83-91

Jokiel PL (1980) Solar ultraviolet radiation and coral reef epifauna. Science 207:1069-1071 
Kaandorp JA, de Kluijver MJ (1992) Verification of fractal growth models of the sponge Haliclona oculata (Porifera) with transplantation experiments. Marine Biology 113:133-143

Kennelly SJ (1987) Physical disturbances in an Australian kelp community. II. Effects on understorey species due to differences in kelp cover. Marine Ecology Progress Series 40:155-165

Kennelly SJ (1989) Effects of kelp canopies on understorey species due to shade and scour. Marine Ecology Progress Series 50:215-224

Knapp ISS, Bell JJ (2010) Effect of depth on sponge assemblage structure at Palmyra Atoll, Central Pacific. The Open Journal of Marine Biology 4:26-30

Knott NA, Underwood AJ, Chapman MG, Glasby TM (2004) Epibiota on vertical and on horizontal surfaces on natural reefs and on artificial structures. Journal of the Marine Biological Association of the United Kingdom 84:1117-1130

Knott NA, Underwood AJ, Chapman MG, Glasby TM (2006) Growth of the encrusting sponge Tedania anhelans (Lieberkuhn) on vertical and on horizontal surfaces of temperate subtidal reefs. Marine and Freshwater Research 57:95-104

Kohler KE, Gill SM (2006) Coral Point Count with Excel extensions (CPCe): A Visual Basic program for the determination of coral and substrate coverage using random point count methodology. Computers and Geosciences 32:12591269

Konar B, Estes JA (2003) The stability of boundary regions between kelp beds and deforested areas. Ecology 84:174-185

Konar B, Iken K (2005) Competitive dominance among sessile marine organisms in a high Arctic boulder community. Polar Biology 29:61-64

Leichter JJ, Witman JD (1997) Water flow over subtidal rock walls: relation to distributions and growth rates of sessile suspension feeders in the Gulf of Maine Water flow and growth rates. Journal of Experimental Marine Biology and Ecology 209:293-307

Leps J, Smilauer P (2003) Multivariate analysis of ecological data using CANOCO. Cambridge University Press, Cambridge

Maldonado M, Giraud K, Carmona C (2008) Effects of sediment on the survival of asexually produced sponge recruits. Marine Biology 154:631-641 
Maldonado M, Young CM (1996) Effects of physical factors on larval behavior, settlement and recruitment of four tropical demosponges. Marine Ecology Progress Series 138:169-180

Maughan BC, Barnes DKA (2000) Epilithic boulder communities of Lough Hyne, Ireland: the influences of water movement and sediment. Journal of the Marine Biological Association of the United Kingdom 80:767-776

Powell AL, Hepburn LJ, Smith DJ, Bell JJ (2010) Patterns of Sponge Abundance Across a Gradient of Habitat Quality in the Wakatobi Marine National Park, Indonesia. The Open Journal of Marine Biology 4:31-38

Preciado I, Maldonado M (2005) Reassessing the spatial relationship between sponges and macroalgae in sublittoral rocky bottoms: a descriptive approach. Helgoland Marine Research 59:141-150

Roberts DE, Cummins SP, Davis AR, Chapman MG (2006a) Structure and dynamics of sponge-dominated assemblages on exposed and sheltered temperate reefs. Marine Ecology Progress Series 321:19-30

Roberts DE, Davis AR, Cummings SP (2006b) Experimental manipulation of shade, silt, nutrients and salinity on the temperate reef sponge Cymbastela concentrica. Marine Ecology Progress Series 307:143-154

Sarà M, Balduzzi A, Barbieri M, Bavestrello G, Burlando B (1992) Biogeographic traits and checklist of Antarctic demosponges. Polar Biology 12:559-585

Shears N, Babcock R (2007) Quantitative description of mainland New Zealand's shallow subtidal rocky reef communities. Science for Conservation 280:126pp

Smith SDA (1996) The macrofaunal community of Ecklonia radiata holdfasts: Variation associated with sediment regime, sponge cover and depth. Australian Journal of Ecology 21:144-153

Teixidó N (2003) Analysing benthic communities in the Weddell Sea (Antarctica): a landscape approach. Ph.D. Thesis, University of Bremen, Bremen

ter Braak CJF, Smilauer P (2002) CANOCO Reference manual and CanoDraw for Windows User's guide: Software for Canonical Community Ordination (version 4.5). Microcomputer Power, Ithaca, N.Y. U.S.A.

Turon X, Tarjuelo I, Uriz MJ (1998) Growth dynamics and mortality of the encrusting sponge Crambe crambe (Poecilosclerida) in contrasting habitats: correlation with population structure and investment in defence. Functional Ecology 12:631-639 
Uriz MJ, Rosell D, Martin D (1992) The sponge population of the Cabrera Archipelago (Balearic Islands): characteristics, distribution and abundance of the most representative species. Marine Ecology 13:101-117

Walker SJ, Schlacher TA, Schlacher-Hoenlinger MA (2007) Spatial heterogeneity of epibenthos on artificial reefs: fouling communities in the early stages of colonization on an East Australian shipwreck. Marine Ecology 28:435-445

Wilkinson CR, Cheshire AC (1989) Patterns in the distribution of sponge populations across the Central Great Barrier Reef. Coral Reefs 8:127-134

Wilkinson CR, Evans E (1989) Sponge distribution across Davies Reel Great Barrier Reef relative to location, depth, and water movement. Coral Reefs 8:1-7

Wilkinson CR, Vacelet J (1979) Transplantation of marine sponges to different conditions of light and current. Journal of Experimental Marine Biology and Ecology 37:91-104

Witman JD, Sebens KP (1990) Distribution and ecology of sponges at a subtidal rock ledge in the Central Gulf of Maine. In: Rützler K (ed) New perspectives in sponge biology. Smithsonian Institution Press, London

Wright JT, Benkendorff K, Davis AR (1997) Habitat associated differences in temperate sponge assemblages: the importance of chemical defence. Journal of Experimental Marine Biology and Ecology 213:199-213

Wulff JL (2006) Ecological interactions of marine sponges. Canadian Journal of Zoology 84:146-166

Zea S (1994) Patterns of coral and sponge abundance in stressed coral reefs at Santa Marta, Colombian Caribbean. In: Soest RWMv, van Kempen TG, Braekman JC (eds) Sponge in time and space; Biology, Chemistry, Paleontology. A.A. Balkema, Rotterdam

G̣uljeviĺ A, Thibaut T, Despalatoviĺ M, Cottalorda J-M, Nikolil V, Cvitkoviĺ I, Antolic B (2011) Invasive alga Caulerpa racemosa var. cylindracea makes a strong impact on the Mediterranean sponge Sarcotragus spinosulus. Biological Invasions 13:2303-2308 
Chapter 3. Facilitation of sponges by canopy-algae

\section{Chapter 3. Positive interactions between canopy-forming algae and sponges}

\subsection{Abstract}

In rocky temperate subtidal systems, canopy-forming algae have the potential to modify the physical environment, which can facilitate or exclude species from the understory. While the relationship between two of the most abundant and ecologically important rocky reef organisms, macroalgae and sponges, has been commonly regarded as negative, here I explore the potential for some sponge species to benefit from the presence of macroalgae through facilitation as a result of habitat modification. Experimental removals of the dominant canopy-forming kelp Ecklonia radiata were conducted at two sites on rocky walls in New Zealand and monitored for approximately 1.5 years. I hypothesised that the removal of the E. radiata canopy would affect the structure of subcanopy assemblages, such that there would be a reduction in sponge species richness and abundance. Furthermore, I investigated the biological and physical (predictor) variables that best explained variability in sponge assemblages after canopy removal. Canopy removal led to a community dominated by turf algae, which corresponded with a decrease in sponge abundance and richness. My results suggest that the Ecklonia canopy facilitates the presence of some sponge species such as Crella incrustans and allows their coexistence with turf algae underneath the canopy and also by altering immediate physical factors that may be detrimental for some sponge species. My results highlight how any loss of canopyforming species might have negative effects on sponge assemblages, which could affect the energy flow and the overall biodiversity found in these habitats. Further replicated experiments are required to confirm if the observed pattern occurs consistently in other sites and also to clarify the effect of separate factors on different species 


\subsection{Introduction}

Species interactions have been widely studied across terrestrial and marine habitats as they play important roles in structuring communities, with the outcomes of these interactions having implications for biodiversity patterns and ecosystem functioning (Reed \& Foster 1984, Goldberg 1987, Callaway 1995, Bertness et al. 1999, OâConnor et al. 2006, Bonanomi et al. 2011). Direct facilitation (sensu Bertness and Callaway 1994) occurs when neighbours modify physical or biotic conditions, which leads to positive effects; these interactions can influence diversity, community structure and productivity, and have the potential to result in cascading effects through the community (Bruno \& Bertness 2001, Stachowicz 2001, Bruno et al. 2003, Gouhier et al. 2011). Mechanisms of facilitation operating in the marine environment include provision of secondary substrata, reduced or enhanced predation or herbivory, reduced competition, and the amelioration of physical stress (see Bulleri 2009 for review). Bulleri (2009) suggested that amelioration of physical stress appears to be the most common mechanism of facilitation in intertidal habitats, whilst reduced consumer pressure (associational defence) is the most important facilitation mechanism in subtidal systems.

Rocky reefs usually support complex and highly diverse communities as a result of habitat diversity and complexity (Dayton 1985a, Sebens 1985, Schiel \& Hickford 2001). Seaweeds are one of the most important components of shallow rocky reef habitats, because of their productivity (Mann 1973) and their ability to modify the physical environment, which can facilitate or exclude species from the understory (Bertness et al. 1999). Sponges are also an important group of organisms in rocky reef communities throughout the world (Dayton et al. 1974, Ayling 1983, Bell \& Barnes 2000b, Bell 2008), and there has been some debate as to the degree to which sponges and algae are competing (e.g. Knott et al. 2004, Preciado \& Maldonado 2005, see Chapter 2).

The increased abundance of seaweeds compared to sponges in high-light environments has led to the hypothesis that seaweeds constitute important spatial competitors of sponges, and are able to outcompete sponges in high-light 
environments (Kennelly \& Underwood 1993, Bell \& Barnes 2000b, Ginn et al. 2000, Bell 2002, Bell 2007). My results (Chapter 2) showed that a combination of inclination and abundance of canopy and turf-forming algae explained a large proportion of the variability in the distribution and abundance of sponges in rocky reefs of New Zealand. I found that most of sponge species were negatively correlated with canopy-forming species and turf algae, but that some sponge species were positively correlated with the abundance of canopy-forming algae. This positive correlation between canopy-forming algae and some sponges suggests that some species might actually benefit from the presence of canopy-forming algae, a situation that has also been previously reported in studies from other temperate and tropical latitudes (Wright et al. 1997, Ávila et al. 2010).

Although many studies have assessed the effect of algal canopies on understory algae and sessile assemblages (e.g. Eckman \& Duggins 1991, BenedettiCecchi 2001, Bulleri et al. 2002, Connell 2003a,b, Edgar et al. 2004), few have specifically evaluated the effect of canopy-forming algae on sponge assemblages. Algal canopies have the potential to affect understory sponge assemblages by modifying the local environment. For example, algal canopies may result in shading (Toohey \& Kendrick 2008), which may benefit light sensitive sponges (Wulff 2012), reduced sedimentation, decreased water movement (Duggins et al. 1990, Connell 2003b; Russell 2007), enhanced nutrient supply (Duggins \& Eckman 1997, Morrow \& Carpenter 2008), and they also provide secondary settlement space for some species (Smith 1996, Ávila et al. 2010). Furthermore, canopy-forming algae may also affect sponges and other subcanopy species as a result of physical abrasion by fronds that can inhibit the recruitment of algae and invertebrates (Velimirov \& Griffiths 1979, Jenkins et al. 1999, Leonard 1999, Fowler-Walker et al. 2005). However, even though the combination of decreased light and reduced sedimentation produced by the algal canopy can facilitate recruitment for some species, physical abrasion seems to overpower any positive effect in structuring invertebrate and turf-algal assemblages (Connell 2003b, Russell 2007).

The habitat-forming kelp Ecklonia radiata (C. Agardh) dominates large areas on shallow-water rocky reefs of New Zealand and temperate Australia, providing food and shelter for many species (Choat \& Schiel 1982). Ecklonia radiata forests alter the 
local physical environment (e.g. light, sediment, wave exposure), influencing the structure of assemblages through canopy-understory interactions (Wernberg et al. 2005). Factors such as abundance, density and morphology of Ecklonia are critical in creating small-scale variation in diversity and structure of understory assemblages (Schiel 1988, Fowler-Walker et al. 2005, Smale et al. 2011). Earlier studies have reported conflicting effects of canopy removal on sponges, although only a few individual sponge species have been considered and these studies have mostly focused on negative impacts of the algal canopy (but see Wright et al. 1997). For example, Kennelly $(1987 b, 1989)$ found no relationship between shade or scour produced by E. radiata on the growth and abundance of the sponge Myxilla sp. in Australia, while Kennelly \& Underwood (1993) suggested that turf algae prevented settlement and affected the abundance of some sponge species after E. radiata was experimentally removed in kelp forests of New South Wales, Australia. More recently, Fowler-Walker et al. (2005) found that sponge abundance was negatively correlated with E. radiata morphology on rocky reefs of temperate Australia. In contrast, Wright et al. (1997) reported a complete shift in the sponge assemblage inside vs outside the Ecklonia canopy, where four Chrondropsis spp. dominated the substratum beneath the canopy. Considering these major differences between the sponge assemblages inside vs outside Ecklonia reported by Wright et al. (1997), here I explore the potential for some sponge species to benefit from the presence of the dominant habitat-forming kelp E. radiata through facilitation as a result of habitat modification. I predict that the removal of the E. radiata canopy would affect the structure of subcanopy assemblages, and hypothesised that if the canopy facilitates sponge assemblages there would be changes in assemblage structure and reduction in sponge species richness and abundance when the canopy is removed. Finally, I also determined whether any change in sponge abundance is an effect of canopy removal per se, as a result of changes in physical conditions (settled sediment), or due to an increase in the abundance of turf algae or other sessile organisms, produced after canopy removal. 


\subsection{Materials and Methods}

\subsubsection{Study sites}

The Wellington south coast is an energetic environment that is subjected to regular southerly swells that move onto the Wellington shelf for more than $80 \%$ of the time (Carter \& Lewis 1995). The subtidal algal assemblage on the Wellington south coast is dominated by Ecklonia radiata, and a mixture of Carpophyllum spp., Lessonia variegata and Landsburgia quercifolia (Shears \& Babcock 2007). The understory is dominated by crustose coralline algae and the overall abundance of sessile invertebrates has been reported to be low (Shears \& Babcock 2007). However, a recent study has described a diverse sponge assemblage in the area (Berman \& Bell 2010), with the highest abundance occurring on vertical walls, but with some species, such as Haliclona sp. Polymastia spp. and Cliona sp., being positively correlated with algal canopy (see Chapter 2).

In order to test the effect of removal of the dominant laminarian E. radiata (hereafter Ecklonia) on subcanopy assemblages, specifically on sponge assemblages, I conducted algal clearances at two sites on the south coast of Wellington $\ddot{I}$ Palmer Head (41 200̂46ò S; $174^{\circ}$ 49ô19ò E) and Breaker Bay (41 19ô58ò S; $174^{\circ}$ 49ô53ò E) $̈$ which are approximately $2 \mathrm{~km}$ apart. A third site (Moa Point) was part of the original experimental design, however it was not possible to survey experimental plots after T1 due to the rapid spread of Caulerpa sp. in cleared plots, which produced substantial changes in the structure of the subcanopy assemblages within 6 weeks following canopy removal. Both sites are characterised by the presence of steep rock walls, which form narrow channels (approx. 2.5 ï $5 \mathrm{~m}$ wide). At each site, I haphazardly selected six walls of similar size, aspect, slope, inclination (approx. $45^{\circ}$ $100^{\circ}$ ) and direction (in relation to light exposure and swell-action). The walls were separated by at least $20 \mathrm{~m}$, and located at depths of 6-9 $\mathrm{m}$. Walls had a high cover of Ecklonia, with adult plant densities ranging between 8-14 plants $\mathrm{m}^{-2}$ (mean $=8.1, \mathrm{SD}$ =3.1). The mean total plant length was $56.7 \mathrm{~cm} \pm 7.5$ SD. Ecklonia plants had short stipes with a mean length of $12.1 \pm 3.6 \mathrm{~cm}$. 
Chapter 3. Facilitation of sponges by canopy-algae

\subsubsection{Experimental design and data analysis}

In July 2010 (winter), I cleared 3 x $3 \mathrm{~m}$ areas (hereafter plots) of Ecklonia on five randomly selected walls and a sixth wall was left undisturbed and acted as a control. The size of the plots ensured the exclusion of any effect of the surrounding canopy (i.e., edge effects) on the cleared plots (Kennelly 1987a,b, Kennelly 1989). Plants were removed from the holdfast either by hand or using a knife when necessary to simulate the effect of storms, which in most cases, remove the entire plant from the substratum. An initial survey of subcanopy assemblages was conducted before the algal canopy was removed, where quadrats were randomly placed avoiding holdfasts. Subsequent surveys were conducted approximately every 6-10 weeks until April 2012 ( $\mathrm{n}=10$, experimental duration was 85 weeks). Removal plots were photographed at each survey interval and Ecklonia recruits were carefully removed. On each survey date, the two sites were sampled during the same day. Sampling dates were: T0 (0 weeks $)=15$ July 2010, T1 $(6$ weeks $)=25$ August 2010, T2 $(19$ weeks $)=27$ October 2010, T3 (27 weeks) = 17 January 2011, T4 (34 weeks) = 18 March 2011, T5 (42 weeks $)=13$ May 2011, T6 $(54$ weeks $)=5$ August 2011, T7 $(65$ weeks $)=12$ October 2011, T8 (72 weeks $)=2$ December 2011, T9 (85 weeks $)=2$ April 2012.

Five $25 \times 25 \mathrm{~cm}$ quadrats were randomly placed within the central $(2 \times 2)$ portion of each plot (to mitigate edge effects only the centre of the $3 \times 3 \mathrm{~m}$ area was used) and photographed. Photo-quadrats were analysed with CPCe v3.5 (Coral Point Count with Excel extensions) (Kohler \& Gill 2006) by superimposing a grid of 100 points onto each image, and determining the percentage cover of sessile organisms, macroalgae, bare rock and settled sediment. Settled sediment was estimated as the area of the quadrat covered in sediment in each picture. During the initial survey, species forming a canopy were moved aside to allow the substrate below them to be photographed. All taxa in photoquadrats were identified to the lowest taxonomic level possible. For analysis, species of algae that were often not identifiable to species level from the photographs were grouped under broad categories of algae. Categories used in the analysis were crustose coralline algae (CCA), erect coralline algae (ECA), red algae and brown algae. 
Ambient irradiance was measured with a Diving-PAM (Walz GmbH, Germany) within the canopy and outside the canopy ( $\mathrm{n}=16 ; 4$ readings on 3 consecutive days). The mean ambient irradiance underneath the canopy was 5.75 $\mu \mathrm{mol}$ quanta $\mathrm{m}^{-2} \mathrm{~s}^{-1}( \pm 2.05 \mathrm{SD})$ whereas the mean value in absence of canopy was $91.66 \pm 20.5 \mu \mathrm{mol}$ quanta $\mathrm{m}^{-2} \mathrm{~s}^{-1}$.

\subsubsection{Effect of canopy removal on the structure of subcanopy assemblages}

Non-metric multidimensional scaling (nMDS) was used to show relative changes over time in cleared and control plots. Data were averaged to obtain a centroid for each sampling time on each plot, and consecutive sampling times are linked by lines representing the trajectory of assemblage change at an individual plot through time (Clarke et al. 2006). The same procedure was used to show relative changes on sponge assemblages over time in cleared and control plots.

The differences in richness and abundance of sponges between control and removal treatments through time were examined by generating $95 \%$ confidence intervals using a bootstrap re-sampling procedure (Appendix 4). For each time point, five random samples (taken with replacement) were taken from the five possible removal plot data points and then averaged to obtain a bootstrap sample average, $\bar{r}$. The same procedure was applied to the control plot data to obtain a bootstrap sample average, $\bar{c}$. The difference between control and removal plot sample averages was then calculated as $\Delta=\bar{r}-\bar{c}$. This procedure was then repeated to obtain 1,000 bootstrap samples, which were representative of the range of values that opcould be given the information available. The mean and $95 \%$ confidence interval were then obtained from the distribution of opvalues. This was performed for each time point and removal plot in each site, using the single control plot at each site as the control for each separate removal plot. The means and $95 \%$ confidence intervals were then plotted against time to examine the pattern of change as the experiment progressed. This approach was used as I only had one control wall on each site due to problems with the lack of walls and also urching grazing in others. 
If canopy removal had no effect on the richness/abundance of sponges then it would be expected that differences between removal and control plots would be maintained, or more likely fluctuate at random about the initial $(t=0)$ difference. Any consistent trend away from this is likely an indication of some difference between control and removal treatments. The initial difference between plots (and its uncertainty expressed through $95 \%$ confidence intervals) is therefore used as a benchmark to compare differences through time, acknowledging the initial preexisting natural variation in abundance between plots. All analyses were performed in R 3.0.2 (R Development Core Team 2013).

To test the effect of canopy removal on the richness/abundance of sponges over time, a repeated measures permutational analysis of variance (PERMANOVA) was performed. Tests were based on Bray-Curtis similarity matrices and four roottransformed data, using site (treated separately; 2 levels, random), treatment ( 2 levels, fixed), and time (10 levels, random) as variables. Statistical differences were tested using 9,999 permutations under a reduced model. Pair-wise post-hoc tests were generated using 9,999 permutations of raw data. Monte Carlo tests were used when the number of unique permutations was low (Anderson et al. 2008).

Similarity percentages analysis (SIMPER) (Clarke 1993) was used to identify taxa contributing most to assemblage dissimilarity between canopy removal and control plots. PERMANOVA tests were performed to test the effect of treatment and time for each dominant taxon (treated as a univariate measure). The percentage cover of organisms was averaged across quadrats for comparisons between treatments. Tests were performed based on Euclidean distances matrices of fourth root-transformed percentage cover data. Statistical differences were further analysed by pair-wise tests based on 9,999 permutations of raw data. Monte Carlo tests were used when the number of unique permutations was low (Anderson et al. 2008). PERMANOVA was chosen for univariate analyses because it does not assume a normal distribution of errors. The same procedure was used to examine the effect of sediment accumulation on benthic assemblages between canopy removal and control plots, as an increase in the cover of settled sediment may affect the composition of understory and sessile invertebrates (Connell 2003a). All analyses were performed in PRIMER v6 (Clarke \& Gorley 2006, Anderson et al. 2008). 


\subsubsection{Factors driving changes in sponge assemblages after canopy removal}

In order to identify factors that best explained changes in sponge abundance after canopy removal, I assessed whether changes in sponge abundance were correlated with the percentage cover of other sessile organisms, increases in turf algae, or with changes in physical conditions (settled sediment), using a permutational distancebased multiple regression technique (DistLM) (McArdle \& Anderson 2001). This was performed for each removal plot at each site. DistLM carries out a partitioning of variation in a data set described by a resemblance matrix according to a multiple regression model. This technique makes no prior assumptions about the nature of the response variable distribution and therefore normality does not have to be satisfied (Anderson et al. 2008). DistLM analyses model the relationship between abundance data (sponge abundance) and one or more variables (predictor variables). Predictor variables tested were: 1) incremental changes in the abundance of turf algae per sampling period. Turf algae included all algal taxa except coralline algae; 2) percentage cover of settled sediment and 3) cover of other dominant benthic groups (based on SIMPER). Models incorporating all possible combinations of predictor variables were generated using the Best procedure within DistLM. All tests were performed on Bray-Curtis dissimilarity matrices using 9,999 permutations. I used modified Akaikeô Information Criterion (AICc) to identify the model that best explained the maximum amount of variation in the sponge data (Burnham \& Anderson 2002, Hobbs \& Hilborn 2006). AICc is recommended for analyses with small sample size. AICc values indicate the goodness of a model fit to the data, penalised for increasing the number of factors. Models with the lowest AICc are considered the most parsimonious (Symonds \& Moussalli 2011). 


\subsection{Results}

\subsubsection{Effect of canopy removal on the structure of subcanopy assemblages}

Changes in the structure of subcanopy assemblages over a 1.5 years following the removal of Ecklonia are shown in Figure 3.1 and 3.2. In most cases, subcanopy assemblages showed a major change immediately after canopy removal in experimental plots. At both sites, subcanopy assemblages showed comparable responses to canopy removal, but with some differences in magnitude.

\subsubsection{Effect of canopy removal on the structure of sponge assemblages}

At both Breaker Bay and Palmer Head, ordination plots showed a divergence in sponge assemblages between control and removal plots following canopy removal (Figs. 3.3 and 3.4).

The removal of the canopy resulted in a reduction in sponge species richness, especially at Breaker Bay, typically staying below those of the control plots for the duration of the experiment (Fig. 3.5). Differences in the number of sponge species per quadrat between control and removal plots increased within 34 weeks following canopy removal, remaining lower than in control plots until the end of the experiment (PERMANOVA Treatment $P=0.001$, Treatment $\mathrm{x}$ Time $P=0.001$; Fig. 3.6). At Breaker Bay, a relative consistent pattern was observed in most removal plots, where a clear divergence in the number of sponge species was observed within 40 weeks following canopy removal (Fig. 3.5). At Palmer Head, differences between removal and control plots were more variable and in some plots no significant differences were found between treatments (Fig. 3.5). 
Chapter 3. Facilitation of sponges by canopy-algae

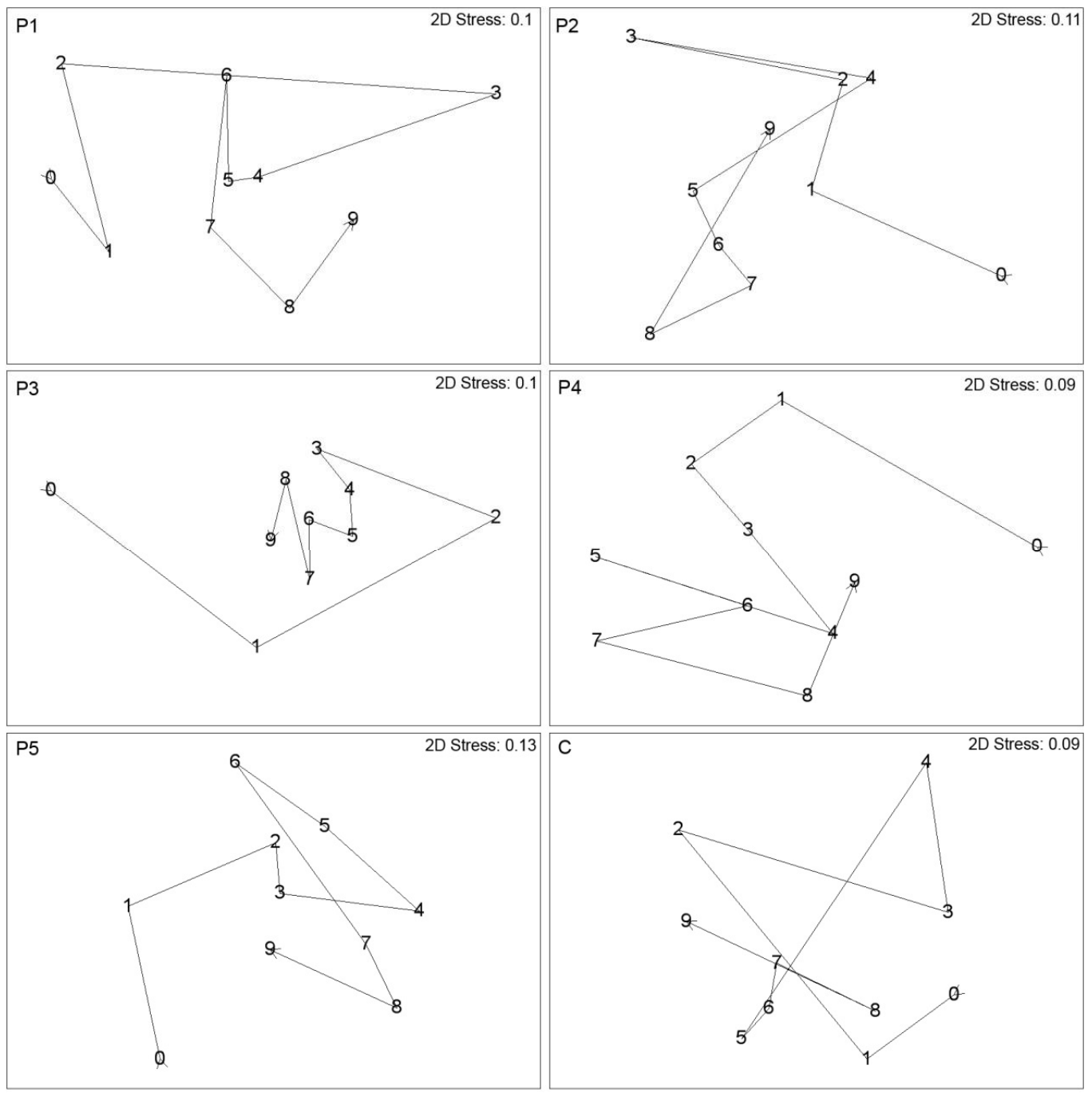

Figure 3.1. Ordination plots (nMDS) showing the effect of Ecklonia radiata on the understory at Breaker Bay. Lines represent trajectory of understory change at an individual plot though time. Ordination based on Bray-Curtis similarity matrices fourth root-transformed percentage cover data of species, with centroids as treatment averages. $\mathrm{P}=$ removal plot, $\mathrm{C}=$ control. 
Chapter 3. Facilitation of sponges by canopy-algae

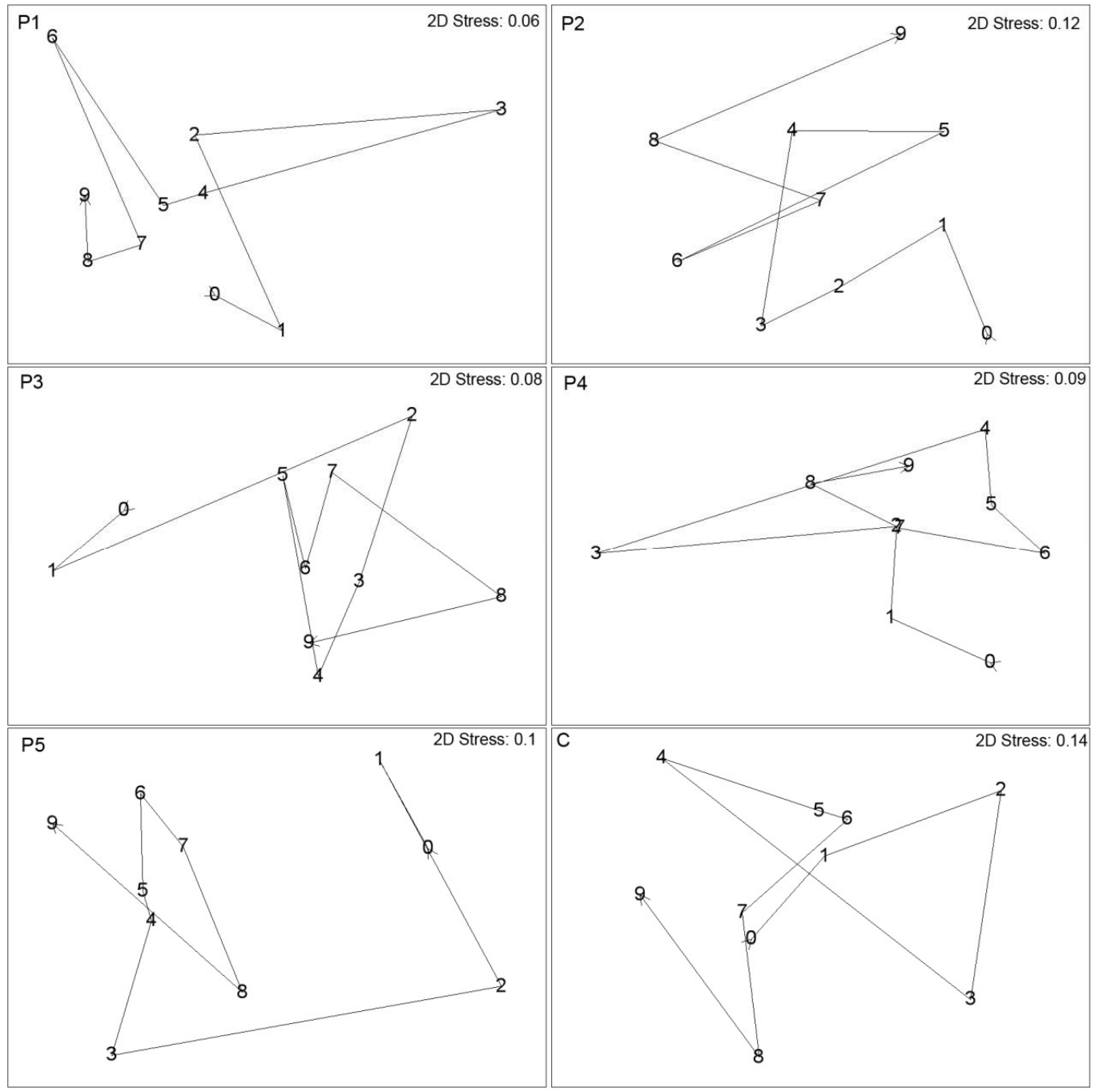

Figure 3.2. Ordination plots (nMDS) showing the effect of Ecklonia radiata on the understory at Palmer Head. Lines represent trajectory of understory change at an individual plot though time. Ordination based on Bray-Curtis similarity matrices fourth root-transformed percentage cover data of species, with centroids as treatment averages. $\mathrm{P}=$ removal plot, $\mathrm{C}=$ control. 
Chapter 3. Facilitation of sponges by canopy-algae

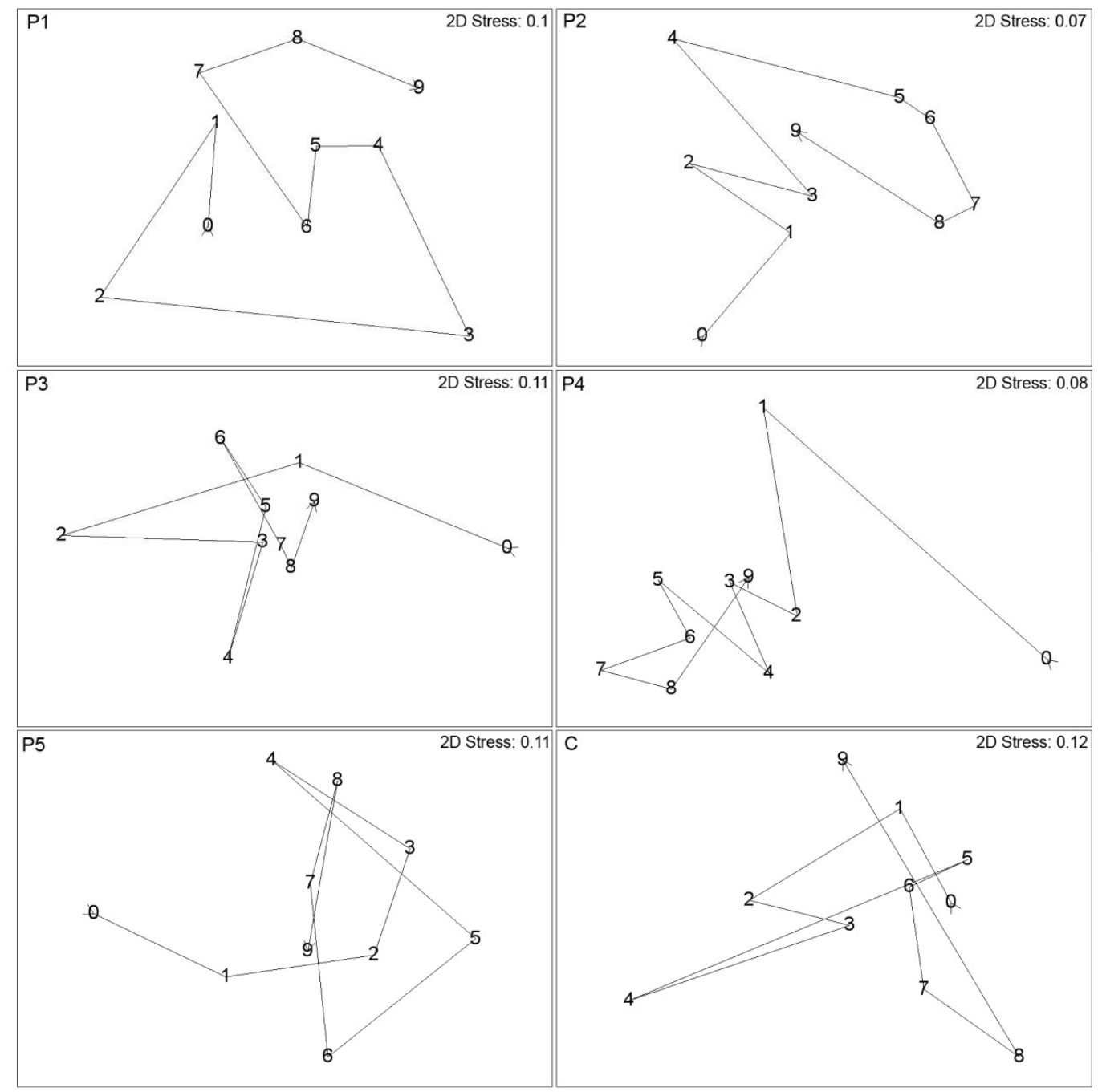

Figure 3.3. Ordination plots (nMDS) showing the effect of Ecklonia radiata on sponge assemblages at Breaker Bay. Lines represent trajectory of understory change at an individual plot though time. Ordination based on Bray-Curtis similarity matrices fourth root-transformed percentage cover data of species, with centroids as treatment averages. $\mathrm{P}=$ removal plot, $\mathrm{C}=$ control. 
Chapter 3. Facilitation of sponges by canopy-algae

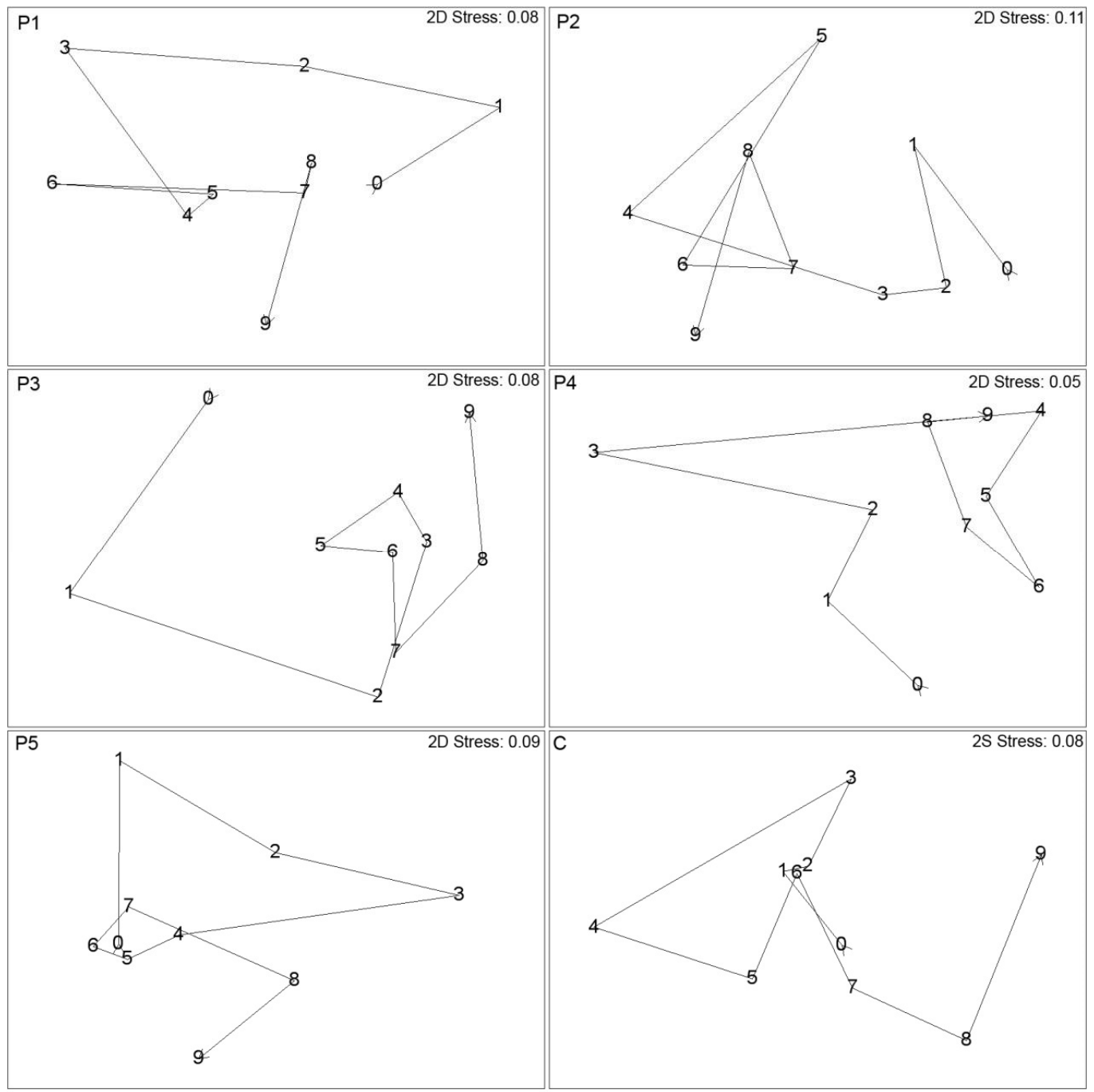

Figure 3.4. Ordination plots (nMDS) showing the effect of Ecklonia radiata on sponge assemblages at Palmer Head. Lines represent trajectory of understory change at an individual plot though time. Ordination based on Bray-Curtis similarity matrices fourth root-transformed percentage cover data of species, with centroids as treatment averages. $\mathrm{P}=$ removal plot, $\mathrm{C}=$ control. 

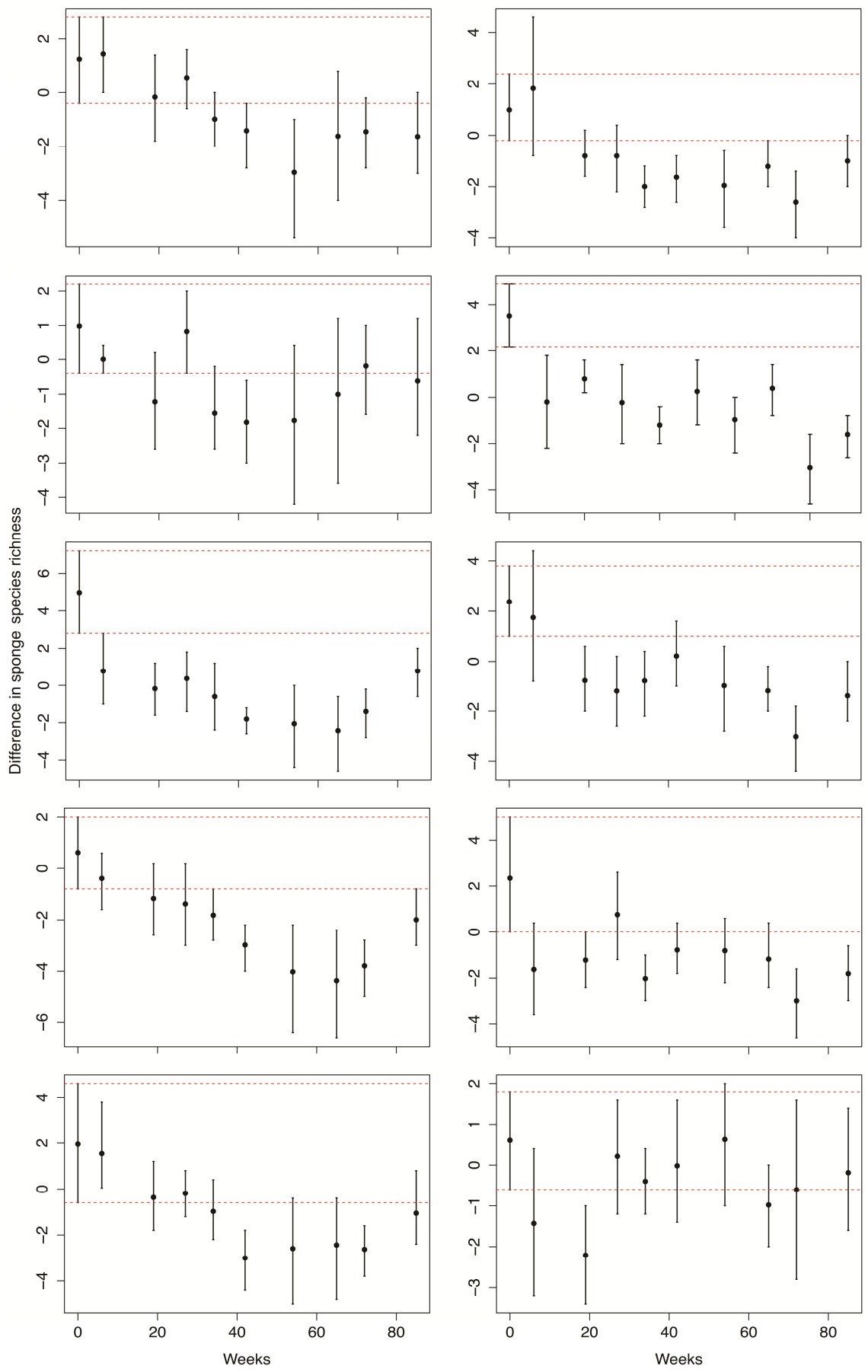

Figure 3.5. Differences in mean sponge species richness between control and removal treatments through time in response to canopy removal, at (left) Breaker Bay and (right) Palmer Head. Each panel shows the effect of canopy removal at an individual plot. Error bars represent 95\% confidence intervals. Dotted lines indicate initial differences $(t=0)$ between control and removal. See methods for further explanation. 


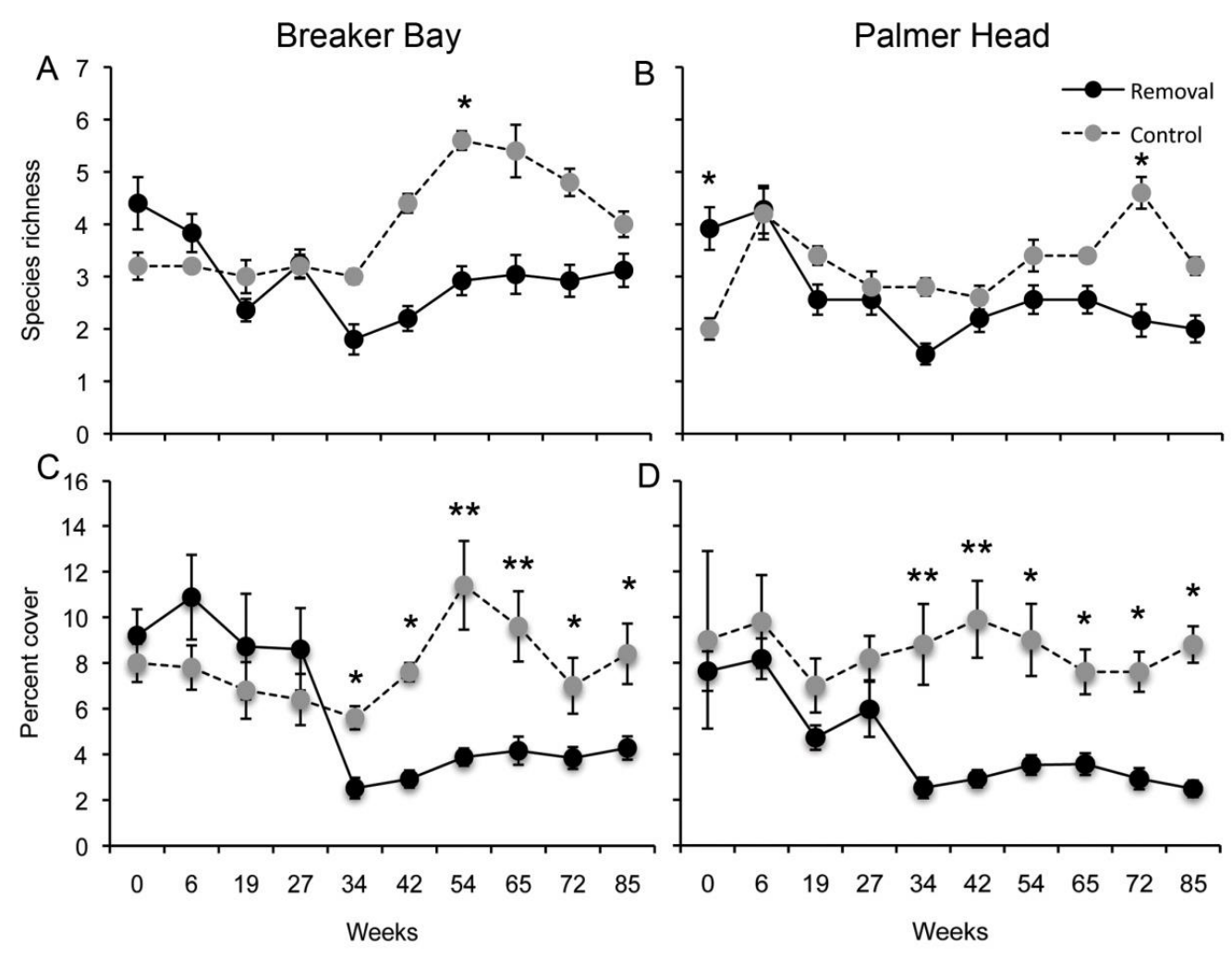

Figure 3.6. Effect of removal of Ecklonia radiata on: (a, b) mean sponge species richness; and (c, d) mean percentage cover of sponges, at Breaker Bay and Palmer Head. Values are means $( \pm$ S.E.) of five quadrats on each experimental plot. $* P<$ $0.05, * * P<0.001$.

The mean percentage cover of sponges decreased after canopy removal at both sites, decreasing more than 3 times within 34 weeks after canopy removal and remained significantly different until the end of the experiment (PERMANOVA Treatment $P=0.001$, Treatment x Time $P=0.01$; Fig. 3.6). At Breaker Bay, sponge abundance decreased from 9.2 to $2.5 \%$, whereas at Palmer Head sponge abundance decreased from 7.6 to $2.5 \%$ after 34 weeks (Fig. 3.6).

At both sites, there was a divergence in sponge assemblages between control and removal plots following canopy removal (Fig. 3.7). This means that assemblages in control and removal plots became less similar over time after canopy removal. However, a few plots did not show significant differences between treatments after removal (Fig. 3.7). 

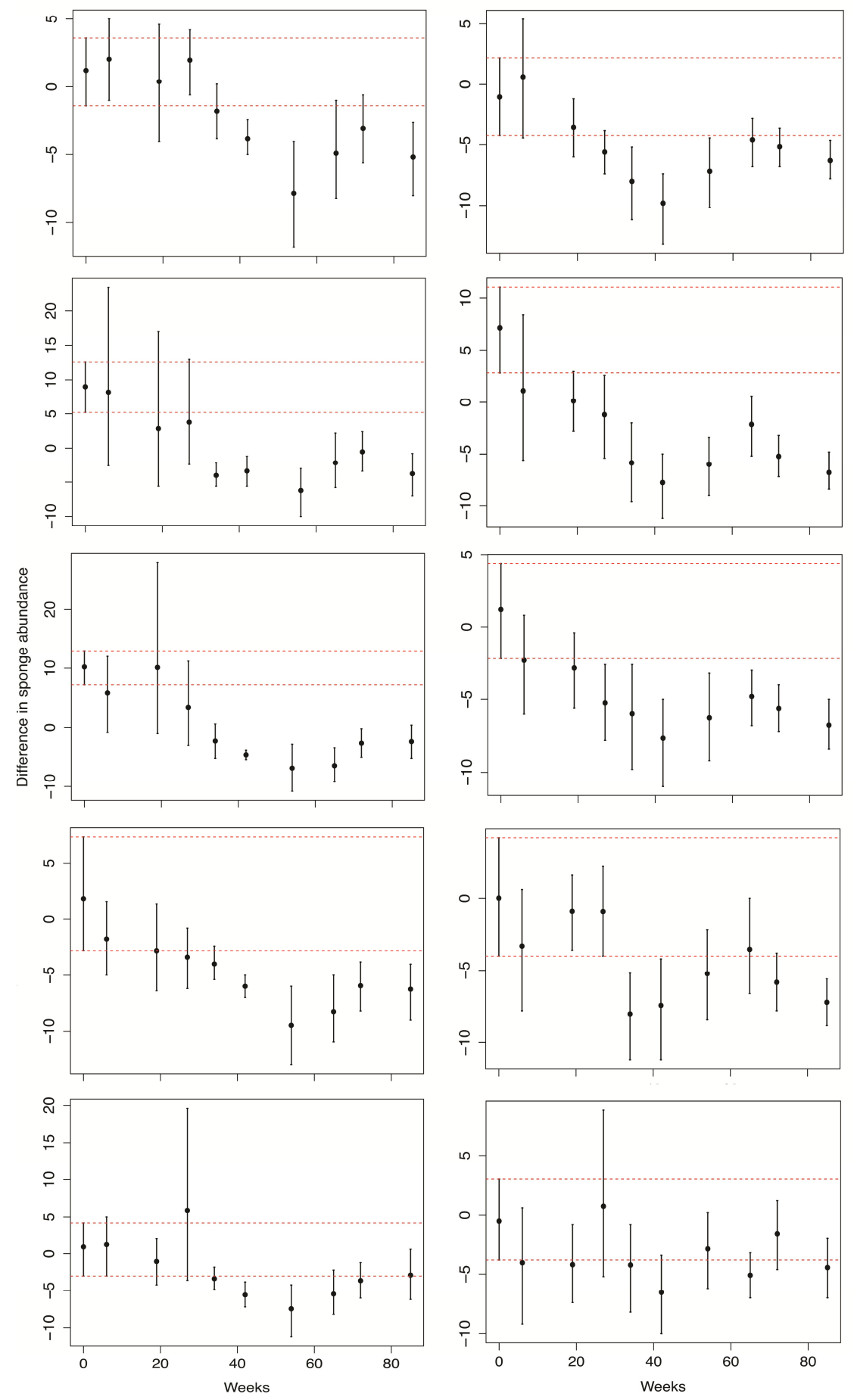

Figure 3.7. Differences in mean sponge abundance between control and removal treatments through time in response to canopy removal, at (left) Breaker Bay and (right) Palmer Head. Each panel shows the effect of canopy removal at an individual plot. Error bars represent 95\% confidence intervals. Dotted lines indicate initial differences $(\mathrm{t}=0)$ between control and removal. See methods for further explanation. 
Differences in sponge abundance between treatments at Breaker Bay were mainly driven by Crella incrustans (13.10\%), Cliona sp. (12.76\%), Strongylacidon conulosa (10.65\%), Haliclona sp. (7.54\%) and Tethya bergquistae (7.01\%). At Palmer Head, four species were responsible for $51 \%$ of the differences in the sponge assemblages between treatments: Crella incrustans (23.97\%), Cliona sp. (12.10\%), Strongylacidon conulosa (11.12\%) and Haliclona sp. (7.40\%). All these species, with the exception of $T$. bergquistae and Cliona sp., had lower abundance in removal compared to control plots. The effect of removal on different sponge species is shown in Table 3.1.

The removal of canopy had a significant effect on the abundance of $C$. incrustans (Table 3.1). Its abundance declined dramatically following canopy removal at both sites and remained low for the rest of the experiment (Fig. 3.8). The effect of removal on other sponge species was site dependent. Species such as Haliclona sp. and $S$. conulosa showed a significant response to canopy removal at Breaker Bay and Palmer Head, respectively. At Breaker, the abundance of Haliclona sp. was 3 and 15 times lower in weeks 6 and 19 than at the start of the experiment (Fig. 3.8). Similarly, the abundance of $S$. conulosa declined from $0.6 \%( \pm 0.15)$ to $0.04 \%( \pm 0.2)$ within $6-$ 19 weeks after removal and remained lower than that in control plots until the end of the experiment (Fig. 3.8).

The effect of canopy removal on sponge taxa contributing most to differences between treatments analysed for each experimental plot is shown in Table 3.2. This results showed the consistent effect of canopy removal on the abundance of $C$. incrustans, being significant in 9 of 10 experimental plots. Other species such as Haliclona sp. showed a more consistent response to canopy removal at Breaker Bay, where a significant effect was found in 4 of 5 plots. In contrast, this species showed a significant response to canopy removal in one plot at Palmer Head 
Chapter 3. Facilitation of sponges by canopy-algae

Table 3.1. Sponge taxa contributing to $50 \%$ of the observed differences in sponge assemblages between treatments, as determined by SIMPER. $P$-values correspond to PERMANOVA results testing the effect of treatment on the percentage cover of dominant sponge taxa $(\mathrm{Tr}=$ treatment, $\mathrm{Ti}=$ time, $\operatorname{Tr} \mathrm{x} \mathrm{Ti}=$ interaction $)$. Statistical differences were tested using 9,999 permutations of raw data. Significant $P$-values are in bold $(P<0.05)$.

\begin{tabular}{|c|c|c|c|c|c|c|}
\hline Site & Taxa & Contribution $\%$ & Cumulative\% & $\mathrm{Tr}$ & $\mathrm{Ti}$ & Tr x Ti \\
\hline \multirow[t]{5}{*}{ Breaker Bay } & Crella incrustans & 13.1 & 13.10 & 0.002 & 0.422 & 0.001 \\
\hline & Haliclona sp. & 12.76 & 25.86 & 0.001 & 0.001 & 0.006 \\
\hline & Cliona sp. & 10.65 & 36.51 & 0.106 & 0.001 & 0.107 \\
\hline & Clathrina sp. 1 & 7.54 & 44.05 & 0.151 & 0.001 & 0.458 \\
\hline & Tethya bergquistae & 7.01 & 51.06 & 0.169 & 0.687 & 0.071 \\
\hline \multirow[t]{5}{*}{ Palmer Head } & Crella incrustans & 23.97 & 23.97 & 0.001 & 0.029 & 0.491 \\
\hline & Cliona sp. & 12.1 & 36.07 & 0.282 & 0.279 & 0.033 \\
\hline & Strongylacidon & & & & & \\
\hline & conulosa & 11.12 & 47.19 & 0.001 & 0.001 & 0.003 \\
\hline & Haliclona sp. & 7.40 & 54.58 & 0.01 & 0.295 & 0.166 \\
\hline
\end{tabular}


Chapter 3. Facilitation of sponges by canopy-algae
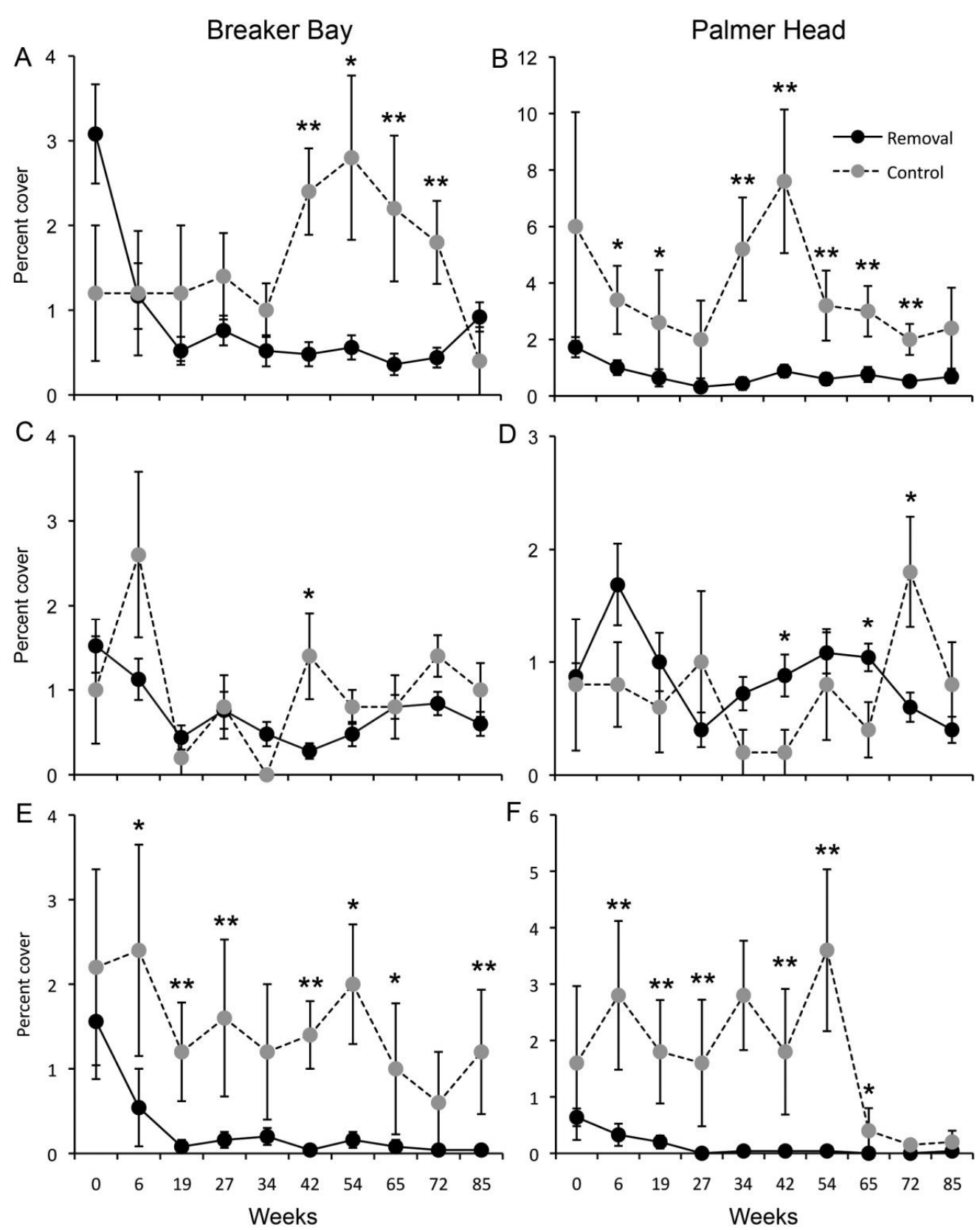

Figure 3.8. Responses of: (a, b) Crella incrustans; (c, d) Cliona sp; (e) Haliclona sp; and (f) Strongylacidon conulosa, to removal of Ecklonia radiata at Breaker Bay and Palmer Head. Values are means ( \pm S.E.) of five quadrats on each experimental plot. $* P<0.05, * * P<0.001$. Note: scale for $\mathrm{Y}$-axis differs between panels. 
Table 3.2. Sponge taxa contributing to $50 \%$ of the observed differences in sponge assemblages between treatments, as determined by SIMPER. PERMANOVA analyses to test the effect of canopy removal were based on Euclidean distances using 9,999 permutations of the raw data. $* P<0.05, * * P<0.001, \mathrm{NS}=$ non significant.

\begin{tabular}{|c|c|c|c|c|c|c|c|c|}
\hline & & & & \multicolumn{5}{|c|}{ Plot } \\
\hline Site & Taxa & Contribution $\%$ & Cumulative\% & 1 & 2 & 3 & 4 & 5 \\
\hline \multicolumn{9}{|c|}{ Breaker } \\
\hline \multirow[t]{5}{*}{ Bay } & Crella incrustans & 13.1 & 13.1 & NS & $* *$ & $* *$ & $*$ & $*$ \\
\hline & Haliclona sp. & 12.76 & 25.86 & $*$ & NS & $* *$ & $*$ & $* *$ \\
\hline & Cliona sp. & 10.65 & 36.51 & NS & $*$ & $*$ & NS & NS \\
\hline & Clathrina sp. & 7.54 & 44.05 & NS & $*$ & $*$ & $* *$ & NS \\
\hline & Tethya bergquistae & 7.01 & 51.06 & $*$ & NS & NS & NS & $*$ \\
\hline \multicolumn{9}{|c|}{ Palmer } \\
\hline \multirow[t]{5}{*}{ Head } & Crella incrustans & 23.97 & 23.97 & $* *$ & $* *$ & $* *$ & $* *$ & $* *$ \\
\hline & Cliona sp. & 12.1 & 36.07 & $* *$ & NS & NS & NS & $*$ \\
\hline & Strongylacidon & & & & & & & \\
\hline & conulosa & 11.12 & 47.19 & $*$ & $*$ & $*$ & NS & NS \\
\hline & Haliclona sp. & 7.4 & 54.58 & NS & NS & NS & NS & $* *$ \\
\hline
\end{tabular}

\subsubsection{Taxon specific responses to Ecklonia removal}

SIMPER analyses identified several taxa as the main contributors to observed differences in community structure between treatments. At Breaker Bay, taxa including hydroids (5.94\%), Haliclona sp. (4.32\%), ECA (4.17\%), Didemnidae (4.15\%) and Crella incrustans $(4.03 \%)$ accounted for more than $22 \%$ of the difference between canopy removal and control assemblages (Table 3.3). Of these taxa, hydroids and didemnids increased their abundance after removal, whereas the abundance of the other three groups/species decreased after canopy removal. At Palmer Head, taxa including C. incrustans (5.55\%), hydroids (5.24\%), Didemnidae (5.17\%), Zonaria turneriana (4.57\%) and erect crustose algae (4.43\%) accounted for almost $25 \%$ of the difference in community composition between treatments (Table 3.3). The effect of canopy removal on different taxa is shown in Table 3.3. In general, sponge species decreased in abundance while brown and red algae increased in abundance after canopy removal. The removal of Ecklonia had a significant effect on abundance in the majority of the experimental plots. 
Table 3.3. Subcanopy taxa contributing to $50 \%$ of observed differences in subcanopy assemblage structure between treatments, as determined by SIMPER. $P$-values correspond to PERMANOVA results testing the effect of treatment on the percentage cover of dominant taxa $(\mathrm{Tr}=$ treatment, $\mathrm{Ti}=$ time, $\operatorname{Tr} \mathrm{x} \mathrm{Ti}=$ interaction $)$. Statistical differences were tested using 9,999 permutations of raw data. Significant $P$-values are in bold $(P<0.05)$.

\begin{tabular}{|c|c|c|c|c|c|c|}
\hline Site & Taxa & Contribution\% & Cumulative\% & $\operatorname{Tr}(\mathrm{p})$ & Ti (p) & $\operatorname{Tr} \times \operatorname{Ti}(\mathrm{p})$ \\
\hline \multirow[t]{13}{*}{$\begin{array}{l}\text { Breaker } \\
\text { Bay }\end{array}$} & Hydrozoa & 5.94 & 5.94 & 0.001 & 0.001 & 0.071 \\
\hline & Haliclona sp. & 4.32 & 10.26 & 0.001 & 0.004 & 0.030 \\
\hline & ECA & 4.17 & 14.42 & 0.002 & 0.563 & 0.740 \\
\hline & Didemnidae & 4.15 & 18.57 & 0.014 & 0.109 & 0.194 \\
\hline & Crella incrustans & 4.03 & 22.60 & 0.002 & 0.400 & 0.001 \\
\hline & Ascidiacea unidentified & 4.01 & 26.61 & 0.014 & 0.379 & 0.125 \\
\hline & Rhodophyta & 3.74 & 30.35 & 0.674 & 0.210 & 0.349 \\
\hline & Phaeophyta unidentified & 3.71 & 34.06 & 0.001 & 0.001 & 0.091 \\
\hline & Cliona sp. & 3.61 & 37.67 & 0.103 & 0.001 & 0.111 \\
\hline & Zonaria turneriana & 3.59 & 41.26 & 0.096 & 0.057 & 0.011 \\
\hline & Catenicellid & 3.32 & 44.58 & 0.004 & 0.649 & 0.195 \\
\hline & Aplidium powelli & 3.02 & 47.60 & 0.133 & 0.005 & 0.897 \\
\hline & Clathrina sp. 1 & 2.81 & 50.41 & 0.151 & 0.001 & 0.458 \\
\hline \multirow[t]{12}{*}{$\begin{array}{l}\text { Palmer } \\
\text { Head }\end{array}$} & Crella incrustans & 5.55 & 5.55 & 0.001 & 0.023 & 0.490 \\
\hline & Hydrozoa & 5.24 & 10.79 & 0.001 & 0.001 & 0.060 \\
\hline & Didemnidae & 5.17 & 15.96 & 0.001 & 0.319 & 0.720 \\
\hline & Zonaria turneriana & 4.57 & 20.54 & 0.161 & 0.117 & 0.003 \\
\hline & Encrusting coralline algae & 4.43 & 24.96 & 0.479 & 0.881 & 0.724 \\
\hline & Catenicellid & 4.09 & 29.06 & 0.002 & 0.003 & 0.024 \\
\hline & Ascidiacea unidentified & 4.09 & 33.15 & 0.585 & 0.305 & 0.977 \\
\hline & Cliona sp. & 3.69 & 36.83 & 0.086 & 0.291 & 0.033 \\
\hline & Smittoidea manganuensis & 3.37 & 40.20 & 0.761 & 0.393 & 0.141 \\
\hline & Strongylacidon conulosa & 3.33 & 3.33 & 0.001 & 0.001 & 0.002 \\
\hline & Rhodophyta & 3.32 & 47.08 & 0.001 & 0.013 & 0.002 \\
\hline & Aplidium powelli & 3.24 & 50.32 & 0.174 & 0.009 & 0.258 \\
\hline
\end{tabular}


Changes in the abundances of algae in response to canopy removal were variable and depended on taxa and site. Red non-calcareous algae (Rhodophyta) showed a consistent response through time between removal and control plots at Palmer Head, being 20 times more abundant in control plots after 27 weeks post removal and remaining at this level until near the end of the experiment (Fig. 3.9, Tables 3.3 and 3.4). In contrast, the response of red algae to canopy removal was not consistent at Breaker Bay (Fig. 3.9, Table 3.3 and 3.4), where the abundance of noncalcareous red algae in control plots remained similar to that in removal plots during most of sampling times, except after 72 weeks following canopy removal (Fig. 3.9).

The response of ECA, Zonaria and other brown algae to canopy removal was also variable (Fig. 3.9, Table 3.4). At Palmer Head, the abundance of ECA increased in removal plots after removal, being higher than in control plots during most of sampling times. The effect of canopy removal on Zonaria was also variable, showing a significant response depending on site and plot. The abundance of other brown algae also increased after removal at Palmer Head, being significantly higher after 34 weeks post removal and returning to control values after 42-72 weeks following canopy removal. At Breaker Bay, the effect of removal was significant after 6 and 42 weeks following canopy removal.

Taxon specific responses to removal of Ecklonia on each experimental plot are shown in Table 3.2 . 
Chapter 3. Facilitation of sponges by canopy-algae
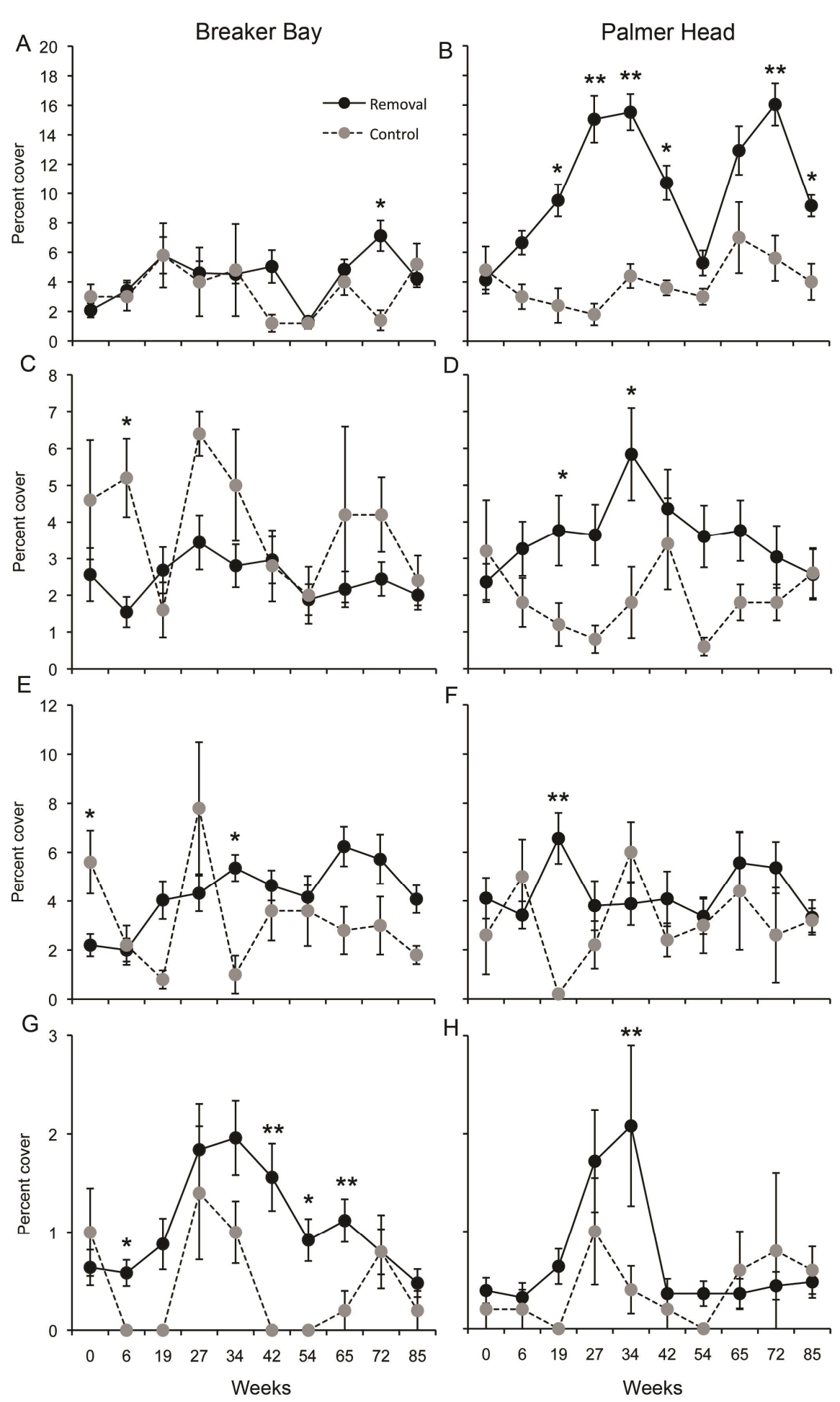

Figure 3.9. Responses of: (a, b) red algae; (c, d) ECA; (e, f) Zonaria turneriana; and $(\mathrm{g}, \mathrm{h})$ other brown algae, to removal of Ecklonia radiata at Breaker Bay and Palmer Head. Values are means ( \pm S.E.) of five quadrats on each experimental plot. $* P<$ $0.05, * * P<0.001$. 
Table 3.4. Subcanopy taxa contributing to $50 \%$ of observed differences in subcanopy assemblage structure between treatments, as determined by SIMPER. PERMANOVA analyses to test the effect of canopy removal were based on Euclidean distances using 9,999 permutations of raw data. $* P<0.05, * * P<0.001, \mathrm{NS}=$ non significant.

\begin{tabular}{|c|c|c|c|c|c|c|c|c|}
\hline \multirow{2}{*}{\multicolumn{2}{|c|}{ Species }} & \multirow[b]{2}{*}{ Contribution \% } & \multirow[b]{2}{*}{ Cumulative $\%$} & \multicolumn{5}{|c|}{ Plots } \\
\hline & & & & 1 & 2 & 3 & 4 & 5 \\
\hline \multicolumn{9}{|c|}{ Breaker } \\
\hline \multirow[t]{13}{*}{ Bay } & Hydrozoa & 5.94 & 5.94 & $*$ & $*$ & $*$ & $* *$ & $* *$ \\
\hline & Haliclona sp. & 4.32 & 10.26 & $*$ & NS & $* *$ & $* *$ & $* *$ \\
\hline & ECA & 4.17 & 14.42 & $* *$ & $*$ & $* *$ & $*$ & NS \\
\hline & Didemnidae & 4.15 & 18.57 & $*$ & NS & $* *$ & $* *$ & $*$ \\
\hline & Crella incrustans & 4.03 & 22.6 & NS & $* *$ & $* *$ & $*$ & $*$ \\
\hline & Ascidiacea unidentified & 4.01 & 26.61 & NS & NS & NS & NS & NS \\
\hline & Rhodophyta unidentified & 3.74 & 30.35 & $*$ & $* *$ & NS & $*$ & $*$ \\
\hline & Phaeophyta unidentified & 3.71 & 34.06 & $*$ & $*$ & NS & $*$ & NS \\
\hline & Cliona sp. & 3.61 & 37.67 & NS & $*$ & $*$ & NS & NS \\
\hline & Zonaria turneriana & 3.59 & 41.26 & $*$ & $*$ & NS & $* *$ & $* *$ \\
\hline & Catenicellid & 3.32 & 44.58 & $* *$ & $*$ & NS & $* *$ & NS \\
\hline & Aplidium powelli & 3.02 & 47.6 & NS & NS & NS & NS & NS \\
\hline & Clathrina sp. & 2.81 & 50.41 & NS & NS & $* *$ & NS & NS \\
\hline \multicolumn{9}{|c|}{ Palmer } \\
\hline \multirow[t]{12}{*}{ Head } & Crella incrustans & 5.55 & 5.55 & $* *$ & $* *$ & $* *$ & $* *$ & $* *$ \\
\hline & Hydrozoa & 5.24 & 10.79 & $*$ & $* *$ & $*$ & NS & $*$ \\
\hline & Didemnidae & 5.17 & 15.96 & $*$ & $* *$ & $*$ & NS & $* *$ \\
\hline & Zonaria turneriana & 4.57 & 20.54 & $*$ & NS & $*$ & $*$ & NS \\
\hline & ECA & 4.43 & 24.96 & NS & $*$ & $*$ & $* *$ & NS \\
\hline & Catenicellid & 4.09 & 29.06 & $*$ & $*$ & NS & NS & NS \\
\hline & Ascidiacea unidentified & 4.09 & 33.15 & $*$ & $* *$ & NS & $* *$ & NS \\
\hline & Cliona sp. & 3.69 & 36.83 & $* *$ & NS & NS & NS & $*$ \\
\hline & Smittoidea manganuensis & 3.37 & 40.2 & $* *$ & NS & NS & $*$ & NS \\
\hline & Strongylacidon conulosa & 3.33 & 3.33 & $*$ & $*$ & $*$ & NS & NS \\
\hline & Rhodophyta unidentified & 3.32 & 47.08 & $* *$ & $* *$ & $* *$ & $*$ & $* *$ \\
\hline & Aplidium powelli & 3.24 & 50.32 & NS & NS & NS & NS & NS \\
\hline
\end{tabular}



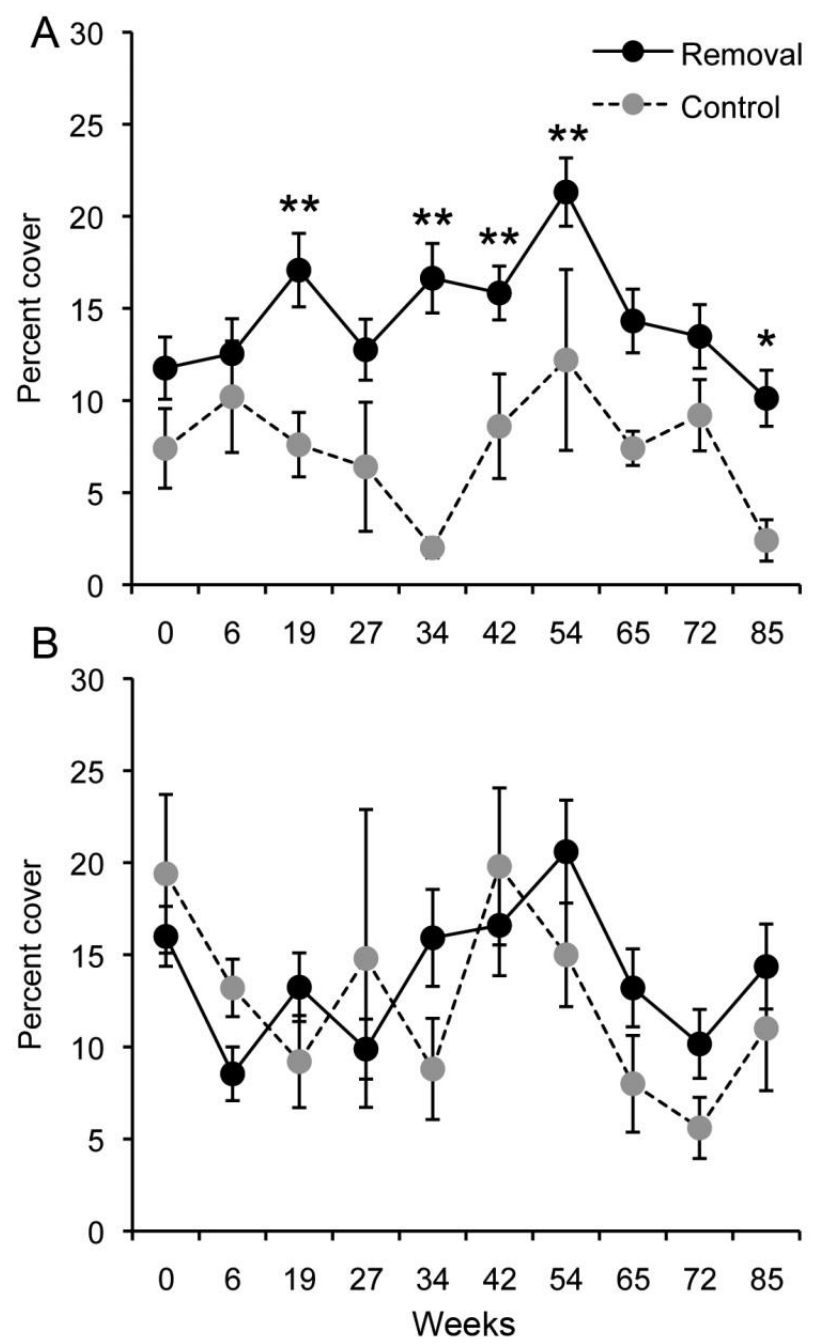

Figure 3.10. Mean percentage cover of sediment at: (a) Breaker Bay and (b) Palmer Head in response to removal of Ecklonia radiata. Values are means ( \pm S.E.) of five quadrats on each experimental plot. $* P<0.05, * * P<0.001$.

The effect of canopy removal on the percentage cover of settled sediment was variable between sites (Fig. 3.10). At Breaker Bay, sediment cover increased after removal. In contrast, sediment cover was highly variable at Palmer Head. However, changes in the coverage of sediment were significant in a few plots at both sites (PERMANOVA $P<0.05$ in plots 1 and 2 at Palmer Head, and plots 3 and 5 at Breaker Bay). 


\subsubsection{Factors driving changes in sponge assemblages after canopy removal}

In general, increased abundance of turf algae after canopy removal was one of the best predictors explaining the decrease in sponge abundance through time in most of the experimental plots (Table 3.5). The abundance of turf algae was negatively correlated with sponge abundance, especially at Palmer Head, explaining a considerable amount of the variation (26-60\%). Settled sediment was also an important predictor in several plots. It explained between 10 to $17 \%$ of the variability, in a couple of cases, it was part of a $2 i ̈$ factor model together with turf algae and hydroids, explaining 79 and $65 \%$ of the variation, respectively (Table 3.5). Other groups including hydroids and didemnid ascidians were the best predictors in some plots (Table 3.5).

Table 3.5. Results of distance-based permutational multivariate multiple regression analyses (DistLM) for associations between the decrease in sponge abundance after canopy removal and predictor variables. Model selection was based on models with lowest modified Akaikeôs Information Criterion (AICc) for each response variable. All tests were based on 9,999 permutations.

\begin{tabular}{|c|c|c|c|c|}
\hline Site & Plot & $\mathrm{AICc}$ & Predictor & $\begin{array}{l}\% \text { of total } \\
\text { variability } \\
\text { explained }\end{array}$ \\
\hline \multirow[t]{7}{*}{ Breaker Bay } & 1 & 49.752 & Turf-cover & 26.45 \\
\hline & 2 & 63.313 & Hydroids & 32.27 \\
\hline & 3 & 68.496 & Sediment & 65.08 \\
\hline & & & Hydroids & \\
\hline & 4 & 59.726 & Hydroids & 60.04 \\
\hline & & & Turf-cover & \\
\hline & 5 & 67.912 & Sediment & 17.81 \\
\hline \multirow[t]{7}{*}{ Palmer Head } & 1 & 69.516 & Sediment & 10.38 \\
\hline & 2 & 56.257 & Sediment & 78.72 \\
\hline & & & Turf-cover & \\
\hline & 3 & 50.865 & Didemnidae & 81.5 \\
\hline & & & Turf-cover & \\
\hline & 4 & 66.427 & Didemnidae & 19.49 \\
\hline & 5 & 51.96 & Turf-cover & 43.3 \\
\hline
\end{tabular}




\subsection{Discussion}

The role of negative interactions, such as competition, predation and physical stress have been extensively studied in marine communities (Connell 1983, Dayton 1985b, Bertness \& Leonard 1997, Sousa 2000, Barott et al. 2012). Such negative interactions have been traditionally considered to be the main forces structuring communities, however, over the last two decades the role of positive interactions has received increased interest, particularly because of the role that facilitation can play in enhancing biodiversity and promoting species coexistence (see Bruno et al. 2003, Thomsen et al. 2010, Gouhier et al. 2011). The role that macroalgae play in facilitating subcanopy species through habitat modification has been well documented for intertidal habitats (Hay 1981, Bertness \& Leonard 1997, Bulleri et al. 2012) but far less is known about these processes in subtidal habitats. Here, I present data suggesting that Ecklonia radiata is important in facilitating some sponge species such as Crella incrustans and how the removal of canopy can negatively affects the species richness and abundance of sponges. My results also highlight the likely role that light, indirectly influencing algal abundance, has in explaining the spatial variation of some sponge species.

The removal of Ecklonia led to substantial increases in the area occupied by turf algae, an effect that is generally consistent with previous studies (Kennelly 1987b, Benedetti-Cecchi 2001, Benedetti-Cecchi et al. 2001). Ecklonia forests modify the physical environment, altering light regimes and sediment cover, which can have wide effects on the diversity, abundance and structure of understory algae (Wernberg et al. 2005, Smale et al. 2011). Although the responses of other subcanopy algae were variable (and often site-specific), there appeared to be a general increase in the percentage cover of understory algae over the course of the experiment in my study plots, and I suggest that Ecklonia appears to indirectly facilitate sponges by influencing the abundance of turf algae through light reduction. In contrast, species such as $C$. incrustans typically declined in abundance following canopy removal. I propose that the negative effect on $C$. incrustans produced by the algal canopy removal was mainly the result of displacement by competitively superior turf algal species (produced by canopy removal). Although similar responses were recorded for 
other sponge species such as Haliclona sp. and $S$. conulosa, their responses were highly localised with respect to site and plot. Alternatively, increased sedimentation and ambient irradiance beyond an acceptable level for sponges or changes in water flow may also have some influence in the decline in sponges once the canopy is removed.

Relationships between canopy-forming species and understory assemblages usually involve both positive and negative interactions. Negative effects include abrasion by fronds and reduced light and sedimentation (Foster \& Schiel 1985, Melville \& Connell 2001, Connell 2003b, Toohey \& Kendrick 2008). Positive direct interactions include increased supply of particulate food via algal detritus (Duggins \& Eckman 1997, Morrow \& Carpenter 2008), provision of shelter and a reduction in some physical factors (Dayton 1975, Wright et al. 1997). Recently, Smale et al. (2013) suggested a positive effect of kelp on sponges in the northern hemisphere. In this case, the whiplash effect provided by fronds of Laminaria digitata facilitates the sponge Halichondria panicea, which without the abrasion provided by the kelp would be outcompeted by the algal understory. Positive and negative interactions are sometimes hard to separate. For example, shade provided by the canopy negatively affects understory algae, which compete for space with sessile invertebrates, which then provides an advantage to the sessile organisms (Benedetti-Cecchi et al. 2001, Connell 2003b, Arkema et al. 2009). Previous research carried out in New Zealand supports the existence of both positive and negative interactions between sponges and canopy-forming species (see Chapter 2). However, a reduction in harsh physical conditions as a result of the presence of the algal canopy can have strong direct positive effects on some subcanopy species (Bertness et al. 1999). A study of Ecklonia forests in temperate Australia found that sponge abundance was negatively related to the canopy (stipe/lamina) morphology, as plants with short stipes and long laminae caused more abrasion on the understory organisms (Fowler-Walker et al. 2005). The results of my experiment, however, support the existence of positive interactions and highlight the importance of the Ecklonia canopy for some sponge species, which is consistent with a previous study from New South Wales, Australia (Wright et al. 1997). As an ecosystem engineer (sensu Jones et al. 1994 - an organism that changes the environment via its own physical structure), Ecklonia can control (directly or indirectly) the availability of resources to other organisms by causing 
physical state changes in biotic or abiotic factors (Jones et al. 1997). Ecklonia forests appear to provide suitable conditions for some species, such as Crella incrustans. Connell (2003a) suggested that sponges might tolerate physical abrasion under existing canopies due to their capacity to feed without projecting their filter feeding appendages outside their bodies. However, it is possible that the early life stages of most sponge species may be affected by abrasion produced by fronds and also by light, which may increase post-settlement mortality due to competition with turf algae (Miller \& Etter 2008), explaining why only a few species are able to survive underneath the canopy.

Negative interactions between turf algae and sponges have been suggested in a number of observational and experimental studies (Kaandorp \& de Kluijver 1992, Kennelly \& Underwood 1993, Turon et al. 1998, Bell \& Barnes 2000a,b). My results partially support this view, but are in contrast to several previous studies suggesting that inclination rather than negative interactions between sponges and algae are the main drivers structuring temperate sponge assemblages (e.g. Knott et al. 2004, Preciado \& Maldonado 2005). Decreases in sponge abundance (especially $C$, incrustans) in removal plots coincided with increases in the abundances of brown and red algae. This apparent negative correlation between sponges and algal abundance appears to be the most likely factor driving changes in several of the plots. The removal of Ecklonia indirectly affected sponges, as increased light availability after removal seemed to favour understory algae (5.75 vs $91.66 \mu \mathrm{mol}$ quanta $\mathrm{m}^{-2} \mathrm{~s}^{-1}$ underneath the canopy and when the canopy was absent, respectively), which may outcompete small encrusting sponges. Increased light availability also affected the temporal variability of turf-forming algae (e.g. red and brown algae), which was greater in magnitude in removal compared to control plots. Consequently, these temporal changes of greater magnitude may have affected encrusting species such as C. incrustans in removal plots. Although previous research has reported detrimental effects of light in sciaphilic sponges (with absence of cyanobacteria) transplanted to high-light environments (Wilkinson \& Vacelet 1979), a direct effect due to increased light levels on adult sponges at my study sites, remains unclear. However, it seems turf-forming algae was not the only important factor as in other plots, settled sediment produced by canopy removal explained a large amount of the variability observed in the sponge assemblages. Settled sediment produced by canopy removal may have a 
direct impact in some areas by inhibiting the growth of sponges occurring underneath the canopy, as it is known that sediment can negatively affect the growth of some sponge species after canopy removal (Eckman \& Duggins 1991).

I did observe some variability in the responses in plots, which is not surprising as it is known that rocky walls are highly dynamic environments where available space is limited, resulting in intense competition (Sebens 1985). Factors such as the size, height and inclination of rock walls and width of the walled channels will have a large impact on communities, as each individual species satisfies its requirements for space, light, water-flow, protection from abrasion and sediment, and protection from predators (Wright et al. 1997, Davis et al. 2003). It is possible that differences observed between sites may be explained by different water-flow and light regimes in the different walled channels where the cleared plots were located. Furthermore, differences in unmeasured physical factors (particularly irradiance regimes and waterflow) may have resulted in differences in algal abundance in different plots. This situation may explain the lack of consistency in the responses of Haliclona sp. and $S$. conulosa to canopy removal. The responses of these species will require further studies to clarify the role that Ecklonia plays in influencing their abundance. Alternatively, the removal of Ecklonia may also affect sponges and other organisms, since mid-canopy kelps such as Ecklonia can also dampen hydrodynamic forces (Eckman \& Duggins 1991, Arkema et al. 2009) and sponges may be more exposed to storms and regular southerly swells (Carter \& Lewis 1995). In this regard, the decrease in sponge abundance in removal plots observed around week 34 - 42 may be related to strong swells produced by a big storm. Unfortunately, this cannot be confirmed, as official reports about occurrence and magnitude of storms were not available for this author.

The Ecklonia canopy seems to play an important role in structuring sponge assemblages and other understory organisms. More specifically, my results suggest that the Ecklonia canopy positively affects the sponge $C$. incrustans, by altering immediate physical factors that may directly affect larval abundance, though increased irradiance and sediment, or indirectly via its effect on understory algae. My results suggest that the decrease in sponge abundance and richness cannot be attributed to a single factor. Physical and biological factors may co-vary and each of 
the factors can have separate effects (positive or negative) on different species, which in many cases are very difficult to separate. The results of my study must be considered with respect to the limitations of this experiment. Although, my study was carried out using one control plot, I found a similar effect of canopy removal at both sites. Further replicated field experiments will be required to clarify the effect of separate factors on different species.

Finally, this study shows the importance of Ecklonia in structuring subcanopy assemblages and the potential effect of canopy loss on sponge assemblages in particular. This, in turn, could affect the flow of energy in these habitats, since sponges can play an important role linking pelagic and benthic habitats on temperate rocky reefs (Perea-Blázquez et al. 2012). The increased sediment loads occurring in coastal regions (Syvitski et al. 2005) may have an extensive impact on canopyforming species, resulting in secondary negative cascading effects on the structure of the entire community that can affect sponges and other suspension feeders, and hence alter community function (Naranjo et al. 1996, Airoldi 2003, Roberts et al. 2006).

\subsection{References}

Airoldi L (2003) The effects of sedimentation on rocky coast assemblages. Oceanography and Marine Biology: an Annual Review 41: 161-236

Anderson MJ, Gorley RN, Clarke KR (2008) Permanova for Primer: Guide to Software and Statistical Methods, PRIMER-E, Plymouth

Arkema KK, Reed DC, Schroeter SC (2009) Direct and indirect effects of giant kelp determine benthic community structure and dynamics. Ecology 90: 3126-3137

Ávila E, Blancas-Gallangos NI, Riosmena-Rodríguez R, Paul-Chávez L (2010) Sponges associated with Sargassum spp. (Phaeophyceae: Fucales) from the south-western Gulf of California. Journal of The Marine Biological Association of the United Kingdom 90: 193-202

Ayling AL (1983) Growth and regeneration rates in thinly encrusting demospongiae from temperate waters. Biological Bulletin 165: 343-352

Barott KL, Williams GJ, Vermeij MJA, Harris J, Smith JE, Rohwer FL, Sandin SA (2012) Natural history of coralī algae competition across a gradient of human activity in the Line Islands. Marine Ecology Progress Series 460: 1-12 
Bell JJ (2002) The sponge community in a semi-submerged temperate sea cave: density, diversity and richness. Marine Ecology 23: 297-311

Bell JJ (2007) The ecology of sponges in Lough Hyne Marine Nature Reserve (southwest Ireland): past, present and future perspectives. Journal of the Marine Biological Association of the United Kingdom 87: 1655-1668

Bell JJ (2008) The functional roles of marine sponges. Estuarine, Coastal and Shelf Science 79: 341-353

Bell JJ, Barnes DKA (2000a) The distribution and prevalence of sponges in relation to environmental gradients within a temperate sea lough: inclined cliff surfaces. Diversity and Distributions 6: 305-323

Bell JJ, Barnes DKA (2000b) A sponge diversity centre within a marine ôslandô Hydrobiologia 440: 55-64

Benedetti-Cecchi L (2001) Variability in abundance of algae and invertebrates at different spatial scales on rocky sea shores. Marine Ecology Progress Series 215: 79-92

Benedetti-Cecchi L, Pannacciulli F, Bulleri F, Moschella PS, Airoldi L, Relini G, Cinelli F (2001) Predicting the consequences of anthropogenic disturbance: large-scale effects of loss of canopy algae on rocky shores. Marine Ecology Progress Series 214: 134-150

Berman J, Bell JJ (2010) Spatial variability of sponge assemblages on the Wellington South Coast, New Zealand. The Open Journal of Marine Biology 4: 12-25

Bertness MD, Callaway R (1994) Positive interactions in communities. Trends in Ecology \& Evolution 9: 191-193

Bertness MD, Leonard GH (1997) The role of positive interactions in communites: lessons from intertidal habitats. Ecology 78: 1976-1989

Bertness MD, Leonard GH, Levine JM, Schmidt PR, Ingraham AO (1999) Testing the relative contribution of positive and negative interactions in rocky intertidal communities. Ecology 80: 2711-2726

Bonanomi G, Incerti G, Mazzoleni S (2011) Assessing occurrence, specificity, and mechanisms of plant facilitation in terrestrial ecosystems. Plant Ecology 212: 1777-1790

Bruno JF, Bertness MD (2001) Habitat modification and facilitation in benthic marine communities. In: M.D. Bertness, Gaine SD, Hay ME (eds) Marine community ecology. Sinauer, Sunderland,MA., pp 201 ï 218 
Bruno JF, Stachowicz JJ, Bertness MD (2003) Inclusion of facilitation into ecological theory. Trends in Ecology \& Evolution 18: 119-125

Bulleri F (2009) Facilitation research in marine systems: state of the art, emerging patterns and insights for future developments. Journal of Ecology 97: 11211130

Bulleri F, Benedetti-Cecchi L, Acunto S, Cinelli F, Hawkins SJ (2002) The influence of canopy algae on vertical patterns of distribution of low-shore assemblages on rocky coasts in the northwest Mediterranean. Journal of Experimental Marine Biology and Ecology 267: 89-106

Bulleri F, Benedetti-Cecchi L, Cusson M, Maggi E, Arenas F, Aspden R, Bertocci I, T. P. Crowe, Davoult D, Eriksson BK, Fraschetti S, Golléty C, Griffin JN, Jenkins SR, J. Kotta, Kraufvelin P, Molis M, Sousa Pinto I, Terlizzi A, Valdivia N, Paterson DM (2012) Temporal stability of European rocky shore assemblages: variation across a latitudinal gradient and the role of habitatformers. Oikos 121: 1801-1809

Burnham KP, Anderson DR (2002) Model selection and multi-model inference: a practical information-theoretic approach. Springer-Verlag, New York

Callaway RM (1995) Positive interactions among plants (Interpreting botanical progress). The Botanical Review 61: 306-349

Carter L, Lewis K (1995) Variability of the modern sand cover on a tide and storm driven inner shelf, south Wellington, New Zealand. New Zealand Journal of Geology and Geophysics 38: 451-470

Choat JH, Schiel DR (1982) Patterns of distribution and abundance of large brown algae and invertebrate herbivores in subtidal regions of northern New Zealand. Journal of Experimental Marine Biology and Ecology 60: 129-162

Clarke KR (1993) Non-parametric multivariate analyses of changes in community structure. Australian Journal of Ecology 18: 117-143

Clarke KR, Gorley RN (2006) Primer v6: user manual/tutorial

Clarke KR, Somerfield PJ, Airoldi L, Warwick RM (2006) Exploring interactions by second-stage community analyses. Journal of Experimental Marine Biology and Ecology 338: 179-192

Connell JH (1983) On the prevalence and relative importance of interspecific competition: evidence from field experiments. The American Naturalist 122: 661-696 
Connell SD (2003a) The monopolization of understorey habitat by subtidal encrusting coralline algae: a test of the combined effects of canopy-mediated light and sedimentation. Marine Biology 142: $10651 ̈ 1071$

Connell SD (2003b) Negative effects overpower the positive of kelp to exclude invertebrates from the understorey community. Oecologia 137: 97-103

Davis AR, Fyfe SK, Turon X, Uriz MJ (2003) Size matters sometimes: wall height and the structure of subtidal benthic invertebrate assemblages in south-eastern Australia and Mediterranean Spain. Journal of Biogeography 30: 1797-1807

Dayton PK (1975) Experimental evaluation of ecological dominance in a rocky intertidal algal community. Ecological Monographs 45: 137ï 159

Dayton PK (1985a) Ecology of kelp communities. Annual Review of Ecology and Systematics 16: 215-245

Dayton PK (1985b) The structure and regulation of some South American kelp communities. Ecological Monographs 55: 447-468

Dayton PK, Robilliard GA, Paine RT, Dayton LB (1974) Biological accommodation in the benthic community at McMurdo Sound, Antarctica. Ecological Monographs 44: 105-128

Duggins D, Eckman JE, Sewell AT (1990) Ecology of understory kelp environments. II. Effects of kelps on recruitment of benthic invertebrates Journal of Experimental Marine Biology and Ecology 143: 27-45

Duggins DO, Eckman JE (1997) Is kelp detritus a good food for suspension feeders? Effects of kelp species, age and secondary metabolites. Marine Biology 128: 489-495

Eckman JE, Duggins DO (1991) Life and death beneath macrophyte canopies: effects of understory kelps on growth rates and survival of marine, benthic suspension feeders. Oecologia 87: 473-487

Edgar GJ, Barrett NS, Morton AJ, Samson CR (2004) Effects of algal canopy clearance on plant, fish and macroinvertebrate communities on eastern Tasmanian reefs. Journal of Experimental Marine Biology and Ecology 312: 67-87

Foster MS, Schiel. DR (1985) The ecology of giant kelp forests in California: a community profile. U.S. Fish and Wildlife Service Biological Report, Washington, D.C., USA. 
Chapter 3. Facilitation of sponges by canopy-algae

Fowler-Walker MJ, Gillanders BM, Connell SD, Irving AD (2005) Patterns of association between canopy-morphology and understorey assemblages across temperate Australia. Journal of Experimental Marine Biology and Ecology 63: 133-141

Ginn BK, Logan A, Thomas MLH (2000) Sponge ecology on sublittoral hard substrates in a high current velocity area. Estuarine, Coastal and Shelf Science 50: $403-414$

Goldberg DE (1987) Neighborhood competition in an old-field plant community. Ecology 68: 1211-1223

Gouhier TC, Menge BA, Hacker SD (2011) Recruitment facilitation can promote coexistence and buffer population growth in metacommunities. Ecology Letters 14: 1201-1210

Hay ME (1981) The functional morphology of turf-forming seaweeds: persistence in stressful marine habitats. Ecology 62: 739-750

Hobbs NT, Hilborn R (2006) Alternatives to statistical hypothesis testing in ecology: a guide to self teaching. Ecological Applications 16: 5-19

Jenkins SR, Norton TA, Hawkins SJ (1999) Settlement and post-settlement interactions between Semibalanus balanoides (L.) (Crustacea: Cirripedia) and three species of fucoid canopy algae. Journal of Experimental Marine Biology and Ecology 236: 49-67

Jones CG, Lawton JH, Shachak M (1994) Organisms as ecosystem engineers. Oikos 69: $373-386$

Jones CG, Lawton JH, Shachak M (1997) Positive and negative effects of organisms as physical ecosystem engeneers. Ecology 78: 1946-1957

Kaandorp JA, de Kluijver MJ (1992) Verification of fractal growth models of the sponge Haliclona oculata (Porifera) with transplantation experiments. Marine Biology 113: 133-143

Kennelly SJ (1987a) Physical disturbances in an Australian kelp community. I. Temporal effects. Marine Ecology Progress Series 40: 145-153

Kennelly SJ (1987b) Physical disturbances in an Australian kelp community. II. Effects on understorey species due to differences in kelp cover. Marine Ecology Progress Series 40: 155-165

Kennelly SJ (1989) Effects of kelp canopies on understorey species due to shade and scour. Marine Ecology Progress Series 50: 215-224 
Kennelly SJ, Underwood AJ (1993) Geographic consistencies of effects of experimental physical disturbance on understorey species in sublittoral kelp forests in central New South Wales. Journal of Experimental Marine Biology and Ecology 168: 35-58

Knott NA, Underwood AJ, Chapman MG, Glasby TM (2004) Epibiota on vertical and on horizontal surfaces on natural reefs and on artificial structures. Journal of the Marine Biological Association of the United Kingdom 84: 1117-1130

Kohler KE, Gill SM (2006) Coral Point Count with Excel extensions (CPCe): A Visual Basic program for the determination of coral and substrate coverage using random point count methodology. Computers and Geosciences 32: $1259-1269$

Leonard GH (1999) Positive and negative effects of intertidal algal canopies on recruitment and survival of barnacles. Marine Ecology Progress Series 178: 241-249

Mann KH (1973) Seaweeds: their productivity and strategy for growth. Science 182: 975-981

McArdle B, Anderson M (2001) Fitting multivariate models to community data: A comment on distance-based redundancy analysis. Ecology 82: 290-297

Melville AJ, Connell SD (2001) Experimental effects of kelp canopies on subtidal coralline algae. Austral Ecology 26: 102-108

Miller RJ, Etter RJ (2008) Shading facilitates sessile invertebrate dominance in the rocky subtidal Gulf of Maine. Ecology 89: $452 i ̈ 462$

Morrow K, Carpenter R (2008) Shallow kelp canopies mediate macroalgal composition: effects on the distribution and abundance of Corynactis californica (Corallimorpharia). Marine Ecology Progress Series 361: 119-127

Naranjo SA, Carballo JL, García-Gómez JC (1996) Effects of environmental stress on ascidian populations in Algeciras bay (southern Spain). Possible marine bioindicators? Marine Ecology Progress Series 144: 119-131

OôConnor NE, Crowe TP, McGrath D (2006) Effects of epibiotic algae on the survival, biomass and recruitment of mussels, Mytilus L. (Bivalvia: Mollusca). Journal of Experimental Marine Biology and Ecology 328: 265-276

Perea-Blázquez A, Davy SK, Bell JJ (2012) Estimates of particulate organic carbon flowing from the pelagic environment to the benthos through sponge assemblages. PLoS One 7: e29569 
Preciado I, Maldonado M (2005) Reassessing the spatial relationship between sponges and macroalgae in sublittoral rocky bottoms: a descriptive approach. Helgoland Marine Research 59: 141-150

R Development Core Team (2013) R: a language and environment for statistical computing. R Foundation for Statistical Computing, Vienna. Available at http://www.R-project.org

Reed DC, Foster MS (1984) The effects of canopy shadings on algal recruitment and growth in a giant kelp forest. Ecology 65: 937-948

Roberts DE, Davis AR, Cummins SP (2006) Experimental manipulation of shade, silt, nutrients and salinity on the temperate reef sponge Cymbastela concentrica. Marine Ecology Progress Series 307: 143-154

Russell BD (2007) Effects of canopy-mediated abrasion and water pow on the early colonisation of turf-forming algae. Marine and Freshwater Research: 657-665

Schiel DR (1988) Algal interactions on shallow subtidal reefs in northern New Zealand: A review. New Zealand Journal of Marine and Freshwater Research 22: 481-489

Schiel DR, Hickford MJH (2001) Biological structure if nearshore rocky subtidal habitats in southern New Zealand. Science for Conservation 182: 1-54

Sebens KP (1985) Community ecology of vertical rock walls in the Gulf of Maine, U.S.A.: Small-scale processes and alternative States. In: Moore PG, Seed R (eds) The ecology of rocky coasts. Columbia University Press, New York, pp 346-371

Shears NT, Babcock RC (2007) Quantitative description of mainland New Zealand's shallow subtidal reef communities. Science for Conservation: 1-126

Smale DA, Burrows MT, Moore P, OâConnor N, Hawkins SJ (2013) Threats and knowledge gaps for ecosystem services provided by kelp forests: a northeast Atlantic perspective. Ecology and Evolution 3: 4016-4038

Smale DA, Kendrick GA, Wernberg T (2011) Subtidal macroalgal richness, diversity and turnover, at multiple spatial scales, along the southwestern Australian coastline. Estuarine, Coastal and Shelf Science 91: 224-231

Smith SDA (1996) The macrofaunal community of Ecklonia radiata holdfasts: Variation associated with sediment regime, sponge cover and depth. Australian Journal of Ecology 21: 144-153 
Chapter 3. Facilitation of sponges by canopy-algae

Sousa W (2000) Natural disturbance and the dynamics of marine benthic communities. In: Bertness MD, Gaines SD, Hay ME (eds) Marine community ecology. Sinauer Associates, Sunderland, MA, pp 85ī 130

Stachowicz JJ (2001) Facilitation, and the structure of ecological communities. BioScience 51: 235-246

Symonds MRE, Moussalli A (2011) A brief guide to model selection, multimodel inference and model averaging in behavioural ecology using Akaikeôs information criterion. Behavioral Ecology Sociobiology 65: 13-21

Syvitski JPM, Vörösmarty CJ, Kettner AJ, Green P (2005) Impact of humans on the flux of terrestrial sediment to the global coastal ocean. Science 308: 376-380

Thomsen MS, Wernberg T, Altieri A, Tuya F, Gulbransen D, McGlathery KJ, Holmer M, Silliman BR (2010) Habitat cascades: the conceptual context and global relevance of facilitation cascades via habitat formation and modification. Integrative and Comparative Biology 50: 158-175

Toohey BD, Kendrick GA (2008) Canopy-understorey relationships are mediated by reef topography in Ecklonia radiata kelp beds. European Journal of Phycology 43: $133-142$

Turon X, Tarjuelo I, Uriz MJ (1998) Growth dynamics and mortality of the encrusting sponge Crambe crambe (Poecilosclerida) in contrasting habitats: correlation with population structure and investment in defence. Functional Ecology 12: 631-639

Velimirov B, Griffiths CL (1979) Wave-induced kelp movement and its importance for community structure. Botanica Marina 22: 169-172

Wernberg T, Kendrick GA, Toohey BD (2005) Modification of the physical environment by an Ecklonia radiata (Laminariales) canopy and implications for associated foliose algae. Aquatic Ecology 39: 419-430

Wilkinson CR, Vacelet J (1979) Transplantation of marine sponges to different conditions of light and current. Journal of Experimental Marine Biology and Ecology 37: 91-104

Wright JT, Benkendorff K, Davis AR (1997) Habitat associated differences in temperate sponge assemblages: the importance of chemical defence. Journal of Experimental Marine Biology and Ecology 213: 199-213

Wulff J (2012) Ecological interactions and the distribution, abundance, and diversity of sponges. Advances in Marine Biology 61:273-344 
Chapter 4: Interactions between understory-algae and sponges

\section{Chapter 4. Effect of the brown alga Zonaria turneriana on the growth and survival of the calcareous sponge Leucetta sp.}

\subsection{Abstract}

Negative interactions between macroalgae and sponges may explain the decreased abundance of sponges in high-light habitats. Earlier research has suggested that turfforming algae are able to outcompete sponges in high-light habitats using a number of different mechanisms including overgrowth, shading, reduction in flow rates, and the production and release of allelochemicals. However, with the exception of a few studies involving fast growing invasive algal species, there is a lack of empirical evidence for the existence of negative interactions between sponges and native algal species. Here I designed a laboratory experiment to test the role of abrasion and shading by the brown alga Zonaria turneriana on growth and survival of the calcareous sponge Leucetta sp. The experiment was designed to expose sponges to algae or synthetic mimics, to examine the importance of abrasion and shading by algae on sponges. Leucetta individuals where exposed to Zonaria plants, or black plastic (to test the effect of abrasion and shading) or clear plastic thalli (to test the effect of scouring without shading). Changes in sponge growth by the end of the experiment ranged from $-2 \%$ in the algal treatment to $1 \%$ and $4 \%$ for controls and treatments with clear mimic, respectively. In the algal treatment I observed that algal fronds remained in direct contact with the surface of the sponge producing discolouration; this may prevent food and oxygen uptake by the sponge. The absence of consistent negative effects could be a result of the short duration (4 weeks) of the experiment, which may not have allowed sufficient time to observe more consistent effects. Alternatively, there may be no negative interactions between the two species I studied. 
Chapter 4: Interactions between understory-algae and sponges

\subsection{Introduction}

The prevalence of macroalgae and the low abundance of sponges in temperate highlight habitats have led some authors to suggest that competition is the main reason for sponges being restricted to cryptic habitats such as the undersides of boulders, overhangs or caves (Kennelly \& Underwood 1993, Bell \& Barnes 2000, Ginn et al. 2000, Bell 2002, Bell 2007). Although, several studies from different latitudes have reported the existence of negative interactions between macroalgae and sponges (e.g. Kaandorp \& de Kluijver 1992, Turon et al. 1998), such interactions have not been empirically demonstrated.

Despite the paucity of data on the interactions between sponges and algae, several studies have demonstrated the existence of negative interactions between macroalgae and other organisms, such as corals (River \& Edmunds 2001, Box \& Mumby 2007, Titlyanov et al. 2007, Morrow et al. 2013) and barnacles (Jenkins et al. 1999, Leonard 1999). Competition between algae and other organisms can be indirect (e.g. through the occupation of primary space) or direct (e.g. by overgrowth) (Titlyanov et al. 2007). Macroalgae can directly affect the growth and survival of other organisms by: 1) physical abrasion produced by fronds (Lirman 2001, River \& Edmunds 2001, Jompa \& McCook 2002, Titlyanov et al. 2007); 2) reducing light availability (Duggins et al. 1990); 3) changing flow rates, which can reduce growth due to flow-limited particle capture success (Sebens \& Johnson 1991) or reduce encounter rates with particles (Sebens 1997); and 4) through the production and release of organic compounds (e.g. allelochemicals) (de Nys et al. 1991, McCook et al. 2001, Titlyanov et al. 2007). In contrast, competition between sponges and macroalgae remains to be demonstrated, with the exception of negative interactions recorded between sponges and rapidly growing invasive species. For example, the invasive green algae Caulerpa spp. can overgrow some sponge species through a network of ramified stolons, blocking sponge oscula and ostia and also causing sediment accumulation (Davis et al. 1997, Baldacconi \& Corriero 2009, G̦ljevil et al. 2011). Recently, de Caralt and Cebrian (2013) described the impact of the overgrowth of the invasive red alga Womersleyella setacea on sponge assemblages in the 
Chapter 4: Interactions between understory-algae and sponges

northwestern Mediterranean. This algal species negatively affects sponge reproduction, resulting in a low number of, or no reproductive structures being produced. Other competitive interactions potentially occurring between sponges and algae (e.g. release of allelochemicals, scouring, and modification of other physical factors) remain to be tested. Connell (2003) suggested that sponges might be able to tolerate abrasion from algae due to their capacity to feed without projecting the filter feeding apparatus outside their bodies. However, the effect of abrasion and other negative interactions between understory algae and sponges has not been empirically demonstrated.

My previous data chapters support the existence of negative interactions between some sponge species and understory algae on the Wellington south coast (see Chapters 2 and 3). I concluded that the removal of the Ecklonia radiata canopy indirectly affected the abundance of sponges occurring underneath the canopy, as a result of displacement produced by competitively superior understory algal species, which increased abundance after canopy removal. Although, the increase in the abundance of the small brown algae was highly correlated with a decrease in the abundance of some sponge species occurring underneath the canopy, there is no information regarding the effect of brown algae (e.g. Z. turneriana) on sponge species and the mechanisms involved in this negative correlation are unclear.

Here I conducted a laboratory experiment to evaluate the effect of the brown algae Z. turneriana on the calcareous sponge Leucetta sp. Previous observations and a pilot laboratory experiment showed some evidence of the existence of negative interactions between both species. The small brown algae Z. turneriana (hereafter referred to Zonaria) is common in the shallow-subtidal region throughout New Zealand. Plants grow up to $15-30 \mathrm{~cm}$ high (Adams 1994), but are usually $10-20 \mathrm{~cm}$ (Nelson 2013), and dominate the understory, covering more than $50 \%$ of the substrate in some areas around the Wellington region (Shears \& Babcock 2007). The calcareous sponge Leucetta sp. was selected for two main reasons. Firstly, because is one of the most common species of sponges on rocky reefs around the Wellington south coast (Berman et al. 2008). It is very abundant on rock walls and is also present on walls with E. radiata, however its abundance is very low in high-light habitats, 
such as on horizontal surfaces. Secondly, because Leucetta sp. was relatively easy to maintain under laboratory conditions.

The aim of this study was to test the effect of the common understory alga Zonaria turneriana on the growth and survival of the sponge Leucetta sp., under laboratory conditions. More specifically I tested if shading and abrasion by algae affect growth and survival of Leucetta.

\subsection{Materials and Methods}

\subsubsection{Collection and experimental design}

Individuals of Leucetta sp. and Zonaria plants were collected using SCUBA from rocky walls (6-10 m depth) at Breaker Bay on the Wellington south coast. Sponges used in the study had a surface area of between 17 to $80 \mathrm{~cm}^{2}$. Zonaria plants were included in the study if the size of the thallus was between 10 and $15 \mathrm{~cm}$ high. After collection, sponges and algae were transported to the Victoria University Coastal Ecology laboratory (VUCEL) and maintained for one week to allow acclimation to laboratory conditions. This experiment was firstly conducted between May and June 2013 however, it was interrupted after Juneôs big storm. The storm damaged the laboratoryôs water intakes, which made impossible to maintain the animals without water supply. Results presented here correspond to the laboratory experiment conducted between June and July 2013.

The experimental design consisted of four treatments (Fig. 4.1): 1) Algal treatment which consisted of 4-5 Zonaria thalli (10 - $15 \mathrm{~cm}$ high) to examine the possibility of negative interactions with Leucetta. Five plants were placed adjacent to one Leucetta sp. individual (see Fig. 4.1);2) algal mimic (ñolackò) which consisted of black plastic thalli distributed around a sponge to simulate the action of Zonaria branches to test the effect of abrasion and shading. Black polypropylene was cut into narrow 1-1.5 cm strips to resemble the shape and size of Zonaria fronds. Mimics were between 10 and $15 \mathrm{~cm}$ high to represent the size range of Zonaria plants (see Nelson 2013); 3) algal mimic ( ñ clearò), made of clear plastic strips that were similar in size to the black mimics and Zonaria plants, to test the effect of scouring without shading. 
Each algal and mimic treatment held different sizes of plants to represent a broad range of plant sizes; 4) Control (without algae or algal mimics), to test the effect of manipulation. Each sponge was randomly assigned to one of four treatments ( $n=12$ individuals per treatment). Each treatment was replicated 3 times in 351 tanks and each tank held four sponges. Tanks were supplied with constantly flowing fresh (unfiltered) seawater at ambient temperature, and placed outside under ambient conditions. The water flow rate though the experimental tanks was $21 \mathrm{~min}^{-1}$. Accumulated sediment was gently removed from the surface of sponges with a small siphon (5 mm diameter) at least twice a day. Algae and mimics were attached with needles to a rubber surface surrounding the sponge.

Tanks were covered with two layers of $1 \mathrm{~mm}$ mesh shade cloth (fibreglass $50 \%$ neutral density screen) in order to represent light levels occurring in situ. Relative light intensity levels in the experimental tanks were measured with a HOBO Pendant ${ }^{\circledR}$ temperature/light data logger (Onset, USA). Measurements were carried out for 2 consecutive days ( 1 measurement every 5 minutes), following River \& Edmunds (2001).

The area of each sponge was calculated using the software CPCe v3.5 (Coral Point Count with Excel extensions) (Kohler \& Gill 2006), where each photograph was first scaled using the calibration tool to a known distance marked on the image. The surface of each sponge was then traced on the image as close as possible, to give the calculated area in $\mathrm{cm}^{2}$. The two-dimensional growth of each sponge was calculated following the procedure described by Knott et al. (2006), where growth was the area covered by the sponge at the end of the experiment (T1) minus the area it covered at the beginning of the experiment (T0), divided by its area at the beginning of the experiment and multiplied by 100 to produce a percentage ((Area T1-Area T0/Area T0) x 100).

In order to test whether interaction with algae/mimics would cause any change in sponge morphology, I calculated the width, length and height of each sponge with calipers. A morphometric index was calculated following the method described by Becerro et al. (1994). Changes in shape were calculated using a directional growth index (D) (D = 1 ï $\mathrm{P} / \mathrm{M})$, where $\mathrm{M}=$ length of maximum straight line through two 
sponge points, and $\mathrm{P}=$ length of maximum straight line perpendicular to $\mathrm{M}$. This index measures sponge elongation. A value of 0 indicates a perfect circle whereas 1 is approached as directional growth increases. Finally, the percentage of survival was measured as the number of sponges remaining in the tanks at the end of the experiment. All measurements were taken every 6-7 days for approximately four weeks.

\subsubsection{Data analysis}

Permutational analysis of variance (PERMANOVA) (Anderson 2001) was used to test for treatment effects on area, length, height, width and directional growth of sponges. A univariate PERMANOVA test was used, as it does not assume normality of distribution and variance. Tests were run on Euclidean distances based on 9,999 permutations of raw data. All tests were conducted in the PRIMER v6 statistical package (Clarke \& Gorley 2006, Anderson et al. 2008). 


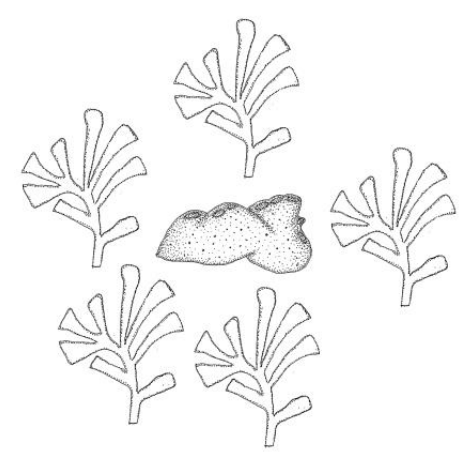

algal mimic (clear)

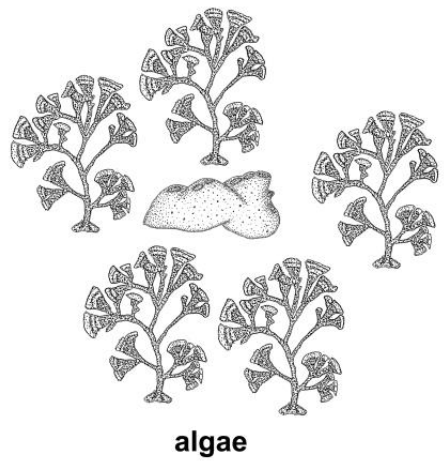

algae

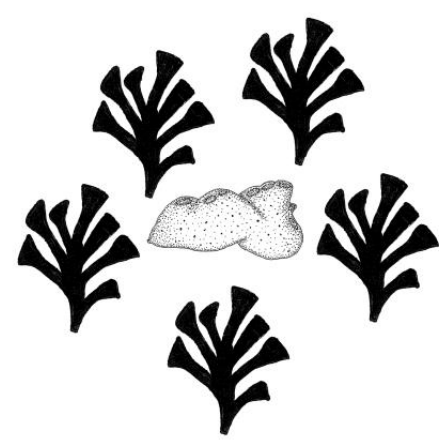

algal mimic (black)

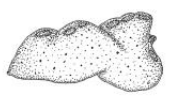

Control

Figure 4.1. Schematic diagram of the experimental treatments showing manipulation control (Leucetta sp. without algae and mimics); algal mimic (clear; Leucetta sp. with clear mimics); algal mimic (black; Leucetta sp. with black mimics), and algal (Zonaria) treatment (Leucetta sp. with Zonaria).

\subsection{Results}

Light intensity varied between treatments $\left(F_{3,63}=62.547, P=0.001\right.$; Fig. 4.2). No differences were found in pairwise comparisons between algal and black mimic treatments $(P>0.05)$ or between control and clear mimic treatments $(P>0.05)$. Light intensity was significantly lower in the algal and black mimic treatments, being more than three times lower than the light intensity recorded in the control and clear mimic treatments (Fig. 4.2). 


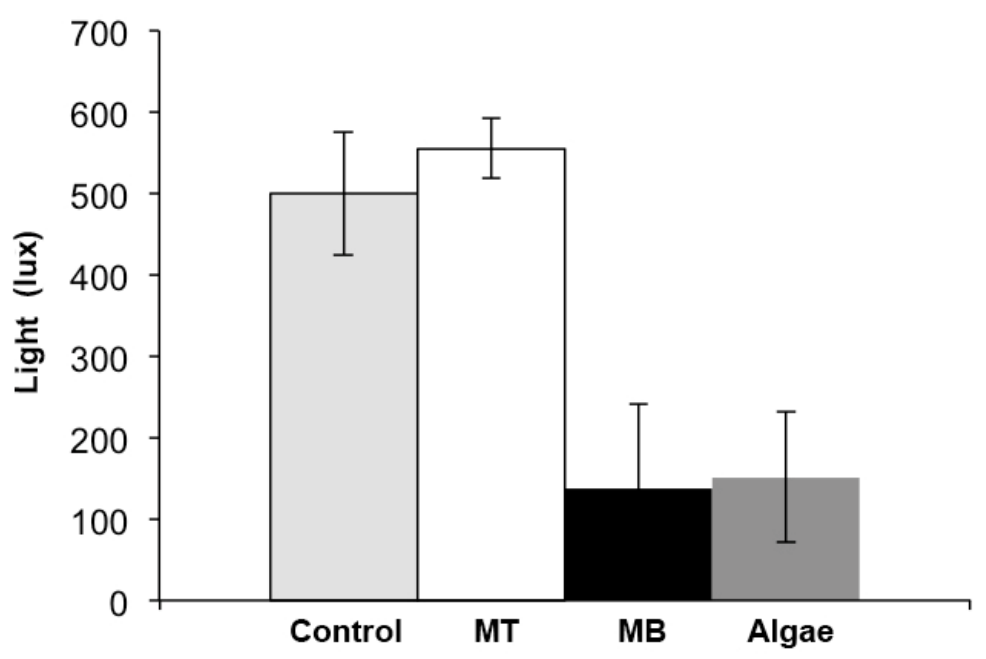

Figure 4.2. Relative light intensity levels recorded in each treatment. $\mathrm{C}=$ control; $\mathrm{MB}$ $=$ algal mimic $($ black); MT = algal mimic $($ clear $) ;$ Algae $=$ algal treatment $($ Zonaria $)$. Error bars indicate $1 \mathrm{SE}$.

The survival rate was highest in the algal and clear mimic treatments, with $92 \%$ of sponges surviving. Survival in the black mimic treatment was $67 \%$, whereas the lowest survival occurred in the control where only $59 \%$ of the sponges had survived by the end of the four-week experiment.

No differences in the initial size (area) of sponges were found between treatments (control $=41.10 \mathrm{~cm}^{2} \pm 11.86$ S.E.; algae $=41.04 \mathrm{~cm}^{2} \pm 11.85$ S.E.; mimic black $=31.36 \mathrm{~cm}^{2} \pm 9.05$ S.E.; mimic clear $=33.35 \mathrm{~cm}^{2} \pm 9.63$ S.E.; PERMANOVA $\left.F_{3,37}=1.2718, P=0.2903\right)$. Overall, treatments showed little change in surface area during the experiment, with the growth (\% increase) at the end of the experiment ranging from $-2 \%$ in the algal treatment to $1 \%$ and $4 \%$ for the control and clear mimic treatment, respectively (Fig. 4.3). However, no significant differences were found between treatments $\left(F_{3,37}=35.273, P=0.982\right)$. The algal treatment had high variability, with $50 \%$ of sponges not growing at all or losing up to $20 \%$ of their surface area. Moreover, there were no differences in the final size (area) of sponges between the control and other treatments (control $=44.23 \mathrm{~cm}^{2} \pm 16.72$ S.E.; algae $=$ $41.53 \mathrm{~cm}^{2} \pm 12.52$ S.E.; mimic black $=34.88 \mathrm{~cm}^{2} \pm 12.33$ S.E.; mimic clear $=34.33$ $\mathrm{cm}^{2} \pm 10.37$ S.E.; PERMANOVA $F_{3,36}=0.4151, P=0.7805$, Fig. 4.3$)$. 
Chapter 4: Interactions between understory-algae and sponges

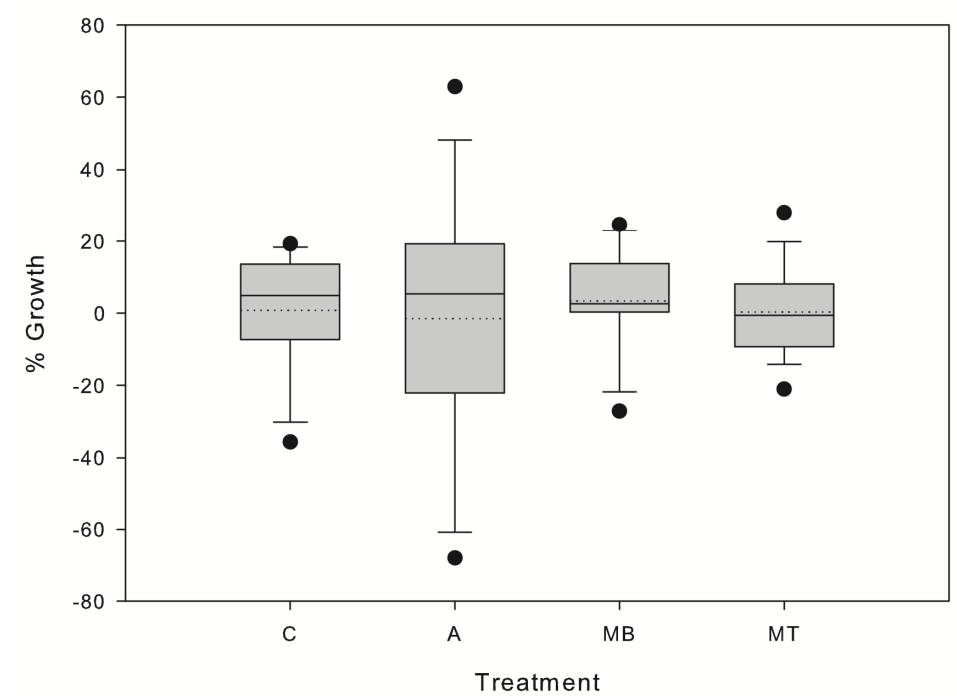

Figure 4.3. Relative changes in growth of Leucetta sp. after four weeks. C=control; A $=$ algal treatment (Zonaria); $\mathrm{MB}=$ algal mimic (black); $\mathrm{MT}=$ algal mimic (clear). The horizontal line in the box interior represents the median and the doted line represents the mean.

The length of sponges was similar at the start of the experiment (PERMANOVA $F_{3,47}=1.6625, P=0.1875$; Table 4.1). Similarly, the length was the same for the different treatments at the end of the experiment (PERMANOVA $F_{3,33}=$ $0.3945, P=0.7812$; Table 4.1). Changes in length during the experiment were highly variable in all treatments (Fig. 4.4a), hence no significant differences were found in the final length of sponges between treatments (PERMANOVA P $<0.05$; Table 4.2).

The initial width of sponges was significantly different between treatments (PERMANOVA $F_{3,47} 3.8829, P=0.01$; Table 4.1), however no difference was found at the end of the experiment (PERMANOVA $F_{3,33}=2.2197, P=0.0975$, Table 4.1). The relative change in width was higher in the control treatment, and less variable in the algal and mimic treatments (Fig. 4.4b). However, a significant effect of treatment was found (PERMANOVA $P<0.05$; Table 4.2; Fig. 4.4b), being consistent through time (PERMANOVA Ti x $\operatorname{Tr} P<0.4)$.

Heights of sponges were similar between treatments at the start (PERMANOVA $F_{3,47}=0.84225, P=0.4928$, Table 4.1 ) and at the end of the 
Chapter 4: Interactions between understory-algae and sponges

experiment (PERMANOVA $F_{3,47}=0.84225, P=0.4928$, Table 4.1). Sponges in the algal treatment tended to decrease in height more than in other treatments, however values were not significantly different between any of the treatments (PERMANOVA $\mathrm{P}<0.05$; Table 4.2; Fig 4c).

Table 4.1. Mean values ( \pm S.E.) for the morphological parameters (length, width and height) of Leucetta sp. measured at the beginning $\left(\mathrm{T}_{0}\right)$ and at the end $\left(\mathrm{T}_{\mathrm{F}}\right)$ of the experiment. $\mathrm{Tr}=$ treatment; $\mathrm{C}=$ control; $\mathrm{A}=$ algal treatment $($ Zonaria $) ; \mathrm{MB}=$ algal mimic (black); MT = algal mimic (clear).

\begin{tabular}{lcccccc}
\hline & \multicolumn{2}{c}{ Length } & \multicolumn{2}{c}{ Width } & \multicolumn{2}{c}{ Height } \\
\hline $\operatorname{Tr}$ & $\mathrm{T}_{0}$ & $\mathrm{~T}_{\mathrm{f}}$ & $\mathrm{T}_{0}$ & $\mathrm{~T}_{\mathrm{f}}$ & $\mathrm{T}_{0}$ & $\mathrm{~T}_{\mathrm{f}}$ \\
\hline $\mathrm{C}$ & $83.85(5.28)$ & $81.40(7.11)$ & $57.00(4.74)$ & $59.40(6.01)$ & $30.67(1.96)$ & $30.40(5.57)$ \\
$\mathrm{A}$ & $83.33(5.46)$ & $82.75(4.60)$ & $59.50(2.88)$ & $58.25(3.05)$ & $31.50(3.20)$ & $24.50(2.15)$ \\
MB & $69.92(2.40)$ & $74.00(3.35)$ & $52.29(4.54)$ & $52.29(4.54)$ & $34.92(3.11)$ & $29.29(2.12)$ \\
MT & $76.17(6.27)$ & $82.30(9.92)$ & $50.83(3.45)$ & $47.20(3.51)$ & $28.83(1.63)$ & $28.10(1.94)$ \\
\hline
\end{tabular}

Table 4.2. PERMANOVA results testing the effect of time (Ti) and treatment (Tr) on the shape (length, width and height) of Leucetta sp. Statistical differences were tested using 9,999 permutations. Significance is indicated by asterisk: $* P<0.05$.

\begin{tabular}{lcccccc}
\hline & \multicolumn{2}{c}{ Length } & \multicolumn{2}{c}{ Width } & \multicolumn{2}{c}{ Height } \\
\hline Source & $F$ & $P$ & $F$ & $P$ & $F$ & $P$ \\
& & & & & & \\
\hline $\mathrm{Ti}$ & 0.16285 & 0.7322 & 0.3056 & 0.6221 & 3.2604 & 0.0697 \\
$\mathrm{Tr}$ & 1.5281 & 0.1977 & 4.6714 & $0.004^{*}$ & 1.2577 & 0.2931 \\
& & & & & & \\
$\mathrm{Ti} \mathrm{Tr}$ & 0.14519 & 0.9535 & 0.97524 & 0.4191 & 0.66734 & 0.5907 \\
& & & & & & \\
\hline
\end{tabular}


Chapter 4: Interactions between understory-algae and sponges
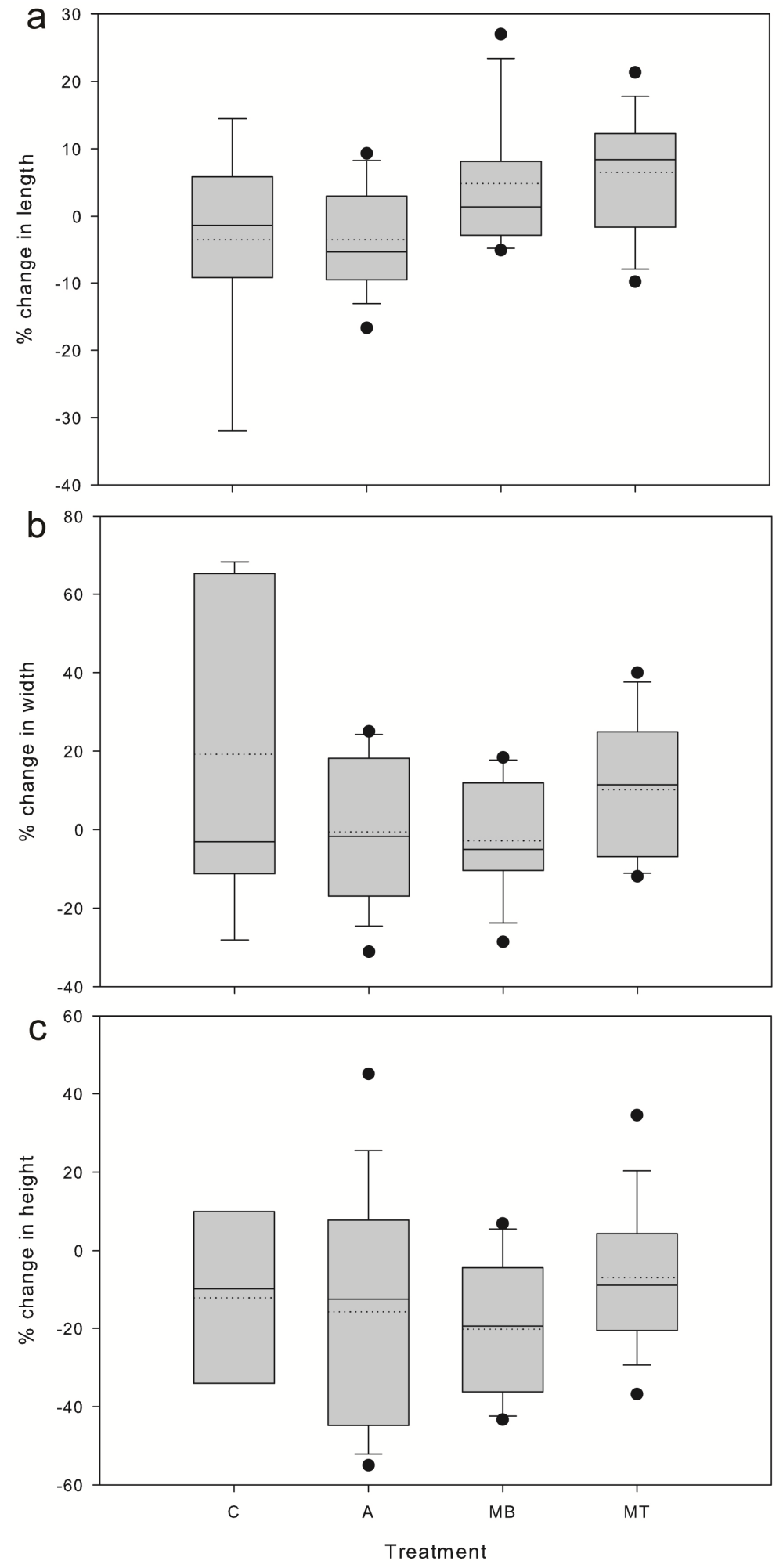

Figure 4.4. Relative changes in (a) length, (b) width, and (c) height of Leucetta sp. after four weeks. $\mathrm{C}=$ control; $\mathrm{A}=$ algal treatment $($ Zonaria $) ; \mathrm{MB}=$ algal mimic (black); MT = algal mimic (clear). The horizontal line in the box interior represents the median and the doted line represents the mean. 
In some cases, individuals in the algae and mimic treatments exhibited discolouration in some areas of the sponge. The occurrence of pale areas was due to Zonaria branches or plastic mimics that remained attached to the sponge surface for long periods of time.

The mean directional growth index was relatively low in all treatments (Fig. 4.5). Index values ranged from 0.05 to 0.63 at the start of the experiment and from 0.04 to 0.69 at the end of the experiment. A slight increase was observed in the clear mimic treatment by the end of the experiment, however no differences were found between treatments at the start or at end of the experiment (time PERMANOVA $F_{1,81}$ $=0,39025, P=1.202$; treatment $F_{3,81}=0.9984, P=0.42$; time $\mathrm{x}$ treatment $F_{3,81}=$ $0.635, P=0.576)$.

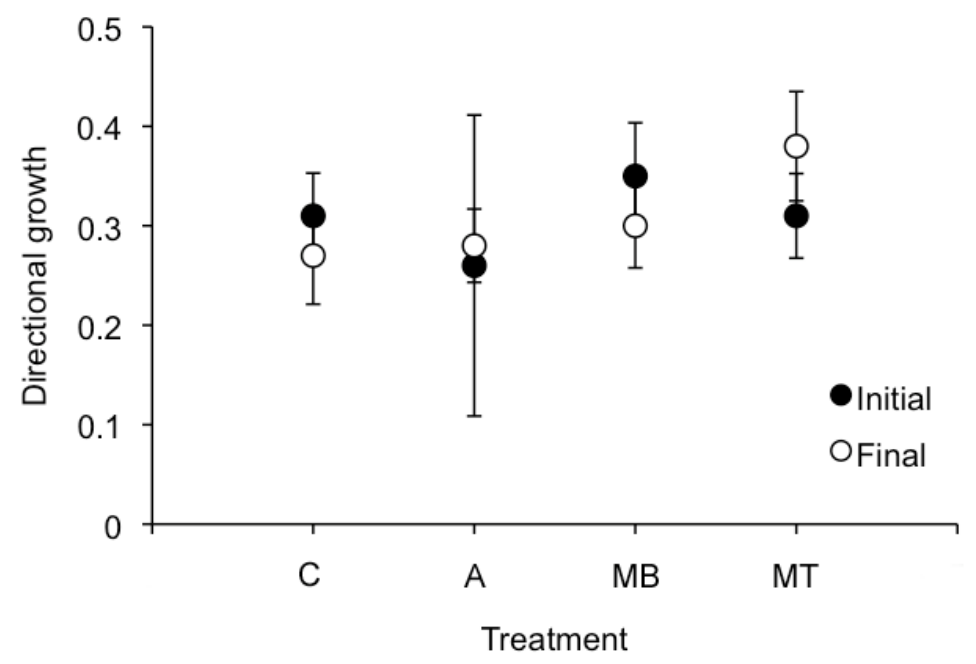

Figure 4.5. Mean values $( \pm \mathrm{SE}$ ) of directional growth of Leucetta sp. for treatments after four weeks. $\mathrm{C}=$ control; $\mathrm{A}=$ algal treatment $($ Zonaria $) ; \mathrm{MB}=$ algal mimic (black); MT = algal mimic (clear).

\subsection{Discussion}

Many studies have suggested that macroalgae are able to outcompete sponges in highlight habitats (e.g. Sebens 1985, Kaandorp \& de Kluijver 1992, Turon et al. 1998), however only a few of them (involving fast-growing invasive species) have reported 
the existence of negative interactions (but see Davis et al. 1997, Baldacconi \& Corriero 2009, Guljeviĺ et al. 2011). These earlier studies have suggested that overgrowth and sediment-trapping caused by the invasive green macroalgae Caulerpa spp. can produce dramatic effects on sponge assemblages. Recently, de Caralt and Cebrian (2013) demonstrated a negative effect of overgrowth by the invasive red alga Womersleyella setacea on several sponge species in the northwestern Mediterranean. This algal species not only affects sponges due to increased sedimentation and passive entrapment of particulate material, but can also affect gamete production. However, such aggressive effects (e.g. the effect of the algal stolons on seawater circulation and sediment accumulation) have not been experimentally tested. My experimental manipulations did not find any evidence of negative interactions between the brown alga Zonaria turneriana and the sponge Leucetta sp.

The ability of algae to modify light regimes (Duggins et al. 1990, Lirman 2001) has been suggested as one of the potential mechanisms that may have a direct impact on sponges (Duggins et al. 1990, Connell 2003). Light intensity recorded in the experimental tanks falls within the levels occurring at $10 \mathrm{~m}$ depth on the Wellington south coast (780 Lux \pm 62 S.E., S. Geange, unpubl. data), being lower in both algal and black mimic treatments. However, results obtained here did not provide clear evidence of a significant effect of shade produced by understory algae on the growth of Leucetta sp., since no significant differences were found between clear and black mimics and algae. The effect of shade, however, may have a greater effect on early life stages of sponges (Maldonado 2006). Shading effects provided by canopy-forming algae seem to have a stronger effect on sponges than algal understory, with the former playing an important role in structuring sponge assemblages on shallow-water temperate rocky reefs (see Chapter 3).

The survival rate was relatively high (more than $70 \%$ ), especially in the algal and mimic treatments. Surprisingly, the survival rate was lower in the control, at $59 \%$. The higher mortality observed in the control may be attributable to damage produced by UV radiation, which can affect growth and survival of sponges (Wilkinson \& Vacelet 1979, Jokiel 1980). Although light levels in the tanks were similar to the levels occurring in shallow waters, the higher ultraviolet (UV) radiation occurring at sea level (compared with those occurring between 5-15 m depth) (Häder et al. 2007), 
may have produced a negative effect in the control treatment, where sponges were more exposed to sunlight/UV radiation than those covered by algae or mimics.

Understory algae have the potential to negatively influence the growth of other organisms by reducing flow rates (Carpenter \& Williams 1993). In addition, water flow can indirectly affect neighbours (e.g. algae). My observations suggest that Zonaria may affect Leucetta sp. in some circumstances, depending on water flow and position of the algal neighbours, however further experiments are needed to confirm this. In some cases I observed that the current flow resulted in the algae remaining in direct contact (attached) with the surface of the sponge. This may disturb food intake (Sebens \& Johnson 1991, Sebens 1997) by preventing sponges taking up water. However, this effect was not consistent among replicates; in fact changes in growth (area) were highly variable, a situation that may be explained by differences in form, size and density of fronds, and direction of the flow causing different degrees of disturbance. Further field experiments are required to test the effect of direct contact between algae and sponges under natural conditions. Although a slight decrease in sponge area was observed in the algal treatment, this change was not significant. This might be explained by the experimental duration, as four weeks may not have allowed sufficient time to observe more consistent or long-term negative effects. More longterm experiments are required along with additional tests for the existence of competitive interactions between Zonaria and other sponge species. Furthermore, the water flow used in my experiment $\left(21 \mathrm{~min}^{-1}\right)$ may have not been sufficient to adequately test the effect of abrasion. It is possible that a stronger water flow may have produced a more consistent negative effect of fronds on Leucetta sp. Alternatively, wave test tanks may have helped to produce more realistic wave conditions in the experimental tanks, however this type of tanks were not available. Further laboratory experiments testing different flow regimes and also wave tanks may help to find a more consistent effect of abrasion produced by fronds on sponges.

In contrast to the documented interactions occurring between macroalgae and other organisms (e.g. corals, see de Nys et al. 1991), the occurrence of allelochemical effects in sponge-algal interactions has not been demonstrated. The discolouration observed in some sponge individuals in the algal and mimic treatments, suggests it might be associated with a physical rather than a chemical interaction. However, this 
effect was not consistent and further experiments will be required to clarify the potential physical interaction between both species.

Sediment accumulation produced by algal turfs (Airoldi 2003) has been also suggested as a negative factor affecting sponges (e.g. de Caralt \& Cebrian 2013). However, I did not considered it as a critical factor in the experimental design since it could have been very difficult to artificially reproduce in the laboratory the highly dynamic conditions occurring along the Wellington south coast.

Although I did not find an effect of Zonaria on Leucetta sp., the negative interaction occurring between sponges and algae cannot be discarded. Recent studies have demonstrated that interactions between corals and algae are species-specific (Bender et al. 2012) and a similar situation may occur in sponges, however this remains to be tested in future experiments involving Leucetta and other sponge species.

\subsection{References}

Adams NM (1994) Seaweeds of New Zealand. Canterbury University Press, Christchurch

Airoldi L (2003) The effects of sedimentation on rocky coast assemblages. Oceanography and Marine Biology: an Annual Review 41: 161-236

Anderson MJ (2001) A new method for non-parametric multivariate analysis of variance. Austral Ecology 26: 32-46

Anderson MJ, Gorley RN, Clarke KR (2008) Permanova for Primer: Guide to Software and Statistical Methods, PRIMER-E, Plymouth

Baldacconi R, Corriero G (2009) Effects of the spread of the alga Caulerpa racemosa var. cylindracea on the sponge assemblage from coralligenous concretions of the Apulian coast (Ionian Sea, Italy). Marine Ecology 30: 337-345

Becerro MA, Uriz MJ, Turon X (1994) Trends in space occupation by the encrusting sponge Crambe crambe: variation in shape as a function of size and environment. Marine Biology 121: 301-307

Bell JJ (2002) The sponge community in a semi-submerged temperate sea cave: density, diversity and richness. Marine Ecology 23: 297-311 
Chapter 4: Interactions between understory-algae and sponges

Bell JJ (2007) The ecology of sponges in Lough Hyne Marine Nature Reserve (southwest Ireland): past, present and future perspectives. Journal of the Marine Biological Association of the United Kingdom 87: 1655-1668

Bell JJ, Barnes DKA (2000) A sponge diversity centre within a marine ôslandô Hydrobiologia 440: 55-64

Bender D, Diaz-Pulido G, Dove S (2012) Effects of macroalgae on corals recovering from disturbance. Journal of Experimental Marine Biology and Ecology 429: $15-19$

Berman J, Perea-Blázquez A, Kelly M, Bell JJ (2008) Sponges of the Wellington South Coast. In: Gardner J (ed) The Taputeranga Marine Reserve. First Edition Publishers, Wellington, pp 225-236

Box SJ, Mumby PJ (2007) Effect of macroalgal competition on growth and survival of juvenile Caribbean corals. Marine Ecology Progress Series 342: 139-149

Carpenter RC, Williams SL (1993) Effects of algal turf canopy height and microscale substratum topography on profiles of flow speed in a coral forereef environment. Limnology and Oceanography 38: 687-694

Clarke KR, Gorley RN (2006) Primer v6: user manual/tutorial

Connell SD (2003) Negative effects overpower the positive of kelp to exclude invertebrates from the understorey community. Oecologia 137:97-103

Davis AR, Roberts DE, Cummins SP (1997) Rapid invasion of a sponge-dominated deep-reef by Caulerpa scalpelliformis (Chlorophyta) in Botany Bay, New South Wales. Australian Journal of Ecology 22: 146-150

de Caralt S, Cebrian E (2013) Impact of an invasive alga (Womersleyella setacea) on sponge assemblages: compromising the viability of future populations. Biological Invasions 15: 1591-1600

de Nys R, Coll JC, Price IR (1991) Chemically mediated interactions between the red alga Plocamium hamatum (Rhodophyta) and the octocoral Sinularia cruciata (Alcyonacea). Marine Biology 108: 315 Ï 320

Duggins D, Eckman JE, Sewell AT (1990) Ecology of understory kelp environments. II. Effects of kelps on recruitment of benthic invertebrates Journal of Experimental Marine Biology and Ecology 143: 27-45

Ginn BK, Logan A, Thomas MLH (2000) Sponge ecology on sublittoral hard substrates in a high current velocity area. Estuarine, Coastal and Shelf Science 50: $403-414$ 
Häder D-P, Kumar HD, Smith RC, Worrest RC (2007) Effects of solar UV radiation on aquatic ecosystems and interactions with climate change. Photochemical \& Photobiological Science 6: 267-285

Jenkins SR, Norton TA, Hawkins SJ (1999) Settlement and post-settlement interactions between Semibalanus balanoides (L.) (Crustacea: Cirripedia) and three species of fucoid canopy algae. Journal of Experimental Marine Biology and Ecology 236: 49-67

Jokiel PL (1980) Solar ultraviolet radiation and coral reef epifauna. Science 207: 1069-1071

Jompa J, McCook LJ (2002) The effects nutrients and herbivory on competition between a hard coral (Porites cylindrica) and a brown alga (Lobophora variegata). Limnology and Oceanography 47: 527-534

Kaandorp JA, de Kluijver MJ (1992) Verification of fractal growth models of the sponge Haliclona oculata (Porifera) with transplantation experiments. Marine Biology 113: 133-143

Kennelly SJ, Underwood AJ (1993) Geographic consistencies of effects of experimental physical disturbance on understorey species in sublittoral kelp forests in central New South Wales. Journal of Experimental Marine Biology and Ecology 168: 35-58

Knott NA, Underwood AJ, Chapman MG, Glasby TM (2006) Growth of the encrusting sponge Tedania anhelans (Lieberkuhn) on vertical and on horizontal surfaces of temperate subtidal reefs. Marine and Freshwater Research 57: 95-104

Kohler KE, Gill SM (2006) Coral Point Count with Excel extensions (CPCe): A Visual Basic program for the determination of coral and substrate coverage using random point count methodology. Computers and Geosciences 32: 1259-1269

Leonard GH (1999) Positive and negative effects of intertidal algal canopies on recruitment and survival of barnacles. Marine Ecology Progress Series 178: 241-249

Lirman D (2001) Competition between macroalgae and corals: effects of herbivore exclusion and increased algal biomass on coral survivorship and growth. Coral Reefs 19: 392-399 
Chapter 4: Interactions between understory-algae and sponges

Maldonado M (2006) The ecology of the sponge larva. Canadian Journal of Zoology 84: $175-194$

McCook LJ, Jompa J, Diaz-Pulido G (2001) Competition between corals and algae on coral reefs: a review of evidence and mechanisms. Coral Reefs 19: 400-417

Morrow KM, Liles MR, Paul VJ, Moss AG, Chadwick NE (2013) Bacterial shifts associated with coralï macroalgal competition in the Caribbean Sea. Marine Ecology Progress Series 488: 103-117

Nelson W (2013) New Zealand seaweeds: an illustrated guide. Te Papa Press, Wellington

River GF, Edmunds PJ (2001) Mechanisms of interaction between macroalgae and scleractinians on a coral reef in Jamaica. Journal of Experimental Marine Biology and Ecology 261: 159-172

Sebens KP (1985) Community ecology of vertical rock walls in the Gulf of Maine, U.S.A.: Small-scale processes and alternative States. In: Moore PG, Seed R (eds) The ecology of rocky coasts. Columbia University Press, New York, pp 346-371

Sebens KP (1997) Adaptive responses to water flow: morphology, energetics and distribution of reef corals. Proceedings of the 8th International Coral Reef Symposium: 1053-1058

Sebens KP, Johnson AS (1991) The effect of water movement on prey capture and distribution of reef corals. Hydrobiologia 226: 91-101

Shears NT, Babcock RC (2007) Quantitative description of mainland New Zealand's shallow subtidal reef communities. Science for Conservation: 1-126

Titlyanov EA, Yakovleva IM, Titlyanova TV (2007) Interaction between benthic algae (Lyngbya boullonii, Dyctiota dichotoma) and scleratinian coral Porites lutea in direct contact. Journal of Experimental Marine Biology and Ecology 342: $282-291$

Turon X, Tarjuelo I, Uriz MJ (1998) Growth dynamics and mortality of the encrusting sponge Crambe crambe (Poecilosclerida) in contrasting habitats: correlation with population structure and investment in defence. Functional Ecology 12: 631-639

Wilkinson CR, Vacelet J (1979) Transplantation of marine sponges to different conditions of light and current. Journal of Experimental Marine Biology and Ecology 37: 91-104 
Chapter 4: Interactions between understory-algae and sponges

G̣uljeviĺ A, Thibaut T, Despalatoviĺ M, Cottalorda J-M, Nikoliĺ V, Cvitkovil I, Antolic B (2011) Invasive alga Caulerpa racemosa var. cylindracea makes a strong impact on the Mediterranean sponge Sarcotragus spinosulus. Biol. Invasions 13: 2303-2308 
Chapter 5. Influence of habitat variation on sponge-associated bacteria

\section{Chapter 5. Effect of environmental irradiance on sponges inhabiting shallow- water rocky reefs and its effect on microbial communities associated with sponges}

\subsection{Abstract}

Sponges are an important component of temperate subtidal marine ecosystems, with a range of important functional roles and extensive symbiotic relationships with microorganisms. However, much remains unknown about their relationships with these symbiotic microorganisms, and specifically the role these symbionts play in sponge physiology, feeding and adaptation to local environmental conditions. Changes in environmental factors may alter relationships between sponges and their symbionts, which could conceivably influence the abundance and distribution patterns of some temperate sponge species. Here I analysed the effect of transplantation of sponges between different habitats in order to test the effect of changes in environmental conditions on the stability of the bacterial communities in specimens of Tethya bergquistae and Ecionemia alata, based on pyrosequencing of amplified 16S rRNA genes. Bacterial communities differed markedly between the two host species. While some morphological changes were observed in transplanted sponges, transplantation had little overall effect on sponge-associated bacterial communities at either phylum or 97\%-OTU level. Our results show the importance of host species and also the stability of sponge-associated bacterial communities under environmental variation. 
Chapter 5. Influence of habitat variation on sponge-associated bacteria

\subsection{Introduction}

Sponges are an important component of temperate subtidal rocky ecosystems and fulfil a range of important functional roles (Bell 2008). At both tropical and temperate latitudes sponges have close associations with a wide variety of microorganisms, often harbouring abundant and diverse microbial communities (Taylor et al. 2007, Webster \& Blackall 2009, Schmitt et al. 2012, Webster \& Taylor 2012). Despite the importance of sponges, much remains unknown about their relationships with the symbiotic communities they harbour, and specifically the role that these symbionts play in sponge physiology, feeding and adaptation to local environmental conditions. Previous research has shown that microbial communities can be sensitive to environmental perturbation (e.g. Allison \& Martiny 2008, Nogales et al. 2011) and competition with other organisms (Morrow et al. 2013). Thus, it is important to consider the potential for sponge symbionts to enable sponges to adapt to changing environmental conditions, with recent studies suggesting that microbial symbionts may provide sponges with an adaptive advantage in the face of climate change (Hentschel et al. 2012). However, more research in this area is needed as existing studies have yielded contrasting results, perhaps because some sponges harbour more stable bacterial communities than others (Friedrich et al. 2001, Thoms et al. 2003, Lemoine et al. 2007, Webster et al. 2008, White et al. 2012, Simister et al. 2013).

A conceptual model proposed by Thacker and Freeman (2012) suggests that environmental factors can alter sponge-microbe symbioses by affecting the balance and interactions between symbionts; however, existing research is largely based on photosymbionts and the effect of variation in environmental factors on nonphotosynthetic microbes remains less certain. Several studies have tested the stability of microbial communities associated with sponges at different temporal and spatial scales (Webster et al. 2008, Anderson et al. 2010, White et al. 2012, Cleary et al. 2013, Pita et al. 2013, Simister et al. 2013). Although, in general, previous research has shown a high stability of bacterial communities associated with sponges, other studies have found that microbial communities associated with some sponge species appear to be more susceptible to changes in environmental factors (e.g. Wichels et al. 2006, Lemoine et al. 2007, Mohamed et al. 2008, Thoms et al. 2008, Anderson et al. 2010). 
Chapter 5. Influence of habitat variation on sponge-associated bacteria

Experimental research has led to different outcomes when testing how spongeassociated microbial communities respond to different factors such as nutrients, antibiotics, light and temperature (Friedrich et al. 2001, Lemoine et al. 2007, Webster et al. 2008, Gerçe et al. 2009, Gochfeld et al. 2012, Simister et al. 2012a). For example, Webster et al. (2008) found changes in the microbial community composition of Rhopaloeides odorabile due to a loss of symbionts when exposed to elevated temperatures $\left(2-3^{\circ} \mathrm{C}\right.$ above mean temperature). Lemoine et al. (2007) also found a strong effect of temperature on the symbiotic community harbored by the temperate sponge Halichondria bowerbanki, suggesting a loss or significant reduction in population size of some microbes in response to stress. In contrast, Friedrich et al. (2001) reported relatively stable bacterial communities in space and time in sponges exposed to starvation in laboratory conditions. Furthermore, Simister et al. (2012a) recently reported highly stable microbial communities in $R$. odorabile, with the bacterial community shifting only in necrotic sponges, suggesting that the host (sponge) rather than its symbionts is highly sensitive to increased temperature. Other recent research has addressed the seasonal variability of bacterial symbionts in two Caribbean sponges in Florida, U.S.A., finding slight seasonal shifts and relatively stable microbial communities across two sampling seasons (White et al. 2012). The shifts observed in bacterial communities, however, have often been restricted to rare or low abundance OTUs (Anderson et al. 2010, Erwin et al. 2012b, Simister et al. 2013). Simister et al. (2013) suggested that this variation in some OTUs might be due to changes in environmental factors such as water flow and temperature.

The importance of habitat in structuring bacterial composition was highlighted recently for some Caribbean and Indonesian sponges (Cleary et al. 2013, Olson \& Gao 2013). Small-scale variation in environmental factors can have dramatic effects on the abundance and distribution of sponges in shallow-water temperate rocky reefs (Preciado \& Maldonado 2005, Abdo et al. 2006, Miller \& Etter 2011). Furthermore, factors such as irradiance regime, water movement and sediment are also some of the most influential environmental factors in shaping sponge morphology (Kaandorp 1999, Bell \& Barnes 2000d, Bell 2004, Meroz-Fine et al. 2005), while other factors such as temperature influence reproductive traits (Sarà 1992). However, the effects of environmental variation on the microbial communities associated with temperate 
Chapter 5. Influence of habitat variation on sponge-associated bacteria

sponges remain poorly understood. Since sponge microbes also play several critical roles including waste elimination and digestion, chemical defense and nutrient cycling (reviewed by Taylor et al. 2007, Thacker \& Freeman 2012), it is important to understand the effects of environmental variation on sponge-associated microbial communities and how eventual shifts in bacterial abundance may alter the stability of the bacterial community. The varying results from earlier studies highlight the need for additional research in order to test how environmental factors occurring in different habitats influence microbial abundance and diversity in temperate regions, and therefore their potential role in determining the abundance and distribution patterns of sponges.

Here, I examine how the bacterial communities in the New Zealand sponges Ecionemia alata and Tethya bergquistae respond to changes in local environmental conditions. E. alata and T. bergquistae are two of the most common sponges inhabiting shallow-water rocky reefs in New Zealand (Berman \& Bell 2010, Berman 2012). T. bergquistae is abundant on rocky slopes and high-light environments with moderate water movement (Battershill et al. 2010). In contrast, E. alata is more abundant under overhangs or boulders, or in caves, which are areas characterised by low levels of light and sediment compared with high-light habitats (Abdo et al. 2006). A recent study described a diverse and abundant microbial community in E. alata (as Ancorina alata) collected from rocky reefs of the northern part of New Zealand (Simister et al. 2013). In contrast, microbes associated with T. bergquistae have not been previously described. Because of their abundance and ecological distribution, I considered these as suitable species for comparative studies to test the stability of sponge-associated microbial communities when transplanted to different habitats.

\subsection{Materials and Methods}

\subsubsection{Sampling and experimental design}

The study site was located at The Sirens Rocks ( $\left.41^{\circ} 21^{\prime} \mathrm{S}, 174^{\circ} 46^{\prime} \mathrm{E}\right)$, Taputeranga Marine Reserve, on the south coast of Wellington, New Zealand. In December 2012, four specimens each of E. alata and T. bergquistae were collected while SCUBA diving from high-light habitats and four specimens of each species were collected from cracks, caves or underneath boulders (low-light habitats) at approximately 6-9 $\mathrm{m}$ 
Chapter 5. Influence of habitat variation on sponge-associated bacteria

depth. Additionally, six specimens of each species were collected from high-light habitats and transplanted to walled channels (low-light habitats), and vice versa. Irradiance levels present in high-light habitats were $108.32 \varepsilon$ mol quanta $\mathrm{m}^{-2} \mathrm{~s}^{-1} \pm$ 7.03 S.E., and $7.21 \varepsilon \mathrm{mol}$ quanta $\mathrm{m}^{-2} \mathrm{~s}^{-1} \pm 0.63$ S.E. in low-light habitats. Irradiance levels were measured following the sampling procedure used by Morelissen et al. (2013). Sponges and a small piece of attached rock were collected using a hammer and chisel. Collected specimens were transported and maintained in the Victoria University Coastal and Ecology Laboratory (VUCEL) aquarium system for one week. Each specimen was glued onto a $15 \times 15 \mathrm{~cm}$ polyvinyl chloride (PVC) plate using underwater epoxy resin (Carboguard A-788 Splashzone). Each plate was labelled and transported to the field at The Sirens Rocks, where it was attached by cable ties to a piece of wood $\sim 1 \mathrm{~m}$ long (hereafter referred to as a óponge arrayô) (Appendix 5). Each sponge array was assigned to a treatment and deployed at 6-9 $\mathrm{m}$ depth in high$\left(98.66 \pm 5.92 \varepsilon \mathrm{\varepsilon mol}\right.$ quanta $\left.\mathrm{m}^{-2} \mathrm{~s}^{-1}\right)$ or low-light habitats $\left(8.66 \pm 0.97 \varepsilon \mathrm{mol}\right.$ quanta $\mathrm{m}^{-2}$ $\mathrm{s}^{-1}$ ), where it was re-attached to the substratum by stainless steel bolts. The health status and morphological changes of transplanted sponges were visually checked after 3 and 6 weeks. Transplanted sponge individuals were collected after 6 weeks. From each specimen, tissue samples were collected following the sampling procedure described by Taylor et al. (2004). Tissue samples (containing ectosome and choanosome layers) collected from experiments were immediately frozen for at least $24 \mathrm{~h}$ and subsequently lyophilized (by freeze-drying) and stored at $-80^{\circ} \mathrm{C}$ for subsequent DNA extraction. Prior to extraction, samples were homogenised by crushing. In the case of $T$. bergquistae it was necessary to crush samples using a sterile mortar and pestle with liquid nitrogen.

\subsubsection{DNA extraction}

DNA was extracted from $5 \mathrm{mg}$ of freeze-dried sponge tissue by bead-beating (Taylor et al. 2004). Briefly, $1 \mathrm{~mL}$ of extraction buffer $(400 \mu \mathrm{L} 6.25 \mathrm{M}$ ammonium acetate; $100 \mu \mathrm{L} 1 \mathrm{M}$ Tris (pH 8.0); $40 \mu \mathrm{L} 0.5$ M EDTA; $460 \mu \mathrm{L}$ molecular grade water) was added to a polypropylene tube containing $200 \mu \mathrm{L}$ of $0.1 \mathrm{~mm}$ silica beads (Biospec Products), 0.015 g polyvinylpolypyrrolidone (PVPP), $300 \mu \mathrm{L}$ of chloroform:isoamyl alcohol (24:1), and the sample. Bead-beating was performed in a FastPrep FP120 BIO-101 bead beater, followed by centrifugation $\left(30 \mathrm{~min}, 15000 \times \mathrm{g}, 15{ }^{\circ} \mathrm{C}\right)$ and 
Chapter 5. Influence of habitat variation on sponge-associated bacteria

collection of the supernatant. This was then precipitated for $1 \mathrm{~h}$ at room temperature with $3 \mathrm{M}$ sodium acetate and isopropanol, followed by centrifugation for $30 \mathrm{~min}$ (15 $000 \times \mathrm{g}, 4^{\circ} \mathrm{C}$ ). Pellets were washed twice with $70 \%$ ethanol, dried, and re-suspended in $50 \mu \mathrm{L}$ molecular grade water.

\subsubsection{PCR and pyrosequencing of $16 \mathrm{~S}$ rRNA genes}

Pyrosequencing of amplified bacterial 16S rRNA genes was carried out essentially as described by Simister et al. (2012a). The 16S rRNA-specific primers (targeting the V4-V5 region) were 454MID_533F (GTGCCAGCAGCYGCGGTMA) and 454_907RC (CCGTCAATTMMYTTGAGTTT), with FLX Titanium adaptors (A adaptor on forward, B adaptor on reverse primer) and a multiplex identifier (MID) sequence on the forward primer. Each $50 \mu \mathrm{L}$ PCR reaction mixture contained $25 \mu \mathrm{L}$ GoTaq (Promega), $1.25 \mu \mathrm{L}$ of each primer (10 $\mu \mathrm{M}$ stock), $0.5 \mu \mathrm{L} 1 \%$ BSA, $19.5 \mu \mathrm{L}$ sterile water and approx. 250 ng DNA template. Touchdown PCR conditions were as follows: 3 min at $94{ }^{\circ} \mathrm{C}$ followed by 20 cycles of $30 \mathrm{~s}$ at $94{ }^{\circ} \mathrm{C}, 30 \mathrm{~s}$ at $60{ }^{\circ} \mathrm{C}\left(-0.5{ }^{\circ} \mathrm{C}\right.$ per cycle), and $45 \mathrm{~s}$ at $72{ }^{\circ} \mathrm{C}$. This was followed by a further 12 cycles of $30 \mathrm{~s}$ at 94 ${ }^{\circ} \mathrm{C}, 30 \mathrm{~s}$ at $50{ }^{\circ} \mathrm{C}$, and $45 \mathrm{~s}$ at $72{ }^{\circ} \mathrm{C}$, with a final extension of $10 \mathrm{~min}$ at $70{ }^{\circ} \mathrm{C}$ (Simister et al. 2012a). PCR products were electrophoresed on 1\% agarose gels containing $0.5 \mu \mathrm{g} \mathrm{ml}^{-1}$ ethidium bromide, and those products of correct size were purified with AMPure XP magnetic beads (Agencourt, Beckman Coulter). Amplicon quality was checked on a Bioanalyzer 2100 DNA 1000 chip (Agilent Technologies) and quantified using PicoGreen (Quant-iT dsDNA kit, Invitrogen). Pyrosequencing was performed by Macrogen Inc. (Seoul, South Korea) using the Roche GS FLX Titanium system. Sequences obtained in this study are deposited in the Sequence Read Archive at GenBank under accession numbers SAMN2584737-2584769

\subsubsection{Processing of raw sequence data}

Sequences were filtered and denoised using the Mothur (Schloss et al. 2009) implementation of AmpliconNoise (Quince et al. 2011). Sequences were removed from the analysis if they were $<200 \mathrm{bp}$, contained ambiguous characters, or had homopolymers longer than $8 \mathrm{bp}$, more than one MID mismatch, or more than two 
Chapter 5. Influence of habitat variation on sponge-associated bacteria

mismatches to the reverse primer sequence. Unique sequences were identified with Mothur, aligned against a SILVA alignment (available at http://www.mothur.org/wiki/Silva_reference_alignment), and chimeric sequences were identified using UCHIME (Edgar et al. 2011). Remaining sequences were grouped into $97 \%$ operational taxonomic units (OTUs) based on uncorrected pairwise distance matrices. A representative sequence of each OTU was used for the taxonomic assignment using custom PERL scripts, similar to a previously used approach (Webster et al. 2010, Schmitt et al. 2012, Simister et al. 2012a). Each pyrotag sequence was subjected to a BLAST search (Altschul et al. 1990) against a manually modified SILVA database (Simister et al. 2012b). A Smithï Waterman algorithm was used to create pairwise global alignments between the 10 best hits against a tag sequence. For assignment, the most similar sequence to the pyrotag sequence (or multiple sequences if within a range of $0.1 \%$ sequence divergence) was used. In cases where the taxonomy of the most similar sequences was inconsistent, a majority rule was applied, and the tag was only assigned if Ó60\% of all reference sequences shared the same taxonomic annotation.

\subsubsection{Analysis of high quality sequence data}

Mothur was used to calculate Chao1 richness estimates and rarefaction curves based on $97 \%$ OTUs. The magnitude of change in bacterial abundance on each treatment was calculated for each phylum/OTU by normalizing the number of reads per phylum/OTU, per sample. Furthermore, the 25 OTUs with the highest number of sequences were selected for more detailed analysis and results were visualized as heat maps generated by using JColorGrid (Joachimiak et al. 2006). I conducted analysis of variance (ANOVA) to test for differences in the number of OTUs between treatments.

Non-metric multidimensional scaling (nMDS) plots were performed to visualize multivariate patterns in microbial community structure. An ordination plot based on the Yue and Clayton-based distance matrix (Yue \& Clayton 2005) was used to represent the variation in the relative abundance of OTUs in each sample, whereas a Jaccard-based distance matrix was used to visualize the ordination plot of presenceabsence data using the Mothur software package. 
Chapter 5. Influence of habitat variation on sponge-associated bacteria

Differences between treatments in genetic differentiation (analysis of molecular variance-AMOVA) and phylogenetic structure (weighted UniFrac) were determined using the Mothur software package v.1.30.1 (Schloss et al. 2009). A SIMPER analysis was then performed to identify the most discriminatory OTUs responsible for differences between treatments. SIMPER analyses were conducted within PRIMER v6 (Clarke \& Gorley 2006, Anderson et al. 2008).

\subsubsection{Sponge growth}

To calculate the area of each sponge, I used the software CPCe v3.5 (Coral Point Count with Excel extensions) (Kohler \& Gill 2006), where each photograph was first scaled using the calibration tool to the length of the plate $(15 \mathrm{~cm})$. The surface of each sponge was then traced as closely as possible to give the calculated projected area in $\mathrm{cm}^{2}$ (Appendix 6).

The two-dimensional growth of each sponge was calculated following the procedure described by Knott et al. (2006), where growth equals the area covered by the sponge at the end of the experiment (T1) minus the area it covered at the beginning of the experiment (T0), divided by its area at the beginning of the experiment and multiplied by 100 to get a percentage ((Area T1-Area T0/Area T0) $\mathrm{x}$ 100). Differences in the two-dimensional growth of explants were tested by using one-way ANOVA.

\subsection{Results}

\subsubsection{Sponge growth}

All sponges survived transplanting and remained healthy for the duration of the experiment. No signs of necrosis were recorded at the end of the experiment. Some morphological changes were observed in E. alata individuals transplanted from low to high-light habitats: some specimens ( $\sim 50 \%$ of explants) exhibited discoloration in certain areas of the body, while all transplanted specimens presented a smoother surface than observed at the start of the experiment (Fig. 5.1). No discoloration was observed in specimens transplanted from high- to low-light habitats. No external visible changes were recorded in T. bergquistae during the experiment. 

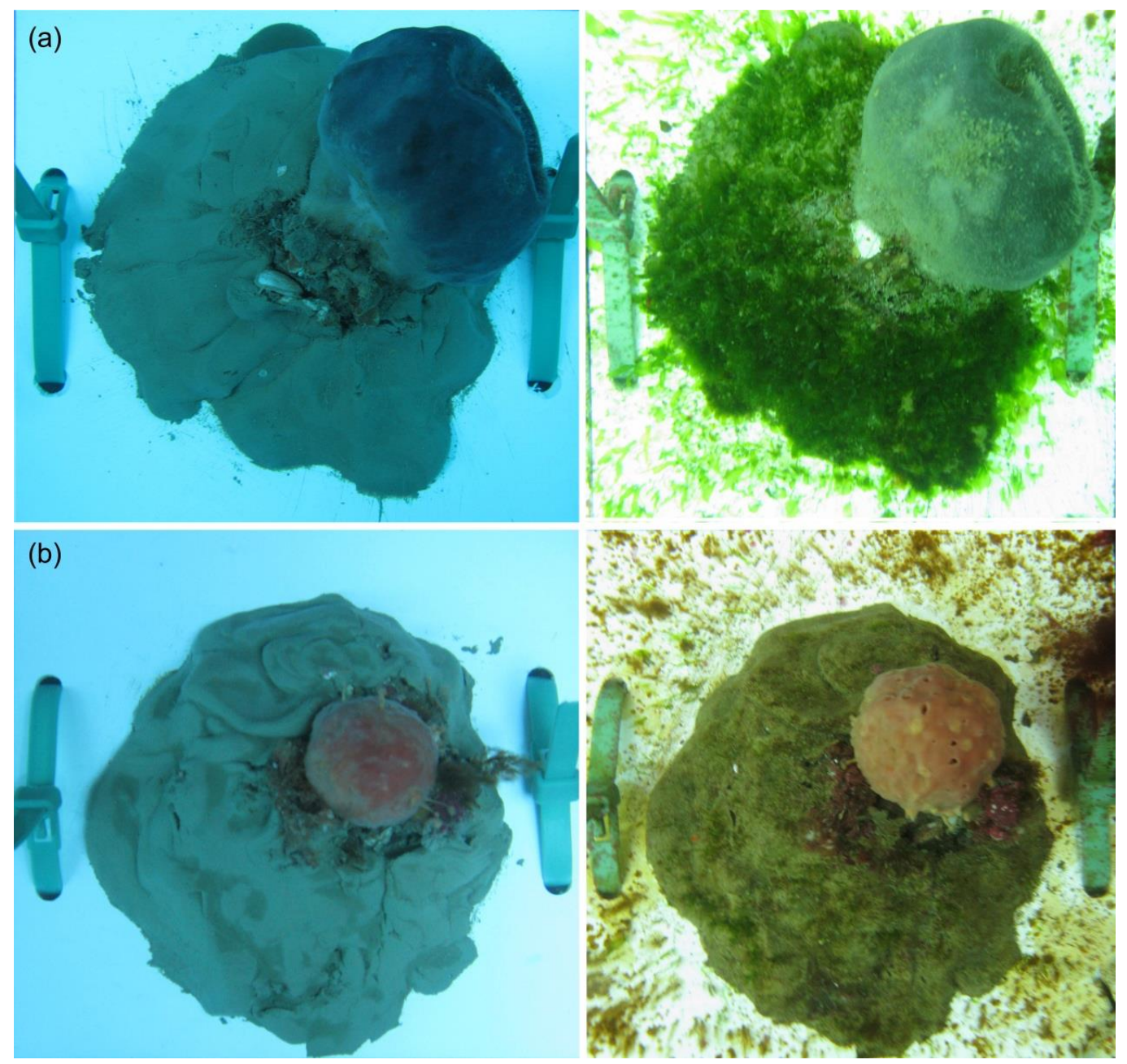

Figure 5.1. a) Ecionemia alata and b) Tethya bergquistae explants at the beginning (left) and end (right) of the experiment after 6 weeks. In both cases photos correspond to explants transplanted from low- to high-light habitats.

An increase in size was recorded for most individuals of E. alata. Individuals transplanted from low-light to high-light habitats increased by $8.48 \pm 2.66 \%$, whereas only a small increase of $0.23 \pm 5.17 \%$ was observed in individuals transplanted from high-light to low-light habitats. However, this difference in growth was not statistically significant $\left(F_{1,8}=1.808, P=0.344\right)$. Individuals of $T$. bergquistae responded positively to transplantation in both treatments, increasing their size by approximately one-third $(33.3 \pm 11.1$ and $37.1 \pm 9.2$ for sponges transplanted from high to low, and from low to high-light habitats, respectively) with no differences between treatments $\left(F_{1,7}=2.104, P=0.206\right)($ Fig. 5.1). 
Chapter 5. Influence of habitat variation on sponge-associated bacteria

\subsubsection{Effect of experimental treatment on bacterial community structure}

A total of 133,121 sequences was recovered after noise reduction and quality filtering, with a mean of $4034( \pm 1013,1 \mathrm{SD})$ sequences per sample. The mean number of 97\%-OTUs per sample ranged from 141 to 169 (mean $157.35 \pm 8.05$ ) in E. alata (Table 5.1), with no obvious relationship between OTU richness and treatment $\left(F_{3,16}\right.$ $=1.039, P=0.428$ ). The number of OTUs recovered from $T$. bergquistae samples varied between treatments $\left(F_{3,15}=4.106, P=0.032\right)$, being slightly higher in transplanted individuals (Table 5.1). The number of OTUs was considerably lower than for E. alata, ranging from 17 to 55 (mean $31.63 \pm 11.71$ ) (Table 5.1). Rarefaction curves based on these 97\%-OTU data indicated that coverage of OTU richness was high for all sampled sponges, with most curves starting to approach asymptotes (Fig. 5.2). Richness estimates based on the Chao1 statistic are reported in Table 5.1 and Appendix 7.
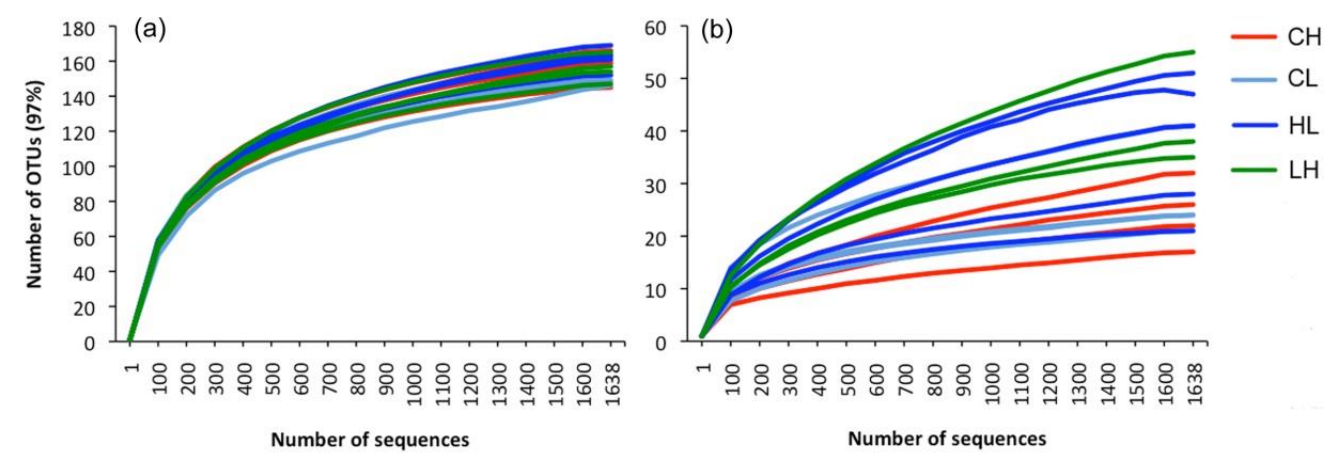

Figure 5.2. Bacterial diversity observed in (a) Ecionemia alata and (b) Tethya bergquistae samples, when transplanted between different habitats. $\mathrm{CH}=$ control high-light, $\mathrm{CL}=$ control low-light, $\mathrm{HL}=$ high- to low-light transplantation, $\mathrm{LH}=$ lowto highï light transplantation. Note: scale for Y-axis differs between panels. 
Chapter 5. Influence of habitat variation on sponge-associated bacteria

Table 5.1. Bacterial diversity (Sobs) and Chao1 estimates based on 16S rRNA gene pyrosequencing derived from Ecionemia alata and Tethya bergquistae samples. ECH $=E$. alata control high-light, $\mathrm{ECL}=E$. alata control low-light, $\mathrm{ETHL}=E$. alata samples transplanted from high- to low-light, ETLH $=E$. alata samples transplanted from low- to high-light, $\mathrm{TCH}=T$. bergquistae control high-light, $\mathrm{TCL}=T$. bergquistae control low-light, TTHL $=T$. bergquistae samples transplanted from high- to low-light, TTLH $=T$. bergquistae samples transplanted from low- to highlight.

\begin{tabular}{|c|c|c|c|c|c|c|c|}
\hline E. alata & $\begin{array}{l}\text { Number of } \\
\text { samples }\end{array}$ & $\begin{array}{l}\text { Mean } \\
\text { number of } \\
\text { sequences }\end{array}$ & SD & Sobs & SD & Chao1 & SD \\
\hline $\mathrm{ECH}$ & 4 & 4550.25 & 900.40 & 158.50 & 9.47 & 190.18 & 17.71 \\
\hline ECL & 4 & 3147.75 & 783.66 & 151.75 & 8.77 & 182.80 & 15.42 \\
\hline ETHL & 4 & 3085.25 & 721.77 & 161.25 & 8.43 & 190.23 & 15.41 \\
\hline ETLH & 5 & 3558.20 & 765.77 & 157.80 & 9.33 & 187.51 & 6.31 \\
\hline \multicolumn{8}{|c|}{ T. bergquistae } \\
\hline $\mathrm{TCH}$ & 4 & 2671.75 & 1347.24 & 24.25 & 6.34 & 39.88 & 13.54 \\
\hline TCL & 4 & 2530.50 & 529.89 & 23.25 & 2.22 & 44.06 & 23.83 \\
\hline TTHL & 5 & 3204.80 & 481.24 & 37.60 & 12.72 & 59.98 & 33.10 \\
\hline TTLH & 3 & 2586.00 & 606.97 & 42.67 & 10.79 & 62.76 & 22.53 \\
\hline
\end{tabular}




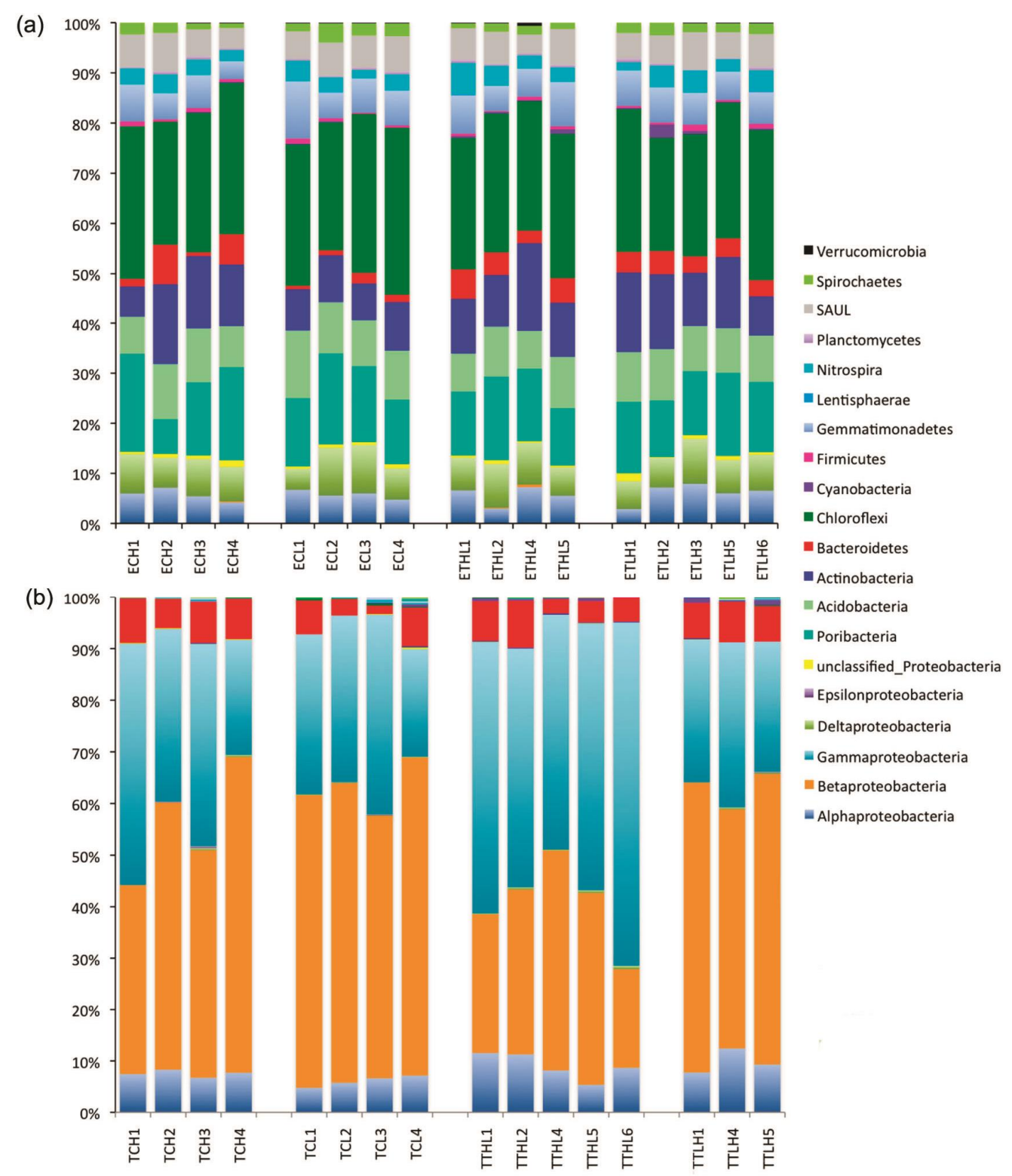

Figure 5.3. Relative abundance of bacterial phyla in (a) Ecionemia alata and (b) Tethya bergquistae samples, when transplanted between different habitats. $\mathrm{ECH}=E$. alata control high-light, $\mathrm{ECL}=E$. alata control low-light, $\mathrm{ETHL}=$ E. alata samples transplanted from high- to low-light, ETLH $=E$. alata samples transplanted from lowto high-light, $\mathrm{TCH}=T$. bergquistae control high-light, $\mathrm{CL}=T$. bergquistae control low-light, TTHL $=T$. bergquistae samples transplanted from high- to low-light, TTLH $=T$. bergquistae samples transplanted from low- to high-light. Number (1-6) in sample code refers to replicate number of samples recovered at the end of the experiment. SAUL $=$ sponge-associated unidentified lineage. 
Chapter 5. Influence of habitat variation on sponge-associated bacteria

In total, 738 unique OTUs (based on 97\% sequence identity) were identified across the 33 sponge samples analyzed in this study. These OTUs could be taxonomically assigned to 17 bacterial phyla in E. alata and 18 in T. bergquistae. The number of sequence reads per phylum was normalized and expressed as a percentage of the total for each sample (Fig. 5.3). At phylum level, bacterial community structure varied relatively little, either within (3-5 individuals sampled) or between experimental treatments. The two sponge species exhibited markedly different bacterial communities (Fig. 5.3). The community of T. bergquistae was dominated by members of the Proteobacteria (especially Alpha, Beta and Gamma classes), with this phylum comprising $90-97 \%$ of sequences in a given sample. Transplantation of $T$. bergquistae individuals from a high- to low-light habitat was accompanied by a shift in the relative abundances of Beta- and Gammaproteobacteria, but no other changes were particularly evident at phylum level. The only notably abundant phylum outside of the Proteobacteria was Bacteroidetes, which represented 2-9\% of sequences. In contrast, the bacterial community of $E$. alata was much more evenly spread, with Chloroflexi (19-28\%), Actinobacteria (5-15\%), Acidobacteria (6-11\%), ñPoribacteriaò (6-17\%), Gemmatimonadetes (3-9\%), sponge-associated unidentified lineage (SAUL) (3-6\%), Deltaproteobacteria (3-8\%) and Alphaproteobacteria (3$7 \%$ ) all contributing substantial numbers of sequences. Transplantation appeared to have negligible effects on phylum-level community composition (Fig. 5.3). 
Chapter 5. Influence of habitat variation on sponge-associated bacteria

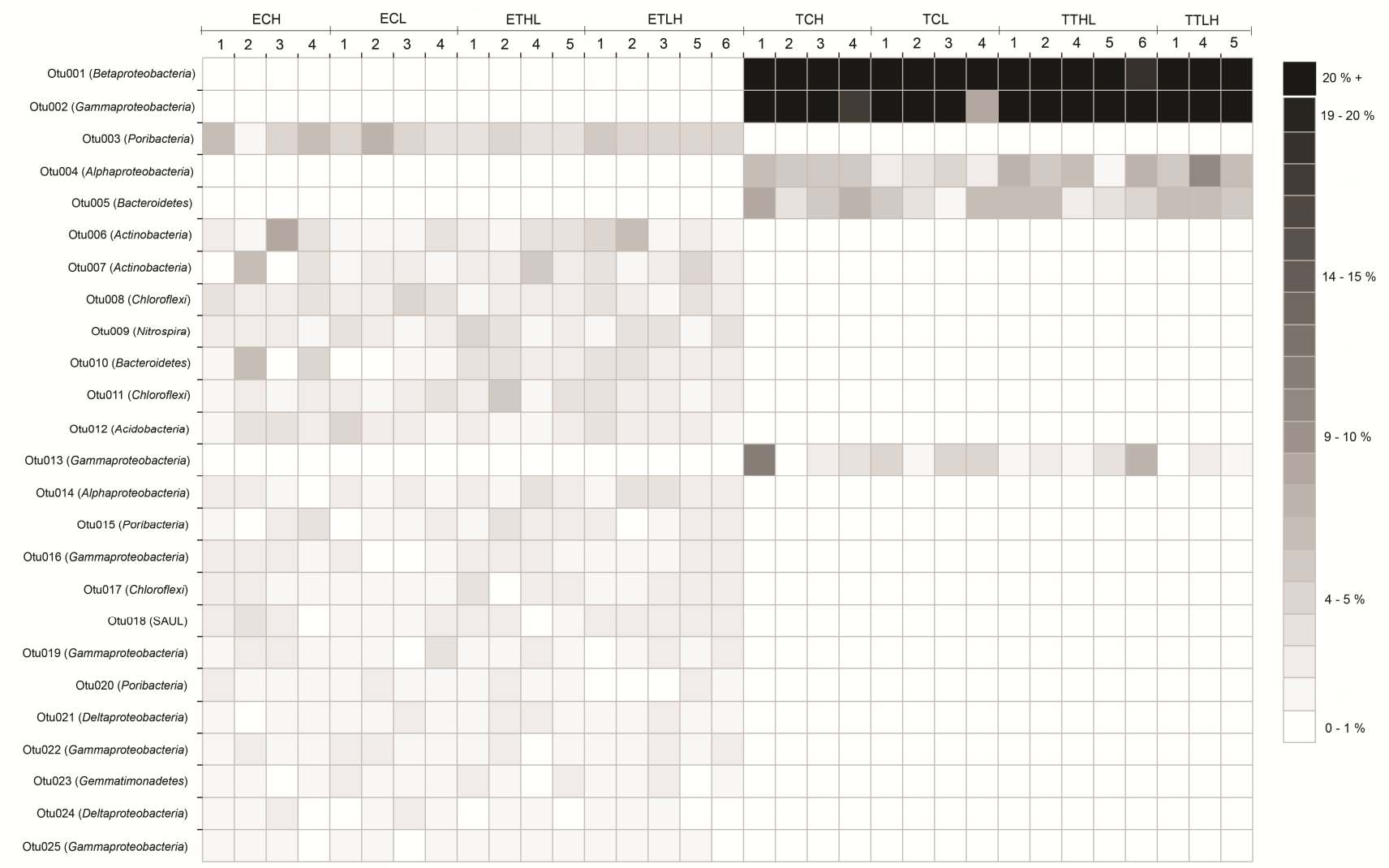

Figure 5.4. Heat map representing the abundance of the 25 most abundant OTUs in Ecionemia alata and Tethya bergquistae, when transplanted between different habitats. Values represent the percentage of all sequence reads for a given sample. See Figure 5.3 for abbreviations. 
Chapter 5. Influence of habitat variation on sponge-associated bacteria

Examination of the sequence data at a finer (97\%-OTU) taxonomic level revealed similar trends. As expected based on the phylum data above, sequences recovered from E. alata were spread across a larger number of abundant OTUs (Fig. 5.4). The most abundant in E. alata was a ñPoribacteriaò OTU (OTU003) which represented $2-7 \%$ of sequence reads per sample, while abundant OTUs from the Actinobacteria, Chloroflexi, Nitrospira, Acidobacteria, Alpha- and Deltaproteobacteria, SAUL and Gemmatimonadetes were also present. Similar to the phylum-level data, OTU abundance could not be closely linked to experimental treatment for either sponge species, as also seen on non-metric multi-dimensional scaling plots (Fig. 5.5). One Betaproteobacteria OTU (OTU001) and one Gammaproteobacteria OTU (OTU002) dominated the bacterial community in $T$. bergquistae, comprising 19-62\% and 18-56\%, respectively, of total bacterial sequence reads within a given sample (Fig. 5.4). One further Gammaproteobacteria OTU, along with a single Alphaproteobacteria OTU and a Bacteroidetes-affiliated OTU, together comprised the vast majority of remaining sequences. UniFrac values ranged from 0.01 to 0.53 in $T$. bergquistae. Unifrac values in E. alata were lower than $T$. bergquistae, ranging from 0.14 to 0.23 . Furthermore, in most cases, AMOVA results revealed no significant differences among treatments in E. alata (Appendices 8 and 9). In contrast, bacterial communities in T. bergquistae showed significant differences between treatments (AMOVA $\mathrm{P}<0.05$ ). Pairwise comparisons showed that the TTHL treatment (sponges shifted from high- to low-light habitat) differed significantly from other treatments (Appendix 8). This significant difference was driven by a switch in relative abundance from the betaproteobacterial OTU001 to the gammaproteobacterial OTU002 (Appendices 9-12). According to SIMPER, these two OTUs accounted for more than $70 \%$ of the cumulative difference between treatments, although the proportional abundance of OTU002 never dropped below 19\% in any of the TTHL samples. 
Chapter 5. Influence of habitat variation on sponge-associated bacteria

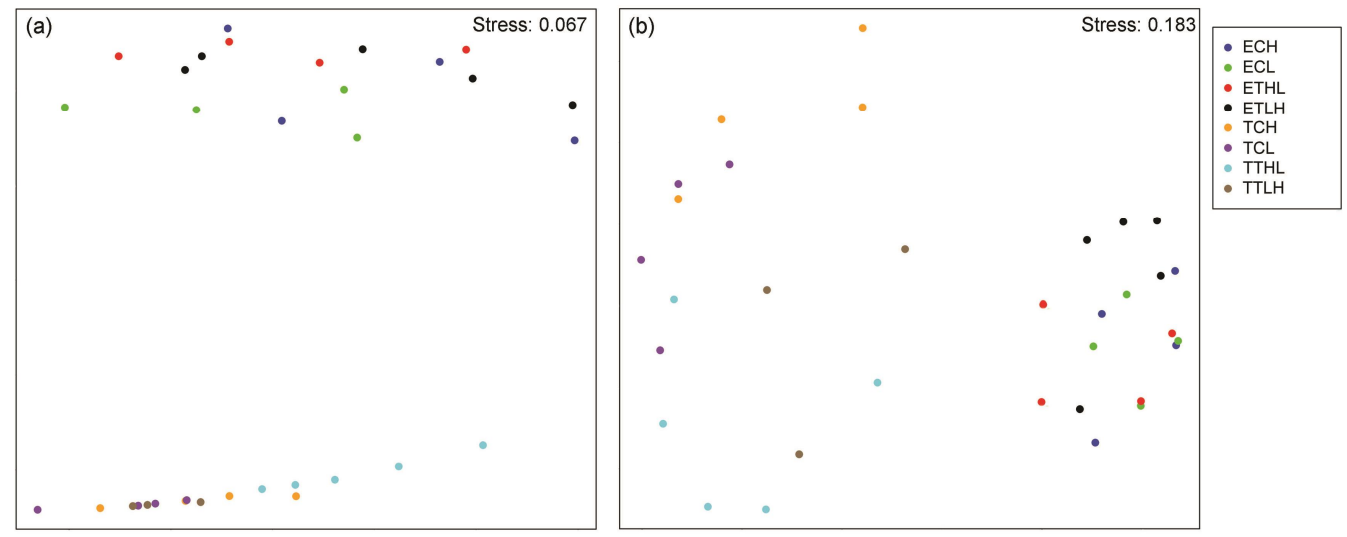

Figure 5.5. Non-metric multidimensional scaling (nMDS) to examine differences in bacterial community structure between species and experimental treatments. (a) Relative abundance of OTUs based on Yue and Clayton distance matrix and (b) presence-absence data based on a Jaccard-based distance matrix. $\mathrm{R} \mathrm{sq}_{(\mathrm{a})}=0.985, \mathrm{R}$ $\mathrm{sq}_{(\mathrm{b})}=0.829$. See Figure 5.3 for abbreviations.

\subsection{Discussion}

The potential for sponge-associated symbionts to enable their host to adapt to changes in environmental conditions has become an important topic of research (Hentschel et al. 2012). Given the well-documented associations of marine sponges with a variety of microbial symbionts, I set out to test the stability of microbial communities when exposed to different environmental conditions occurring on different habitats. Any resulting impact on the sponge microbiome could conceivably influence the distribution and abundance of sponges. Here, I combined experimental marine ecology approaches with next-generation sequencing of sponge-associated bacteria to investigate the effect of environmental variation on the microbiota of two New Zealand sponges, Ecionemia alata and Tethya bergquistae.

Variation in environmental factors can have critical effects at the population level by affecting sponge abundance and distribution, and also at the individual level by affecting growth, morphology and reproductive traits of sponges (Sarà 1992, Kaandorp 1999, Bell \& Barnes 2000d, Bell 2004). Sponges occurring in low-light habitats such as on vertical walls, and under overhangs or boulders, are exposed to 
Chapter 5. Influence of habitat variation on sponge-associated bacteria

different conditions than those in high-light habitats (e.g. flat reefs with an abundance of fast-growing algae). Both habitat types exhibit strong differences in physical factors, especially light, as well as in sediment regimes (Abdo et al. 2006), nutrient levels, and competitive pressures (Uriz et al. 1995). It has been proposed that local environmental conditions, along with other factors, can alter the interactions and balance between symbionts (Thacker \& Freeman 2012); however the impact of changes in environmental conditions on sponge-associated microbes in temperate latitudes remains poorly understood.

Individuals of both species responded well to manipulation, with no signs of necrosis or reduced growth. The morphological changes observed in some individuals of E. alata confirm the capacity of some sponges to acclimate morphologically when exposed to different habitats (e.g. Meroz-Fine et al. 2005). However, in spite of the increased growth and morphological changes observed in transplanted sponges, overall, transplantation to different habitats had little effect on sponge-associated bacterial communities. This was evident at both broad (phylum) and fine-scale (97\%OTU) taxonomic levels. This situation is in accordance with previous studies in other sponges that have reported the absence of changes in microbial communities despite the occurrence of morphological changes (e.g. biomass loss, discoloration, tissue degradation) (Thoms et al. 2003, Klöppel et al. 2008, but see Thoms et al. 2008, Gerçe et al. 2009).

The existence of highly stable microbial communities associated with sponges has been reported in several studies (Friedrich et al. 2001, Luter et al. 2010, Luter et al. 2012, Simister et al. 2012a, Simister et al. 2013). However, the presence of less stable microbial communities has also been reported for some sponge species (e.g. Lemoine et al. 2007, Mohamed et al. 2008, Thoms et al. 2008, Anderson et al. 2010). This situation has led some authors to suggest that different sponge species exhibit different degrees of stability in their microbiome depending on environmental factors (Olson \& Gao 2013). For example, Thoms et al. (2008) found that individuals of Aplysinella sp. exhibited significant variation in the composition and diversity of microbes in sponges exposed to stressful conditions in the laboratory and in the field. Temporal variations were also seen in the bacterial community of the New Zealand sponge Mycale hentscheli (Anderson et al. 2010), while recent pyrosequencing 
Chapter 5. Influence of habitat variation on sponge-associated bacteria

studies found shifts in the composition of bacterial communities (Erwin et al. 2012b, White et al. 2012). However, these studies also revealed the presence of relatively stable ñcoreò bacterial communities, with changes only occurring in rare taxa. My results support the notion of highly stable sponge-associated bacterial communities, as no major shifts were found in the microbial communities associated with either species. Although a statistically significant change in the bacterial community was found in individuals of $T$. bergquistae transplanted from high- to low-light habitats, the observed differences were mainly driven by changes in the relative abundance of the two most dominant OTUs, with no pronounced change in the abundance of other taxa. Of the two dominant OTUs, one (OTU001) belongs to a clade of Betaproteobacteria that is commonly found in sponges, but for which no phenotypic information is available due to a lack of cultivated representatives or metagenomic data. Therefore I can only speculate as to why this bacterium could be affected by changing light or other environmental conditions. The second OTU, OTU002, is a gammaproteobacterium that is loosely affiliated with the Chromatiales, members of which are photosynthetic. The short pyrosequencing reads (which preclude detailed phylogenetic analyses) and lack of available functional data mean that the precise affiliation of this organism is also unclear. Interestingly, a slight increase in bacterial diversity was observed in transplanted individuals of $T$. bergquistae. However, this increase had no major effect on the structure of the bacterial community since it was produced mostly by low-abundance OTUs ( $<2 \%$ of sequence reads) affiliated with Alpha- and Gammaproteobacteria, Cyanobacteria and Bacteroidetes).

Although some previous experimental work has suggested that environmental stress (e.g. temperature) may induce a change in sponge feeding behaviour to favour uptake of phototrophic bacteria (Massaro et al. 2012, Simister et al. 2012a), my experimental transplantation did not induce a similar response. Despite the appearance of ñnewò cyanobacterial OTUs in some of the transplanted individuals, there was no evidence of a significant increase, which is consistent with other studies involving in situ transplantation experiments to more light-exposed habitats (Vacelet 1959, Thoms et al. 2003). Thoms et al. (2003) explained the absence of an exchange of cyanobacteria in sponges transplanted to more light-exposed habitats as being due to the existence of physical barriers or chemical defenses. However, the mechanism(s) involved remain to be tested in future experiments. 
Chapter 5. Influence of habitat variation on sponge-associated bacteria

Despite a few contrasting results, generally sponge-associated bacterial communities appear to be highly stable compared with more sensitive bacterial communities occurring in other environments (e.g. soil, lakes), where changes in environmental conditions tend to produce shifts in community composition (Eiler et al. 2003, Beisner et al. 2006) and hence have the potential to affect ecosystem processes (Allison \& Martiny 2008). Changes in environmental conditions did not affect the stability of the highly stable ñcoreò bacterial communities existing in $E$. alata and T. bergquistae. This ñcoreò fraction of the community may be essential for maintaining the health of the sponge, playing important symbiotic roles that still remain little understood.

There were marked differences between the microbial communities of E. alata and $T$. bergquistae. This was expected based on a previous analysis of the active bacterial community (assessed by examining the ribosomal RNA itself) in E. alata (previously named Ancorina alata) and Tethya stolonifera, both collected from northeastern New Zealand, some $550 \mathrm{~km}$ away from the collection site in this study (Simister et al. 2013). In that earlier study, a single betaproteobacterium comprised $>50 \%$ of the $16 \mathrm{~S}$ rRNA sequence reads from $T$. stolonifera, while a related betaproteobacterial OTU constituted $19-62 \%$ of DNA-based T. bergquistae reads in the current study. Interestingly, a second proteobacterial OTU (OTU002, affiliated with Gammaproteobacteria) was also highly abundant according to my DNA sequencing data. The occurrence of one (or in this case two) dominant Proteobacteria phylotype has been widely reported for ñow-microbial-abundanceò (LMA) sponges (Sipkema et al. 2009, Kamke et al. 2010, Erwin et al. 2012a, Luter et al. 2012, Giles et al. 2013, Simister et al. 2013), and is in stark contrast to the much more even distribution of OTUs in ñhigh-microbial-abundanceò (HMA) sponges such as $E$. alata. Even the most abundant OTU recovered from E. alata (ñPoribacteriaò OTU003) only comprised $7 \%$ or less of sequence reads from a given sample. In the RNA-based paper by Simister et al. (2013), the 10 most abundant OTUs (including the ñPoribacteriaò OTU which dominated in the current study) represented on average only $35 \%$ of total sequences per sample. 
Chapter 5. Influence of habitat variation on sponge-associated bacteria

In conclusion, my results demonstrate the stability of bacterial communities in two temperate sponges exposed to environmental variation, which is consistent with previous research on other temperate sponges. The next-generation sequencing approach employed here shows how different components of bacterial communities associated with E. alata and T. bergquistae respond to environmental variation in situ. The similarity observed in bacterial communities among specimens occupying different habitats suggests that environmental variation occurring in those habitats does not affect the stability of the community, and hence most likely does not radically alter the metabolism of these sponges. Although environmental factors such as light and sediment may have an effect on early sponge stages (Maldonado 2006), other environmental (e.g. nutrients, temperature, wave action) and biotic factors, such as competition with macroalgae (Chapter 2), are more likely to influence the growth, survival and distribution of sponges on temperate rocky reefs. Further studies are necessary to improve our understanding of how microbial symbiont communities may affect the physiology and ecology of sponges on temperate rocky reefs. More data are needed to improve our knowledge about physiological traits and responses of bacterial communities, and also resilience in sponge-associated bacteria that seem to be more sensitive to environmental variation.

\subsection{References}

Abdo DA, Battershill CN, Harvey ES (2006) Manipulation of environmental variables and the effect on the growth of Haliclona sp.: Implications for openwater aquaculture. Marine Biology Research 2:326-332

Allison SD, Martiny JBH (2008) Resistance, resilience, and redundancy in microbial communities. Proceedings of the National Academy of Sciences of the United States of America 105:11512-11519

Altschul SF, Gish W, Miller W, Myers EW, Lipman, D.J. (1990) Basic local alignment search tool. Journal of Molecular Biology 215:403-410

Anderson MJ, Gorley RN, Clarke KR (2008) Permanova for Primer: Guide to Software and Statistical Methods, PRIMER-E, Plymouth

Anderson SA, Northcote PT, Page MJ (2010) Spatial and temporal variability of the bacterial community in different chemotypes of the New Zealand marine sponge Mycale hentscheli. FEMS Microbiology Ecology 72:328-342 
Chapter 5. Influence of habitat variation on sponge-associated bacteria

Battershill CN, Bergquist PR, Cook SdC (2010) Porifera. In: Cook SdC (ed) New Zealand Coastal Marine Invertebrates. Canterbury University Press, Christchurch, p 58-135

Beisner BE, Peres-Neto PR, Lindström ES, Longhi ML (2006) The role of environmental and spatial processes in structuring lake communities from bacteria to fish. Ecology 87:2985-2991

Bell JJ (2004) Evidence for morphology-induced sediment settlement prevention on the tubular sponge Haliclona urceolus. Marine Biology 146:29-38

Bell JJ (2008) The functional roles of marine sponges. Estuarine, Coastal and Shelf Science 79:341-353

Bell JJ, Barnes DKA (2000) The influences of bathymetry and flow regime upon the morphology of sublittoral sponge communities. Journal of the Marine Biological Association of the United Kingdom 80:707-718

Berman J (2012) Patterns of temporal and spatial variability of sponge assemblages. $\mathrm{PhD}$ thesis, Victoria University of Wellington

Berman J, Bell JJ (2010) Spatial variability of sponge assemblages on the Wellington South Coast, New Zealand. The Open Journal of Marine Biology 4:12-25

Clarke KR, Gorley RN (2006) Primer v6: user manual/tutorial, Vol 1

Cleary DFR, Becking LE, de Voogd NJ, Pires ACC, Polónia ARM, Egas C, Gomes NCM (2013) Habitat- and host-related variation in sponge bacterial symbiont communities in Indonesian waters. FEMS Microbiology Ecology 85:465-482

Edgar RC, Haas BJ, Clemente JC, Quince C, Knight R (2011) UCHIME improves sensitivity and speed of chimera detection. Bioinformatics 27:2194ï 2200

Eiler A, Langenheder S, Bertilsson S, Tranvik LJ (2003) Heterotrophic bacterial growth efficiency and community structure at different natural organic carbon concentrations. Applied and Environmental Microbiology 69:3701-3709

Erwin PM, Olson JB, Thacker RW (2012a) Phylogenetic diversity, host-specificity and community profiling of sponge-associated bacteria in the Northern Gulf of Mexico. PLoS ONE 6:e26806

Erwin PM, Pita L, López-Legentil S, Turon X (2012b) Stability of sponge-associated bacteria over large seasonal shifts in temperature and irradiance. Applied and Environmental Microbiology 78:7358-7368 
Chapter 5. Influence of habitat variation on sponge-associated bacteria

Friedrich AB, Fischer I, Proksch P, Hacker J, Hentschel U (2001) Temporal variation of the microbial community associated with the mediterranean sponge Aplysina aerophoba. FEMS Microbiology Ecology 38:105-113

Gerçe B, Schwartz T, Voigt M, Rühle S, Kirchen S, Putz A, Proksch P, Obst U, Syldatk C, Hausmann R (2009) Morphological, bacterial, and secondary metabolite changes of Aplysina aerophoba upon long-term maintenance under artificial conditions. Microbial Ecology 58:865-878

Giles EC, Kamke J, Moitinho-Silva L, Taylor MW, Hentschel U, Ravasi T, Schmitt S (2013) Bacterial community profiles in low microbial abundance sponges. FEMS Microbiology Ecology 83:232-241

Gochfeld DJ, Easson CG, Freeman CJ, Thacker RW, Olso JB (2012) Disease and nutrient enrichment as potential stressors on the Caribbean sponge Aplysina cauliformis and its bacterial symbionts. Marine Ecology Progress Series 456:101-111

Hentschel U, Piel J, Degnan SM, Taylor MW (2012) Genomic insights into the marine sponge microbiome. Nature Reviews Microbiology 10:641-654

Joachimiak MP, Weisman JL, May BCH (2006) ColorGrid: Software for the visualization of biological measurements. BMC Bioinformatics 7:225

Kaandorp JA (1999) Morphological analysis of growth forms of branching marine sessile organisms along environmental gradients. Marine Biology 134:295306

Kamke J, Taylor MW, Schmitt S (2010) Activity profiles for marine spongeassociated bacteria obtained by $16 \mathrm{~S}$ rRNA vs $16 \mathrm{~S}$ rRNA gene comparisons. The ISME Journal 4:498-508

Klöppel A, Pfannkuchen M, Putz A, Proksch P, Brümmer F (2008) Ex situ cultivation of Aplysina aerophoba close to in situ conditions: ecological, biochemical and histological aspects. Marine Ecology 2:259-272

Knott NA, Underwood AJ, Chapman MG, Glasby TM (2006) Growth of the encrusting sponge Tedania anhelans (Lieberkuhn) on vertical and on horizontal surfaces of temperate subtidal reefs. Marine and Freshwater Research 57:95-104

Kohler KE, Gill SM (2006) Coral Point Count with Excel extensions (CPCe): A Visual Basic program for the determination of coral and substrate coverage 
Chapter 5. Influence of habitat variation on sponge-associated bacteria

using random point count methodology. Computers and Geosciences 32:12591269

Lemoine N, Buell N, Hill A, Hill M (2007) Assessing the utility of sponge microbial symbiont communities as models to study global climate change: a case study with Halichondria bowerbanki. In: Custodio MR, Lobo-Hajdu G, Hajdu E, Muricy G (eds) Porifera research: biodiversity, innovation and sustainability. Museu Nacional, Rio de Janeiro, Brazil, p 419-425

Luter HM, Whalan S, Webster NS (2010) Exploring the role of microorganisms in the disease-like syndrome affecting the sponge Ianthella basta. Applied and Environmental Microbiology 76:5736-5744

Luter HM, Whalan S, Webster NS (2012) The marine sponge Ianthella basta can recover from stress-induced tissue regression. Hydrobiologia 687:227-235

Maldonado M (2006) The ecology of the sponge larva. Canadian Journal of Zoology 84:175-194

Massaro AJ, Weisz JB, Hill MS, Webster NS (2012) Behavioral and morphological changes caused by thermal stress in the Great Barrier Reef sponge Rhopaloeides odorabile. Journal of Experimental Marine Biology and Ecology 416-417:55-60

Meroz-Fine E, Shefer S, Ilan M (2005) Changes in morphology and physiology of an East Mediterranean sponge in different habitats. Marine Biology 147:243-250

Miller RJ, Etter RJ (2011) Rock walls: small-scale diversity hotspots in the subtidal Gulf of Maine. Marine Ecology Progress Series 425:153-165

Mohamed NM, Enticknap JJ, Lohr JE, McIntosh SM, Hill RT (2008) Changes in bacterial communities of the marine sponge Mycale laxissima on transfer into aquaculture. Applied and Environmental Microbiology 74:1209-1222

Morelissen B, Dudley BD, Geange SW, Phillips NE (2013) Gametophyte reproduction and development of Undaria pinnatifida under varied nutrient and irradiance conditions. Journal of Experimental Marine Biology and Ecology 448: 197-206

Morrow KM, Liles MR, Paul VJ, Moss AG, Chadwick NE (2013) Bacterial shifts associated with coralï macroalgal competition in the Caribbean Sea. Marine Ecology Progress Series 488:103-117 
Chapter 5. Influence of habitat variation on sponge-associated bacteria

Nogales B, Lanfranconi MP, Piña-Villalonga JM, Bosch R (2011) Anthropogenic perturbations inmarine microbial communities. FEMS Microbiology Ecology $35: 275-298$

Olson JB, Gao X (2013) Characterizing the bacterial associates of three Caribbean sponges along a gradient from shallow to mesophotic depths. FEMS Microbiology Ecology 85:74-84

Pita L, Turon X, Lopez-Legentil S, Erwin PM (2013) Host rules: spatial stability of bacterial communities associated with marine sponges (Ircinia spp.) in the Western Mediterranean Sea. FEMS Microbiology Ecology 86:268-276

Preciado I, Maldonado M (2005) Reassessing the spatial relationship between sponges and macroalgae in sublittoral rocky bottoms: a descriptive approach. Helgoland Marine Research 59:141-150

Quince C, Lanzen A, Davenport RJ, Turnbaugh PJ (2011) Removing noise from pyrosequenced amplicons. BMC Bioinformatics 12:38

Sarà M (1992) Porifera. In: Adiyodi KG, Adiyodi RG (eds) Reproductive Biology of Invertebrates, Vol V. Wiley-Interscience, Chichester, p 1-29

Schloss PD, Westcott SL, Ryabin T, Hall JR, Hartmann M, Hollister EB, Lesniewski RA, Oakley BB, Parks DH, Robinson CJ, Sahl JW, Stres B, Thallinger GG, Van Horn DJ, Weber CF (2009) Introducing mothur: Open-source, platformindependent, community-supported software for describing and comparing microbial communities. Applied and Environmental Microbiology 75:7537ї 7541

Schmitt S, Tsai P, Bell J, Fromont J, Ilan M, Lindquist N, Perez T, Rodrigo A, Schupp PJ, Vacelet J, Webster N, Hentschel U, Taylor MW (2012) Assessing the complex sponge microbiota: core, variable and species-specific bacterial communities in marine sponges. The ISME Journal 6:564-576

Simister R, Taylor MW, Rogers KM, Schupp PJ, Deines P (2013) Temporal molecular and isotopic analysis of active bacterial communities in two New Zealand sponges. FEMS Microbiology Ecology 85:195-205

Simister R, Taylor MW, Tsai P, Fan L, Bruxner TJ, Crowe ML, Webster N (2012a) Thermal stress responses in the bacterial biosphere of the Great Barrier Reef sponge, Rhopaloeides odorabile. Environmental Microbiology 14:3232-3246 
Chapter 5. Influence of habitat variation on sponge-associated bacteria

Simister RL, Deines P, Botté ES, Webster NS, Taylor MW (2012b) Sponge-specific clusters revisited: a comprehensive phylogeny of sponge-associated microorganisms. Environmental Microbiology 14:517-524

Sipkema D, Holmes B, Nichols SA, Blanch HW (2009) Biological characterisation of Haliclona (?gellius) sp.: sponge and associated microorganisms. Microbial Ecology 58:903-920

Taylor MW, Radax R, Steger D, Wagner M (2007) Sponge-associated microorganisms: evolution, ecology, and biotechnological potential. Microbiology and Molecular Biology Reviews 71:295-347

Taylor MW, Schupp PJ, Dahllöf I, Kjelleberg S, Steinberg PD (2004) Host speciýcity in marine sponge-associated bacteria, and potential implications for marine microbial diversity. Environmental Microbiology 6:21ï 130

Thacker RW, Freeman CJ (2012) Spongeï microbe symbioses: recent advances and new directions. Advances in Marine Biology 62:57-111

Thoms C, Hentschel U, Schmitt S, Schupp PJ (2008) Rapid tissue reduction and recovery in the sponge Aplysinella sp. Marine Biology 156:141-153

Thoms C, Horn M, Wagner M, Hentschel U, Proksch P (2003) Monitoring microbial diversity and natural product proýles of the sponge Aplysina cavernicola following transplantation. Marine Biology 142:685-692

Uriz MJ, Turon X, Becerro MA, Galera J, Lozano J (1995) Patterns of resource allocation to somatic, defensive, and reproductive functions in the Mediterranean encrusting sponge Crambe crambe (Demospongiae, Poecilosclerida). Marine Ecology Progress Series 124:159-170

Vacelet J (1959) Repartition generale des eponges et systematique des eponges cornees de la region de Marseille et de quelques stations Mediterraneenes. Recueil des Travaux de la Station Marine d' Endoume 16:39-109

Webster N, Taylor M (2012) Marine sponges and their microbial symbionts: love and other relationships. Environmental Microbiology 14:335-346

Webster NS, Blackall LL (2009) What do we really know about sponge-microbial symbioses? The ISME Journal 3:1-3

Webster NS, Cobb RE, Negri AP (2008) Temperature thresholds for bacterial symbiosis with a sponge. The ISME Journal 2:830-842

Webster NS, Taylor MW, Behnam F, Lücker S, Rattei T, Whalan S, Horn M, Wagner M (2010) Deep sequencing reveals exceptional diversity and modes of 
Chapter 5. Influence of habitat variation on sponge-associated bacteria

transmission for bacterial sponge symbionts. Environmental Microbiology $12: 2070-2082$

White JR, Patel J, Ottesen A, Arce G, Blackwelder P, Lopez JV (2012) Pyrosequencing of bacterial symbionts within Axinella corrugata sponges: diversity and seasonal variability. PloS ONE 7:e38204

Wichels A, Würtz S, Döpke H, Schütt C, Gerdts G (2006) Bacterial diversity in the breadcrumb sponge Halichondria panicea (Pallas). FEMS Microbiology Ecology 56:102-118

Yue JC, Clayton MK (2005) A similarity measure based on species proportions. Communications in Statistics-Theory and Methods 34:2123-2131 


\section{Chapter 6. General discussion}

Changes in the distribution of organisms not only alter community composition and food web structure, but also initiate important changes at the ecosystem level (Berg et al. 2010). Understanding the interactions between biotic and abiotic factors affecting speciesô distribution patterns in temperate habitats is important for predicting responses to future environmental change.

Sponge assemblages inhabiting rocky substrata are influenced by a number of abiotic factors including water movement, light regime, inclination and stability of the substratum, as well as complex ecological interactions (reviewed by Wulff 2012). Understanding how these factors interact is not an easy task, since abiotic factors can determine the outcomes of ecological interactions, and at the same time, biotic interactions can often moderate the influence of abiotic factors.

The aim of this thesis was to investigate the interactions between sponges and macroalgae in shallow-water rocky reefs of Wellington, New Zealand, assessing if the distribution patterns of sponges are independent of algal populations. I used a combination of observational studies, and manipulative field and laboratory experiments to explore the existence of interactions between sponges and macroalgae and also to explore the effect of environmental factors on the distribution and abundance of temperate sponges. In summary, my contributions to sponge ecology in temperate reefs were: (1) Chapter 2 highlights the importance of small-scale environmental variation in influencing the structure and diversity of sponge assemblages; it highlights that most sponge species occurring in shallow waters rocky reefs in Wellington, New Zealand, are strongly correlated with inclination and also

supports previous studies in the northern hemisphere suggesting that sponge abundance and algal abundance are negatively correlated; (2) Chapter 3 expands upon chapter 2 by exploring the less studied positive interactions existing between canopy forming species and sponges. This chapter provides evidence to support the importance of the laminarian Eckonia radiata in facilitating the existence of sponge species such as Crella incrustans on vertical rocky walls; (3) Chapter 4 investigates 
the effect of the brown alga Zonaria turneriana on Leucetta sp.; results from this chapter provide no evidence to support previous hypotheses that understory algae negatively affect sponges; (4) Chapter 5 contributes to research studying microorganisms associated with sponges combining experimental marine ecology approaches with next-generation sequencing; and (5) shows the stability in the bacterial communities of Ecionemia alata and Tethya bergquistae when exposed to environmental variation and also highlights the importance of host species; finally (6) these results suggest that environmental factors, such as light, do not affect the stability of the microbial community, and hence most likely do not radically alter the metabolism of these sponges. Thus, an effect in determining the abundance and distribution patterns of sponges its unlikely, contrary to what occurs in tropical environments (e.g. Thacker 2005, Erwin \& Thacker 2008).

In this chapter I will discuss how my results contribute to the existing knowledge of sponge ecology on temperate rocky reefs and also suggest areas of research that should be addressed in the future.

\subsection{Factors affecting diversity and abundance of sponge assemblages}

\subsubsection{Abiotic factors}

In recent years, a considerable amount of research has focused on the factors influencing the diversity and distribution of sponge assemblages in different habitats (Wilkinson \& Evans 1989, Bell \& Barnes 2000c, Preciado \& Maldonado 2005, de Voogd \& Cleary 2007, Carballo et al. 2008). Particular consideration has been given to the observed distribution patterns of sponges in relation to either abiotic factors, such as light or sediment, or due to competition with macroalgae. My research shows the importance on surface inclination in influencing the distribution patterns of sponges and macroalgae. Surface inclination has a strong effect on sponge assemblages by modifying different levels of disturbance, such as sedimentation and light regimes, which not only affect species but also competition between sponges and macroalgae (Bell \& Barnes 2000a,b). Light seems to play a critical role by indirectly influencing algal abundance, and hence competition for space between both groups. 
While previous studies have suggested a negative effect of light on sponges (e.g. Wilkinson \& Vacelet 1979, Jokiel 1980), my research suggests that a strong negative effect in adults seems less probable. My results on the effect of transplantation to different light regimes showed that light does not affect adult sponges harbouring abundant bacteria (Chapter 5), and hence most likely does not

radically alter the metabolism of these sponges. This is contrary to what has been suggested for other temperate sponges in Australia (Roberts et al. 1999), where it was suggested that reduction in light may alter the relationships between sponges and their symbionts. Wilkinson and Vacelet (1979) found a strong effect of light inhibiting the growth of sciaphilic sponges transplanted to low-light habitats in the Mediterranean. In addition, other studies on sponges containing abundant cyanobacteria in the Mediterranean (Arillo et al. 1993) and Micronesia (Thacker 2005), have shown that light can influence the metabolism of the host, affecting their growth, abundance and distribution. Although an effect of light on the early stages of development may be critical (Maldonado 2006), another likely important indirect role of light on temperate sponges seems to be overgrowth or inhibition of recruitment by algae (Miller \& Etter 2008). Determining the tolerance of sponge recruits to light and its indirect effect on algal recruitment on different species should help to understand its overall effect at assemblage level on temperate rocky reefs.

Sediment deposition plays a very important role in other habitats (Bell \& Barnes 2000b, Carballo 2006, Knapp et al. 2013, Powell et al. 2014), however, its role in rocky reefs of Wellington, seems to be less important due to the highly dynamic conditions produced by regular southerly swells (Carter \& Lewis 1995), which cause resuspension of sediment (but see Chapter 3).

\subsubsection{Biotic factors: interactions with macroalgae}

Traditionally, sponges are less abundant in high-light habitats, and are often restricted to low-light habitats, where macroalgae are abundant, which has been explained by sponges being outcompeted by algae (Witman \& Sebens 1990, Bell \& Barnes 2000c). To date, a considerable proportion of the research studying spatial relationships between sponges and algae has been conducted in the northern hemisphere (Bell \& Barnes 2000b, c, Bell 2002, Maldonado et al. 2008). One of the few exceptions is the 
work of Knott et al. (2004), who found no evidence of negative correlations between sponges and macroalgae on the south-east coast of Australia. Chapter 2 contradicts Knottôs findings and confirms the generalization described from previous studies in the northern hemisphere that both groups are negatively correlated (e.g. Preciado \& Maldonado 2005). However, it is important to mention that my results contrast with Preciado and Maldonadố results, as they found that a high proportion of sponge species were strongly correlated with algal abundance. In contrast, only a few species where correlated with understory algae and canopy abundance in my study sites. Moreover, results of experimental removals of canopy form vertical rocky walls suggests that decreases in sponge abundance where highly correlated with increased abundance of understory algae in some plots (Chapter 3). Unfortunately, my laboratory experiment (Chapter 4) did not provide strong evidence of the mechanisms involved in this interaction and further experiments are required to clarify the effect of direct contact between algae and sponge on different species, under natural conditions.

As previously mentioned, the interactions between sponges and macroalgae has been commonly reported as negative (see Wulff 2006, 2012). Although less common in literature, positive interactions between both groups have also been reported in a few cases. For example, Halichondria panicea can be positively influenced by red algae, as they provide substrate to cope with strong currents (Barthel 1986). The same species can benefit from coralline alga as the latter provides protection from desiccation in the intertidal (Palumbi 1985). In other cases, seaweeds can be important for some sponges by providing protection against grazers (Wright et al. 1997, Maldonado \& Uriz 1998). My results from Chapter 2 and 3 are in accordance with the previous research by supporting the existence of negative association, but it also shows the role of algal canopy in positively influencing some sponge species.

The positive interaction occurring between the Ecklonia canopy and some sponge species is a good example on the complexity of interactions between biotic and abiotic factors, showing how environmental factors can determine the outcomes of ecological interactions occurring in a specific habitat (Fig. 6.1). In this case, the canopy-forming species seems to facilitate the presence of $C$. incrustans and other 
sponge species, by altering immediate physical factors (e.g. light and sediment accumulation) that may be detrimental for some sponge species. At the same time, the canopy indirectly facilitates sponges by influencing the abundance of understory algae, and hence competition with sponges, through light reduction. Thus, interactions between sponges and understory algae remain in balance when the canopy is present and light levels are reduced (Fig. 6.1).

\subsection{The role of grazers}

Urchins are known to play a central role in determining the structure of communities in subtidal reefs flats in New Zealand and in many other places around the world (Ayling 1981, Choat \& Andrew 1986, Norderhaug \& Christie 2009). Urchins also can structure benthic assemblages in vertical walls in cases (Palacin et al. 1998, Davis et al. 2003, Newcombe et al. 2012). The effect of Evechinus chloroticus on sessile organisms fluctuates through time and depends on changes in several factors including density of conspecifics in the area, size of urchins, time of the year and food availability (Ayling 1981, Choat \& Schiel 1982). Even though, in general, stable urchin-laminarian borders are found at intermediate depths on rocky reefs flats throughout New Zealand (Choat \& Schiel 1982), in some cases, the balance between urchin grazing and algal colonization can be heavily altered. This was observed in one of my experiments (Chapter 3) as on two occasions (start of the experiment and 85 weeks after removal), groups of urchins migrated to the study area, removing important amounts of macrophytes and sessile organisms in some of the experimental

plots, creating newly available space. Unfortunately, the causes of this urchin ñnvasionò remain unknown. This contradicts previous studies from the Poor Knights Islands, where urchins were only reported to have a minor role on vertical walls (Battershill 1987). This contradiction may be explained by differences in the density of urchins, which can be heavily influenced by topography (height of walls), depth and water movement (Davis et al. 2003). In contrast, my observations from low-light habitats (walled channels or caves) are in accordance with Battershillôs results from similar habitats, which suggests that assemblages occurring on these habitats are undisturbed by E. chloroticus. 


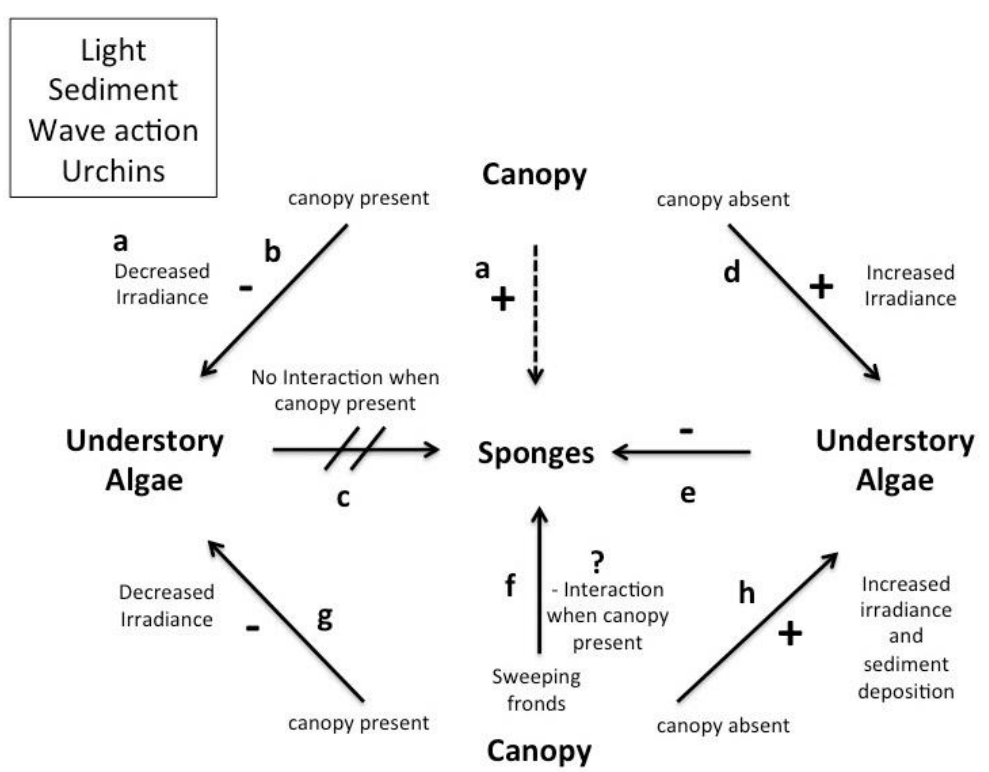

Figure 6.1. Schematic of the effects of Ecklonia canopy on sponge assemblages on open reefs habitats (vertical walls). Solid lines are direct interactions and dashed lines are indirect interactions. (+) Indicates positive effect; (ï) indicates a negative effect; $(?)=$ effect unknown or unstudied. Canopy indirectly affects sponges (a) by reducing algal abundance (b) and allows the coexistence of both groups (c). In contrast when canopy is absent, the abundance of understory algae (d), due to increased irradiance, may result in sponges being outcompeted by algae (e). Direct negative interactions (e.g. effects of sweeping fronds) between canopy and sponges were not addressed in this study and remain unclear (f). Algal canopies limit algal recruitment (g). In contrast, when absent, increased light levels positively affect recruitment and growth of understory algae (h). Urchins, even at low densities, can modify the structure of the understory as they are capable of removing sponges, algae and other organisms, thus creating free space available for other species. However, their role seems to be highly variable in space and time being driven by factors that remain unknown. Wave action also influences the interactions occurring between canopy and sponge assemblages. Ecklonia canopy is also important as it limits its own recruitment. Depending on its growth and density it will have a direct effect on light availability for the understory, thus affecting algal and sponge recruitment and growth as well as the structure of the assemblage. Furthermore, wave action is responsible of plant removal, which creates gaps that can be used for new recruits that will take advantage of these new gaps. 


\subsection{Influence of abiotic factors on sponge-associated bacteria and their role on temperate rocky reefs}

The potential for sponge-associated symbionts to enable their host to adapt to changes in environmental conditions has become an important topic, with recent studies suggesting that microbial symbionts may provide sponges with an adaptive advantage in the face of climate change (Hentschel et al. 2012). Although, in general, previous studies have reported the presence of relatively stable bacterial communities when exposed to environmental variability, others have reported contrasting results, perhaps because some sponge species harbour more stable bacterial communities than others (Friedrich et al. 2001, Thoms et al. 2003, Lemoine et al. 2007, Webster et al. 2008, White et al. 2012, Simister et al. 2013). In my thesis, a transplantation experiment (Chapter 5) provided confirmation of the stability of ñcoreò bacterial communities as previously suggested for other sponge species (see Friedrich et al. 2001, Luter et al. 2010, Luter et al. 2012, Simister et al. 2012, Simister et al. 2013). The next-generation sequencing approach used in my experiment also provided important high-resolution data on the diversity and abundance of microbial communities associated with temperate sponges, showing the importance of host species to the microbial community. My results reinforce the critical role of host species on the composition of their symbiotic bacterial communities species, showing that species living in relatively similar conditions/habitats host very different bacterial communities. This suggests that different sponge species likely represent different ecological niches for bacteria, each selectively maintaining a specific microbial acquired from vertical transmission (from parents to embryo) (Lee et al. 2009) or from the environment (Webster et al. 2010). The highly diverse and stable sponge-associated bacterial communities may increase the ecological plasticity of the host and also adaptation to environmental change (Reveillaud et al. 2014). However, more research is needed in order to understand the role of heterotrophic bacteria in temperate sponges of New Zealand, which based on existing studies (Anderson et al. 2010, Schmitt et al. 2012, Simister et al. 2013) appear to be diverse and abundant and may play relevant roles in growth, by fixing nitrogen for the host or providing defences against predation, fouling and diseases (Turon et al. 2013). However, roles played by heterotrophic bacteria are mostly unclear and further research is needed to improve our 
understanding of sponge-microbe relationships and how microbial symbionts may affect the physiology and ecology of their host in temperate latitudes.

\subsection{Conceptual model of sponge ecology on temperate rocky reefs}

With the better understanding of sponge assemblages provided by my thesis along with exiting research on temperate sponges, I have developed a conceptual model of sponge ecology showing the interactions between abiotic and biotic factors influencing sponge assemblages on temperate rocky reefs (Fig. 6.2 and 6.3). Conceptual models are very useful for predicting the effects of perturbation in complex ecological communities (e.g. Auster 1998, Ramsey \& Veltman 2005). Recently, Pawlik (2011) proposed a conceptual model predicting the effect of changes in the abundance of sponge-eating fishes on Caribbean sponges, however conceptual models on sponge assemblages are relatively rare. Although more information is still required to understand the effect of abiotic factors on life history traits of sponge species, this conceptual model can be helpful in predicting how changes in physical factors and the removal of some biological components can have a cascading impact on sponge assemblages and hence, affecting the entire community ecosystem functioning. The conceptual model presented here shows the most important abiotic factors (e.g. inclination, light, sediment) and their interactions with biotic factors. It also shows how the interactions between biotic and abiotic factor can influence the diversity and abundance of temperate sponges and the ecological interactions with macroalgae and other organisms (Fig. 6.2 and 6.3).

Inclination is one of the most important factors affecting sponge assemblages on temperate rocky reefs. Surface inclination can directly or indirectly affect other abiotic (e.g. light and sediment) and biotic factors (e.g. grazing by urchins) (Fig. 6.3). Its role is critical for sponges by influencing the amount of light and sediment reaching the substrate, which directly affects settlement of sponges. At the same time, it can indirectly affect sponge and algal abundance and also ecological interactions between both groups and other organisms such as urchins.

Increased turbidity and sedimentation can have a direct effect on canopyforming species due to decreased light, hence having an indirect negative effect on the 
structure of the understory, which may also alter the interactions between algae and sponges. Furthermore, increased sedimentation can also have deleterious effects on sponges, affecting the recruitment and survival of some sponge species occurring on horizontal and inclined surfaces (Fig. 6.3).

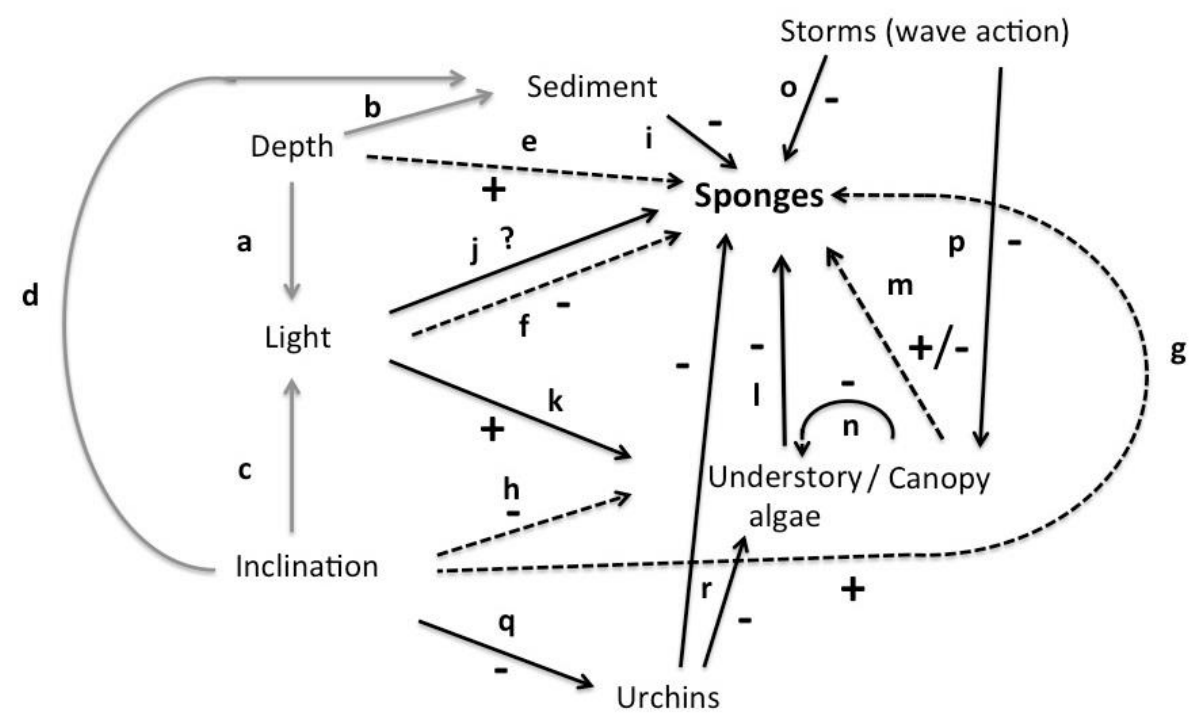

Figure 6.2. Schematic showing the relationships between abiotic and biotic factors influencing temperate sponge assemblages. Grey lines represent effects of abiotic factors (associated with gradients). Solid lines are direct effects and dashed lines are indirect effects. (+) Indicates positive effect; (ï) indicates a negative effect; (?) = unclear. Inclination is probably the most important factor affecting sponge assemblages on temperate rocky reefs. Factors such as sediment and light are directly influenced by inclination and depth $(\mathrm{a}, \mathrm{b}, \mathrm{c}, \mathrm{d})$ and thus, they indirectly affect sponge and algal abundance by altering abiotic factors (light and sediment) (e, f, g, h). Inclination also affects settlement of sponges by affecting the amount of light and sediment reaching the substrate. While sediment is detrimental for most sponge species (i), the direct role of light on adult sponges remain unclear (j), however, it may have a negative effect on sponge recruits. The effect of macroalgae is variable and is highly dependent on abiotic factors (e.g. inclination, light) (h, k). Understory algae negatively affect most sponge species in habitats with high irradiance (1). Algal canopy positively affects only some sponge species (m), and when present indirectly 
facilitates sponge abundance, by reducing algal abundance (n). Grazing by urchins can also play an important role structuring sponge assemblages by removing sponges and other organisms thus creating free space available for other species. The effect of grazing by urchins is heavily influence by inclination (q). Storms (wave action) can influence the structure of sponge assemblages and also the interactions occurring between canopy and sponges (o, p). Storms (wave action) are responsible of plant removal, which creates gaps that can be used for new recruits that will take advantage of these new gaps (p). Biological disturbance produced by urchin grazing and therefore the defensive strategies of sponge species (e.g. physical or chemical) may also play a key role on open reefs (r), however the effect of grazing and the strategies of prey sponges was not studied on this thesis. 

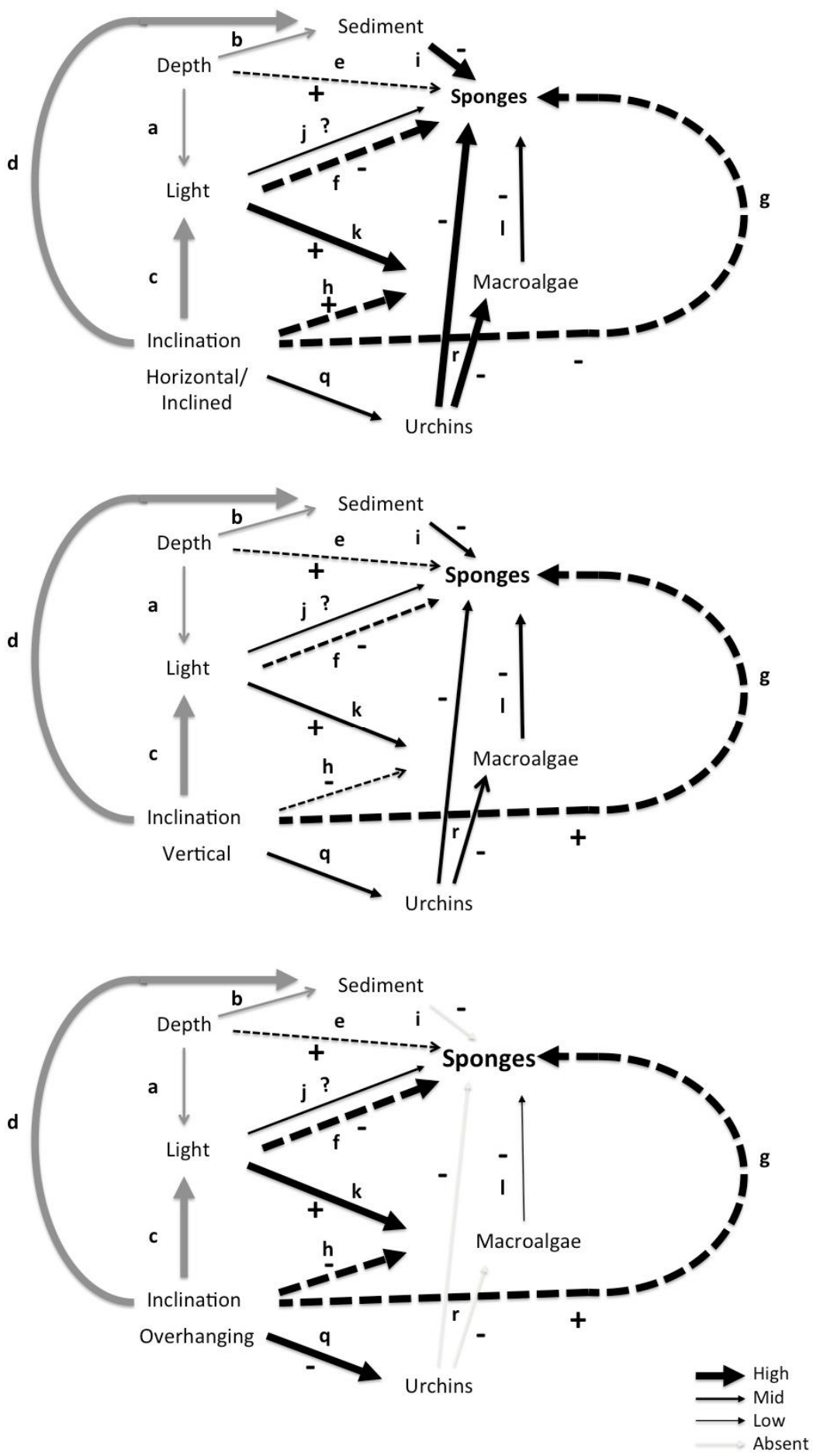

Figure 6.3. Conceptual model showing the relationships between abiotic and biotic factors influencing temperate sponge assemblages. Panels show different scenarios influenced by surface inclination (top $=$ horizontal/inclined, middle $=$ vertical, bottom = overhanging). Grey lines represent effects of abiotic factors (associated with gradients). Solid lines are direct effects and dashed lines are indirect effects. (+) 
Indicates positive effect; (ï) indicates a negative effect; (?) = unclear. Line thickness represents the strength of the interaction. Note that in the bottom panel white arrows represent the absence of an effect produced by urchins and sediment. See Figure 6.2 for further explanation on interactions described by letters.

\subsection{Further research of sponge assemblages on temperate rocky reefs}

My thesis has increased our understanding of temperate rocky reefs sponges, and especially on the less studied sponge assemblages occurring in Ecklonia stands on vertical rocky walls. However, further research will be important in order to: 1) test the effect of macroalgae on sponge recruits; 2) clarify the existence of negative interactions between understory algae and different sponge species and also identify the mechanisms involved; 3 ) test whether there is a negative effect of canopy (e.g. scour by fronds) on sponge species that are rare or absent in the understory, or it is more related with indirect effects produced by Ecklonia plants. The effect of environmental factors on life history traits (e.g. growth rates, fecundity) remain poorly understood, further observational and experimental studies are required in order to understand how environmental variation influences life history traits of different sponge species. Improving our understanding of the roles of heterotrophic bacteria to temperate sponges is also an important area of research that should be addressed in future studies. In addition a recent study has demonstrated the existence of a ñsponge loopò where sponges play a critical role by making the majority of dissolved organic matter (DOM) available (as particulate detritus) to mobile organisms and non-sponge filter feeders (de Goeij et al. 2013). The habitat cascade produced by kelps such as Ecklonia (Thomsen et al. 2010) is an interesting topic addressed in future studies. The potential existence of a sponge loop associated with Ecklonia stands will be important to be studied in order to know how energy is transferred from the basal organism (Ecklonia) to intermediate or secondary organism (sponges) and subsequently to tertiary organisms (other non-sponge filter feeders and mobile fauna). 


\subsection{Concluding remarks}

Temperate sponge assemblages are strongly influenced by interactions between a number of abiotic and biotic factors (Fig. 6.2). The outcomes of the ecological interactions are controlled by environment (e.g. influence of inclination on competition between sponges and understory algae) and at the same time, biological interactions (e.g. facilitation) can moderate the influence of abiotic factors like light, sedimentation and wave action, thus coexistence between sponge and macroalgae underneath the Ecklonia canopy (Figs. 6.1 and 6.2).

Highly dynamic environment such as rocky walls are also influenced by several other factors. Factors such as the size, height, and inclination of rock walls and width of the walled channels may have a large impact on communities, as each individual species satisfies its requirements for space, light, water-flow, protection from abrasion and sediment, and protection from predators (Wright et al. 1997, Davis et al. 2003).

The distribution of sponge assemblages associated with Ecklonia stands occurring on rocky walls that are more exposed to light, are likely to be influenced by habitat heterogeneity inherent in rocky walls, variability in morphology and density of Ecklonia (Fowler-Walker et al. 2005, Smale et al. 2011). In this sense, wave disturbance may play a critical role in generating patchiness in canopy, density and cover of plants (Wernberg \& Connell 2008) occurring in these dynamic habitats. In contrast assemblages occurring in darker conditions such as narrow walled channels or caves, are exposed to more diverse competition pressures (strong intra- and interphyletic interactions), which result in increased investment in defensive/supportive structures and lower investment in somatic growth and reproductive output (Becerro et al. 1994, Uriz et al. 1995).

\subsection{References}

Anderson SA, Northcote PT, Page MJ (2010) Spatial and temporal variability of the bacterial community in different chemotypes of the New Zealand marine sponge Mycale hentscheli. FEMS Microbiology Ecology 72:328-342 
Arillo A, Bavestrello G, Burlando B, Sarà M (1993) Metabolic integration between symbiotic cyanobacteria and sponges: a possible mechanism. Marine Biology $117: 159-162$

Auster PJ (1998) A conceptual model of the impacts of fishing gear on the integrity of fish habitats. Conservation Biology 12: 1198-1203

Ayling AM (1981) The role of biological disturbance in temperate subtidal encrusting communities. Ecology 62:830-847

Barthel D (1986) On the ecophysiology of the sponge Halichondria panicea in Kiel Bight. I. Substrate specificity, growth and reproduction. Marine Ecology Progress Series 32:291-298

Battershill CN (1987) Factors affecting the structure and dynamics of subtidal communities characterised by sponges. Ph.D. Thesis, The University of Auckland

Becerro MA, Uriz MJ, Turon X (1994) Trends in space occupation by the encrusting sponge Crambe crambe: variation in shape as a function of size and environment. Marine Biology 121:301-307

Bell JJ (2002) The sponge community in a semi-submerged temperate sea cave: density, diversity and richness. Marine Ecology 23:297-311

Bell JJ, Barnes DKA (2000a) The distribution and prevalence of sponges in relation to environmental gradients within a temperate sea lough: inclined cliff surfaces. Diversity and Distributions 6:305-323

Bell JJ, Barnes DKA (2000b) The distribution and prevalence of sponges in relation to environmental gradients within a temperate sea lough: vertical cliff surfaces. Diversity and Distributions 6:282-303

Bell JJ, Barnes DKA (2000c) A sponge diversity centre within a marine áslandô Hydrobiologia 440:55-64

Berg MP, Kiers ET, Driessen G, Heijden Mvd, Kooi BW, Kuenen F, Liefting M, Verhoef hA, Ellers J (2010) Adapt or disperse: understanding species persistence in a changing world. Global Change Biology 16:587-598

Carballo JL (2006) Effect of natural sedimentation on the structure of tropical rocky sponge assemblages. Ecoscience 13:119-130

Carballo JL, Vega C, Cruz-Barraza JA, Yanez B, Nava H, Avila E, Wilson M (2008) Short- and long-term patterns of sponge diversity on a rocky tropical coast: evidence of large-scale structuring factors. Marine Ecology 29:216-236 
Carter L, Lewis K (1995) Variability of the modern sand cover on a tide and storm driven inner shelf, south Wellington, New Zealand. New Zealand Journal of Geology and Geophysics 38:451-470

Choat JH, Andrew NL (1986) Interactions amongst species in a guild of subtidal benthic herbivores. Oecologia 68:387-394

Choat JH, Schiel DR (1982) Patterns of distribution and abundance of large brown algae and invertebrate herbivores in subtidal regions of northern New Zealand. Journal of Experimental Marine Biology and Ecology 60:129-162

Davis AR, Fyfe SK, Turon X, Uriz MJ (2003) Size matters sometimes: wall height and the structure of subtidal benthic invertebrate assemblages in south-eastern Australia and Mediterranean Spain. Journal of Biogeography 30:1797-1807

de Goeij JM, van Oevelen D, Vermeij MJA, Osinga R, Middelburg JJ, de Goeij AFPM, Admiraal W (2013) Surviving in a marine desert: the sponge loop retains resources within coral reefs. Science 342:108-110

de Voogd NJ, Cleary D, F.R. (2007) Relating species traits to environmental variables in Indonesian coral reef sponge assemblages. Marine and Freshwater Research 58:240-249

Erwin PM, Thacker RW (2008) Phototrophic nutrition and symbiont diversity of two Caribbean spongeï cyanobacteria symbioses. Marine Ecology Progress Series $362: 139-147$

Fowler-Walker MJ, Gillanders BM, Connell SD, Irving AD (2005) Patterns of association between canopy-morphology and understorey assemblages across temperate Australia. Journal of Experimental Marine Biology and Ecology 63:133-141

Friedrich AB, Fischer I, Proksch P, Hacker J, Hentschel U (2001) Temporal variation of the microbial community associated with the mediterranean sponge Aplysina aerophoba. FEMS Microbiology Ecology 38:105-113

Hentschel U, Piel J, Degnan SM, Taylor MW (2012) Genomic insights into the marine sponge microbiome. Nature Reviews Microbiology 10:641-654

Jokiel PL (1980) Solar ultraviolet radiation and coral reef epifauna. Science 207:1069-1071

Knapp ISS, Williams GJ, Carballo JL, Cruz-Barraza JA, Gardner JPA, Bell JJ (2013) Restriction of sponges to an atoll lagoon as a result of reduced environmental quality. Marine Pollution Bulletin 66:209-220 
Knott NA, Underwood AJ, Chapman MG, Glasby TM (2004) Epibiota on vertical and on horizontal surfaces on natural reefs and on artificial structures. Journal of the Marine Biological Association of the United Kingdom 84:1117-1130

Lee OO, Chui PY, Wong YH, Pawlik JR, Qian P-Y (2009) Evidence for vertical transmission of bacterial symbionts from adult to embryo in the Caribbean sponge Svenzea zeai. Applied and Environmental Microbiology 75:6147-6156

Lemoine N, Buell N, Hill A, Hill M (2007) Assessing the utility of sponge microbial symbiont communities as models to study global climate change: a case study with Halichondria bowerbanki. In: Custodio MR, Lobo-Hajdu G, Hajdu E, Muricy G (eds) Porifera research: biodiversity, innovation and sustainability. Museu Nacional, Rio de Janeiro, Brazil, p 419-425

Luter HM, Whalan S, Webster NS (2010) Exploring the role of microorganisms in the disease-like syndrome affecting the sponge Ianthella basta. Applied and Environmental Microbiology 76:5736-5744

Luter HM, Whalan S, Webster NS (2012) The marine sponge Ianthella basta can recover from stress-induced tissue regression. Hydrobiologia 687:227-235

Maldonado M, Giraud K, Carmona C (2008) Effects of sediment on the survival of asexually produced sponge recruits. Marine Biology 154:631-641

Maldonado M, Uriz MJ (1998) Microrefuge exploitation by subtidal encrusting sponges: patterns of settlement and post settlement survival. Marine Ecology Progress Series 174:141-150

Miller RJ, Etter RJ (2008) Shading facilitates sessile invertebrate dominance in the rocky subtidal Gulf of Maine. Ecology 89:452ï 462

Newcombe EM, Cárdenas CA, Geange SW (2012) Green sea urchins structure invertebrate and macroalgal communities in the Magellan Strait, southern Chile. Aquatic Biology 15:135-144

Norderhaug KM, Christie HC (2009) Sea urchin grazing and kelp re-vegetation in the NE Atlantic. Marine Biology Research 5:515-528

Palacin C, Giribet G, Carner S, Dantart L, Turon X (1998) Low densities of sea urchins inpuence the structure of algal assemblages in the western Mediterranean. Journal of Sea Research 39:281-290

Palumbi SR (1985) Spatial variation in an algal-sponge commensalism and the evolution of ecological interactions. American Naturalist 126:267-275 
Pawlik JR (2011) The chemical ecology of sponges on Caribbean reefs: natural products shape natural systems. BioScience 61: $888 і ̈ 898$

Powell A, Smith DJ, Hepburn LJ, Jones T, Berman J, Jompa J, Bell JJ (2014) Reduced Diversity and High Sponge Abundance on a Sedimented Indo-Pacific Reef System: Implications for Future Changes in Environmental Quality PLoS ONE 9:e85253

Preciado I, Maldonado M (2005) Reassessing the spatial relationship between sponges and macroalgae in sublittoral rocky bottoms: a descriptive approach. Helgoland Marine Research 59:141-150

Ramsey D, Veltman C (2005) Predicting the effects of perturbations on ecological communities: what can qualitative models offer? Journal of Animal Ecology 74: $905-916$

Reveillaud J, Maignien L, Eren AM, Huber JA, Apprill A, Sogin ML, Vanreusel A (2014) Host-specificity among abundant and rare taxa in the sponge microbiome. The ISME Journal (online):1-12

Roberts D, Cummins S, Davis A, Pangway C (1999) Evidence for symbiotic algae in sponges from temperate coastal reefs in New South Wales, Australia. Memoirs of the Queensland Museum 44:493-497

Schmitt S, Tsai P, Bell J, Fromont J, Ilan M, Lindquist N, Perez T, Rodrigo A, Schupp PJ, Vacelet J, Webster N, Hentschel U, Taylor MW (2012) Assessing the complex sponge microbiota: core, variable and species-specific bacterial communities in marine sponges. The ISME Journal 6:564-576

Simister R, Taylor MW, Rogers KM, Schupp PJ, Deines P (2013) Temporal molecular and isotopic analysis of active bacterial communities in two New Zealand sponges. FEMS Microbiology Ecology 85:195-205

Simister R, Taylor MW, Tsai P, Fan L, Bruxner TJ, Crowe ML, Webster N (2012) Thermal stress responses in the bacterial biosphere of the Great Barrier Reef sponge, Rhopaloeides odorabile. Environmental Microbiology 14:3232-3246

Smale DA, Kendrick GA, Wernberg T (2011) Subtidal macroalgal richness, diversity and turnover, at multiple spatial scales, along the southwestern Australian coastline. Estuarine, Coastal and Shelf Science 91:224-231

Thacker RW (2005) Impacts of shading on sponge-cyanobacteria symbioses: a comparison between host-speciýc and generalist associations. Integrative and Comparative Biology 45:369-376 
Thoms C, Horn M, Wagner M, Hentschel U, Proksch P (2003) Monitoring microbial diversity and natural product proýles of the sponge Aplysina cavernicola following transplantation. Marine Biology 142:685-692

Thomsen MS, Wernberg T, Altieri A, Tuya F, Gulbransen D, McGlathery KJ, Holmer M, Silliman BR (2010) Habitat cascades: the conceptual context and global relevance of facilitation cascades via habitat formation and modification. Integrative and Comparative Biology 50:158-175

Turon X, Garriga A, Erwin PM (2013) Lights and shadows: growth patterns in three sympatric and congeneric sponges (Ircinia spp.) with contrasting abundances of photosymbionts. Marine Biology 160:2743-2754

Uriz MJ, Turon X, Becerro MA, Galera J, Lozano J (1995) Patterns of resource allocation to somatic, defensive, and reproductive functions in the Mediterranean encrusting sponge Crambe crambe (Demospongiae, Poecilosclerida). Marine Ecology Progress Series 124:159-170

Webster NS, Cobb RE, Negri AP (2008) Temperature thresholds for bacterial symbiosis with a sponge. The ISME Journal 2:830-842

Webster NS, Taylor MW, Behnam F, Lücker S, Rattei T, Whalan S, Horn M, Wagner M (2010) Deep sequencing reveals exceptional diversity and modes of transmission for bacterial sponge symbionts. Environmental Microbiology 12:2070-2082

Wernberg T, Connell SD (2008) Physical disturbance and subtidal habitat structure on open rocky coasts: effects of wave exposure, extent and intensity. Journal of Sea Research 59:237-248

White JR, Patel J, Ottesen A, Arce G, Blackwelder P, Lopez JV (2012) Pyrosequencing of bacterial symbionts within Axinella corrugata sponges: diversity and seasonal variability. PloS ONE 7:e38204

Wilkinson CR, Evans E (1989) Sponge distribution across Davies Reel Great Barrier Reef relative to location, depth, and water movement. Coral Reefs 8:1-7

Wilkinson CR, Vacelet J (1979) Transplantation of marine sponges to different conditions of light and current. Journal of Experimental Marine Biology and Ecology 37:91-104

Witman JD, Sebens KP (1990) Distribution and ecology of sponges at a subtidal rock ledge in the Central Gulf of Maine. In: Rützler K (ed) New perspectives in sponge biology. Smithsonian Institution Press, London, p 391-396 
Wright JT, Benkendorff K, Davis AR (1997) Habitat associated differences in temperate sponge assemblages: the importance of chemical defence. Journal of Experimental Marine Biology and Ecology 213:199-213

Wulff J (2012) Ecological interactions and the distribution, abundance, and diversity of sponges. Advances in Marine Biology 61:273-344

Wulff JL (2006) Ecological interactions of marine sponges. Canadian Journal of Zoology 84:146-166 


\section{Appendix 1}

Superimposed grid used to estimate the percent cover of canopy and understory for canopy (first layer) and understory (second layer) using the software CPCe v3.5 (Coral Point Count with Excel extensions). A grid of 100 points was superimposed over each photo-quadrat in order to estimate canopy cover and 100 points were used for each section of the quadrat (4 for each quadrat) to estimate the percentage cover of the understory (400 points in total).

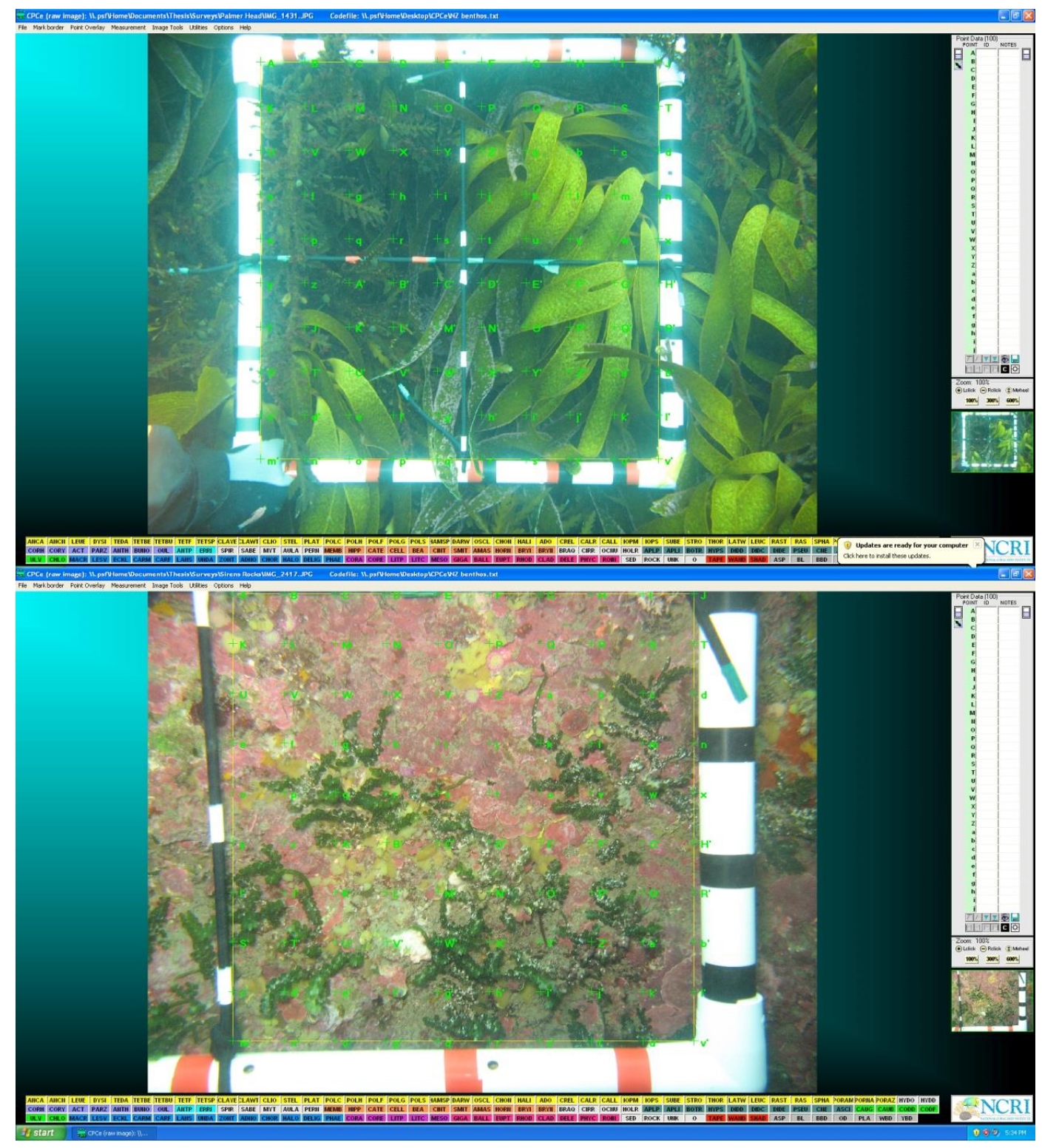




\section{Appendix 2}

Mean percentage $(\mathrm{SE})$ cover of biotic and abiotic categories across sites studied on the south coast of Wellington and at Kapiti Island. PB = Princess Bay; SR = The Sirens Rocks; BR = Barrett Reef; PH = Palmer Head; BB = Breaker Bay; KP = Kaiwharawhara Point; TP = Trig Point.

\begin{tabular}{lccccccc}
\hline Taxa & PB & SR & BR & PH & BB & KP \\
\hline Porifera & $3.85(1.37)$ & $19.90(6.97)$ & $6.35(2.10)$ & $4.33(0.81)$ & $28.90(6.03)$ & $17.15(3.41)$ & $20.6(3.04)$ \\
Hydrozoa & $1.68(1.46)$ & $0.05(0.05)$ & $0.36(0.27)$ & $0.00(0.00)$ & $9.90(3.88)$ & $5.18(1.67)$ & $8.98(2.64)$ \\
Anthozoa & $0.10(0.04)$ & $0.55(0.17)$ & $0.00(0.00)$ & $0.45(0.20)$ & $1.35(0.91)$ & $3.78(0.94)$ & $0.55(0.27)$ \\
Polychaeta & $0.03(0.03)$ & $0.75(0.31)$ & $0.10(0.06)$ & $0.23(0.10)$ & $0.60(0.16)$ & $0.40(0.19)$ & $0.10(0.08)$ \\
Bryozoa & $1.00(0.52)$ & $0.60(0.48)$ & $2.80(0.83)$ & $0.75(0.25)$ & $2.90(1.02)$ & $7.58(2.16)$ & $9.08(3.08)$ \\
Ascidiacea & $1.05(0.66)$ & $4.35(1.90)$ & $2.28(0.95)$ & $6.58(2.39)$ & $10.70(2.92)$ & $7.25(2.31)$ & $7.05(1.61)$ \\
Rhodophyta & $1.08(0.42)$ & $2.70(1.14)$ & $17.34(4.79)$ & $12.38(1.86)$ & $2.65(1.22)$ & $5.05(0.82)$ & $6.75(1.44)$ \\
Chlorophyta & $6.03(1.49)$ & $7.95(2.46)$ & $0.05(0.05)$ & $0.10(0.08)$ & $0.00(0.00)$ & $0.00(0.00)$ & $0.15(0.08)$ \\
Phaeophyta & $2.35(1.63)$ & $0.15(0.15)$ & $3.05(0.92)$ & $6.40(1.56)$ & $6.35(2.50)$ & $16.10(3.52)$ & $14.40(2.80)$ \\
CCA & $45.48(9.53)$ & $49.55(3.78)$ & $37.50(10.30)$ & $53.73(4.37)$ & $26.7(9.62)$ & $27.35(6.45)$ & $21.40(4.50)$ \\
Sediment & $35.43(8.80)$ & $7.10(1.41)$ & $26.87(8.60)$ & $4.83(2.26)$ & $3.90(1.42)$ & $3.43(1.34)$ & $6.03(2.44)$ \\
Bare rock & $1.55(0.57)$ & $5.95(4.79)$ & $2.88(0.96)$ & $10.13(1.08)$ & $0.63(0.24)$ & $5.63(1.53)$ & $4.23(1.61)$ \\
\hline
\end{tabular}




\section{Appendix 3}

Key for taxon names used on the redundancy analysis (Fig. 10b)

Anc.ala: Ecionemia alata; Anc.nov: Ecionemia novaezelandiae; Cally.sp: Callyspongia sp.; Cho.top: Chondropsis topsenti; Clat.sp: Clathria sp.; Cla.sp1: Clathrina sp. 1; Cla.sp2: Clathrina sp. 2; Cla.sp3: Clathrina sp. 3; Cli.sp: Cliona sp.; Crel.sp: Crella sp.; Dar.gar: Darwinella sp.; Dys.sp: Dysidea sp.; Hal.sp 1: Haliclona sp. 1; Hal.sp 2: Haliclona sp. 2; Hal.ven: Haliclona venustina; Hal.duj: Halisarca dujardini; Hal.sp: Halisarca sp.; Iop.sp: Iophon sp.; Lat.wel: Latruncullia wellingtonensis Leuc.sp: Leucetta sp.; Leu.ech: Leucosolenia echinata; Leu.sp: Leucosolenia sp.; Myc.sp: Mycale sp.; Osc.lob: Oscarella lobularis; Pla.tri: Plakina trilopha; Pla.sp: Plakina sp.; Pol. cro: Polymastia crocea; Pol.sp: Polymastia sp. Por.1: Unidentified Porifera 1; Por.2: Unidentified Porifera 2; Por.3: Unidentified Porifera 3; Ste.sp1: Stelletta sp. 1; Ste.sp2: Stelletta sp. 2; Str.con: Strongylacidon conulosum; Syc.sp: Sycon sp.; Ted.sp: Tedania sp.; Tet.ber: Tethya bergquistae; Tet.bur: Tethya burtoni; Tet.sp: Tethya sp.; Haplo1: Unidentified haplosclerid 1. 


\section{Appendix 4}

$\mathrm{R}$ code used to test for differences in richness and abundance of sponges between control and removal treatments through time. Differences were examined by generating 95\% confidence intervals using a bootstrap re-sampling procedure. $\mathrm{R}$ code written by Timothy Jones.

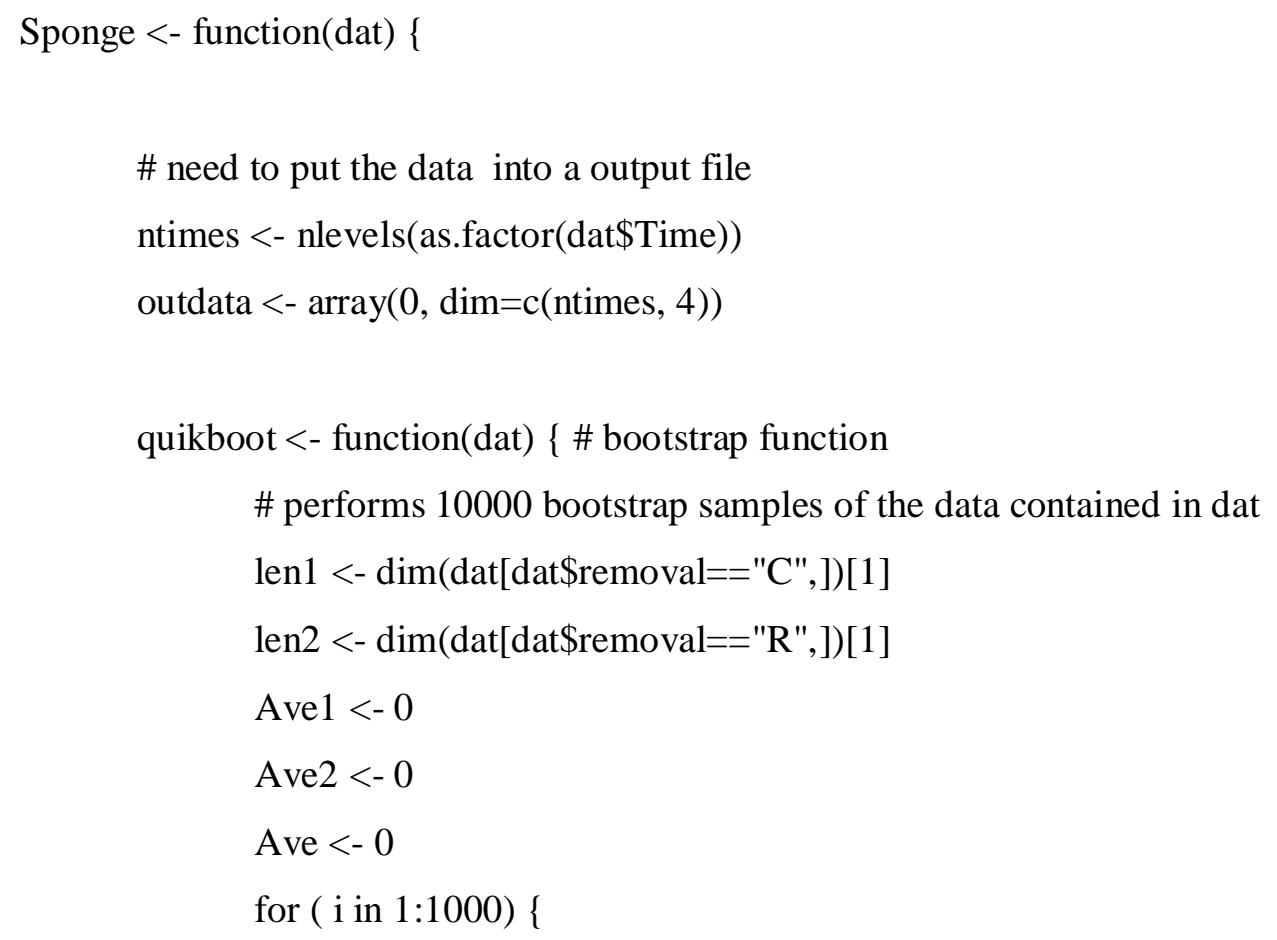

1st1 <- floor(runif(len1, $\min =1, \max =(\operatorname{len} 1+.999999999999)))$

lst2 <- floor(runif(len2, $\min =1, \max =($ len2 +.999999999999$)))$

Ave1[i] <- sum(dat\$Abundance[dat\$removal=="C"][1st1])/len1

Ave2[i] <- sum(dat\$Abundance[dat\$removal=="R"][1st2])/len2

Ave[i] <- Ave2[i] - Ave1[i]

\}

meden <- Ave[rank(Ave, ties.method="random")==500]

upen <- Ave[rank(Ave, ties.method="random")==975]

lowen <- Ave[rank(Ave, ties.method="random")==25]

meanen <- sum(Ave)/1000 
outdat <- c(meden, lowen, upen, meanen)

return(outdat)

\}

for ( $\mathrm{i}$ in $1:$ ntimes) \{

outdata[i,]

quikboot(dat[as.factor(dat\$Time)==levels(as.factor(dat\$Time))[i],])

\}

Time <- as.numeric(levels(as.factor(dat\$Time)))

spongeout $<$ - data.frame $($ Time, outdata)

names(spongeout) <- c("Time", "Median", "Low95CI", "Up95CI", "Mean")

$\operatorname{plot}($ Mean $\sim$ Time, data=spongeout, ylab="Difference in sponge abundance", xlab="Weeks", $\quad$ ylim=c(min(spongeout\$Low95CI), $\max ($ spongeout\$Up95CI)),

type $=" p ", p c h=16, b g=1)$

timelist <- as.numeric(levels(as.factor(spongeout\$Time)))

for ( $i$ in $1:$ ntimes) \{

segments(timelist[i], spongeout\$Low95CI[as.factor(spongeout\$Time)==levels (as.factor( spongeout\$Time))[i]], timelist[i], spongeout\$Up95CI[as.factor(spongeout\$Time)==levels(as.factor(spongeout\$Time))[i]], $\operatorname{lwd}=1.5)$

segments(timelist[i]-.15, spongeout\$Low95CI[as.factor(spongeout\$Time)==levels(as.factor(spongeout $\$$ Time)) [i ]], timelist $[\mathrm{i}]+0.15$, spongeout\$Low95CI[as.factor $($ spongeout $\$$ Time $)==$ levels $($ as.factor $(\operatorname{spongeout} \$$ Time $))[\mathrm{i}$ ]], lwd=1.5)

segments(timelist[i]-0.15, spongeout\$Up95CI[as.factor(spongeout\$Time)==levels(as.factor(spongeout\$Time))[i]], 
timelist[i]+0.15,

spongeout\$Up95CI[as.factor(spongeout\$Time)==levels(as.factor(spongeout\$Time))[i]], $\operatorname{lwd}=1.5)$

\}

abline $(\mathrm{h}=$ spongeout $\$$ Low95CI[ spongeout $\$$ Time==0], col=2, 1 ty=2)

abline $(\mathrm{h}=$ spongeout $\$ \mathrm{Up} 95 \mathrm{CI}[$ spongeout $\$$ Time $==0]$, col=2, lty=2)

$\operatorname{rect}(-10, \quad$ spongeout\$Low95CI[spongeout\$Time==0], $\max ($ timelist $)+5$, spongeout $\$ \mathrm{Up} 95 \mathrm{CI}[\mathrm{spongeout} \$ \mathrm{Time}==0], \mathrm{col}=\mathrm{rgb}(0.5,0.5,0.5,0.2)$, border=NA)

return(spongeout)

\} 


\section{Appendix 5}

Sponge array with Ecionema alata individuals (explants) transplanted to walled channels on the south coast of Wellington, New Zealand.

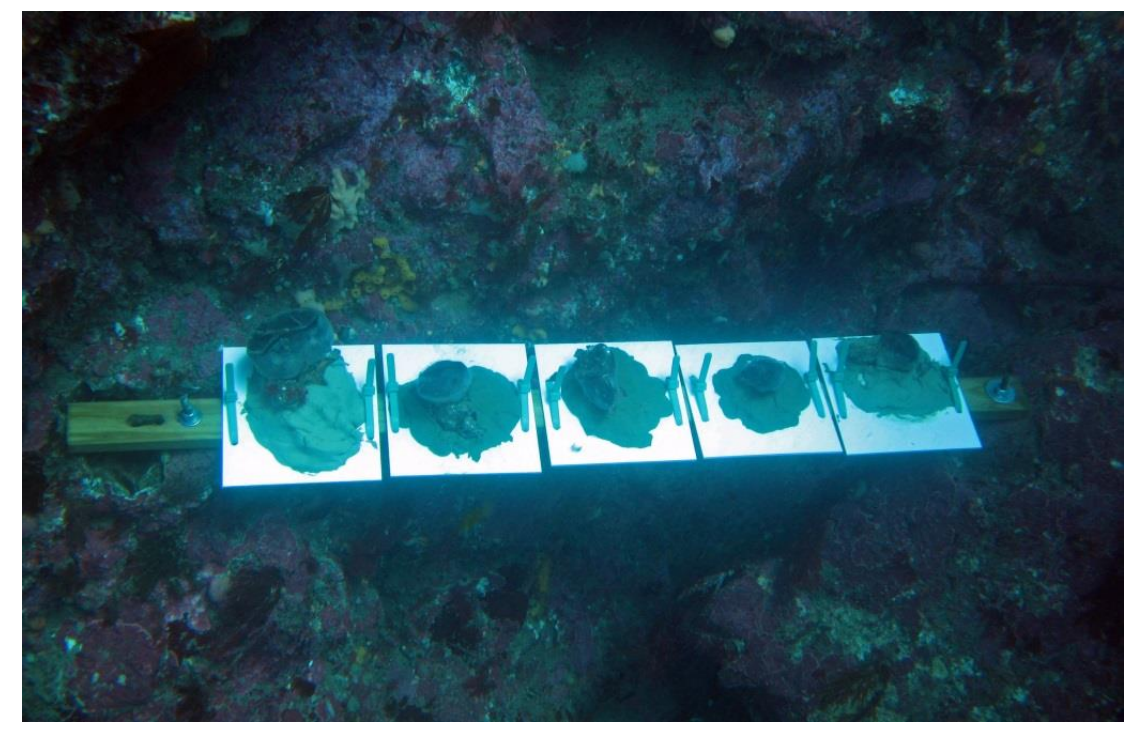




\section{Appendix 6}

Screenshot showing the traced area of a sponge in order to estimate the two-dimensional growth of sponge explants. Calculations were done using the software CPCe v3.5 (Coral Point Count with Excel extensions; Kohler \& Gill 2006).

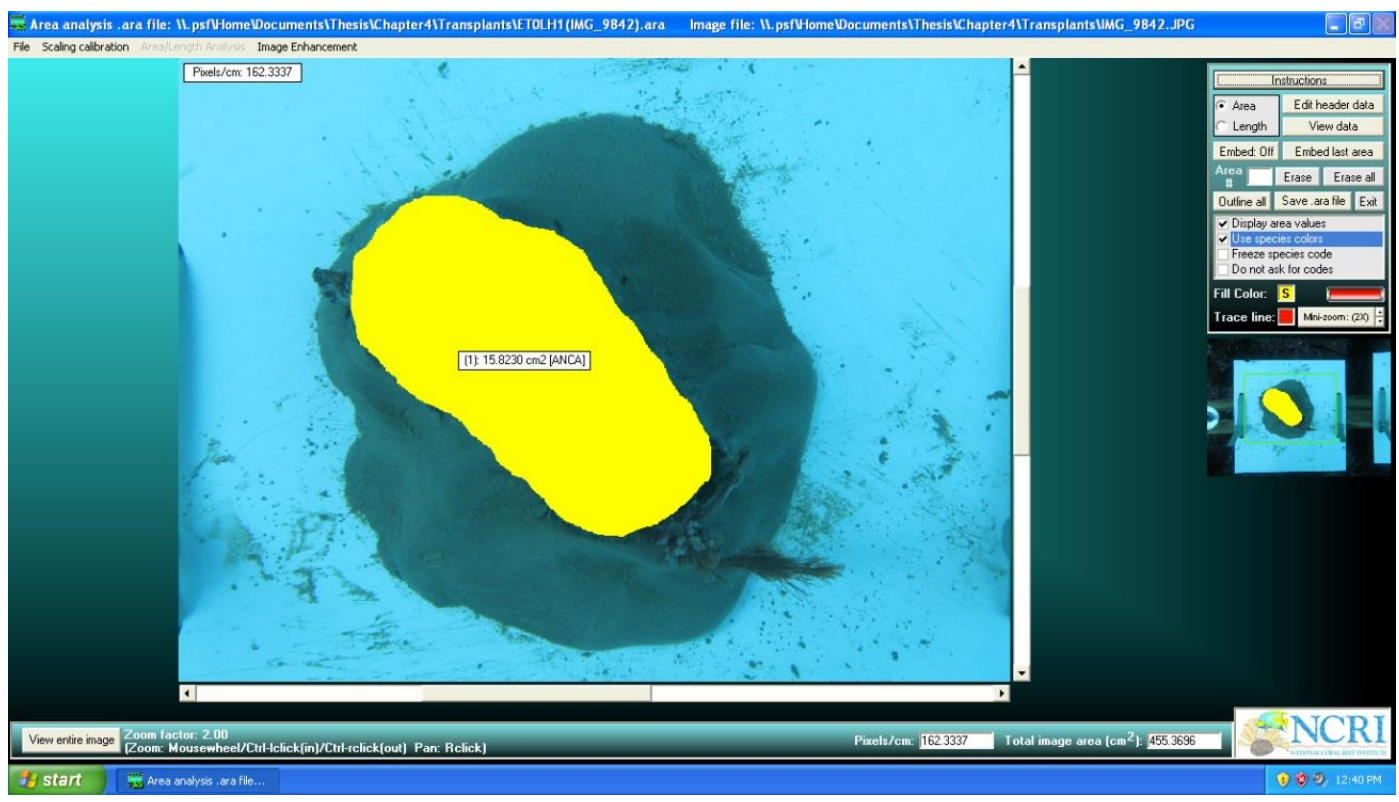




\section{Appendix 7}

Bacterial diversity observed (Sobs) and Chao1 estimates in Ecionemia alata and Tethya bergquistae samples. lci $=$ lower $95 \%$ confidence interval, hci $=$ higher $95 \%$ confidence interval. $\mathrm{ECH}=E$. alata control high-light, $\mathrm{ECL}=E$. alata control low-light, $\mathrm{ETHL}=$ E. alata samples transplanted from high- to low-light, ETLH $=$ E. alata samples transplanted from low- to high-light, $\mathrm{TCH}=T$. bergquistae control high-light, $\mathrm{CL}=T$. bergquistae control low-light, TTHL $=T$. bergquistae samples transplanted from highto low-light, $\mathrm{TTLH}=T$. bergquistae samples transplanted from low- to high-light.

\begin{tabular}{|c|c|c|c|c|c|}
\hline \multicolumn{6}{|l|}{ E.alata } \\
\hline sample & $\begin{array}{l}\text { Number of } \\
\text { sequences }\end{array}$ & Sobs & Chao1 & lci & hci \\
\hline ECH.1 & 4276 & 166 & 201.15 & 181.70 & 244.67 \\
\hline ECH.2 & 4177 & 145 & 164.12 & 152.36 & 194.66 \\
\hline ECH.3 & 3872 & 159 & 194.00 & 174.29 & 239.10 \\
\hline ECH.4 & 5876 & 164 & 201.43 & 181.37 & 244.68 \\
\hline ECL.1 & 3232 & 149 & 173.17 & 158.88 & 208.14 \\
\hline ECL. 2 & 2235 & 146 & 179.21 & 159.62 & 227.00 \\
\hline ECL.3 & 2988 & 163 & 217.67 & 187.60 & 284.48 \\
\hline ECL.4 & 4136 & 149 & 161.16 & 153.31 & 183.28 \\
\hline ETHL.1 & 3831 & 169 & 208.00 & 186.54 & 255.71 \\
\hline ETHL.2 & 3549 & 163 & 187.70 & 174.17 & 217.60 \\
\hline ETHL.4 & 2654 & 152 & 170.90 & 159.51 & 199.59 \\
\hline ETHL.5 & 2307 & 161 & 194.30 & 175.74 & 236.22 \\
\hline ETLH.1 & 2362 & 147 & 182.77 & 161.60 & 234.61 \\
\hline ETLH.2 & 3939 & 154 & 180.40 & 165.21 & 216.17 \\
\hline ETLH.3 & 3294 & 157 & 202.88 & 177.68 & 258.79 \\
\hline ETLH.5 & 4340 & 165 & 176.45 & 169.43 & 194.62 \\
\hline ETLH.6 & 3856 & 166 & 195.06 & 177.99 & 236.45 \\
\hline \multicolumn{6}{|c|}{ T.bergquistae } \\
\hline TCH.1 & 2036 & 17 & 27.50 & 19.03 & 71.19 \\
\hline ТCH.2 & 1638 & 32 & 49.50 & 37.12 & 91.84 \\
\hline ТCH.3 & 2371 & 26 & 53.50 & 32.66 & 139.50 \\
\hline TCH.4 & 4642 & 22 & 29.00 & 23.45 & 55.75 \\
\hline TCL.1 & 1966 & 24 & 31.00 & 25.34 & 60.54 \\
\hline
\end{tabular}




\begin{tabular}{lccccc}
\hline \multicolumn{1}{l}{ Appendix 7. Continued } & & & \\
\hline TCL.2 & 2918 & 21 & 28.00 & 22.34 & 57.54 \\
TCL.3 & 2196 & 26 & 38.00 & 26.92 & 91.11 \\
TCL.4 & 3042 & 22 & 79.25 & 52.59 & 167.21 \\
TTHL.1 & 3797 & 47 & 112.00 & 69.65 & 233.52 \\
TTHL.2 & 3569 & 51 & 65.25 & 55.75 & 93.74 \\
TTHL.4 & 3177 & 28 & 46.33 & 32.48 & 103.08 \\
TTHL.5 & 2815 & 41 & 54.13 & 44.88 & 85.38 \\
TTHL.6 & 2666 & 21 & 22.20 & 21.14 & 31.37 \\
TTLH.1 & 1895 & 38 & 62.00 & 45.12 & 118.89 \\
TTLH.4 & 2830 & 35 & 40.63 & 36.32 & 59.06 \\
TTLH.5 & 3033 & 55 & 85.67 & 66.15 & 139.35 \\
\hline
\end{tabular}




\section{Appendix 8}

Pairwise comparisons of analyses of molecular variance (AMOVA) of bacterial communities in Ecionemia alata and Tethya bergquistae samples from different treatments. Bold values indicate significance at $0.05 . \mathrm{ECH}=E$. alata control high-light, $\mathrm{ECL}=E$. alata control low-light, $\mathrm{ETHL}=E$. alata samples transplanted from high- to low-light, ETLH = E. alata samples transplanted from low- to high-light, $\mathrm{TCH}=T$. bergquistae control high-light, $\mathrm{CL}=T$. bergquistae control low-light, $\mathrm{TTHL}=T$. bergquistae samples transplanted from high- to low-light, TTLH $=T$. bergquistae samples transplanted from low- to high-light.

\begin{tabular}{|c|c|c|c|}
\hline Species & Treatment & $F$ & $p$-value \\
\hline \multirow[t]{6}{*}{ E. alata } & ECH-ECL & 0.877457 & 0.67 \\
\hline & ECH-ECH & 0.610369 & 0.872 \\
\hline & ECH-ETLH & 0.254507 & 0.976 \\
\hline & ECL-ETHL & 1.91267 & 0.023 \\
\hline & ECL-ETLH & 1.38077 & 0.147 \\
\hline & ETHL-ETLH & 0.50986 & 0.966 \\
\hline \multirow[t]{6}{*}{ T. bergquistae } & TCH-TCL & 3.01127 & 0.223 \\
\hline & TCL-TTHL & 18.761 & 0.012 \\
\hline & TCH-TTLH & 0.305607 & 0.54 \\
\hline & TCL-TTHL & 60.1428 & 0.011 \\
\hline & TCL-TTLH & 0.813406 & 0.447 \\
\hline & TTHL-TTLH & 44.7574 & 0.006 \\
\hline
\end{tabular}




\section{Appendix 9}

UniFrac pairwise comparisons of bacterial communities in (a) Ecionemia alata and (b) Tethya bergquistae samples. ECH $=$ E. alata control highlight, $\mathrm{ECL}=E$. alata control low-light, $\mathrm{ETHL}=E$. alata samples transplanted from high- to low-light, ETLH $=E$. alata samples transplanted from low- to high-light, $\mathrm{TCH}=T$. bergquistae control high-light, $\mathrm{CL}=T$. bergquistae control low-light, TTHL $=T$. bergquistae samples transplanted from high- to low-light, TTLH = T. bergquistae samples transplanted from low- to high-light.

\begin{tabular}{|c|c|c|c|c|c|c|c|c|c|c|c|c|c|c|c|c|}
\hline & ETLH6 & ETLH5 & ETLH3 & ETLH2 & ETLH1 & ETHL5 & ETHL4 & ETHL2 & ETHL1 & ECL4 & ECL3 & ECL2 & ECL1 & $\mathrm{ECH} 4$ & ECH3 & ECH2 \\
\hline $\begin{array}{l}\text { ECH1 } \\
\text { ECH2 }\end{array}$ & 0.153156 & 0.156044 & $\begin{array}{l}0.177078 \\
0.17545\end{array}$ & $\begin{array}{r}0.19305 \\
0.18940\end{array}$ & $\begin{array}{l}0.178621 \\
0.201694\end{array}$ & 0.178497 & 0.193292 & $\begin{array}{l}0.170119 \\
\end{array}$ & $\begin{array}{l}0.176575 \\
0.17963\end{array}$ & 0.151027 & $\begin{array}{r}0.14511 \\
0\end{array}$ & 0.141682 & 0.158519 & $\begin{array}{l}0.157922 \\
\end{array}$ & 0.158058 & 0.224443 \\
\hline ECH3 & $\begin{array}{l}0.186147 \\
0.157495\end{array}$ & $\begin{array}{l}0.184485 \\
0.154743\end{array}$ & $\begin{array}{l}0.175456 \\
0.167492\end{array}$ & $\begin{array}{l}0.189401 \\
0.165626\end{array}$ & $\begin{array}{l}0.201694 \\
0.164213\end{array}$ & $\begin{array}{l}0.197644 \\
0.174704\end{array}$ & $\begin{array}{l}0.192469 \\
0.17705\end{array}$ & $\begin{array}{l}0.189713 \\
0.172862\end{array}$ & $\begin{array}{l}0.179632 \\
0.159052\end{array}$ & $\begin{array}{l}0.201887 \\
0.18114\end{array}$ & $\begin{array}{l}0.227616 \\
0.156968\end{array}$ & $\begin{array}{l}0.215465 \\
0.166353\end{array}$ & $\begin{array}{l}0.199882 \\
0.15612\end{array}$ & $\begin{array}{l}0.188032 \\
0.15593\end{array}$ & & \\
\hline $\mathrm{ECH} 4$ & 0.169411 & $\begin{array}{l}0.134443 \\
0.141461\end{array}$ & $\begin{array}{l}0.10 \\
0.175522\end{array}$ & $\begin{array}{l}0.103020 \\
0.191976\end{array}$ & 0.1048765 & 0.1749 & $\begin{array}{r}0.17427 \\
\end{array}$ & 0.151504 & 0.171147 & $\begin{array}{l}0.14114 \\
0.176938\end{array}$ & $\begin{array}{r}.153000 \\
0.16595\end{array}$ & 0.157348 & $\begin{array}{l}0.1300189 \\
0.191899\end{array}$ & & & \\
\hline ECL1 & 0.159163 & 0.177434 & 0.164315 & 0.185715 & 0.198552 & 0.159805 & 0.208139 & 0.177941 & 0.168559 & 0.155889 & 0.173375 & 0.182554 & & & & \\
\hline & 0.161485 & 0.153001 & 0.174878 & 0.194529 & 0.18174 & & 0.19094 & 0.153454 & 0.189733 & 0.164628 & 0.16547 & & & & & \\
\hline ECL3 & 0.150111 & 0.15759 & 0.166472 & 0.192848 & 0.166033 & 0.16064 & 0.18196 & 0.170632 & 0.169355 & 0.143834 & & & & & & \\
\hline ECL4 & 0.140261 & 0.16353 & 0.15429 & 0.169809 & 0.159789 & 0.142345 & 0.177526 & 0.146348 & 0.151915 & & & & & & & \\
\hline $\begin{array}{l}\text { ETHL1 } \\
\text { ETHL2 }\end{array}$ & 0.148581 & 0.160112 & 0.141548 & 0.150487 & 0.163147 & 0.1368 & 0.178544 & 0.149507 & & & & & & & & \\
\hline $\begin{array}{l}\text { TEHL2 } \\
\text { ETHL4 }\end{array}$ & 0.141222 & $\begin{array}{l}0.15401 \\
0.150693\end{array}$ & $\begin{array}{l}0.152874 \\
0.170898\end{array}$ & 0.172329 & $\begin{array}{l}0.148262 \\
0.16739\end{array}$ & $\begin{array}{r}0.16708 \\
\end{array}$ & & & & & & & & & & \\
\hline ETHL5 & 0.155863 & 0.155524 & 0.157677 & 0.168857 & 0.165036 & & & & & & & & & & & \\
\hline & 0.172399 & 0.152168 & 0.184201 & 0.168936 & & & & & & & & & & & & \\
\hline ETLH2 & 0.169873 & 0.162993 & 0.151644 & & & & & & & & & & & & & \\
\hline \multirow{3}{*}{$\begin{array}{l}\text { ETLH5 } \\
\text { ETLH6 } \\
\end{array}$} & 0.137939 & 0.145656 & & & & & & & & & & & & & & \\
\hline & & & & & & & & & & & & & & & & \\
\hline & TLHLH & $\pi L H 4$ & П내1 & THLL & THHL5 & TTHL4 & TTHL2 & THL1 & TCL4 & TCL3 & TCL2 & TCL1 & TCH4 & $\mathrm{TCH} 3$ & & \\
\hline TCH1 & 0.247102 & 0.176503 & 0.236831 & 0.275953 & 0.186337 & 0.200122 & 0.181132 & 0.236831 & 0.321201 & 0.212712 & 0.248125 & 0.230254 & 0.185253 & 0.131158 & & \\
\hline TCH3 & 0.181456 & 0.130578 & 0.184041 & 0.328615 & 0.191394 & 0.14717 & 0.204493 & 0.184041 & 0.272773 & 0.150701 & 0.175899 & 0.186718 & 0.162215 & & & \\
\hline TCH4 & 0.082588 & 0.147448 & 0.101902 & 0.357858 & 0.259538 & 0.220706 & 0.257311 & 0.101902 & 0.086601 & 0.149344 & 0.0932 & 0.082743 & & & & \\
\hline TCL1 & 0. & 0.182557 & 0.107211 & 0.4 & $\begin{array}{l}0.279078 \\
\end{array}$ & 0.259834 & 0.324037 & 0.107211 & 0.134258 & 0.145835 & 0.09609 & & & & & \\
\hline TCL3 & 0.169 & & & & & 0.2 & $\begin{array}{l}0.318599 \\
0.303003\end{array}$ & $\begin{array}{l}0.132242 \\
0.17239\end{array}$ & $\begin{array}{l}0.182658 \\
0.24310\end{array}$ & 0.105008 & & & & & & \\
\hline TCL4 & 0.1 & 0. & & & 0.365525 & 0.359122 & 0.397441 & 0.194602 & & & & & & & & \\
\hline TTHL1 & 0.32 & 0.243 & 0.310974 & 0.170507 & 0.211204 & 0.214988 & 0.111166 & & & & & & & & & \\
\hline & & 0. & 0.273135 & 0.248202 & 0.160818 & 0.179629 & & & & & & & & & & \\
\hline $\begin{array}{l}\text { THL4 } \\
\text { THLL5 }\end{array}$ & 0.239723 & $\begin{array}{r}0.165957 \\
0.21943\end{array}$ & $\begin{array}{l}0.211261 \\
0.26042\end{array}$ & 0.284724 & 0.122277 & & & & & & & & & & & \\
\hline TTHLG & 0.433619 & 0.355727 & 0.413268 & & & & & & & & & & & & & \\
\hline TILH1 & $\begin{array}{r}0.09483 \\
0\end{array}$ & 0.133853 & & & & & & & & & & & & & & \\
\hline 45 & & & & & & & & & & & & & & & & \\
\hline
\end{tabular}




\section{Appendix 10}

Relative abundance of the 50 most abundant OTUs in Ecionemia alata, when transplanted between different habitats. Values represent the percentage of all sequence reads for a given sample. Information is reported at 97\% sequence similarity See Appendix 9 for abbreviations.

\begin{tabular}{|c|c|c|c|c|c|c|c|c|c|c|c|c|c|c|c|c|c|}
\hline & ECH1 & $\mathrm{ECH} 2$ & ECH3 & ECH4 & EDC1 & EDC2 & EDC3 & EDC4 & ETHL1 & ETHL2 & ETHL4 & ETHL5 & ETLH1 & ETLH2 & ETLH3 & ETLH5 & ETLH6 \\
\hline Otu001 & 0.00 & 0.00 & 0.00 & 0.16 & 0.00 & 0.00 & 0.00 & 0.00 & 0.00 & 0.05 & 0.00 & 0.00 & 0.00 & 0.00 & 0.00 & 0.00 & 0.00 \\
\hline Otu002 & 0.00 & 0.00 & 0.05 & 0.02 & 0.00 & 0.00 & 0.00 & 0.00 & 0.00 & 0.05 & 0.00 & 0.00 & 0.00 & 0.02 & 0.03 & 0.00 & 0.00 \\
\hline Otu003 & 6.68 & 1.86 & 4.93 & 6.90 & 4.63 & 7.45 & 4.81 & 3.83 & 3.72 & 4.66 & 4.15 & 3.67 & 5.44 & 4.78 & 5.23 & 5.07 & 4.88 \\
\hline Otu004 & 0.00 & 0.00 & 0.00 & 0.21 & 0.00 & 0.00 & 0.00 & 0.00 & 0.00 & 0.00 & 0.00 & 0.00 & 0.00 & 0.00 & 0.00 & 0.00 & 0.00 \\
\hline Otu005 & 0.00 & 0.00 & 0.07 & 0.00 & 0.00 & 0.00 & 0.00 & 0.00 & 0.00 & 0.00 & 0.00 & 0.00 & 0.00 & 0.00 & 0.00 & 0.00 & 0.00 \\
\hline Otu006 & 2.25 & 2.04 & 8.49 & 3.34 & 1.77 & 1.82 & 1.40 & 3.32 & 3.07 & 1.90 & 3.86 & 3.34 & 4.84 & 7.25 & 1.35 & 2.97 & 1.18 \\
\hline Otu007 & 0.41 & 6.63 & 0.86 & 4.06 & 1.65 & 2.32 & 2.23 & 1.65 & 2.99 & 2.31 & 5.96 & 2.80 & 3.64 & 1.81 & 2.82 & 5.18 & 2.89 \\
\hline Otu008 & 3.49 & 2.14 & 3.09 & 3.23 & 2.66 & 2.90 & 4.46 & 3.32 & 1.08 & 2.36 & 2.53 & 3.09 & 3.20 & 2.30 & 1.93 & 3.81 & 2.61 \\
\hline Otu009 & 2.84 & 3.05 & 2.60 & 1.90 & 3.33 & 2.24 & 1.47 & 2.60 & 5.23 & 3.38 & 2.02 & 2.46 & 1.44 & 3.67 & 3.77 & 2.08 & 3.38 \\
\hline Otu010 & 1.24 & 6.32 & 0.44 & 5.05 & 0.56 & 0.75 & 1.31 & 1.25 & 3.97 & 3.65 & 2.13 & 2.71 & 3.56 & 3.38 & 2.62 & 2.58 & 2.54 \\
\hline Otu011 & 2.05 & 2.40 & 1.87 & 2.82 & 2.27 & 1.95 & 2.99 & 3.76 & 2.89 & 5.47 & 1.70 & 3.26 & 4.00 & 2.15 & 2.24 & 1.66 & 2.34 \\
\hline Otu012 & 1.75 & 3.78 & 3.85 & 2.70 & 4.34 & 2.28 & 2.80 & 1.91 & 2.79 & 1.82 & 1.19 & 2.30 & 3.52 & 2.97 & 2.42 & 2.34 & 1.21 \\
\hline Otu013 & 0.00 & 0.00 & 0.00 & 0.00 & 0.00 & 0.00 & 0.00 & 0.00 & 0.00 & 0.00 & 0.00 & 0.00 & 0.00 & 0.00 & 0.00 & 0.00 & 0.00 \\
\hline Otu014 & 2.29 & 3.05 & 1.84 & 1.01 & 2.36 & 1.45 & 2.48 & 1.84 & 2.76 & 1.45 & 3.21 & 2.55 & 1.80 & 3.17 & 3.83 & 2.21 & 2.32 \\
\hline Otu015 & 1.90 & 0.33 & 2.21 & 3.89 & 0.97 & 1.53 & 1.94 & 3.00 & 2.09 & 3.86 & 2.64 & 2.67 & 2.88 & 0.72 & 2.10 & 2.76 & 2.29 \\
\hline Otu016 & 2.55 & 2.94 & 2.53 & 1.55 & 3.10 & 0.75 & 0.83 & 1.44 & 2.16 & 2.12 & 2.28 & 1.96 & 1.28 & 2.03 & 1.81 & 2.58 & 2.74 \\
\hline Otu017 & 2.53 & 2.23 & 1.89 & 1.96 & 1.42 & 1.78 & 1.98 & 1.97 & 3.17 & 0.56 & 3.14 & 2.59 & 1.76 & 1.55 & 2.44 & 2.38 & 2.15 \\
\hline Otu018 & 2.16 & 3.24 & 2.45 & 0.47 & 1.42 & 1.66 & 1.85 & 2.74 & 2.49 & 2.52 & 0.36 & 1.84 & 2.16 & 2.20 & 2.67 & 2.21 & 2.42 \\
\hline Otu019 & 1.99 & 2.51 & 2.16 & 1.44 & 1.59 & 1.28 & 0.83 & 3.37 & 1.23 & 1.77 & 3.07 & 1.29 & 0.92 & 1.62 & 2.16 & 1.14 & 2.49 \\
\hline
\end{tabular}




\begin{tabular}{|c|c|c|c|c|c|c|c|c|c|c|c|c|c|c|c|c|c|}
\hline \multicolumn{18}{|c|}{ Appendix 10. Continued } \\
\hline Otu020 & 2.49 & 1.67 & 1.30 & 2.07 & 1.56 & 3.15 & 1.24 & 1.91 & 1.91 & 2.39 & 1.88 & 1.67 & 0.88 & 0.89 & 0.95 & 3.04 & 1.33 \\
\hline Otu021 & 1.94 & 1.01 & 1.57 & 2.09 & 1.09 & 1.33 & 2.77 & 1.72 & 1.83 & 2.44 & 2.35 & 1.21 & 2.04 & 1.64 & 2.67 & 1.49 & 1.36 \\
\hline Otu022 & 1.53 & 2.77 & 1.74 & 1.85 & 2.33 & 2.15 & 1.43 & 1.28 & 1.48 & 2.20 & 0.47 & 1.88 & 1.68 & 1.38 & 2.13 & 1.29 & 2.12 \\
\hline Otu023 & 1.75 & 1.97 & 1.03 & 1.41 & 2.60 & 1.45 & 1.40 & 1.77 & 2.36 & 1.47 & 1.01 & 3.09 & 1.28 & 1.26 & 2.59 & 0.74 & 1.28 \\
\hline Otu024 & 1.29 & 1.34 & 2.45 & 0.74 & 1.00 & 1.53 & 2.55 & 1.30 & 0.78 & 1.74 & 1.91 & 0.88 & 1.80 & 1.21 & 1.24 & 0.83 & 0.96 \\
\hline Otu025 & 1.44 & 1.15 & 1.40 & 0.76 & 1.42 & 1.66 & 0.54 & 1.18 & 1.48 & 1.61 & 1.73 & 1.38 & 1.12 & 1.50 & 1.35 & 1.66 & 0.79 \\
\hline Otu026 & 0.74 & 1.03 & 1.28 & 1.22 & 0.44 & 1.41 & 1.18 & 0.86 & 1.86 & 1.21 & 1.95 & 0.88 & 0.44 & 1.01 & 1.96 & 1.38 & 1.90 \\
\hline Otu027 & 0.89 & 1.36 & 0.54 & 0.92 & 1.00 & 1.28 & 1.37 & 1.25 & 1.21 & 1.34 & 0.83 & 1.96 & 0.92 & 1.04 & 1.55 & 0.77 & 1.26 \\
\hline Otu028 & 1.72 & 1.03 & 0.83 & 1.46 & 1.06 & 1.90 & 1.18 & 0.93 & 1.08 & 1.18 & 1.01 & 1.17 & 0.84 & 0.85 & 0.98 & 0.66 & 0.67 \\
\hline Otu029 & 0.92 & 1.62 & 0.39 & 0.63 & 0.89 & 1.12 & 0.64 & 1.42 & 1.41 & 0.83 & 0.98 & 0.92 & 2.28 & 0.87 & 2.42 & 0.87 & 0.99 \\
\hline Otu030 & 2.03 & 0.49 & 0.37 & 0.35 & 1.71 & 1.70 & 0.48 & 0.44 & 1.03 & 1.26 & 0.76 & 1.38 & 2.00 & 2.13 & 1.04 & 0.96 & 1.01 \\
\hline Otu031 & 2.92 & 0.00 & 0.81 & 0.62 & 2.92 & 0.04 & 1.91 & 0.86 & 1.53 & 0.21 & 1.59 & 0.17 & 1.48 & 1.57 & 0.12 & 0.09 & 0.91 \\
\hline Otu032 & 0.65 & 0.63 & 1.47 & 0.40 & 2.74 & 0.33 & 1.50 & 0.84 & 0.45 & 0.67 & 1.73 & 0.33 & 0.00 & 1.47 & 0.58 & 1.64 & 1.33 \\
\hline Otu033 & 0.55 & 1.67 & 0.98 & 1.08 & 1.00 & 0.54 & 0.80 & 0.77 & 0.60 & 1.02 & 0.79 & 0.88 & 0.36 & 1.84 & 0.86 & 1.27 & 0.52 \\
\hline Otu034 & 0.57 & 0.61 & 1.03 & 1.09 & 1.06 & 1.04 & 1.53 & 1.49 & 0.95 & 1.05 & 0.40 & 0.71 & 1.04 & 0.51 & 0.55 & 0.87 & 1.41 \\
\hline Otu035 & 0.92 & 0.92 & 0.66 & 1.49 & 0.71 & 1.53 & 1.08 & 0.67 & 1.31 & 0.67 & 0.43 & 1.25 & 1.64 & 0.80 & 0.89 & 0.68 & 0.49 \\
\hline Otu036 & 1.35 & 1.03 & 1.37 & 1.17 & 0.89 & 1.45 & 0.64 & 0.70 & 0.30 & 0.11 & 1.37 & 0.63 & 0.32 & 1.26 & 0.83 & 1.25 & 0.84 \\
\hline Otu037 & 0.89 & 0.52 & 0.54 & 0.46 & 0.97 & 2.28 & 1.66 & 0.95 & 0.38 & 0.80 & 0.65 & 0.38 & 0.80 & 1.40 & 1.27 & 1.36 & 0.59 \\
\hline Otu038 & 1.13 & 0.70 & 0.86 & 0.79 & 1.39 & 1.78 & 0.83 & 0.46 & 0.18 & 1.18 & 0.29 & 1.04 & 0.16 & 1.04 & 0.75 & 0.87 & 1.75 \\
\hline Otu039 & 0.13 & 0.02 & 0.34 & 0.33 & 0.50 & 1.16 & 0.61 & 0.74 & 0.00 & 0.03 & 0.18 & 0.63 & 0.80 & 0.94 & 0.35 & 0.35 & 0.12 \\
\hline Otu040 & 1.40 & 0.92 & 0.32 & 1.08 & 0.27 & 1.70 & 0.67 & 0.53 & 0.83 & 0.91 & 0.18 & 0.42 & 0.48 & 0.85 & 1.32 & 1.40 & 0.69 \\
\hline Otu041 & 1.11 & 0.38 & 1.57 & 0.93 & 0.41 & 1.04 & 1.72 & 0.70 & 0.75 & 0.19 & 0.61 & 0.13 & 0.36 & 0.60 & 0.83 & 1.40 & 0.74 \\
\hline
\end{tabular}




\begin{tabular}{|c|c|c|c|c|c|c|c|c|c|c|c|c|c|c|c|c|c|}
\hline \multicolumn{18}{|c|}{ Appendix 10. Continued } \\
\hline Otu042 & 0.50 & 0.63 & 0.74 & 0.89 & 0.09 & 0.95 & 1.31 & 0.98 & 0.63 & 0.78 & 1.77 & 0.96 & 0.68 & 2.01 & 0.32 & 0.35 & 0.54 \\
\hline Otu043 & 1.68 & 0.85 & 1.40 & 1.39 & 1.42 & 0.87 & 1.12 & 0.58 & 0.63 & 0.19 & 0.18 & 0.75 & 0.04 & 0.12 & 0.63 & 0.24 & 0.79 \\
\hline Otu044 & 0.52 & 1.20 & 0.37 & 1.82 & 2.63 & 0.08 & 0.35 & 0.21 & 0.23 & 1.61 & 1.05 & 0.00 & 0.16 & 0.31 & 0.98 & 0.57 & 0.54 \\
\hline Otu045 & 0.26 & 0.61 & 0.12 & 0.47 & 0.68 & 0.21 & 1.72 & 0.63 & 1.86 & 0.78 & 1.08 & 2.00 & 1.48 & 0.56 & 0.69 & 0.44 & 0.57 \\
\hline Otu046 & 0.57 & 0.49 & 0.59 & 1.09 & 1.68 & 0.46 & 1.12 & 0.42 & 0.90 & 0.24 & 0.58 & 0.79 & 0.92 & 0.63 & 0.49 & 1.14 & 0.72 \\
\hline Otu047 & 0.44 & 0.94 & 0.74 & 0.59 & 1.24 & 0.25 & 0.45 & 1.05 & 0.60 & 0.51 & 0.69 & 1.21 & 0.52 & 0.27 & 1.12 & 1.22 & 0.86 \\
\hline Otu048 & 0.74 & 0.02 & 1.03 & 0.70 & 1.68 & 0.70 & 0.57 & 1.05 & 0.25 & 0.88 & 0.69 & 1.29 & 1.28 & 0.56 & 0.92 & 0.33 & 0.57 \\
\hline Otu049 & 0.68 & 1.01 & 0.25 & 0.44 & 0.62 & 0.58 & 0.61 & 0.44 & 0.98 & 1.66 & 0.40 & 0.38 & 1.52 & 0.82 & 0.52 & 0.46 & 0.81 \\
\hline Otu050 & 0.70 & 0.54 & 0.12 & 0.43 & 0.38 & 0.17 & 0.35 & 0.98 & 0.90 & 0.97 & 1.70 & 0.46 & 0.60 & 1.23 & 1.06 & 0.31 & 0.72 \\
\hline
\end{tabular}




\section{Appendix 11}

Relative abundance of the 50 most abundant OTUs in Tethya bergquistae, when transplanted between different habitats. Values represent the percentage of all sequence reads for a given sample. Information is reported at 97\% sequence similarity See Appendix 9 for abbreviations.

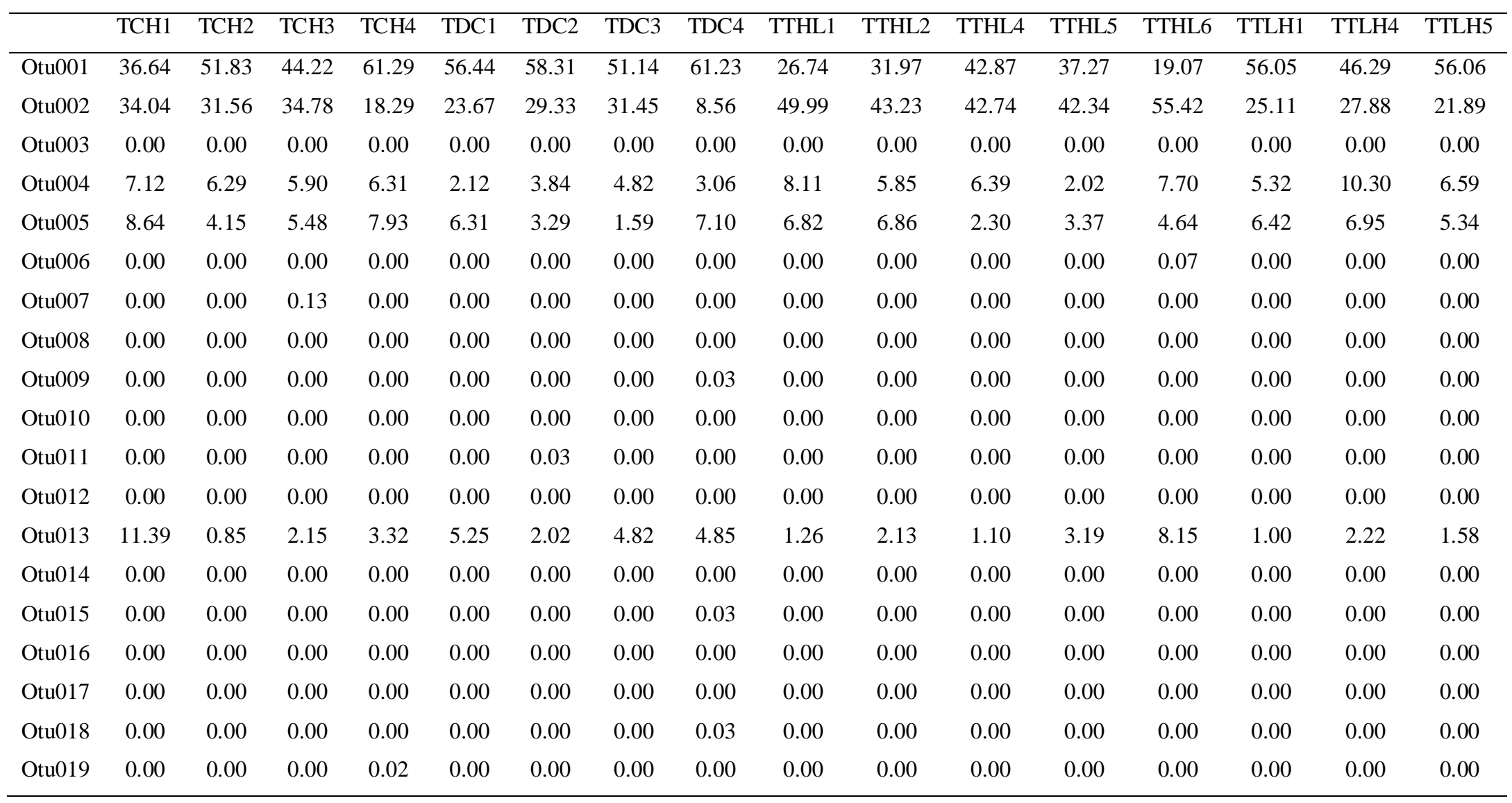




\begin{tabular}{|c|c|c|c|c|c|c|c|c|c|c|c|c|c|c|c|c|}
\hline & ppen & 11. $\mathrm{C}$ & inued & & & & & & & & & & & & & \\
\hline Otu020 & 0.00 & 0.00 & 0.00 & 0.00 & 0.00 & 0.00 & 0.00 & 0.00 & 0.00 & 0.00 & 0.00 & 0.00 & 0.00 & 0.00 & 0.00 & 0.00 \\
\hline Otu021 & 0.00 & 0.00 & 0.00 & 0.00 & 0.00 & 0.00 & 0.00 & 0.00 & 0.00 & 0.00 & 0.00 & 0.00 & 0.00 & 0.00 & 0.00 & 0.00 \\
\hline Otu022 & 0.00 & 0.00 & 0.00 & 0.00 & 0.00 & 0.00 & 0.00 & 0.00 & 0.00 & 0.00 & 0.00 & 0.00 & 0.00 & 0.00 & 0.00 & 0.00 \\
\hline Otu023 & 0.00 & 0.00 & 0.00 & 0.00 & 0.00 & 0.03 & 0.00 & 0.00 & 0.00 & 0.00 & 0.00 & 0.00 & 0.00 & 0.00 & 0.00 & 0.00 \\
\hline Otu024 & 0.00 & 0.00 & 0.08 & 0.00 & 0.00 & 0.00 & 0.00 & 0.00 & 0.00 & 0.00 & 0.00 & 0.00 & 0.00 & 0.00 & 0.07 & 0.00 \\
\hline Otu025 & 0.00 & 0.00 & 0.00 & 0.00 & 0.00 & 0.00 & 0.00 & 0.00 & 0.00 & 0.00 & 0.00 & 0.00 & 0.00 & 0.00 & 0.00 & 0.00 \\
\hline Otu026 & 0.00 & 0.00 & 0.00 & 0.00 & 0.00 & 0.00 & 0.00 & 0.00 & 0.00 & 0.00 & 0.00 & 0.00 & 0.22 & 0.00 & 0.00 & 0.00 \\
\hline Otu027 & 0.00 & 0.00 & 0.00 & 0.00 & 0.00 & 0.00 & 0.00 & 0.00 & 0.00 & 0.00 & 0.00 & 0.00 & 0.00 & 0.00 & 0.00 & 0.00 \\
\hline Otu028 & 0.00 & 0.00 & 0.00 & 0.00 & 0.00 & 0.00 & 0.00 & 0.00 & 0.00 & 0.00 & 0.00 & 0.00 & 0.00 & 0.00 & 0.00 & 0.00 \\
\hline Otu029 & 0.00 & 0.00 & 0.00 & 0.00 & 0.00 & 0.00 & 0.00 & 0.00 & 0.00 & 0.00 & 0.00 & 0.00 & 0.00 & 0.00 & 0.00 & 0.00 \\
\hline Otu030 & 0.00 & 0.00 & 0.00 & 0.00 & 0.00 & 0.00 & 0.00 & 0.00 & 0.00 & 0.00 & 0.00 & 0.00 & 0.00 & 0.00 & 0.00 & 0.00 \\
\hline Otu031 & 0.00 & 0.00 & 0.00 & 0.00 & 0.00 & 0.00 & 0.00 & 0.00 & 0.00 & 0.00 & 0.00 & 0.00 & 0.00 & 0.00 & 0.00 & 0.00 \\
\hline Otu032 & 0.00 & 0.00 & 0.00 & 0.00 & 0.00 & 0.00 & 0.00 & 0.00 & 0.00 & 0.00 & 0.00 & 0.00 & 0.00 & 0.00 & 0.00 & 0.00 \\
\hline Otu033 & 0.00 & 0.00 & 0.00 & 0.00 & 0.00 & 0.00 & 0.00 & 0.00 & 0.00 & 0.00 & 0.00 & 0.00 & 0.00 & 0.00 & 0.00 & 0.00 \\
\hline Otu034 & 0.00 & 0.00 & 0.00 & 0.00 & 0.00 & 0.00 & 0.00 & 0.00 & 0.00 & 0.00 & 0.00 & 0.00 & 0.00 & 0.00 & 0.00 & 0.00 \\
\hline Otu035 & 0.00 & 0.00 & 0.00 & 0.00 & 0.00 & 0.00 & 0.00 & 0.03 & 0.00 & 0.00 & 0.00 & 0.00 & 0.00 & 0.00 & 0.00 & 0.00 \\
\hline Otu036 & 0.00 & 0.00 & 0.00 & 0.00 & 0.00 & 0.00 & 0.00 & 0.00 & 0.00 & 0.00 & 0.00 & 0.00 & 0.00 & 0.00 & 0.00 & 0.00 \\
\hline Otu037 & 0.00 & 0.00 & 0.00 & 0.00 & 0.00 & 0.00 & 0.00 & 0.00 & 0.00 & 0.00 & 0.00 & 0.00 & 0.00 & 0.00 & 0.00 & 0.00 \\
\hline Otu038 & 0.00 & 0.00 & 0.00 & 0.00 & 0.00 & 0.00 & 0.00 & 0.00 & 0.00 & 0.00 & 0.00 & 0.00 & 0.00 & 0.00 & 0.00 & 0.00 \\
\hline Otu039 & 0.88 & 0.67 & 2.07 & 0.28 & 0.66 & 0.34 & 0.41 & 1.33 & 0.87 & 0.03 & 0.41 & 0.92 & 1.91 & 0.42 & 0.21 & 0.03 \\
\hline Otu040 & 0.00 & 0.00 & 0.00 & 0.00 & 0.00 & 0.00 & 0.00 & 0.00 & 0.00 & 0.00 & 0.00 & 0.00 & 0.00 & 0.00 & 0.00 & 0.00 \\
\hline Otu041 & 0.00 & 0.00 & 0.00 & 0.00 & 0.00 & 0.00 & 0.00 & 0.00 & 0.00 & 0.00 & 0.00 & 0.00 & 0.00 & 0.00 & 0.00 & 0.00 \\
\hline
\end{tabular}




\begin{tabular}{|c|c|c|c|c|c|c|c|c|c|c|c|c|c|c|c|c|}
\hline \multicolumn{17}{|c|}{ Appendix 11. Continued } \\
\hline Otu042 & 0.00 & 0.00 & 0.00 & 0.00 & 0.00 & 0.00 & 0.00 & 0.00 & 0.00 & 0.00 & 0.00 & 0.00 & 0.00 & 0.00 & 0.00 & 0.00 \\
\hline Otu043 & 0.00 & 0.00 & 0.00 & 0.00 & 0.00 & 0.00 & 0.00 & 0.00 & 0.00 & 0.00 & 0.00 & 0.00 & 0.00 & 0.00 & 0.00 & 0.00 \\
\hline Otu044 & 0.00 & 0.00 & 0.00 & 0.00 & 0.00 & 0.00 & 0.00 & 0.00 & 0.00 & 0.00 & 0.00 & 0.00 & 0.00 & 0.00 & 0.00 & 0.00 \\
\hline Otu045 & 0.00 & 0.00 & 0.00 & 0.00 & 0.00 & 0.00 & 0.00 & 0.00 & 0.00 & 0.00 & 0.00 & 0.00 & 0.00 & 0.00 & 0.00 & 0.00 \\
\hline Otu046 & 0.00 & 0.00 & 0.00 & 0.00 & 0.00 & 0.00 & 0.00 & 0.00 & 0.00 & 0.00 & 0.00 & 0.00 & 0.00 & 0.00 & 0.00 & 0.00 \\
\hline Otu047 & 0.00 & 0.00 & 0.00 & 0.00 & 0.00 & 0.00 & 0.00 & 0.00 & 0.00 & 0.00 & 0.00 & 0.00 & 0.00 & 0.00 & 0.00 & 0.00 \\
\hline Otu048 & 0.00 & 0.00 & 0.00 & 0.00 & 0.00 & 0.00 & 0.00 & 0.00 & 0.00 & 0.00 & 0.00 & 0.00 & 0.00 & 0.00 & 0.00 & 0.00 \\
\hline Otu049 & 0.00 & 0.00 & 0.00 & 0.00 & 0.00 & 0.00 & 0.00 & 0.00 & 0.00 & 0.00 & 0.00 & 0.00 & 0.00 & 0.00 & 0.00 & 0.00 \\
\hline Otu050 & 0.00 & 0.00 & 0.00 & 0.00 & 0.00 & 0.00 & 0.00 & 0.00 & 0.00 & 0.00 & 0.00 & 0.00 & 0.00 & 0.00 & 0.00 & 0.00 \\
\hline
\end{tabular}




\section{Appendix 12}

Taxonomic assignment of the 50 most abundant OUTs in Ecionemia alata and Tethya bergquistae, when transplanted between different habitats.

\begin{tabular}{|c|c|}
\hline & Classification \\
\hline Otu001 & Proteobacteria/Betaproteobacteria/unclassified_Betaproteobacteria/unclassified_Betaproteobacteria \\
\hline Otu002 & Proteobacteria/Gammaproteobacteria/unclassified_Gammaproteobacteria \\
\hline Otu003 & Poribacteria \\
\hline Otu004 & Proteobacteria/Alphaproteobacteria/Rhizobiales/unclassified_Rhizobiales \\
\hline Otu005 & Bacteroidetes/Sphingobacteria/Sphingobacteriales/Flammeovirgaceae/Flammeovirgaceae/Acidimicrobineae/Iamiaceae \\
\hline Otu006 & Actinobacteria/Actinobacteria/Acidimicrobidae/Acidimicrobiales/ \\
\hline Otu007 & Actinobacteria/Actinobacteria/Acidimicrobidae/Acidimicrobiales/Acidimicrobineae/Iamiaceae \\
\hline Otu008 & Chloroflexi/unclassified_Chloroflexi \\
\hline Otu009 & Nitrospira/Nitrospira/Nitrospirales/Nitrospiraceae/Nitrospira \\
\hline Otu010 & Bacteroidetes/Sphingobacteria/Sphingobacteriales/Rhodothermaceae/Salisaeta \\
\hline Otu011 & Chloroflexi/Caldilineae/Caldilineales/Caldilineaceae/Caldilinea \\
\hline Otu012 & Acidobacteria/Acidobacteria/Acidobacteria_Gp9/Gp9 \\
\hline Otu013 & Proteobacteria/Gammaproteobacteria/Chromatiales/Ectothiorhodospiraceae/Thioalkalispira \\
\hline Otu014 & Proteobacteria/Alphaproteobacteria/Rhodospirillales/Rhodospirillaceae/unclassified_Rhodospirillaceae \\
\hline Otu015 & Poribacteria \\
\hline Otu016 & Proteobacteria/Gammaproteobacteria/ Chromatiales/Ectothiorhodospiraceae/unclassified_Ectothiorhodospiraceae \\
\hline Otu017 & Chloroflexi/unclassified_Chloroflexi \\
\hline Otu018 & SAUL \\
\hline
\end{tabular}




\begin{tabular}{|c|c|}
\hline \multicolumn{2}{|c|}{ Appendix 12. Continued } \\
\hline Otu019 & Proteobacteria/Gammaproteobacteria/Chromatiales/unclassified_Chromatiales \\
\hline Otu020 & Poribacteria \\
\hline Otu021 & Proteobacteria/Deltaproteobacteria/unclassified_Deltaproteobacteria \\
\hline Otu022 & Proteobacteria \\
\hline Otu023 & Gemmatimonadetes/Gemmatimonadetes/Gemmatimonadales/Gemmatimonadaceae/ \\
\hline Otu024 & Proteobacteria/Deltaproteobacteria/unclassified_Deltaproteobacteria \\
\hline Otu025 & Proteobacteria/Gammaproteobacteria/unclassified_Gammaproteobacteria \\
\hline Otu026 & Proteobacteria/Deltaproteobacteria/unclassified_Deltaproteobacteria \\
\hline Otu027 & SAUL \\
\hline Otu028 & SAUL \\
\hline Otu029 & Actinobacteria/Actinobacteria/Acidimicrobidae/Acidimicrobiales/Acidimicrobineae/Iamiaceae \\
\hline Otu030 & Gemmatimonadetes/Gemmatimonadetes/Gemmatimonadales/Gemmatimonadaceae \\
\hline Otu031 & Poribacteria \\
\hline Otu032 & Gemmatimonadetes/Gemmatimonadetes/Gemmatimonadales \\
\hline Otu033 & Proteobacteria/Gammaproteobacteria/Chromatiales/unclassified_Chromatiales \\
\hline Otu034 & Chloroflexi/unclassified_Chloroflexi \\
\hline Otu035 & Chloroflexi/unclassified_Chloroflexi \\
\hline Otu036 & Proteobacteria/Alphaproteobacteria/Rhodospirillales/Rhodospirillaceae/unclassified_Rhodospirillaceae \\
\hline Otu037 & Spirochaetes/Spirochaetes/Spirochaetales/Spirochaetaceae \\
\hline Otu038 & Acidobacteria/Acidobacteria_Gp6/Gp6/ \\
\hline Otu039 & Proteobacteria/Gammaproteobacteria/Oceanospirillales/Hahellaceae/Endozoicomonas \\
\hline Otu040 & Proteobacteria/Deltaproteobacteria/unclassified_Deltaproteobacteria \\
\hline
\end{tabular}




\begin{tabular}{ll}
\hline Appendix 12. Continued \\
\hline Otu041 & Poribacteria \\
Otu042 & Acidobacteria/Acidobacteria_Gp10/Gp10 \\
Otu043 & Chloroflexi/unclassified_Chloroflexi \\
Otu044 & Proteobacteria/Gammaproteobacteria/unclassified_Gammaproteobacteria \\
Otu045 & Proteobacteria/Gammaproteobacteria/unclassified_Gammaproteobacteria \\
Otu046 & Chloroflexi/unclassified_Chloroflexi \\
Otu047 & Acidobacteria/Acidobacteria_Gp3/Gp3 \\
Otu048 & Acidobacteria/Acidobacteria_Gp11/Gp11 \\
Otu049 & Acidobacteria/Acidobacteria_Gp6/Gp6 \\
Otu050 & Chloroflexi/unclassified_Chloroflexi \\
\hline
\end{tabular}




\section{Appendix 13}

Cárdenas CA, Davy SK \& Bell JJ (2012) Correlations between algal abundance, environmental variables and sponge distribution patterns on southern hemisphere temperate rocky reefs. Aquatic Biology 16: 229-239. 


\begin{tabular}{c|c|c}
\hline \hline $\begin{array}{c}\text { Vol. 16: 229-239, 2012 } \\
\text { doi: } 10.3354 / a b 00449\end{array}$ & $\begin{array}{c}\text { AQUATIC BIOLOGY } \\
\text { Aquat Biol }\end{array}$ & Published September 5 \\
\hline \hline
\end{tabular}

\title{
Correlations between algal abundance, environmental variables and sponge distribution patterns on southern hemisphere temperate rocky reefs
}

\author{
César A. Cárdenas*, Simon K. Davy, James J. Bell \\ School of Biological Sciences, Victoria University of Wellington, PO Box 600, Wellington 6140, New Zealand
}

\begin{abstract}
Sponges are important components of temperate rocky reefs whose abundance and diversity are influenced by a range of biological and physical factors. In high light environments, sponges are generally less abundant and are often restricted to shaded microhabitats. However, this generalisation stems primarily from research conducted in the northern hemisphere, with comparatively little information from the southern hemisphere. The aim of the present study was to examine correlations between sponge abundance and assemblage composition and between algal abundance and environmental variables. We measured the distribution patterns of sponges relative to macroalgal abundance, physical factors (including depth, surface inclination, turbidity, rugosity and temperature) and the abundance of other phyletic groups at multiple sites in New Zealand. A negative correlation was found between sponge abundance and algal abundance, with surface inclination strongly correlating with the distribution patterns of both groups. Our results support the generalisation from previous studies in the northern hemisphere that sponge and algal abundance are negatively correlated.
\end{abstract}

KEY WORDS: Sponge - Macroalgae - Distribution patterns - Competition - Shallow water · Rocky reefs

Resale or republication not permitted without written consent of the publisher

\section{INTRODUCTION}

Sponges are abundant components of rocky benthic communities in temperate (Ayling 1983, Bell \& Barnes 2000a), tropical (Diaz et al. 1990, Diaz \& Rützler 2001, Bell \& Smith 2004, de Voogd et al. 2009) and polar regions (Dayton et al. 1974, Barthel et al. 1991, Sarà et al. 1992, Teixidó 2003) whose abundance patterns are strongly influenced by a range of biological and physical factors. For example, the distribution and abundance patterns of sponges are strongly influenced by depth (Bell \& Barnes 2000d), water flow (Bell \& Barnes 2003), sedimentation (Carballo 2006), predation (Ayling 1981), salinity (Roberts et al. 2006), nutrient concentrations (Wilkinson \& Evans 1989), substrate type and angle (Bell \& Barnes 2000b), and turbidity (Zea 1994). In addition, a num- ber of these earlier studies suggest that these factors can indirectly influence sponges through their effects on other organisms; for example, light influences the abundance of algae, a potential spatial competitor of sponges. Separating the relative importance of these different factors remains challenging, and far less is known about how biological factors influence sponges compared to physical factors, particularly in the southern hemisphere.

Although sponges are dominant in many habitats, they are often restricted to the undersides of boulders or shaded surfaces in high light environments where macroalgae are abundant (Baynes 1999, Irving \& Connell 2002, Konar \& Iken 2005). Several authors have tried to clarify the spatial relationships between sponges and algae and have examined correlations between these 2 groups. For example, Bell \& Barnes 
$(2000 a, b)$ proposed that the higher diversity of sponges on vertical surfaces, compared to horizontal surfaces, was a result of reduced light intensity, resulting in reduced algal abundance. Furthermore, these authors also found strong correlations between depth and sponge abundance; where algal abundance declined, sponge abundance increased. Bell $(2002,2007)$ suggested that such negative correlations between sponges and algae might be explained by sponges only being able to persist in areas that are unsuitable or less suitable for algae or by sponges preferring habitats that are less favourable for algae (i.e. low light). Konar \& Iken (2005) proposed that the dominance of algae over sponges on the tops of boulders was the result of micro-habitat differences among surface orientations, including differences in sediment load and light intensity, preventing sponges from occurring on horizontal surfaces (Wilkinson \& Vacelet 1979, Maldonado et al. 2008). More recently, Preciado \& Maldonado (2005) found that substratum inclination strongly correlated with sponge and algal distribution patterns, suggesting that substratum inclination was the main factor structuring sponge assemblages in the shallow waters of the Mediterranean. These authors found that sponges were mostly restricted to overhangs, where factors considered to be detrimental to sponges (e.g. high light and high sedimentation) are reduced (Wilkinson \& Vacelet 1979, Jokiel 1980, Ginn et al. 2000, Roberts et al. 2006). However, in contrast to these results from northern hemisphere studies, no correlation was found between sponge and macroalgae abundance in rocky reefs on the south-east coast of Australia (Knott et al. 2004).

While there has been comparatively less study of the correlations between sponge and algal abundance in the southern hemisphere, the information that is available for correlations between sponges and algae seems to contrast with that from the better studied northern hemisphere. Therefore, the aims of our study were to: (1) re-examine the correlations between sponge abundance and distribution patterns with algal abundance and other environmental variables at study sites in the southern hemisphere; and (2) consider the specific influence of depth and surface inclination on sponge abundance and assemblage structure because these 2 variables are also likely to influence algal abundance.

\section{MATERIALS AND METHODS}

\section{Study sites}

Subtidal surveys were carried out at 7 sites along the south coast of Wellington and at Kapiti Island on the coast of North Island in New Zealand. Study sites on the coast of Wellington included Breaker Bay, Barrett Reef, Palmer Head, Princess Bay and The Sirens Rocks; the 2 sites studied at Kapiti Island were Trig Point and Kaiwharawhara Point (Fig. 1).

The Wellington coast sites were chosen to represent a wide range of different environmental and biological characteristics, enabling us to determine which factor or combination of factors best explained sponge spatial distribution patterns. The sites were characterised by the presence of relatively continuous bedrock and steep walls. The Wellington coast is an energetic environment that is subjected to regular southerly swells that move onto the Wellington shelf $>80 \%$ of the time (Carter \& Lewis 1995). The algal assemblage is mainly dominated by Ecklonia radiata and a mixture of Carpophyllum spp., Lessonia variegata and Landsburgia quercifolia (Shears \& Babcock 2007). The understory is dominated by crustose coralline algae (CCA), and the overall abundance of
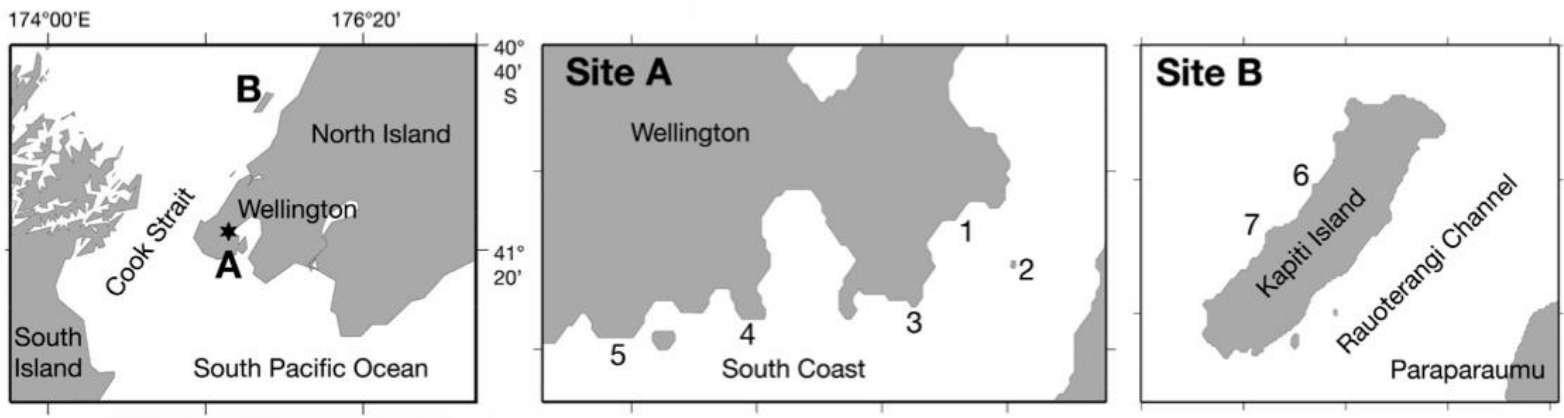

Fig. 1. Location of study sites at Site A: south coast of Wellington, and Site B: Kapiti Island, New Zealand. 1: Breaker Bay; 2: Barrett Reef; 3: Palmer Head; 4: Princess Bay; 5: The Sirens Rocks; 6: Trig Point; 7: Kaiwharawhara Point 
sessile invertebrates has been reported to be low (Shears \& Babcock 2007). Nevertheless, recently Berman \& Bell (2010) reported a diverse sponge assemblage in this region, where sponge cover exceeds $50 \%$ of the substratum at some sites.

Kapiti Island is located off the west coast of the North Island of New Zealand, $\sim 50 \mathrm{~km}$ north of Wellington. Our study sites were located on the west coast of the island and are exposed to relatively strong tidal currents and regular strong north-westerly or south-westerly winds (Chiswell \& Stevens 2010). The area is characterised by an extensive boulder reef and larger blocks of bedrock (Baxter 1987). The habitats are dominated by a mixed Ecklonia radiata/Carpophyllum spp. forest in the shallow zone and forest consisting of only E. radiata in the deeper zone (below $10 \mathrm{~m}$ ). The understory contains a rich community of turf algae, bryozoans, sponges and ascidians (Battershill et al. 1993, Shears \& Babcock 2007).

\section{Sampling}

Surveys were conducted by SCUBA at 2 depths ( 5 and $15 \mathrm{~m}$ ) at each site. Breaker Bay and The Sirens Rocks were only surveyed at $5 \mathrm{~m}$ because of the absence of rocky reefs below $10 \mathrm{~m}$. At each depth, a series of five $0.25 \mathrm{~m}^{2}$ quadrats were haphazardly placed on the benthos and photographed with a digital camera (all sites had similar levels of available vertical, horizontal, inclined and overhanging surfaces). Quadrats were photographed in 2 layers: canopy (first layer) and understory (second layer). Quadrats were subdivided into 4 smaller sections to improve the level of resolution for the different groups of organisms. Each quarter was photographed, first with the canopy in place and then after the canopy was moved aside, and the picture quality enabled even the smallest sponge patches $(<1 \mathrm{~mm})$ to be identified. Depth was measured using a dive computer (UWATEC Smart Pro). Additional information was collected for each quadrat, including inclination, rugosity and orientation with respect to the dominant swells (as a surrogate of exposure). The inclination angle was categorised into horizontal $\left(\sim 0^{\circ}\right)$, inclined $\left(\sim 45^{\circ}\right)$, vertical $\left(\sim 90^{\circ}\right)$ and overhanging surfaces $\left(\sim 125^{\circ}\right)$. The rugosity was estimated in situ by measuring the bottom contour distance between the corners of the quadrat. Subsequently, a rugosity index was estimated based on the ratio of the measured bottom contour distance and the straight-line distance between the extremes of the quadrat $(70 \mathrm{~cm})$. The orientation of each quadrat (with respect to dominant swells) was included as an ordinal categorical variable: sheltered (for quadrats facing $\mathrm{W}-\mathrm{NE}$ ) = 0 ; semi-exposed $($ ENE-E) $=1$; exposed $($ SE-SW $)=2$. At each site, physical variables of the water column were recorded at both depths with a CTD (RBR $\mathrm{XR}-420$ ). Variables included turbidity, temperature, salinity, conductivity and chlorophyll (Table 1).

Each photo-quadrat was analysed with CPCe v3.5 (Coral Point Count with Excel extensions; Kohler $\&$ Gill 2006) by superimposing a grid of points onto each picture. The percentage cover of the first layer (canopy) was measured, and then the cover of the second layer containing the sponges, macroalgae (erect non-calcareous algae), coralline algae (erect and encrusting), other encrusting organisms, bare rock and settled sediment was estimated in each quadrat. Settled sediment was estimated as the area of rock surface covered in sediment in each picture. Organisms were placed in the following categories: Porifera, Hydrozoa, Anthozoa, Polychaeta, Bryozoa, Ascidiacea, Rhodophyta (erect non-calcareous algae), Chlorophyta, Phaeophyta and CCA. Abiotic categories included bare rock and sediment. Percentage cover estimates were made for each category/taxon. All taxa in the photo-quadrats were identified to the lowest taxonomic level possible. A grid of 100 points was superimposed over each photo-quadrat to estimate canopy cover, and 100 points were used for each section of the quadrat (4 for each quadrat) to estimate the cover of the understory ( 400 points in total).

\section{Data analysis}

The number of sponge taxa was estimated for each quadrat, and mean values were obtained for each site. To estimate the mean number of sponge species for the different surface inclinations, the number of species per quadrat, for each inclination, was combined to obtain a mean value for each surface inclination across all sites for each depth. Differences in the mean number of species between sites ( 7 levels, random), depth (2 levels, fixed) and surface inclinations (4 levels, fixed) were tested using a permutational ANOVA (PERMANOVA) (Anderson 2001).

The percentage cover of organisms, bare rock and settled sediment were averaged across quadrats for comparisons among sites $(\mathrm{n}=8$ per site as there were 2 depths, except for those sites where only $5 \mathrm{~m}$ was sampled; see 'Sampling'). The same routine was undertaken for comparisons among depths ( $\mathrm{n}=$ 5 per depth) and surface inclinations $\left(n_{\text {horizontal }}=19\right.$; 
Table 1. Mean values $( \pm 1 \mathrm{SE})$ for the physical parameters of the water column measured at each study site on the south coast of Wellington and at Kapiti Island

\begin{tabular}{|lrcrrrr|}
\hline Site & $\begin{array}{c}\text { Depth } \\
(\mathrm{m})\end{array}$ & $\begin{array}{c}\text { Temperature } \\
\left({ }^{\circ} \mathrm{C}\right)\end{array}$ & $\begin{array}{c}\text { Salinity } \\
(\mathrm{PSU})\end{array}$ & $\begin{array}{c}\text { Turbidity } \\
(\mathrm{NTU})\end{array}$ & $\begin{array}{c}\text { Chlorophyll } \\
\left(\mu \mathrm{g} \mathrm{l^{-1 }}\right)\end{array}$ & $\begin{array}{c}\text { Conductivity } \\
\left(\mathrm{mS} \mathrm{cm}^{-1}\right)\end{array}$ \\
\hline Breaker Bay & 5 & $13.99 \pm 0.04$ & $34.76 \pm 0.02$ & $4.65 \pm 0.75$ & $0.39 \pm 0.06$ & $41.68 \pm 0.01$ \\
Barrett Reef & 5 & $15.25 \pm 0.01$ & $35.17 \pm 0.02$ & $3.00 \pm 0.78$ & $0.65 \pm 0.05$ & $43.34 \pm 0.03$ \\
& 15 & $15.24 \pm 0.01$ & $35.10 \pm 0.07$ & $5.33 \pm 0.65$ & $1.00 \pm 0.08$ & $43.17 \pm 0.08$ \\
Palmer Head & 5 & $16.66 \pm 0.01$ & $34.91 \pm 0.01$ & $1.35 \pm 0.24$ & $0.45 \pm 0.07$ & $44.47 \pm 0.01$ \\
& 15 & $16.53 \pm 0.01$ & $34.90 \pm 0.01$ & $3.35 \pm 0.41$ & $0.40 \pm 0.06$ & $44.71 \pm 0.04$ \\
Princess Bay & 5 & $15.22 \pm 0.01$ & $35.18 \pm 0.01$ & $0.73 \pm 0.01$ & $0.69 \pm 0.01$ & $43.34 \pm 0.01$ \\
& 10 & $14.99 \pm 0.04$ & $35.16 \pm 0.02$ & $8.67 \pm 1.24$ & $0.47 \pm 0.01$ & $43.11 \pm 0.04$ \\
The Sirens Rocks & 5 & $14.56 \pm 0.01$ & $34.73 \pm 0.01$ & $13.03 \pm 0.01$ & $0.39 \pm 0.01$ & $42.19 \pm 0.01$ \\
Kaiwharawhara Point & 5 & $18.14 \pm 0.02$ & $35.10 \pm 0.01$ & $1.88 \pm 0.35$ & $2.2 \pm 0.51$ & $46.17 \pm 0.02$ \\
& 15 & $17.75 \pm 0.01$ & $35.11 \pm 0.02$ & $2.53 \pm 0.42$ & $0.71 \pm 0.01$ & $45.78 \pm 0.01$ \\
Trig Point & 5 & $15.80 \pm 0.01$ & $35.11 \pm 0.01$ & $0.35 \pm 0.01$ & $0.55 \pm 0.01$ & $43.83 \pm 0.01$ \\
& 15 & $15.72 \pm 0.01$ & $35.01 \pm 0.01$ & $11.7 \pm 0.97$ & $0.59 \pm 0.01$ & $43.64 \pm 0.01$ \\
\hline
\end{tabular}

$\mathrm{n}_{\text {inclined }}=12 ; \mathrm{n}_{\text {vertical }}=22 ; \mathrm{n}_{\text {overhanging }}=12$ as data was combined across all sites). Percentage cover data were double square root transformed to downweigh the influence of extreme values (i.e. rare and very abundant species); this enabled us to test for differences in cover between sites, depths and inclinations. PERMANOVA (Anderson 2001) based on a Bray-Curtis similarity matrix (Bray \& Curtis 1957) was performed to test for differences in assemblage structure among these a priori factors. This test was used because the data did not meet the assumptions of normality and equal variance, even after transformation. Factors considered in the analysis were site (5 levels, random), depth (2 levels, fixed) and inclination (4 levels, fixed). Statistical differences were tested using 9999 permutations under a reduced model. PERMANOVA tests were applied to the full dataset to examine multivariate patterns at the category level. PERMANOVA tests were also used to examine differences in the percentage cover of the dominant benthic groups (treated as univariate measures) between sites, depths and inclinations. All procedures were conducted within PRIMER v6 (Clarke \& Gorley 2006, Anderson et al. 2007).

Scatterplots were used to visualise the relationships among sponge, CCA and algal abundance (separated into canopy and understory), and the curve fitter option in the software SlideWrite v5 (Advanced Graphics Software 1999) was used to fit linear and non-linear functions to plots to determine the best fit to the data. The curve fitter function fits 40 different linear functions and 60 different non-linear functions (10 exponential, 25 power and 25 polynomial) to each scatter plot. For the non-linear functions, the method employs the Levenberg-Marquardt algorithm in an unconstrained optimisation approach to estimate the coefficients of the equation (Advanced Graphics Software 1999).

To analyse the relationship between the percentage cover of benthic organisms and the different environmental factors and biological groups, an ordination method was applied using CANOCO v4.5 (ter Braak \& Smilauer 2002). Two ordination analyses were performed to test the relationship between organisms and environmental variables. The first analysis was for the whole data set to analyse the overall community at the category level, and the second analysis included sponges at species level. To downweigh the influence of rare species, the cover data were double square root transformed. The environmental and biological variables used in the analysis were inclination, depth, orientation, turbidity, rugosity, water temperature, salinity, conductivity, percentage cover of CCA, percentage cover of canopy algae (first layer), algal understory (erect algae-second layer) and percentage of settled sediment on the substrate. Detrended canonical correspondence analysis (DCCA) was conducted to calculate the gradient length. DCCA yielded a short gradient $(>3)$ for both cases, and a redundancy analysis (RDA) was then applied (ter Braak \& Smilauer 2002, Leps \& Smilauer 2003). A Monte-Carlo test was used to test the statistical significance of the first axis and all canonical axes combined using 9999 permutations under the reduced model. Automatic selections of variables were used to identify the 5 most significant variables. The variance inflation factors (VIF) were used to assess linear dependencies among the variables. Variables with a VIF $<5$ were maintained in the analysis. RDA results were represented graphically in a scaling bi-plot (2dimensional ordination), focusing on inter-species 
distances. Categories/species were graphically represented as circles and variables as vectors. The vectors show the direction in which the value of the variable of interest increases, and the length shows its relative importance in explaining species' distributions. The category/species symbols can be projected onto the vectors (variables) to approximate the optimal individual category/species with respect to values of the variable.

\section{RESULTS}

\section{Sponge species richness}

The mean $( \pm \mathrm{SE})$ number of taxa per quadrat varied between sites (PERMANOVA, $\mathrm{p}<0.05$; Table 2); the lowest value was observed at Princess Bay (3.6 \pm $1.00)$ and the highest at Breaker Bay $(13.5 \pm 1.32)$, with the latter site significantly different from the majority of the other sites (Fig. 2a). Although the area sampled by each quadrat was small $\left(0.25 \mathrm{~m}^{2}\right)$, the high values obtained for species richness suggest that quadrat size did not significantly bias our sampling. No differences were found in the number of taxa per quadrat between depths (PERMANOVA, $p>0.05)$. The number of taxa per quadrat ranged between $6.9( \pm 0.92)$ at $15 \mathrm{~m}$ and $7.9( \pm 0.92)$ at $5 \mathrm{~m}$. The mean number of taxa per quadrat varied significantly between surface inclinations (PERMANOVA, $\mathrm{p}<0.05$; Table 2), ranging from 2.92 ( \pm 0.57 ) on horizontal surfaces to 13.3 ( \pm 0.92 ) on overhanging surfaces (Fig. 2b). In most cases, the species richness differed between inclination types (Fig. 2).

\section{Distribution patterns of benthic organisms}

The mean $( \pm \mathrm{SE})$ percentage cover of CCA differed among sites (PERMANOVA, $\mathrm{p}<0.05$ ) and was greatest at Palmer Head $(53.7 \pm 4.4 \%)$ and lowest at Trig Point $(21.4 \pm 4.5 \%)$. Red erect algae (Rhodophyta) was most abundant at Barrett Reef, with a mean percentage cover of $17 \%$, while Phaeophyta was most conspicuous at Kapiti Island sites, with $14 \%$ cover; differences among sites were significant (Table 3 ). Chlorophyta abundance was generally low and was only abundant at Princess Bay and The Sirens Rocks (Fig. 3a). Sponges were the most conspicuous sessile invertebrates; their mean percentage cover was significantly different among sites (Table 3 ), being highest at Trig Point $(20.6 \pm 3.0 \%)$ and lowest at Princess Bay $(3.9 \pm 1.4 \%)$. Sponge cover was also high at
Table 2. Permutational analysis of variance (PERMANOVA) based on a Bray-Curtis similarity matrix, testing the effect of site ( 7 levels, random), depth (2 levels, fixed) and inclination (4 levels, fixed) on species/taxa richness. Statistical differences were tested using 9999 permutations under a reduced model. " $\mathrm{p}<0.05$

\begin{tabular}{|lcccl|}
\hline Factor & df & MS & $F$ & $p$ \\
\hline Site & 6 & 2121.5 & 2.5893 & $0.018^{*}$ \\
Depth & 1 & 149.07 & 0.1429 & 0.8708 \\
Inclination & 3 & 2134.9 & 3.1509 & $0.0197^{*}$ \\
Site $\times$ Depth & 4 & 1190.9 & 1.4535 & 0.235 \\
Site $\times$ Inclination & 12 & 7508.3 & 0.7636 & 0.672 \\
Depth $\times$ Inclination & 3 & 2370 & 0.7568 & 0.6347 \\
Site $\times$ Depth $\times$ Incl. & 3 & 3214.2 & 1.3076 & 0.2823 \\
Residual & 32 & 819.34 & & \\
Total & 64 & & & \\
\hline
\end{tabular}
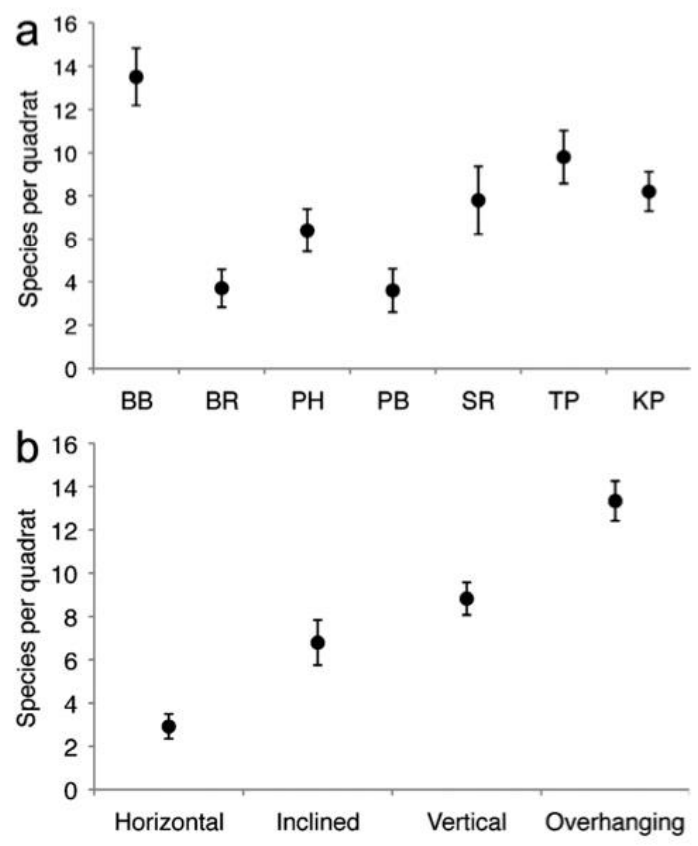

Fig. 2. (a) Mean $( \pm \mathrm{SE})$ sponge species richness recorded at different sites. (b) Mean $( \pm \mathrm{SE}$ ) species richness recorded for surface inclinations. BB: Breaker Bay; BR: Barrett Reef; PH: Palmer Head; PB: Princess Bay; SR: The Sirens Rocks; TP: Trig Point; KP: Kaiwharawhara Point. Percentage cover values of each sample were pooled for each site and surface inclination. Pairwise comparisons for sites showed significant differences between $\mathrm{BR}$ and $\mathrm{BB}, \mathrm{KP}$ and $\mathrm{BB}, \mathrm{PB}$ and $\mathrm{BB}, \mathrm{PH}$ and $\mathrm{PB}, \mathrm{SR}$ and $\mathrm{BB}, \mathrm{TP}$ and $\mathrm{BR}, \mathrm{PB}$ and $\mathrm{KP}$ and TP and $\mathrm{PB}$ $(p<0.05)$. Significant differences were found in all comparisons between inclinations, except for vertical vs. inclined $(\mathrm{p}>0.05)$ 
The Sirens Rocks and Breaker Bay in Wellington (Fig. 3a), where both sites were characterised by the presence of steep-walled channels.

Differences in community structure were found among sites (PERMANOVA, $\mathrm{p}<0.001$; Table 4) and types of surface inclinations; there was also a significant interaction between site and depth (PERMANOVA, $p<0.05$; Table 4 ), meaning that the effect of depth varied among sites. There was a significant effect of depth at Barrett Reef, Princess Bay and Kaiwharawhara Point (PERMANOVA, $p<0.05$ ) but not at Palmer Head and Trig Point $(p>0.05)$. The greatest differences in community structure were observed between Trig Point at Kapiti Island and most of the sites on the Wellington south coast, except Breaker Bay, which was more similar to the sites studied at Kapiti Island than the sites located in Wellington. Percentage cover of sponges, CCA and red erect algae varied between depths (PERMANOVA, $p<0.001)$, whereas no differences were found in the cover of Phaeophyta and Chlorophyta (PERMANOVA, $p>0.05$; Table 3).

We also found significant differences in sponge percentage cover (mean $\pm \mathrm{SE}$ ) on different surface inclinations, ranging from $5.5 \pm 2.0 \%$ on horizontal surfaces to $38.8 \pm 5.8 \%$ on overhanging surfaces (PERMANOVA, $\mathrm{p}<0.001$; Table 3). In contrast, the cover of erect algae decreased with increasing inclination, having the lowest abundance on overhangs (PERMANOVA, $p<0.001$; Fig. 3b). CCA had lowest abundance on inclined surfaces $(42.8 \pm 6.44 \%)$ and highest abundance on overhangs $(13.7 \pm 7.67 \%$; PERMANOVA, $\mathrm{p}<0.05)$. Canopy cover was greatest at Palmer Head, with $89 \pm 3.3 \%$ cover at $5 \mathrm{~m}$ and 39 $\pm 11.2 \%$ at $15 \mathrm{~m}$. Sites at Kapiti Island showed the same pattern of decreased canopy cover with depth. The most important canopy-forming species were Ecklonia radiata, Lessonia variegata and Carpophyllum maschalocarpum.

When sponge abundance was correlated with algal cover and canopy cover, an exponential relationship was observed in both cases (Fig. 4). However, the lat-
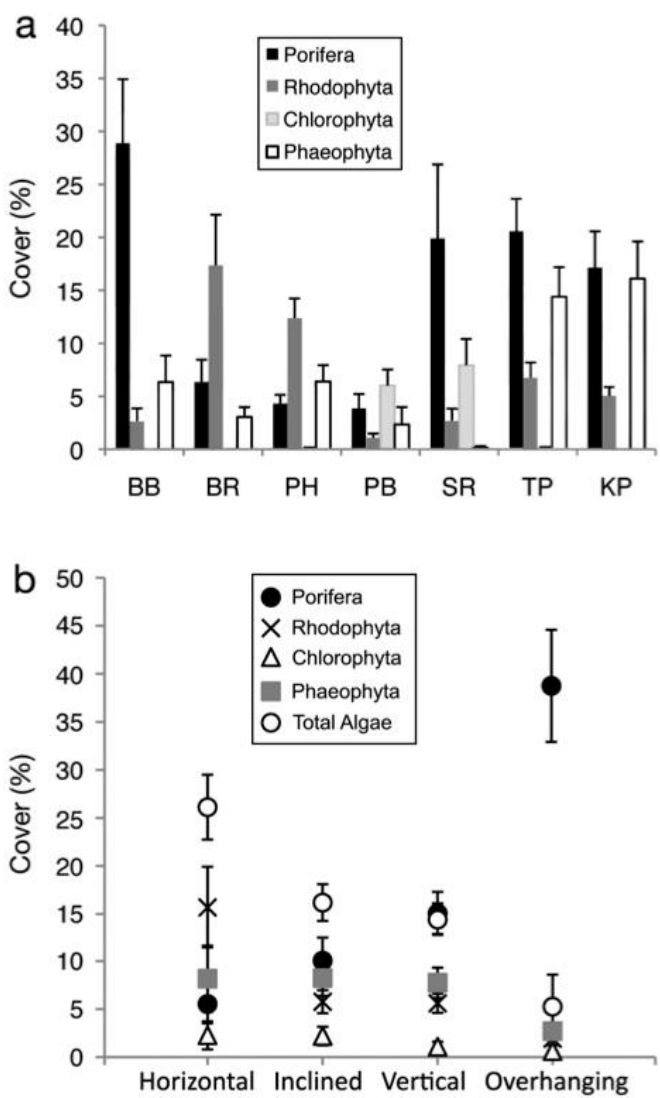

Fig. 3. (a) Mean ( \pm SE) percent cover of sponges and macroalgae across sites studied on the south coast of Wellington and at Kapiti Island. See Fig. 2 for site labels. (b) Mean $( \pm \mathrm{SE})$ percent cover of sponges and macroalgae for different surface inclinations. Percentage cover values for each sample were pooled for each surface inclination

ter correlation was weak $\left(\mathrm{r}^{2}=0.387, \mathrm{p}<0.001\right)$. Nonetheless, when sponge cover was correlated against canopy cover (first layer), a significant negative correlation was found $\left(r^{2}=0.546, p<0.001\right)$. Linear relationships fitted to both data sets were much

Table 3. PERMANOVA to test for differences between sites, depths and inclinations in the percentage cover of dominant benthic groups. Statistical differences were tested using 9999 permutations of raw data. ${ }^{*} p<0.05,{ }^{* *} p<0.001$

\begin{tabular}{|c|c|c|c|c|c|c|}
\hline \multirow{2}{*}{ Taxa } & \multicolumn{2}{|c|}{ Site } & \multicolumn{2}{|c|}{ - Depth } & \multicolumn{2}{|c|}{ Inclination } \\
\hline & $F(\mathrm{df})$ & $\mathrm{p}$ & $F(\mathrm{df})$ & $\mathrm{p}$ & $F(\mathrm{df})$ & $\mathrm{p}$ \\
\hline Porifera & $4.9068(6,64)$ & $0.0001^{* *}$ & $4.733(1,64)$ & 0.057 & $5.3415(3,64)$ & $0.0002^{* *}$ \\
\hline Rhodophyta & $10.664(6,64)$ & $0.001^{* *}$ & $6.1242(1,64)$ & $0.014^{*}$ & $4.7227(3,64)$ & $0.002^{* *}$ \\
\hline Chlorophyta & $27.983(6,64)$ & $0.0001^{* *}$ & $0.2080(1,64)$ & 0.6693 & $0.5095(3,64)$ & 0.6936 \\
\hline Phaeophyta & $4.796(6,64)$ & $0.0001^{* *}$ & $1.9618(1,64)$ & 0.1398 & $1.5838(3,64)$ & 0.1665 \\
\hline $\mathrm{CCA}$ & $2.4961(6,64)$ & $0.0227^{*}$ & $7.2963(1,64)$ & $0.0045^{* *}$ & $6.9703(3,64)$ & $0.0004^{* *}$ \\
\hline
\end{tabular}


Table 4. PERMANOVA based on a Bray-Curtis similarity variation in the community -

Relationships between algal abundance, environmental variables and benthic assemblages

The variation in community composition relative to the different environmental variables is shown in Fig. 5a. The first 2 axes accounted for $64.4 \%$ of the mined mainly by canopy cover $(\mathrm{r}=-0.61)$, inclination $(\mathrm{r}=0.56)$ and CCA $(\mathrm{r}=-0.49)$, and the second axis was determined by algal abundance $(r=-0.43)$. The RDA showed that most taxa were highly correlated with inclination. The majority of sponge taxa were negatively correlated with algal canopy cover (first layer), and algal understory and CCA, whereas a few species, such as Polymastia crocea and Haliclona sp.
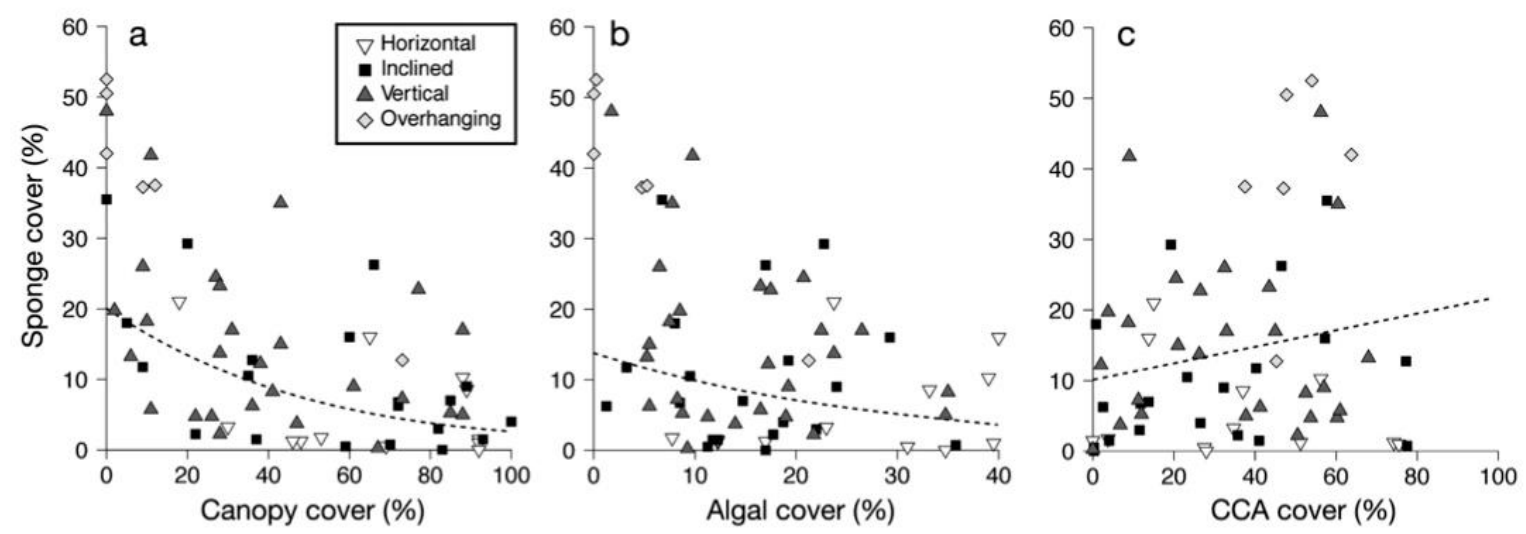

Fig. 4. (a) Relationship between sponge and canopy cover per quadrat $\left(y=35.2678 \times \exp ^{-0.0296 x}, r^{2}=0.546, p<0.001\right)$. (b) Relationship between sponge and macroalgae cover per quadrat $\left(y=35.3829 \times \exp ^{-0.0799 x}, \mathrm{r}^{2}=0.387, \mathrm{p}<0.001\right)$. (c) Relationship between sponge and crustose coralline algae (CCA) cover per quadrat $\left(y=\exp ^{0.0415 x}, \mathrm{r}^{2}=0.004, \mathrm{p}<0.001\right)$. Curves were fitted by the SlideWrite curve fitter (Advanced Graphics Software 1999). Scale for $x$-axis differs among panels 

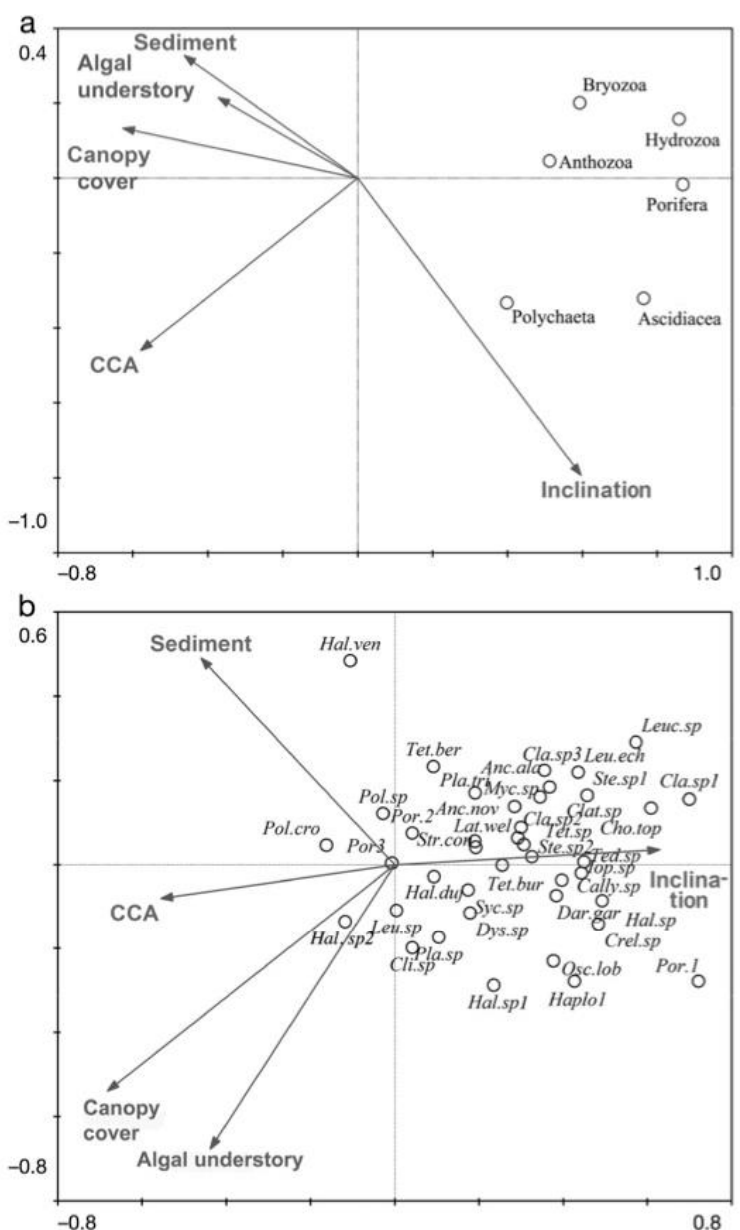

Fig. 5. Ordination plot of (a) the overall community and variables and (b) sponge assemblages and variables based on a redundancy analysis (RDA-biplot). Vectors represent the environmental variables, and species are represented as circles. Anc.ala: Ancorina alata; Anc.nov: Ancorina novaezelandiae; Cally.sp: Callyspongia sp.; Cho.top: Chondropsis topsenti; Clat.sp: Clathria sp.; Cla.sp1: Clathrina sp. 1; Cla.sp2: Clathrina sp. 2; Cla.sp3: Clathrina sp. 3; Cli.sp: Cliona sp.; Crel.sp: Crella sp.; Dar.gar: Darwinella sp.; Dys.sp: Dysidea sp.; Hal.sp 1: Haliclona sp. 1; Hal.sp 2: Haliclona sp. 2; Hal.ven: Haliclona venustina; Hal.duj: Halisarca dujardini; Hal.sp: Halisarca sp.; Iop.sp: Iophon sp.; Lat.wel: Latruncullia wellingtonensis Leuc.sp: Leucetta sp.; Leu.ech: Leucosolenia echinata; Leu.sp: Leucosolenia sp.; Myc.sp: Mycale sp.; Osc.lob: Oscarella lobularis; Pla.tri: Plakina trilopha; Pla.sp: Plakina sp.; Pol.cro: Polymastia crocea; Pol.sp: Polymastia sp. Por.1: Unidentified Porifera 1; Por.2: Unidentified Porifera 2; Por.3: Unidentified Porifera 3; Ste.sp1: Stelletta sp. 1; Ste.sp2: Stelletta sp. 2; Str.con: Strongylacidon conulosum; Syc.sp: Sycon sp.; Ted.sp: Tedania sp.; Tet.ber. Tethya bergquistae; Tet.bur: Tethya burtoni;

Tet.sp: Tethya sp.; Haplo1: Unidentified haplosclerid 1
2 , were positively correlated with these variables. The settled sediment cover on the substratum negatively correlated with the abundance of the majority of the sponge species, with most being associated with low levels of settled sediment. Some species, such as Tedania sp., Oscarella lobularis and the calcareous sponges Clathrina spp. and Leucosolenia echinata, were more abundant on vertical and overhanging surfaces.

\section{DISCUSSION}

Supporting previous studies from the northern hemisphere, we found that sponge abundance and richness were strongly correlated with surface inclination. We also found a negative correlation between sponge abundance and the abundance of erect algae, CCA (note that this was only based on the result of the RDA) and especially algal canopy cover. A considerable number of sponge species $(>80 \%$ ) were strongly positively associated with the degree of surface inclination and turbidity and negatively correlated with the percentage of canopy, CCA and erect algal cover. In contrast, only a few sponge species were positively correlated with algae. This is in contrast to what was reported for the Mediterranean by Preciado \& Maldonado (2005), where a higher proportion of species were strongly correlated with algal abundance.

Despite the overall negative correlation between sponge and algal abundance that we observed, some individual species showed the reverse pattern. It is possible that some sponge species, such as Polymastia spp. and Haliclona sp. 2, might be adapted to high light habitats that are generally dominated by fastgrowing algae. Turon et al. (1998) found that growth rates were higher for sponges inhabiting high-light habitats compared to shaded habitats in the western Mediterranean. These authors argued that these sponge species have an opportunistic strategy in such habitats, which are dominated by fast-growing algae that might outcompete the sponges when space is limited, as the sponges are able to colonise the patches of bare substratum that frequently become available when algae die (because algae tend to be short lived).

The low explanatory value obtained when overall sponge cover was correlated with algal and CCA cover is most likely a result of the high variability recorded in the sponge cover, as we considered sponges as a single group, rather than constituent species. This problem could explain why other au- 
thors have not found a negative relationship between both groups, as it is difficult to show a clear pattern if different sponges show different responses to algal abundance and other environmental factors. Supporting this, our analysis at species level showed variable responses by different sponge species to algal abundance; however, negative correlations were much more common. Previous studies have reported contrasting patterns with respect to the effect of algal canopies on sponge species. For example, Kennelly $(1987,1989)$ did not find any relationship between shade or scour produced by Ecklonia radiata on the growth and abundance of the sponge Myxilla sp. in Australia. However, Eckman \& Duggins (1991) found that higher sedimentation rates existed beneath kelp canopies in Washington (USA), but this did not result in higher mortality of Myxilla sp.; however, these authors also found that sediment deposition negatively affected the sponge's growth (noting that their study organisms had been collected from a sediment-free environment). Thus, the probability of finding a negative effect of light and sedimentation were highly likely because it has been demonstrated that both factors may be detrimental for some species (Jokiel 1980, Maldonado et al. 2008). In contrast, some sponge species appear to be positively influenced by conditions (e.g. shade and sedimentation) that occur underneath the canopy (Smith 1996, Bulleri et al. 2002).

The effect of surface inclination on sessile organisms has been considered extensively (Barnes 1995, Turon et al. 1998, Baynes 1999, Bell \& Barnes 2000b,c, Maughan \& Barnes 2000, Bell 2001, Irving \& Connell 2002, Knott et al. 2006, Walker et al. 2007). Generally, sessile invertebrates are more abundant on vertical and overhanging surfaces compared to inclined and horizontal surfaces (Witman \& Sebens 1990, Baynes 1999, Irving \& Connell 2002, Konar \& Iken 2005). Different surface inclinations have been previously correlated with differences in the composition and diversity of sponge assemblages (Bell \& Barnes 2000b,c, Bell \& Smith 2004) as well as the growth of some species (Knott et al. 2006). Our results support these previous studies and highlight the importance of small-scale environmental variability in influencing sponge assemblage structure. These differences between surface inclinations may be explained by the different levels of disturbance (e.g. from sedimentation) occurring on horizontal compared to vertical or overhanging surfaces, which may affect sponge species and especially competition between sponges and algae (Bell \& Barnes 2000b). Algal whiplash effects will also differ among surface inclinations (see Konar \& Estes 2003) as algal abundance is reduced, which could affect the settlement of sponges. Despite the potential for algalsponge interactions to cause the patterns we reported, Maldonado \& Young (1996) suggested that the dominance of sponges on vertical and overhanging surfaces at bathyal depths, where light and macroalgae do not occur, demonstrate that factors other than competition with macroalgae are responsible for these patterns. However, we believe that in shallow water, competition with macroalgae cannot be discarded as an important factor influencing the distribution of sponges.

Depth has been considered an important factor influencing sponge distribution patterns (Wilkinson \& Evans 1989, Diaz et al. 1990, Witman \& Sebens 1990) through its relationship with physical factors, particularly light, the degree of disturbance from wave action and sedimentation (Wilkinson \& Evans 1989), and its impact on algae as a sponge competitor. Our results showed a significant interaction between site and depth, with depth being important to explain differences in community structure at 3 sites. However, the effect of depth was less important than other physical variables measured at our study sites (e.g. sedimentation).

In conclusion, sponge abundance was negatively correlated with algal abundance, which is consistent with a number of previous studies carried out in northern latitudes, but contradicts findings from an earlier study in the southern hemisphere. Nevertheless, we acknowledge that we have only demonstrated a correlation between these groups, and further manipulative experimental approaches are needed to critically identify the factors and mechanisms explaining the interactions occurring between sponges and the algal canopy. The distribution and abundance of sponges cannot be attributed to substratum inclination alone because this factor also affects algae. In fact, several physical factors, including inclination and settled sediment, as well as biological factors (including the abundance of canopy forming species, erect algae and CCA) correlate with the spatial distribution and abundance of sponge assemblages at our study sites.

Acknowledgements. The authors thank all of the divers and skippers at the Victoria University Coastal Ecology Lab (VUCEL) for help and support during diving activities. We also thank J. Berman for confirming certain sponge identifications and S. Geange, E. Newcombe and T. Jones for their helpful advice. C.A.C. was funded by a CONICYT-VUW PhD Scholarship. 


\section{LITERATURE CITED}

Advanced Graphics Software (1999) SlideWrite Plus user's guide. Advanced Graphics Software, Encinitas, CA

c. Anderson MJ (2001) A new method for non-parametric multivariate analysis of variance. Austral Ecol 26:32-46

Anderson MJ, Gorley RN, Clarke KR (2007) Permanova for PRIMER: guide to software and statistical methods. PRIMER-E, Plymouth

* Ayling AM (1981) The role of biological disturbance in temperate subtidal encrusting communities. Ecology 62: 830-847

*. Ayling AM (1983) Factors affecting the spatial distributions of thinly encrusting sponges from temperate waters. Oecologia 60:412-418

* Barnes DKA (1995) Sublittoral epifaunal communities at Signy Island, Antarctica. II. Below the ice foot zone. Mar Biol 121:565-572

* Barthel D, Gutt J, Tendal OS (1991) New information on the biology of Antarctic deep-water sponges derived from underwater photography. Mar Ecol Prog Ser 69:303-307

Battershill CN, Murdoch RC, Grange KR, Singleton RJ, Arron ES, Page MJ, Oliver MD (1993) A survey of the marine habitats and communities of Kapiti Island. Department of Conservation, Wellington

Baxter A (1987) Kapiti Island: subtidal ecology survey. In: Book 87/2. MAF Central Fisheries Area Internal Report, Napier, New Zealand

Baynes TW (1999) Factors structuring a subtidal encrusting community in the southern Gulf of California. Bull Mar Sci $64: 419-450$

c. Bell JJ (2001) The influence of water flow rate, depth and surface inclination on the density and the distribution of five species of temperate anthozoa at Lough Hyne, Ireland. J Mar Biol Assoc UK 81:883-884

. Bell JJ (2002) The sponge community in a semi-submerged temperate sea cave: density, diversity and richness. PSZN I Mar Ecol 23:297-311

- Bell JJ (2007) The ecology of sponges in Lough Hyne Marine Nature Reserve (south-west Ireland): past, present and future perspectives. J Mar Biol Assoc UK 87:1655-1668

- Bell JJ, Barnes DKA (2000a) A sponge diversity centre within a marine 'island'. Hydrobiologia 440:55-64

2. Bell JJ, Barnes DKA (2000b) The distribution and prevalence of sponges in relation to environmental gradients within a temperate sea lough: inclined cliff surfaces. Divers Distrib 6:305-323

Bell JJ, Barnes DKA (2000c) The distribution and prevalence of sponges in relation to environmental gradients within a temperate sea lough: vertical cliff surfaces. Divers Distrib 6:282-303

* Bell JJ, Barnes DKA (2000d) The influences of bathymetry and flow regime upon the morphology of sublittoral sponge communities. J Mar Biol Assoc UK 80:707-718

Bell JJ, Barnes DKA (2003) Effect of disturbance on assemblages: an example using porifera. Biol Bull 205:144-159

- Bell JJ, Smith D (2004) Ecology of sponge assemblages (Porifera) in the Wakatobi region, south-east Sulawesi, Indonesia: richness and abundance. J Mar Biol Assoc UK 84:581-591

- Berman J, Bell JJ (2010) Spatial variability of sponge assemblages on the Wellington South Coast, New Zealand. The Open Mar Biol J 4:12-25

- Bray JR, Curtis JT (1957) An ordination of the upland forest communities of southern Wisconsin. Ecol Monogr 27:
325-349

- Bulleri F, Benedetti-Cecchi L, Acunto S, Cinelli F, Hawkins SJ (2002) The influence of canopy algae on vertical patterns of distribution of low-shore assemblages on rocky coasts in the northwest Mediterranean. J Exp Mar Biol Ecol 267:89-106

- Carballo JL (2006) Effect of natural sedimentation on the structure of tropical rocky sponge assemblages. Ecoscience 13:119-130

Carter L, Lewis K (1995) Variability of the modern sand cover on a tide and storm driven inner shelf, south Wellington, New Zealand. NZ J Geol Geophys 38:451-470

- Chiswell SM, Stevens CL (2010) Lagrangian and Eulerian estimates of circulation in the lee of Kapiti Island, New Zealand. Cont Shelf Res 30:515-532

Clarke KR, Gorley RN (2006) PRIMER v6: user manual/ tutorial, Vol 1. PRIMER-E, Plymouth

Dayton PK, Robilliard GA, Paine RT, Dayton LB (1974) Biological accommodation in the benthic community at McMurdo Sound, Antarctica. Ecol Monogr 44:105-128

de Voogd NJ, Becking LE, Cleary DFR (2009) Sponge community composition in the Derawan Islands, NE Kalimantan, Indonesia. Mar Ecol Prog Ser 396:169-180

Diaz MC, Rützler K (2001) Sponges: an essential component of Caribbean coral reefs. Bull Mar Sci 69:535-546

Diaz MC, Alvarez B, Laughlin RA (1990) The sponge fauna on a fringing coral reef in Venezuela, II: community structure. In: Rützler K (ed) New perspectives in sponge biology. Smithsonian Institution Press, London, p 367-375

- Eckman JE, Duggins DO (1991) Life and death beneath macrophyte canopies: effects of understory kelps on growth rates and survival of marine, benthic suspension feeders. Oecologia 87:473-487

c. Ginn BK, Logan A, Thomas MLH (2000) Sponge ecology on sublittoral hard substrates in a high current velocity area. Estuar Coast Shelf Sci 50:403-414

- Irving AD, Connell SD (2002) Sedimentation and light penetration interact to maintain heterogeneity of subtidal habitats: algal versus invertebrate dominated assemblages. Mar Ecol Prog Ser 245:83-91

Jokiel PL (1980) Solar ultraviolet radiation and coral reef epifauna. Science 207:1069-1071

. Kennelly SJ (1987) Physical disturbances in an Australian kelp community. II. Effects on understorey species due to differences in kelp cover. Mar Ecol Prog Ser 40:155-165

* Kennelly SJ (1989) Effects of kelp canopies on understorey species due to shade and scour. Mar Ecol Prog Ser 50: 215-224

Knott NA, Underwood AJ, Chapman MG, Glasby TM (2004) Epibiota on vertical and on horizontal surfaces on natural reefs and on artificial structures. J Mar Biol Assoc UK 84: $1117-1130$

Knott NA, Underwood AJ, Chapman MG, Glasby TM (2006) Growth of the encrusting sponge Tedania anhelans (Lieberkuhn) on vertical and on horizontal surfaces of temperate subtidal reefs. Mar Freshw Res 57:95-104

\% Kohler KE, Gill SM (2006) Coral Point Count with Excel extensions (CPCe): a Visual Basic program for the determination of coral and substrate coverage using random point count methodology. Comput Geosci 32:1259-1269

Konar B, Estes JA (2003) The stability of boundary regions between kelp beds and deforested areas. Ecology 84: 174-185

Konar B, Iken K (2005) Competitive dominance among sessile marine organisms in a high Arctic boulder commu- 
nity. Polar Biol 29:61-64

Leps J, Smilauer P (2003) Multivariate analysis of ecological data using CANOCO. Cambridge University Press, Cambridge

* Maldonado M, Young CM (1996) Bathymetric patterns of sponge distribution on the Bahamian slope. Deep-Sea Res I 43:897-915

* Maldonado M, Giraud K, Carmona C (2008) Effects of sediment on the survival of asexually produced sponge recruits. Mar Biol 154:631-641

* Maughan BC, Barnes DKA (2000) Epilithic boulder communities of Lough Hyne, Ireland: the influences of water movement and sediment. J Mar Biol Assoc UK 80: 767-776

c. Preciado I, Maldonado M (2005) Reassessing the spatial relationship between sponges and macroalgae in sublittoral rocky bottoms: a descriptive approach. Helgol Mar Res 59:141-150

. Roberts DE, Davis AR, Cummings SP (2006) Experimental manipulation of shade, silt, nutrients and salinity on the temperate reef sponge Cymbastela concentrica. Mar Ecol Prog Ser 307:143-154

Sarà M, Balduzzi A, Barbieri M, Bavestrello G, Burlando B (1992) Biogeographic traits and checklist of Antarctic demosponges. Polar Biol 12:559-585

Shears N, Babcock R (2007) Quantitative description of mainland New Zealand's shallow subtidal rocky reef communities. Science for Conservation 280, NZ Department of Conservation, Wellington

Smith SDA (1996) The macrofaunal community of Ecklonia radiata holdfasts: variation associated with sediment regime, sponge cover and depth. J Ecol 21:144-153

Editorial responsibility: Sean Connell, Adelaide, Australia
Teixidó N (2003) Analysing benthic communities in the Weddell Sea (Antarctica): a landscape approach. $\mathrm{PhD}$ Thesis, University of Bremen

ter Braak CJF, Smilauer P (2002) CANOCO Reference manual and CanoDraw for Windows user's guide: software for canonical community ordination (version 4.5). Microcomputer Power, Ithaca, NY

. Turon X, Tarjuelo I, Uriz MJ (1998) Growth dynamics and mortality of the encrusting sponge Crambe crambe (Poecilosclerida) in contrasting habitats: correlation with population structure and investment in defence. Funct Ecol 12:631-639

Walker SJ, Schlacher TA, Schlacher-Hoenlinger MA (2007) Spatial heterogeneity of epibenthos on artificial reefs: fouling communities in the early stages of colonization on an East Australian shipwreck. PSZN I Mar Ecol 28: 435-445

- Wilkinson CR, Evans E (1989) Sponge distribution across Davies Reel Great Barrier Reef relative to location, depth, and water movement. Coral Reefs 8:1-7

. Wilkinson CR, Vacelet J (1979) Transplantation of marine sponges to different conditions of light and current. J Exp Mar Biol Ecol 37:91-104

Witman JD, Sebens KP (1990) Distribution and ecology of sponges at a subtidal rock ledge in the Central Gulf of Maine. In: Rützler K (ed) New perspectives in sponge biology. Smithsonian Institution Press, London, p 391-396

Zea S (1994) Patterns of coral and sponge abundance in stressed coral reefs at Santa Marta, Colombian Caribbean. In: van Soest RWM, van Kempen TG, Braekman JC (eds) Sponge in time and space: biology, chemistry, paleontology. AA Balkema, Rotterdam, p 257-264

Submitted: January 20, 2012; Accepted: May 28, 2012 Proofs received from author(s): July 28, 2012 


\section{Appendix 14}

Cárdenas CA, Bell JJ, Davy SK, Hoggard M. \& Taylor M.W. (2014) Influence of environmental variation on symbiotic bacterial communities of two temperate sponges. FEMS Microbiology Ecology 88: 516-527 
RESEARCH ARTICLE

\title{
Influence of environmental variation on symbiotic bacterial communities of two temperate sponges
}

\author{
César A. Cárdenas ${ }^{1}$, James J. Bell ${ }^{1}$, Simon K. Davy ${ }^{1}$, Michael Hoggard² \& Michael W. Taylor ${ }^{2}$
}

${ }^{1}$ School of Biological Sciences, Victoria University of Wellington, Wellington, New Zealand; and ${ }^{2}$ Centre for Microbial Innovation, School of

Biological Sciences, The University of Auckland, Auckland, New Zealand

Correspondence: César A. Cárdenas, School of Biological Sciences, Victoria University of Wellington, PO Box, 600, Wellington 6140 , New Zealand. Tel.: +64 04 4709255; fax: +64 04 3834172;

e-mail: cesar.cardenas@vuw.ac.nz

Received 15 January 2014; revised 27 February 2014; accepted 3 March 2014. Final version published online 26 March 2014.

DOI: 10.1111/1574-6941.12317

Editor: Gary King

\section{Keywords}

sponges; bacteria; temporal variability; environmental factors; pyrosequencing.

\begin{abstract}
Sponges are an important component of temperate subtidal marine ecosystems with a range of important functional roles and extensive symbiotic relationships with microorganisms. However, much remains unknown about their relationships with these symbiotic microorganisms, and specifically, the role that these symbionts play in sponge physiology, feeding and adaptation to local environmental conditions. Changes in environmental factors may alter relationships between sponges and their symbionts, which could conceivably influence the abundance and distribution patterns of some temperate sponge species. Here, we analyzed the effect of transplantation of sponges between different habitats to test the effect of changes in environmental conditions on the stability of the bacterial communities in specimens of Tethya bergquistae and Ecionemia alata, based on pyrosequencing of amplified 16S rRNA genes. Bacterial communities differed markedly between the two host species. While some morphological changes were observed in transplanted sponges, transplantation had little overall effect on sponge-associated bacterial communities at either phylum or 97\%-OTU level. Our results show the importance of host species and also the stability of sponge-associated bacterial communities under environmental variation.
\end{abstract}

\section{Introduction}

Sponges are an important component of temperate subtidal rocky ecosystems and fulfill a range of important functional roles (Bell, 2008). At both tropical and temperate latitudes, sponges have close associations with a wide variety of microorganisms, often harboring abundant and diverse microbial communities (Taylor et al., 2007; Webster \& Blackall, 2009; Schmitt et al., 2012; Webster \& Taylor, 2012). Despite the importance of sponges, much remains unknown about their relationships with the symbiotic communities they harbor, and specifically, the role that these symbionts play in sponge physiology, feeding and adaptation to local environmental conditions. Previous research has shown that microbial communities can be sensitive to environmental perturbation (e.g., Allison \& Martiny, 2008; Nogales et al., 2011) and competition with other organisms (Morrow et al., 2013). Thus, it is important to consider the potential for sponge symbionts to enable sponges to adapt to changing environmental conditions, with recent studies suggesting that microbial symbionts may provide sponges with an adaptive advantage in the face of climate change (Hentschel et al., 2012). However, more research in this area is needed as existing studies have yielded contrasting results, perhaps because some sponges harbor more stable bacterial communities than others (Friedrich et al., 2001; Thoms et al., 2003; Lemoine et al., 2007; Mohamed et al., 2008; Webster et al., 2008; White et al., 2012; Pita et al., 2013; Simister et al., 2013).

A conceptual model proposed by Thacker and Freeman (2012) suggests that environmental factors can alter sponge-microbe symbioses by affecting the balance and interactions between symbionts; however, existing research is largely based on photosymbionts, and the effect of variation in environmental factors on non-photosynthetic microbes remains less certain. Experimental research has led to different outcomes when testing how sponge-associated microbial communities respond to different factors such as nutrients, antibiotics, light, and 
temperature (Friedrich et al., 2001; Lemoine et al., 2007; Webster et al., 2008; Gerçe et al., 2009; Gochfeld et al., 2012; Simister et al., 2012a). For example, Webster et al. (2008) found changes in the microbial community composition of Rhopaloeides odorabile due to a loss of symbionts when exposed to elevated temperatures $\left(2-3{ }^{\circ} \mathrm{C}\right.$ above mean temperature). Lemoine et al. (2007) also found a strong effect of temperature on the symbiotic community harbored by the temperate sponge Halichondria bowerbanki, suggesting a loss or significant reduction in population size of some microbes in response to stress. In contrast, Friedrich et al. (2001) reported relatively stable bacterial communities in space and time in sponges exposed to starvation in laboratory conditions. Furthermore, Simister et al. (2012a) recently reported highly stable microbial communities in $R$. odorabile, with the bacterial community shifting only in necrotic sponges, suggesting that the host (sponge) rather than its symbionts is highly sensitive to increased temperature. Other recent research has addressed the seasonal variability of bacterial symbionts in two Caribbean sponges in Florida, USA, finding slight seasonal shifts and relatively stable microbial communities across two sampling seasons (White et al., 2012). The shifts observed in bacterial communities, however, have often been restricted to rare or low-abundance operational taxonomic units (OTUs) (Anderson et al., 2010; Erwin et al., 2012b; Simister et al., 2013). Simister et al. (2013) suggested that this variation in some OTUs might be due to changes in environmental factors such as water flow and temperature.

The importance of habitat in structuring bacterial composition was highlighted recently for some Caribbean and Indonesian sponges (Cleary et al., 2013; Olson \& Gao, 2013). Small-scale variation in environmental factors can have dramatic effects on the abundance and distribution of sponges in shallow-water temperate rocky reefs (Preciado \& Maldonado, 2005; Abdo et al., 2006; Miller \& Etter, 2011; Cárdenas et al., 2012). Furthermore, factors such as irradiance regime, water movement and sediment are also some of the most influential environmental factors in shaping sponge morphology (Kaandorp, 1999; Bell \& Barnes, 2000; Bell, 2004; Meroz-Fine et al., 2005), while other factors such as temperature influence reproductive traits (Sarà, 1992). However, the effects of environmental variation on the microbial communities associated with temperate sponges remain poorly understood. As sponge microbes also play several critical roles including waste elimination and digestion, chemical defense and nutrient cycling (reviewed by Taylor et al., 2007; Thacker \& Freeman, 2012), it is important to understand the effects of environmental variation on microbial communities and how eventual shifts in bacterial abundance may alter the stability of the bacterial community. The varying results from earlier studies highlight the need for additional research to test how environmental factors occurring in different habitats influence microbial abundance and diversity in temperate regions and, therefore, their potential role in determining the abundance and distribution patterns of sponges.

Here, we examine how the bacterial communities in the New Zealand sponges Ecionemia alata and Tethya bergquistae respond to changes in local environmental conditions. Ecionemia alata and T. bergquistae are two of the most common sponges inhabiting shallow-water rocky reefs in New Zealand (Berman \& Bell, 2010; Berman, 2012). T. bergquistae is abundant on rocky slopes and high-light environments with moderate water movement (Battershill et al., 2010). In contrast, E. alata is more abundant under overhangs or boulders, or in caves, which are areas characterized by low levels of light and sediment compared with high-light habitats (Abdo et al., 2006). A recent study described a diverse and abundant microbial community in E. alata (as Ancorina alata) collected from rocky reefs of the northern part of New Zealand (Simister et al., 2013). In contrast, microbes associated with $T$. bergquistae have not been previously described. Because of their abundance and ecological distribution, we considered these as suitable species for comparative studies to test the stability of sponge-associated microbial communities when transplanted to different habitats.

\section{Materials and methods}

\section{Sampling and experimental design}

The study site was located at The Sirens Rocks $\left(41^{\circ} 21^{\prime} \mathrm{S}\right.$, $174^{\circ} 46^{\prime} \mathrm{E}$ ), Taputeranga Marine Reserve, on the south coast of Wellington, New Zealand. In December 2012, four specimens each of E. alata and T. bergquistae were collected, while SCUBA diving from high-light habitats and four specimens of each species were collected from cracks, caves or underneath boulders (low-light habitats) at c. 6-9 m depth. Additionally, six specimens of each species were collected from high-light habitats and transplanted to walled channels (low-light habitats) and vice versa. Irradiance levels present in high-light habitats were $108.32 \mu \mathrm{mol}$ quanta $\mathrm{m}^{-2} \mathrm{~s}^{-1} \pm 7.03 \mathrm{SE}$, and $7.21 \mu \mathrm{mol}$ quanta $\mathrm{m}^{-2} \mathrm{~s}^{-1} \pm 0.63 \mathrm{SE}$ in low-light habitats. Irradiance levels were measured following the sampling procedure used by Morelissen et al. (2013). Sponges and a small piece of attached rock were collected using a hammer and chisel. Collected specimens were transported and maintained in the Victoria University Coastal and Ecology Laboratory (VUCEL) aquarium system for 1 week. Each specimen was glued onto a $15 \times 15 \mathrm{~cm}$ polyvinyl 
chloride (PVC) plate using underwater epoxy resin (Carboguard A-788 Splashzone). Each plate was labeled and transported to the field at The Sirens Rocks, where it was attached by cable ties to a piece of wood c. $1 \mathrm{~m}$ long (hereafter referred to as a 'sponge array'). Each sponge array was assigned to a treatment and deployed at 6-9 m depth in high- $\left(98.66 \pm 5.92 \mu \mathrm{mol}\right.$ quanta $\left.\mathrm{m}^{-2} \mathrm{~s}^{-1}\right)$ or low-light habitats $\left(8.66 \pm 0.97 \mu \mathrm{mol}\right.$ quanta $\left.\mathrm{m}^{-2} \mathrm{~s}^{-1}\right)$, where it was re-attached to the substratum by stainless steel bolts. The health status and morphological changes of transplanted sponges were visually checked after 3 and 6 weeks. Transplanted sponge individuals were collected after 6 weeks. From each specimen, tissue samples were collected following the sampling procedure described by Taylor et al. (2004). Tissue samples (containing ectosome and choanosome layers) collected from experiments were immediately frozen for at least $24 \mathrm{~h}$ and subsequently lyophilized (by freeze-drying) and stored at $-80^{\circ} \mathrm{C}$ for subsequent DNA extraction. Prior to extraction, samples were homogenized by crushing. In the case of $T$. bergquistae, it was necessary to crush samples using a sterile mortar and pestle with liquid nitrogen.

\section{DNA extraction}

DNA was extracted from $5 \mathrm{mg}$ of freeze-dried sponge tissue by bead-beating (Taylor et al., 2004). Briefly, $1 \mathrm{~mL}$ of extraction buffer $(400 \mu \mathrm{L} 6.25 \mathrm{M}$ ammonium acetate; $100 \mu \mathrm{L} 1 \mathrm{M}$ Tris $(\mathrm{pH} 8.0$ ); $40 \mu \mathrm{L} 0.5 \mathrm{M}$ EDTA; $460 \mu \mathrm{L}$ molecular grade water) was added to a polypropylene tube containing $200 \mu \mathrm{L}$ of $0.1 \mathrm{~mm}$ silica beads (Biospec Products), $0.015 \mathrm{~g}$ polyvinylpolypyrrolidone, $300 \mu \mathrm{L}$ of chloroform : isoamyl alcohol $(24: 1)$, and the sample. Bead-beating was performed in a FastPrep FP120 BIO101 bead beater, followed by centrifugation $(30 \mathrm{~min}, 15$ $000 \mathrm{~g}, 15^{\circ} \mathrm{C}$ ) and collection of the supernatant. This was then precipitated for $1 \mathrm{~h}$ at room temperature with $3 \mathrm{M}$ sodium acetate and isopropanol, followed by centrifugation for $30 \mathrm{~min}\left(15000 \mathrm{~g}, 4^{\circ} \mathrm{C}\right)$. Pellets were washed twice with $70 \%$ ethanol, dried, and resuspended in $50 \mu \mathrm{L}$ molecular grade water.

\section{PCR and pyrosequencing of 16S rRNA genes}

Pyrosequencing of amplified bacterial 16S rRNA genes was carried out essentially as described by Simister et al. (2012a). The $16 \mathrm{~S}$ rRNA-specific primers (targeting the V4-V5 region) were 454MID_533F (GTGCCAGCAG CYGCGGTMA) and 454_907RC (CCGTCAATTMMYTT GAGTTT), with FLX Titanium adaptors (A adaptor on forward, B adaptor on reverse primer) and a multiplex identifier (MID) sequence on the forward primer. Each $50-\mu \mathrm{L}$ PCR reaction mixture contained $25 \mu \mathrm{L}$ GoTaq
(Promega), $1.25 \mu \mathrm{L}$ of each primer (10 $\mu \mathrm{M}$ stock), $0.5 \mu \mathrm{L}$ $1 \%$ BSA, $19.5 \mu \mathrm{L}$ sterile water and c. $250 \mathrm{ng}$ DNA template. Touchdown PCR conditions were as follows: $3 \mathrm{~min}$ at $94{ }^{\circ} \mathrm{C}$ followed by 20 cycles of $30 \mathrm{~s}$ at $94{ }^{\circ} \mathrm{C}, 30 \mathrm{~s}$ at $60{ }^{\circ} \mathrm{C}\left(-0.5^{\circ} \mathrm{C}\right.$ per cycle), and $45 \mathrm{~s}$ at $72{ }^{\circ} \mathrm{C}$. This was followed by a further 12 cycles of $30 \mathrm{~s}$ at $94{ }^{\circ} \mathrm{C}, 30 \mathrm{~s}$ at $50{ }^{\circ} \mathrm{C}$, and $45 \mathrm{~s}$ at $72{ }^{\circ} \mathrm{C}$, with a final extension of $10 \mathrm{~min}$ at $70{ }^{\circ} \mathrm{C}$ (Simister et al., 2012a). PCR products were electrophoresed on $1 \%$ agarose gels containing $0.5 \mu \mathrm{g} \mathrm{mL} \mathrm{m}^{-1}$ ethidium bromide, and those products of correct size were purified with AMPure XP magnetic beads (Agencourt, Beckman Coulter). Amplicon quality was checked on a Bioanalyzer 2100 DNA 1000 chip (Agilent Technologies) and quantified using PicoGreen (Quant-iT dsDNA kit, Invitrogen). Pyrosequencing was performed by Macrogen Inc. (Seoul, South Korea) using the Roche GS FLX Titanium system. Sequences obtained in this study are deposited in the Sequence Read Archive at GenBank under accession numbers SAMN25847372584769 .

\section{Processing of raw sequence data}

Sequences were filtered and denoised using the MOTHUR (Schloss et al., 2009) implementation of AMPLiconNoIsE (Quince et al., 2011). Sequences were removed from the analysis if they were $<200 \mathrm{bp}$, contained ambiguous characters, or had homopolymers longer than $8 \mathrm{bp}$, more than one MID mismatch, or more than two mismatches to the reverse primer sequence. Unique sequences were identified with MOTHUR, aligned against a SILVA alignment (available at http://www.mothur.org/wiki/Silva_reference_alignment), and chimeric sequences were identified using UCHIME (Edgar et al., 2011). Remaining sequences were grouped into $95 \%, 97 \%$, and $99 \%$ OTUs based on uncorrected pairwise distance matrices. As subsequent analyses revealed only negligible differences between the three OTU definitions, only 97\%-OTU data are presented here. A representative sequence of each OTU was used for the taxonomic assignment using custom PERL scripts, similar to a previously used approach (Webster et al., 2010; Schmitt et al., 2012; Simister et al., 2012a). Each pyrotag sequence was subjected to a BLAST search (Altschul et al., 1990) against a manually modified sILVA database (Simister et al., 2012b). A Smith-Waterman algorithm was used to create pairwise global alignments between the 10 best hits against a tag sequence. For assignment, the most similar sequence to the pyrotag sequence (or multiple sequences if within a range of $0.1 \%$ sequence divergence) was used. In cases where the taxonomy of the most similar sequences was inconsistent, a majority rule was applied, and the tag was only assigned if $\geq 60 \%$ of all reference sequences shared the same taxonomic annotation. 


\section{Analysis of high-quality sequence data}

MOTHUR was used to calculate Chaol richness estimates and rarefaction curves based on $97 \%$ OTUs. The magnitude of change in bacterial abundance on each treatment was calculated for each phylum/OTU by normalizing the number of reads per phylum/OTU, per sample. Furthermore, the 25 OTUs with the highest number of sequences were selected for more detailed analysis, and results were visualized as heat maps generated by using JCOLORGRID (Joachimiak et al., 2006). We conducted analysis of variance (ANOVA) to test for differences in the number of OTUs between treatments.

Non-metric multidimensional scaling (nMDS) plots were performed to visualize multivariate patterns in microbial community structure. An ordination plot based on the Yue and Clayton-based distance matrix (Yue \& Clayton, 2005) was used to represent the variation in the relative abundance of OTUs in each sample, whereas a Jaccard-based distance matrix was used to visualize the ordination plot of presence-absence data using the MотHUR software package.

Differences between treatments in genetic differentiation (analysis of molecular variance: AMOvA) were determined using the MOTHUR software package v.1.30.1 (Schloss et al., 2009). A SIMPER analysis was then performed to identify the most discriminatory OTUs responsible for differences between treatments. SIMPER analyses were conducted within PRIMER v6 (Clarke \& Gorley, 2006; Anderson et al., 2008).

\section{Sponge growth}

To calculate the area of each sponge, we used the software CPCE v3.5 (Coral Point Count with Excel extensions) (Kohler \& Gill, 2006), where each photograph was first scaled using the calibration tool to the length of the plate $(15 \mathrm{~cm})$. The surface of each sponge was then traced as closely as possible to give the calculated projected area in $\mathrm{cm}^{2}$.

The two-dimensional growth of each sponge was calculated following the procedure described by Knott et al. (2006), where growth equals the area covered by the sponge at the end of the experiment $\left(\mathrm{T}_{1}\right)$ minus the area it covered at the beginning of the experiment $\left(\mathrm{T}_{0}\right)$, divided by its area at the beginning of the experiment and multiplied by 100 to get a percentage ( $\left(\right.$ Area $T_{1}-$ Area $T_{0} /$ Area $\left.\left.\mathrm{T}_{0}\right) \times 100\right)$. Differences in the two-dimensional growth of explants were tested by using one-way ANOVA.

\section{Results}

\section{Sponge growth}

All sponges survived transplanting and remained healthy for the duration of the experiment. No signs of necrosis were recorded at the end of the experiment. Some morphological changes were observed in E. alata individuals transplanted from low- to high-light habitats: some specimens (c. $50 \%$ of explants) exhibited discoloration in certain areas of the body, while all transplanted specimens presented a smoother surface than observed at the start of the experiment (Fig. 1). No discoloration was observed in specimens transplanted from high- to low-light habitats. No external visible changes were recorded in T. bergquistae during the experiment.

An increase in size was recorded for most individuals of E. alata. Individuals transplanted from low-light to high-light habitats increased by $8.48 \pm 2.66 \%$, whereas only a small increase of $0.23 \pm 5.17 \%$ was observed in individuals transplanted from high-light to low-light habitats. However, this difference in growth was not statistically significant $\left(F_{1,8}=1.808, P=0.344\right)$. Individuals of T. bergquistae responded positively to transplantation in both treatments, increasing their size by approximately one-third $(33.3 \pm 11.1$ and $37.1 \pm 9.2$ for sponges transplanted from high- to low- and from low-light habitat to high-light habitat, respectively) with no differences between treatments $\left(F_{1,7}=2.104, P=0.206\right)$ (Fig. 1 ).

\section{Effect of experimental treatment on bacterial community structure}

A total of 133121 sequences was recovered after noise reduction and quality filtering, with a mean of 4034 ( $\pm 1013,1 \mathrm{SD})$ sequences per sample. The mean number of 97\%-OTUs per sample ranged from 141 to 169 (mean $157.35 \pm 8.05$ ) in E. alata (Table 1), with no obvious relationship between OTU richness and treatment $\left(F_{3,16}=1.039, P=0.428\right)$. The number of OTUs recovered from $T$. bergquistae samples varied between treatments $\left(F_{3,15}=4.106, P=0.032\right)$, being slightly higher in transplanted individuals (Table 1 ). The number of OTUs was considerably lower than for E. alata, ranging from 17 to 55 (mean $31.63 \pm 11.71$ ) (Table 1). Rarefaction curves based on these $97 \%$-OTU data indicate that coverage of OTU richness was high for all sampled sponges, with most curves starting to approach asymptotes (Fig. 2). Richness estimates based on the Chaol statistic are reported in Table 1.

In total, 738 unique OTUs (based on 97\% sequence identity) were identified across the 33 sponge samples analyzed in this study. These OTUs could be taxonomically assigned to 17 bacterial phyla in E. alata and 18 in $T$. bergquistae. The number of sequence reads per phylum was normalized and expressed as a percentage of the total for each sample (Fig. 3). At phylum level, bacterial community structure varied relatively little, either within (3-5 individuals sampled) or between experimental treatments. 

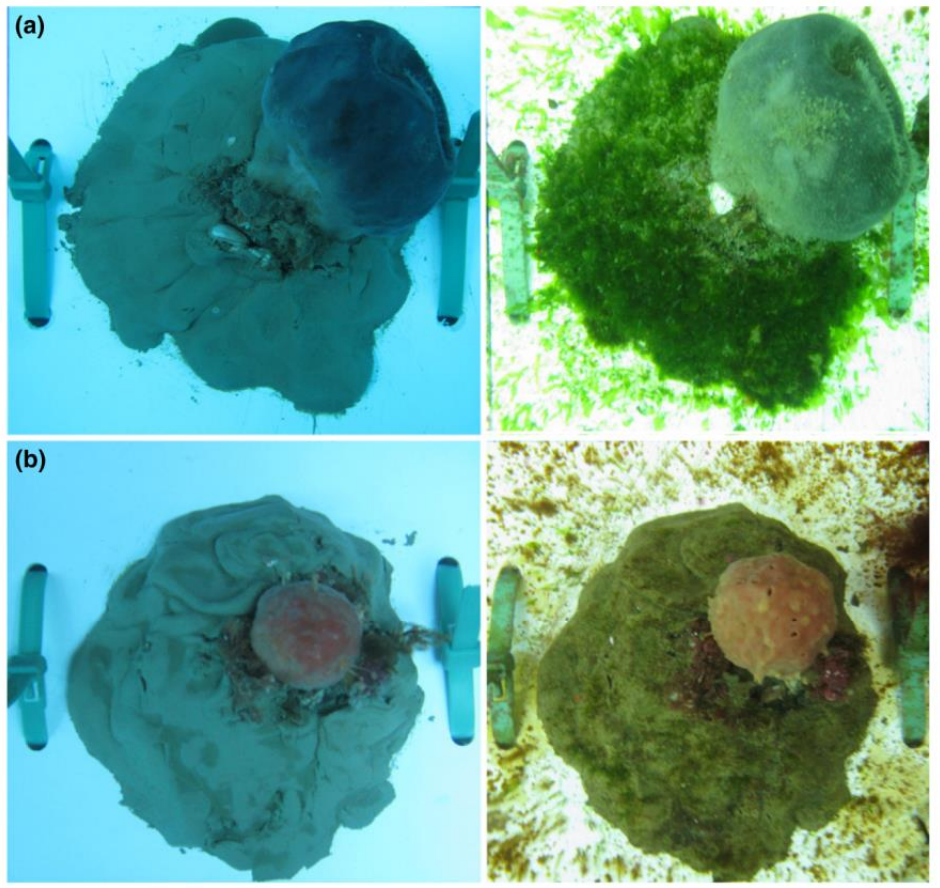

Fig. 1. (a) Ecionemia alata and (b) Tethya bergquistae explants at the beginning (left) and end (right) of the experiment after 6 weeks. In both cases, photographs correspond to explants transplanted from lowto high-light habitats.

Table 1. Bacterial diversity (Sobs) and Chao1 estimates based on 16S rRNA gene pyrosequencing derived from Ecionemia alata and Tethya bergquistae samples

\begin{tabular}{|c|c|c|c|c|c|c|c|}
\hline & $\begin{array}{l}\text { Number of } \\
\text { samples }\end{array}$ & $\begin{array}{l}\text { Mean number } \\
\text { of sequences }\end{array}$ & SD & Sobs & SD & Chao1 & SD \\
\hline \multicolumn{8}{|l|}{ E. alata } \\
\hline $\mathrm{ECL}$ & 4 & 3147.75 & 783.66 & 151.75 & 8.77 & 182.80 & 15.42 \\
\hline ETHL & 4 & 3085.25 & 721.77 & 161.25 & 8.43 & 190.23 & 15.41 \\
\hline ETLH & 5 & 3558.20 & 765.77 & 157.80 & 9.33 & 187.51 & 6.31 \\
\hline $\mathrm{TCL}$ & 4 & 2530.50 & 529.89 & 23.25 & 2.22 & 44.06 & 23.83 \\
\hline TTHL & 5 & 3204.80 & 481.24 & 37.60 & 12.72 & 59.98 & 33.10 \\
\hline TTLH & 3 & 2586.00 & 606.97 & 42.67 & 10.79 & 62.76 & 22.53 \\
\hline
\end{tabular}

$\mathrm{ECH}$, E. alata control high-light; ECL, E. alata control low-light; ETHL, E. alata samples transplanted from high- to low-light; ETLH, E. alata samples transplanted from low- to high-light; TCH, T. bergquistae control high-light; TCL, T. bergquistae control low-light; TTHL, T. bergquistae samples transplanted from high-to low-light; TTLH, T. bergquistae samples transplanted from low- to high-light.

The two sponge species exhibited markedly different bacterial communities (Fig. 3). The community of T. bergquistae was dominated by members of the Proteobacteria (especially Alpha, Beta and Gamma classes), with this phylum comprising $90-97 \%$ of sequences in a given sample. Transplantation of $T$. bergquistae individuals from a high- to low-light habitat was accompanied by a shift in the relative abundances of Beta- and Gammaproteobacteria, but no other changes were particularly evident at phylum level. The only notably abundant phylum outside of the Proteobacteria was Bacteroidetes, which represented $2-9 \%$ of sequences. By contrast, the bacterial community of $E$. alata was much more evenly spread, with Chloroflexi (19-28\%), Actinobacteria (5-15\%), Acidobacteria (6$11 \%)$, Poribacteria (6-17\%), Gemmatimonadetes (3-9\%), sponge-associated unidentified lineage (SAUL) (3-6\%), Deltaproteobacteria (3-8\%) and Alphaproteobacteria (3$7 \%)$ all contributing substantial numbers of sequences. Transplantation appeared to have negligible effects on phylum-level community composition (Fig. 3). 

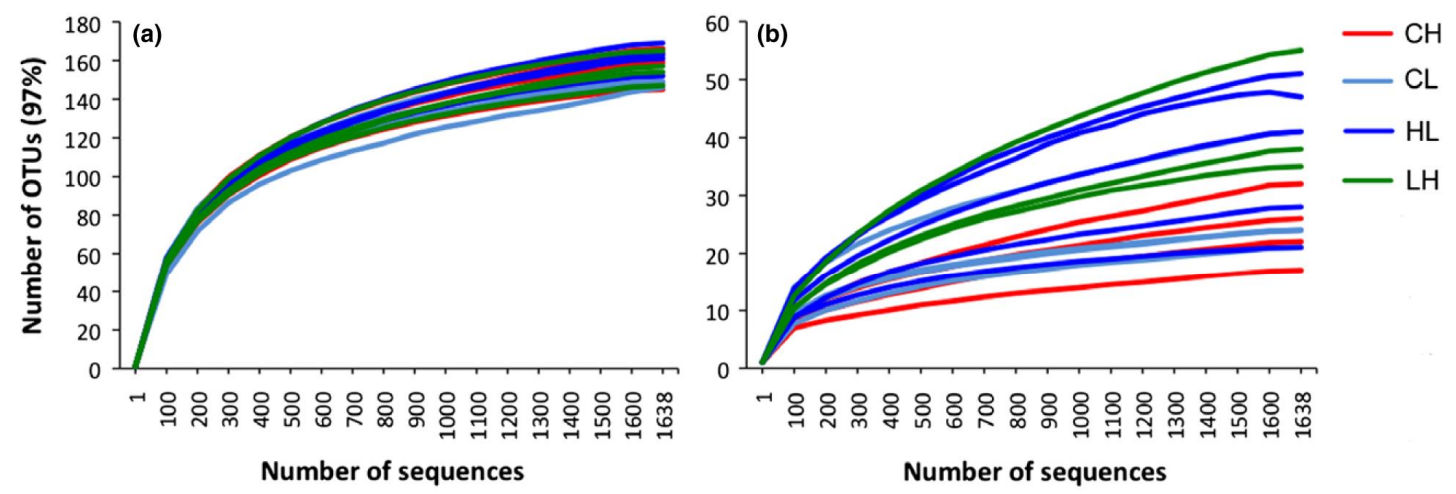

Fig. 2. Bacterial diversity observed in (a) Ecionemia alata and (b) Tethya bergquistae samples, when transplanted between different habitats. $\mathrm{CH}$, control high-light; $\mathrm{CL}$, control low-light; HL, high- to low-light transplantation; LH, low- to high-light transplantation. Note: scale for $y$-axis differs between panels.

Examination of the sequence data at a finer (97\%OTU) taxonomic level revealed similar trends. As expected based on the phylum data above, sequences recovered from E. alata were spread across a larger number of abundant OTUs (Fig. 4). The most abundant in E. alata was a Poribacteria OTU (OTU003) which represented $2-7 \%$ of sequence reads per sample, while abundant OTUs from the Actinobacteria, Chloroflexi, Nitrospira, Acidobacteria, Alpha- and Deltaproteobacteria, SAUL and Gemmatimonadetes were also present. Similar to the phylum-level data, OTU abundance could not be closely linked to experimental treatment for either sponge species, as also seen on non-metric multidimensional scaling plots (Fig. 5). One Betaproteobacteria OTU (OTU001) and one Gammaproteobacteria OTU (OTU002) dominated the bacterial community in T. bergquistae, comprising $19-62 \%$ and $18-56 \%$, respectively, of total bacterial sequence reads within a given sample (Fig. 4). One further Gammaproteobacteria OTU, along with a single Alphaproteobacteria OTU and a Bacteroidetes-affiliated OTU, together comprised the vast majority of remaining sequences. Furthermore, in most cases, AMOVA results revealed no significant differences between treatments in E. alata (Supporting Information, Tables S1). In contrast, bacterial communities in $T$. bergquistae showed significant differences between treatments (amova $P<0.05$ ). Pairwise comparisons showed that the $T$. bergquistae samples transplanted from high- to low-light (TTHL) treatment (sponges shifted from high- to low-light habitat) differed significantly from other treatments (Table S1). This significant difference was driven by a switch in relative abundance from the betaproteobacterial OTU001 to the gammaproteobacterial OTU002 (Table S2). According to SIMPER, these two OTUs accounted for more than $70 \%$ of the cumulative difference between treatments, although the proportional abundance of OTU002 never dropped below $19 \%$ in any of the TTHL samples.

\section{Discussion}

The potential for sponge-associated symbionts to enable their host to adapt to changes in environmental conditions has become an important topic of research (Hentschel et al., 2012). Given the well-documented associations of marine sponges with a variety of microbial symbionts, we set out to test the stability of microbial communities when exposed to different environmental conditions occurring on different habitats. Any resulting impact on the sponge microbiome could conceivably influence the distribution and abundance of sponges. Here, we combined experimental marine ecology approaches with next-generation sequencing of spongeassociated bacteria to investigate the effect of environmental variation on the microbiota of two New Zealand sponges, E. alata and T. bergquistae.

Variation in environmental factors can have critical effects at the population level by affecting sponge abundance and distribution, and also at the individual level by affecting growth, morphology and reproductive traits of sponges (Sarà, 1992; Kaandorp, 1999; Bell \& Barnes, 2000; Bell, 2004; Cárdenas et al., 2012). Sponges occurring in low-light habitats such as on vertical walls, and under overhangs or boulders, are exposed to different conditions than those in high-light habitats (e.g., flat reefs with an abundance of fast-growing algae). Both habitat types exhibit strong differences in physical factors, especially light, as well as in their sediment regimes (Abdo et al., 2006), nutrient levels, and competitive pressures (Uriz et al., 1995). It has been proposed that local environmental conditions, along with other factors, can alter 


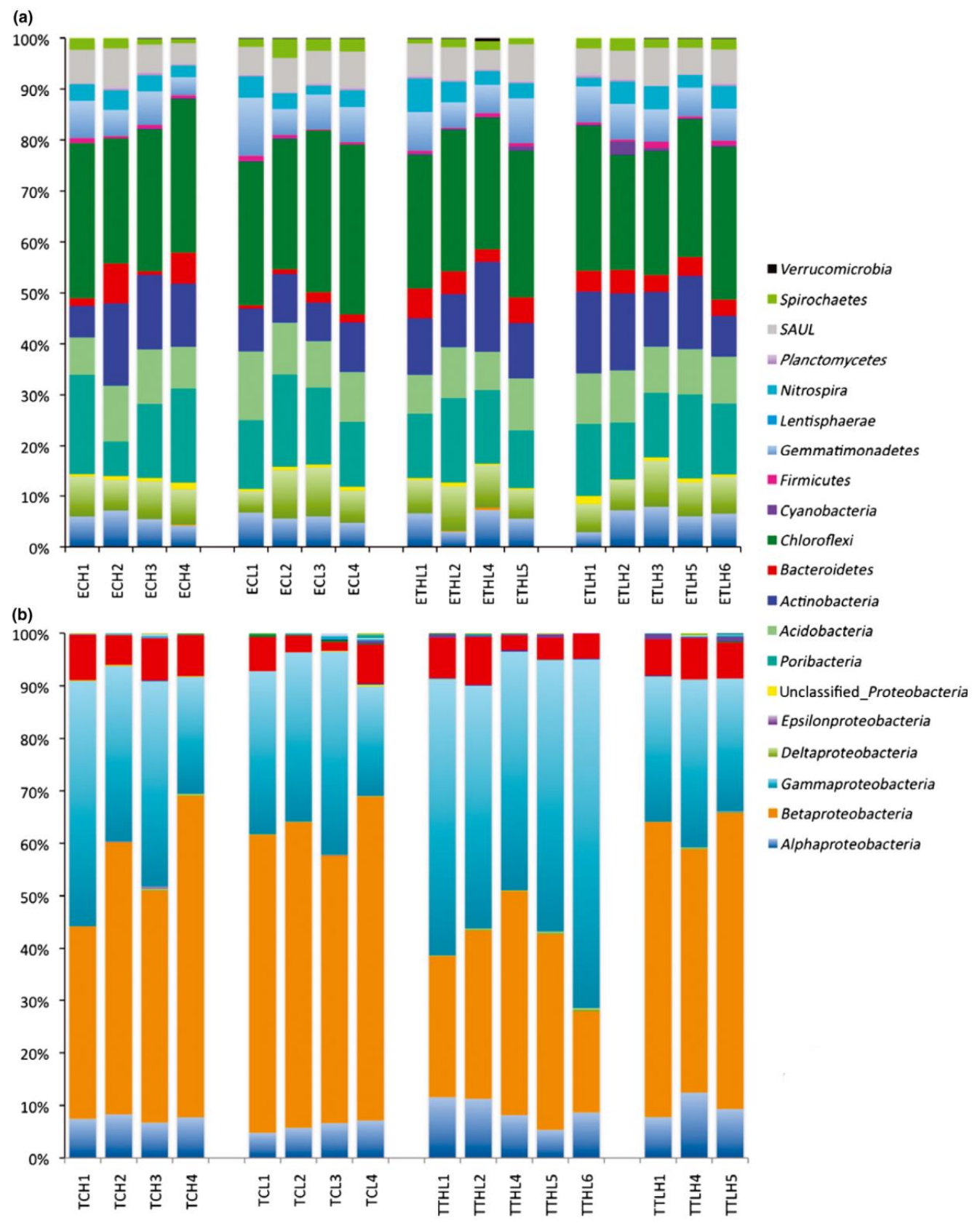

Fig. 3. Relative abundance of bacterial phyla in (a) Ecionemia alata and (b) Tethya bergquistae samples, when transplanted between different habitats. ECH, E. alata control high-light; ECL, E. alata control low-light; ETHL, E. alata samples transplanted from high- to low-light; ETLH, E. alata samples transplanted from low- to high-light; TCH, T. bergquistae control high-light; $\mathrm{CL}, \mathrm{T}$. bergquistae control low-light; TTHL, T. bergquistae samples transplanted from high- to low-light; TTLH, T. bergquistae samples transplanted from low- to high-light.. Number (1-6) in sample code refers to replicate number of samples recovered at the end of the experiment. 


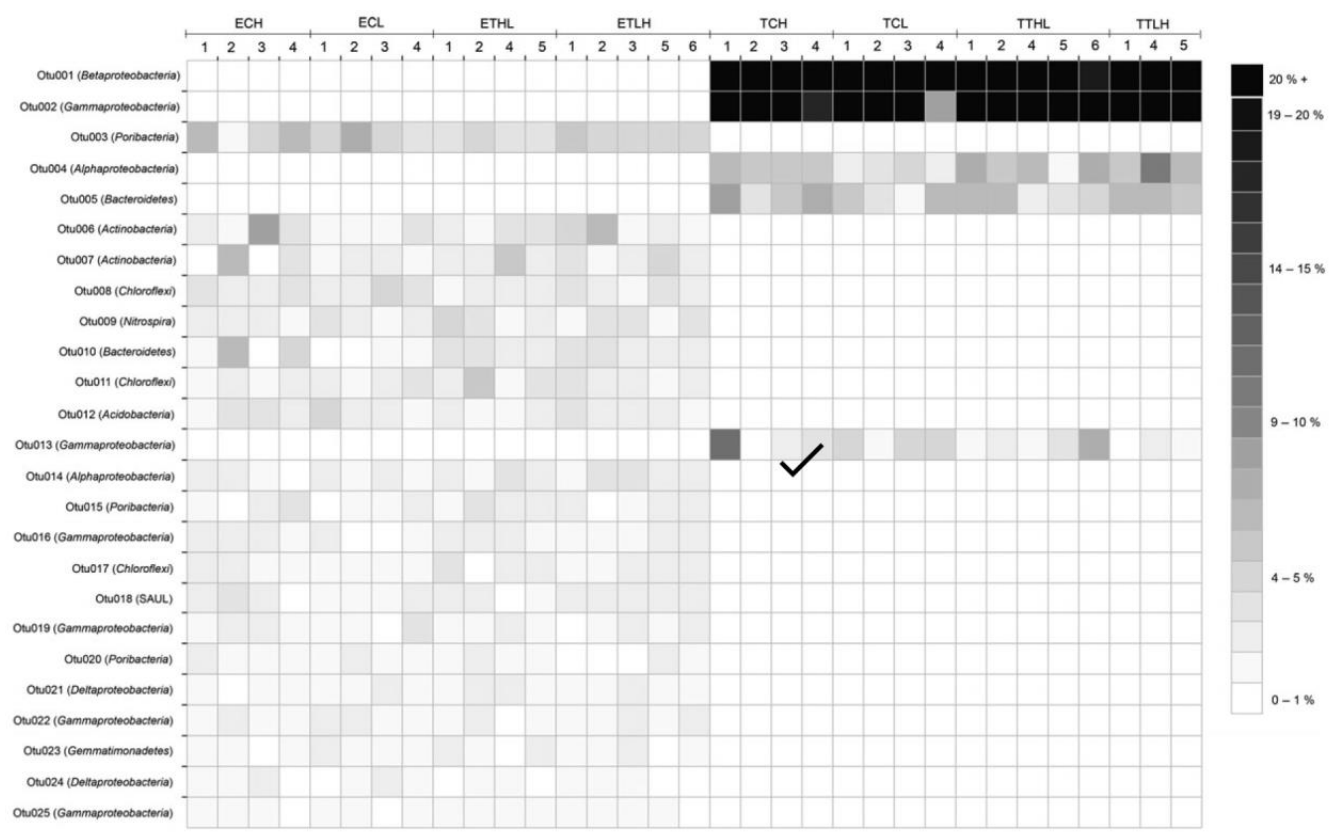

Fig. 4. Heat map representing the abundance of the 25 most abundant OTUs in Ecionemia alata and Tethya bergquistae, when transplanted between different habitats. Values represent the percentage of all sequence reads for a given sample. See Fig. 3 for abbreviations.
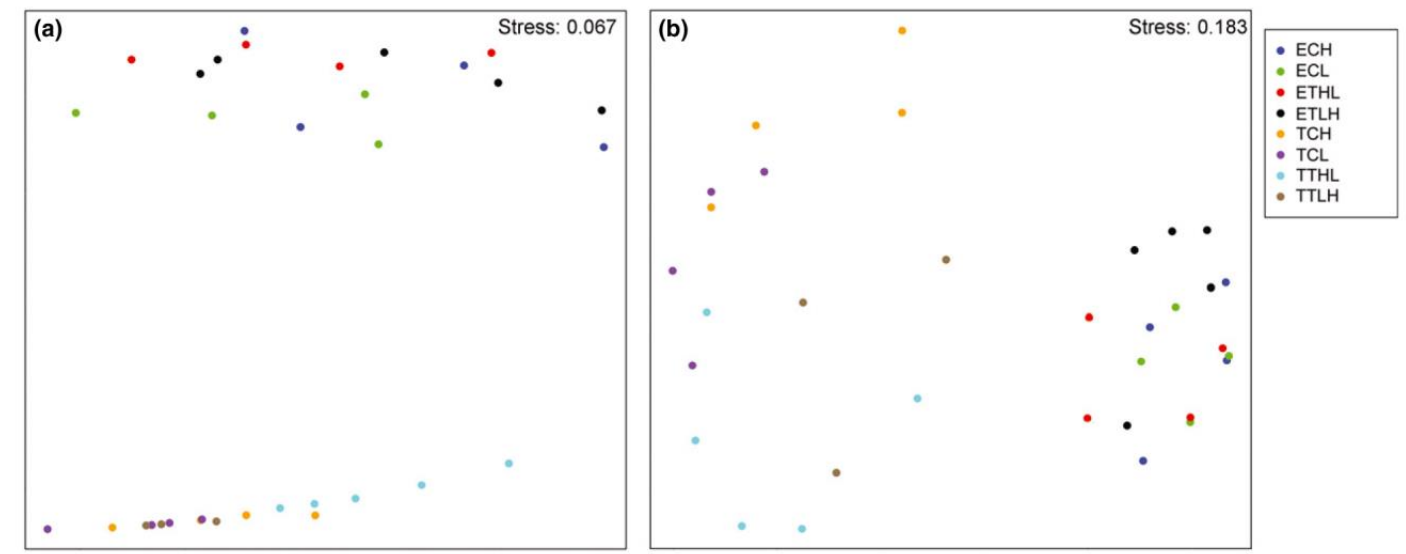

Fig. 5. nMDS to examine differences in bacterial community structure between species and experimental treatments. (a) Relative abundance of OTUs based on Yue and Clayton distance matrix and (b) presence-absence data based on a Jaccard-based distance matrix. Rsq(a) $=0.985$, $R_{s q}(b)=0.829$. See Fig. 3 for abbreviations.

the interactions and balance between symbionts (Thacker \& Freeman, 2012); however, the impact of changes in environmental conditions on sponge-associated microbes in temperate latitudes remains poorly understood.

Individuals of both species responded well to manipulation, with no signs of necrosis or reduced growth. The morphological changes observed in some individuals of E. alata confirm the capacity of some sponges to acclimate morphologically when exposed to different habitats (e.g., Meroz-Fine et al., 2005). However, in spite of the increased growth and morphological changes observed in transplanted sponges, overall, transplantation to different 
habitats had little effect on sponge-associated bacterial communities. This was evident at both broad (phylum) and fine-scale (97\%-OTU) taxonomic levels. This situation is in accordance with previous studies in other sponges that have reported the absence of changes in microbial communities despite the occurrence of morphological changes (e.g., biomass loss, discoloration, tissue degradation) (Thoms et al., 2003; Klöppel et al., 2008; but see Thoms et al., 2008; Gerçe et al., 2009). It has been suggested that different sponge species exhibit different degrees of stability in their microbiome depending on environmental factors (Olson \& Gao, 2013). For example, Thoms et al. (2008) found that individuals of Aplysinella sp. exhibited significant variation in the composition and diversity of microbes in sponges exposed to stressful conditions in the laboratory and in the field. Temporal variations were also seen in the bacterial community of the New Zealand sponge Mycale hentscheli (Anderson et al., 2010), while recent pyrosequencing studies found shifts in the composition of bacterial communities (Erwin et al., 2012b; White et al., 2012). However, these studies also revealed the presence of relatively stable 'core' bacterial communities, with changes only occurring in rare taxa. Our results support the notion of highly stable sponge-associated bacterial communities, as no major shifts were found in the microbial communities associated with either species. Although a statistically significant change in the bacterial community was found in individuals of $T$. bergquistae transplanted from high- to low-light habitats, the observed differences were mainly driven by changes in the relative abundance of the two most dominant OTUs, with no pronounced change in the abundance of other taxa. Of the two dominant OTUs, one (OTU001) belongs to a clade of Betaproteobacteria that is commonly found in sponges, but for which no phenotypic information is available due to a lack of cultivated representatives or metagenomic data. We can thus only speculate as to why this bacterium could be affected by changing light or other environmental conditions. The second OTU, OTU002, is a gammaproteobacterium that is loosely affiliated with the Chromatiales, members of which are photosynthetic. The short pyrosequencing reads (which preclude detailed phylogenetic analyses) and lack of available functional data mean that the precise affiliation of this organism is also unclear. A shotgun metagenome, or single-cell genome, approach would yield valuable insights into both the phylogeny and functional potential of the two major OTUs, but is beyond the scope of this study.

Although some previous experimental work has suggested that environmental stress (e.g., temperature) may induce a change in sponge-feeding behavior to favor uptake of phototrophic bacteria (Massaro et al., 2012;
Simister et al., 2012a), our experimental transplantation did not induce a similar response. Despite the appearance of 'new' cyanobacterial OTUs in some of the transplanted individuals, there was no evidence of a significant increase, which is consistent with other studies involving in situ transplantation experiments to more light-exposed habitats (Vacelet, 1959; Thoms et al., 2003). Thoms et al. (2003) explained the absence of an exchange of cyanobacteria in sponges transplanted to more light-exposed habitats as being due to the existence of physical barriers or chemical defenses. However, the mechanism(s) involved remain to be tested in future experiments.

Despite a few contrasting results, generally sponge-associated bacterial communities appear to be highly stable compared with more sensitive bacterial communities occurring in other environments (e.g., soil, lakes), where changes in environmental conditions tend to produce shifts in community composition (Eiler et al., 2003; Beisner et al., 2006) and hence have the potential to affect ecosystem processes (Allison \& Martiny, 2008). Changes in environmental conditions did not affect the stability of the highly stable 'core' bacterial communities existing in E. alata and T. bergquistae. This 'core' fraction of the community may be essential for maintaining the health of the sponge, playing important symbiotic roles that remain incompletely understood.

There were marked differences between the microbial communities of E. alata and T. bergquistae. This was expected based on a previous analysis of the active bacterial community (assessed by examining the ribosomal RNA itself) in E. alata (previously named A. alata) and $T$. stolonifera, both collected from northeastern New Zealand, some $550 \mathrm{~km}$ away from the collection site in this study (Simister et al., 2013). In that earlier study, a single betaproteobacterium comprised $>50 \%$ of the $16 \mathrm{~S}$ rRNA sequence reads from $T$. stolonifera, while a related betaproteobacterial OTU constituted 19-62\% of DNA-based $T$. bergquistae reads in the current study. Interestingly, a second proteobacterial OTU (OTU002, affiliated with Gammaproteobacteria) was also highly abundant according to our DNA sequencing data. The occurrence of one (or in this case two) dominant Proteobacteria phylotype has been widely reported for 'low-microbial-abundance' (LMA) sponges (Sipkema et al., 2009; Kamke et al., 2010; Erwin et al., 2012a; Luter et al., 2012; Giles et al., 2013; Simister et al., 2013) and is in stark contrast to the much more even distribution of OTUs in 'high-microbial-abundance' (HMA) sponges such as E. alata. Even the most abundant OTU recovered from E. alata (Poribacteria OTU003) only comprised 7\% or less of sequence reads from a given sample. In the RNA-based paper by Simister et al. (2013), the 10 most abundant OTUs (including the Poribacteria OTU which dominated in the current study) 
represented on average only $35 \%$ of total sequences per sample.

In conclusion, our results demonstrate the stability of bacterial communities in two temperate sponges exposed to environmental variation, which is consistent with previous research on other temperate sponges. The next-generation sequencing approach employed here shows how different components of bacterial communities associated with $E$. alata and T. bergquistae respond to environmental variation in situ. The similarity observed in bacterial communities among specimens occupying different habitats suggests that environmental variation occurring in those habitats does not affect the stability of the community, and hence, most likely does not radically alter the metabolism of these sponges. Although environmental factors such as light and sediment may have an effect on early sponge stages (Maldonado, 2006), other environmental (e.g., nutrients, temperature, wave action) and biotic factors, such as competition with macroalgae (Cárdenas et al., 2012), are more likely to influence the growth, survival and distribution of sponges on temperate rocky reefs. Further studies are necessary to improve our understanding of how microbial symbiont communities may affect the physiology and ecology of sponges on temperate rocky reefs. More data are needed to improve our knowledge about physiological traits and responses of bacterial communities, and also resilience in sponge-associated bacteria that seem to be more sensitive to environmental variation.

\section{Acknowledgements}

The authors thank S.W. Geange and all the divers and skippers at the Victoria University Coastal Ecology Laboratory (VUCEL) for help and support during diving activities. We also thank D. Waite for his helpful advice on bioinformatics. This project was supported by a Tertiary Education Council (TEC) and a VUW Faculty Research Grant (202305). The Department of Conservation is also acknowledged for permitting this experimental research within the Taputeranga Marine Reserve (permit DocDM-816684). C.A.C. was funded by a CONICYT-VUW PhD Scholarship.

\section{References}

Abdo DA, Battershill CN \& Harvey ES (2006) Manipulation of environmental variables and the effect on the growth of Haliclona sp.: implications for open-water aquaculture. Mar Biol Res 2: 326-332.

Allison SD \& Martiny JBH (2008) Resistance, resilience, and redundancy in microbial communities. P Natl Acad Sci USA 105: $11512-11519$.
Altschul SF, Gish W, Miller W, Myers EW \& Lipman DJ (1990) Basic local alignment search tool. J Mol Biol 215: 403-410.

Anderson MJ, Gorley RN \& Clarke KR (2008) PERMANOVA for Primer: Guide to Software and Statistical Methods. PRIMERE, Plymouth.

Anderson SA, Northcote PT \& Page MJ (2010) Spatial and temporal variability of the bacterial community in different chemotypes of the New Zealand marine sponge Mycale hentscheli. FEMS Microbiol Ecol 72: 328-342.

Battershill CN, Bergquist PR \& Cook SdC (2010) Porifera. New Zealand Coastal Marine Invertebrates, (Cook SdC, Ed), pp. 58-135. Canterbury University Press, Christchurch.

Beisner BE, Peres-Neto PR, Lindström ES \& Longhi ML (2006) The role of environmental and spatial processes in structuring lake communities from bacteria to fish. Ecology 87: 2985-2991.

Bell JJ (2004) Evidence for morphology-induced sediment settlement prevention on the tubular sponge Haliclona urceolus. Mar Biol 146: 29-38.

Bell JJ (2008) The functional roles of marine sponges. Estuar Coast Shelf Sci 79: 341-353.

Bell JJ \& Barnes DKA (2000) The influences of bathymetry and flow regime upon the morphology of sublittoral sponge communities. J Mar Biol Assoc UK 80: 707-718.

Berman J (2012) Patterns of temporal and spatial variability of sponge assemblages. $\mathrm{PhD}$ Thesis, Victoria University of Wellington, Wellington, New Zealand.

Berman J \& Bell JJ (2010) Spatial variability of sponge assemblages on the Wellington South Coast, New Zealand. Open Mar Biol J 4: 12-25.

Cárdenas CA, Davy SK \& Bell JJ (2012) Correlations between algal abundance, environmental variables and sponge distribution patterns on southern hemisphere temperate rocky reefs. Aquat Biol 16: 229-239.

Clarke KR \& Gorley RN (2006) Primer v6: User Manual/ Tutorial. PRIMER-E, Plymouth.

Cleary DFR, Becking LE, de Voogd NJ, Pires ACC, Polónia ARM, Egas C \& Gomes NCM (2013) Habitat-and host-related variation in sponge bacterial symbiont communities in Indonesian waters. FEMS Microbiol Ecol 85: 465-482.

Edgar RC, Haas BJ, Clemente JC, Quince C \& Knight R (2011) UCHIME improves sensitivity and speed of chimera detection. Bioinformatics 27: 2194-2200.

Eiler A, Langenheder S, Bertilsson S \& Tranvik LJ (2003) Heterotrophic bacterial growth efficiency and community structure at different natural organic carbon concentrations. Appl Environ Microbiol 69: 3701-3709.

Erwin PM, Olson JB \& Thacker RW (2012a) Phylogenetic diversity, host-specificity and community profiling of sponge-associated bacteria in the Northern Gulf of Mexico. PLoS One 6: e26806.

Erwin PM, Pita L, López-Legentil S \& Turon X (2012b) Stability of sponge-associated bacteria over large seasonal 
shifts in temperature and irradiance. Appl Environ Microbiol 78: 7358-7368.

Friedrich AB, Fischer I, Proksch P, Hacker J \& Hentschel U (2001) Temporal variation of the microbial community associated with the mediterranean sponge Aplysina aerophoba. FEMS Microbiol Ecol 38: 105-113.

Gerçe B, Schwartz T, Voigt M et al. (2009) Morphological, bacterial, and secondary metabolite changes of Aplysina aerophoba upon long-term maintenance under artificial conditions. Microb Ecol 58: 865-878.

Giles EC, Kamke J, Moitinho-Silva L, Taylor MW, Hentschel U, Ravasi T \& Schmitt S (2013) Bacterial community profiles in low microbial abundance sponges. FEMS Microbiol Ecol 83: 232-241.

Gochfeld DJ, Easson CG, Freeman CJ, Thacker RW \& Olso JB (2012) Disease and nutrient enrichment as potential stressors on the Caribbean sponge Aplysina cauliformis and its bacterial symbionts. Mar Ecol Prog Ser 456: 101-111.

Hentschel U, Piel J, Degnan SM \& Taylor MW (2012) Genomic insights into the marine sponge microbiome. Nat Rev Microbiol 10: 641-654.

Joachimiak MP, Weisman JL \& May BCH (2006) COLORGRID: Software for the visualization of biological measurements. BMC Bioinformatics 7: 225.

Kaandorp JA (1999) Morphological analysis of growth forms of branching marine sessile organisms along environmental gradients. Mar Biol 134: 295-306.

Kamke J, Taylor MW \& Schmitt S (2010) Activity profiles for marine sponge-associated bacteria obtained by $16 \mathrm{~S}$ rRNA vs 16S rRNA gene comparisons. ISME J 4: 498-508.

Klöppel A, Pfannkuchen M, Putz A, Proksch P \& Brümmer F (2008) Ex situ cultivation of Aplysina aerophoba close to in situ conditions: ecological, biochemical and histological aspects. Mar Ecol 2: 259-272.

Knott NA, Underwood AJ, Chapman MG \& Glasby TM (2006) Growth of the encrusting sponge Tedania anhelans (Lieberkuhn) on vertical and on horizontal surfaces of temperate subtidal reefs. Mar Freshw Res 57: 95-104.

Kohler KE \& Gill SM (2006) Coral Point Count with Excel extensions (CPCe): a Visual Basic program for the determination of coral and substrate coverage using random point count methodology. Comput Geosci 32: 1259-1269.

Lemoine N, Buell N, Hill A \& Hill M (2007) Assessing the utility of sponge microbial symbiont communities as models to study global climate change: a case study with Halichondria bowerbanki. Porifera Research: Biodiversity, Innovation and Sustainability, (Custodio MR, Lobo-Hajdu G, Hajdu E \& Muricy G, eds), pp. 419-425. Museu Nacional, Rio de Janeiro, Brazil.

Luter HM, Whalan S \& Webster NS (2012) The marine sponge Ianthella basta can recover from stress-induced tissue regression. Hydrobiologia 687: 227-235.

Maldonado M (2006) The ecology of the sponge larva. Can J Zool 84: 175-194.

Massaro AJ, Weisz JB, Hill MS \& Webster NS (2012) Behavioral and morphological changes caused by thermal stress in the Great Barrier Reef sponge Rhopaloeides odorabile. J Exp Mar Biol Ecol 416-417: 55-60.

Meroz-Fine E, Shefer S \& Ilan M (2005) Changes in morphology and physiology of an East Mediterranean sponge in different habitats. Mar Biol 147: 243-250.

Miller RJ \& Etter RJ (2011) Rock walls: small-scale diversity hotspots in the subtidal Gulf of Maine. Mar Ecol Prog Ser 425: 153-165.

Mohamed NM, Enticknap JJ, Lohr JE, McIntosh SM \& Hill RT (2008) Changes in bacterial communities of the marine sponge Mycale laxissima on transfer into aquaculture. Appl Environ Microbiol 74: 1209-1222.

Morelissen B, Dudley BD, Geange SW \& Phillips NE (2013) Gametophyte reproduction and development of Undaria pinnatifida under varied nutrient and irradiance conditions. J Exp Mar Biol Ecol 448: 197-206.

Morrow KM, Liles MR, Paul VJ, Moss AG \& Chadwick NE (2013) Bacterial shifts associated with coral-macroalgal competition in the Caribbean Sea. Mar Ecol Prog Ser 488: 103-117.

Nogales B, Lanfranconi MP, Piña-Villalonga JM \& Bosch R (2011) Anthropogenic perturbations in marine microbial communities. FEMS Microbiol Ecol 35: 275-298.

Olson JB \& Gao X (2013) Characterizing the bacterial associates of three Caribbean sponges along a gradient from shallow to mesophotic depths. FEMS Microbiol Ecol 85: 74-84.

Pita L, Turon X, Lopez-Legentil S \& Erwin PM (2013) Host rules: spatial stability of bacterial communities associated with marine sponges (Ircinia spp.) in the Western Mediterranean Sea. FEMS Microbiol Ecol 86: 268-276.

Preciado I \& Maldonado M (2005) Reassessing the spatial relationship between sponges and macroalgae in sublittoral rocky bottoms: a descriptive approach. Helgol Mar Res 59: 141-150.

Quince C, Lanzen A, Davenport RJ \& Turnbaugh PJ (2011) Removing noise from pyrosequenced amplicons. $B M C$ Bioinformatics 12: 38 .

Sarà M (1992) Porifera. Reproductive Biology of Invertebrates, Vol. V (Adiyodi KG \& Adiyodi RG, eds), pp. 1-29. WileyInterscience, Chichester.

Schloss PD, Westcott SL, Ryabin T et al. (2009) Introducing MOTHUR: open-source, platform-independent, communitysupported software for describing and comparing microbial communities. Appl Environ Microbiol 75: 7537-7541.

Schmitt S, Tsai P, Bell J et al. (2012) Assessing the complex sponge microbiota: core, variable and species-specific bacterial communities in marine sponges. ISME J 6: 564-576.

Simister R, Taylor MW, Tsai P, Fan L, Bruxner TJ, Crowe ML \& Webster N (2012a) Thermal stress responses in the bacterial biosphere of the Great Barrier Reef sponge, Rhopaloeides odorabile. Environ Microbiol 14: 3232-3246.

Simister RL, Deines P, Botté ES, Webster NS \& Taylor MW (2012b) Sponge-specific clusters revisited: a comprehensive phylogeny of sponge-associated microorganisms. Environ Microbiol 14: 517-524. 
Simister R, Taylor MW, Rogers KM, Schupp PJ \& Deines P (2013) Temporal molecular and isotopic analysis of active bacterial communities in two New Zealand sponges. FEMS Microbiol Ecol 85: 195-205.

Sipkema D, Holmes B, Nichols SA \& Blanch HW (2009) Biological characterisation of Haliclona (?gellius) sp.: sponge and associated microorganisms. Microb Ecol 58: 903-920.

Taylor MW, Schupp PJ, Dahllöf I, Kjelleberg S \& Steinberg PD (2004) Host specificity in marine sponge-associated bacteria, and potential implications for marine microbial diversity. Environ Microbiol 6: 21-130.

Taylor MW, Radax R, Steger D \& Wagner M (2007) Spongeassociated microorganisms: evolution, ecology, and biotechnological potential. Microbiol Mol Biol Rev 71: 295-347.

Thacker RW \& Freeman CJ (2012) Sponge-microbe symbioses: recent advances and new directions. Adv Mar Biol 62: 57-111.

Thoms C, Horn M, Wagner M, Hentschel U \& Proksch P (2003) Monitoring microbial diversity and natural product profiles of the sponge Aplysina cavernicola following transplantation. Mar Biol 142: 685-692.

Thoms C, Hentschel U, Schmitt S \& Schupp PJ (2008) Rapid tissue reduction and recovery in the sponge Aplysinella sp. Mar Biol 156: 141-153.

Uriz MJ, Turon X, Becerro MA, Galera J \& Lozano J (1995) Patterns of resource allocation to somatic, defensive, and reproductive functions in the Mediterranean encrusting sponge Crambe crambe (Demospongiae, Poecilosclerida). Mar Ecol Prog Ser 124: 159-170.

Vacelet J (1959) Repartition generale des eponges et systematique des eponges cornees de la region de Marseille et de quelques stations Mediterraneenes. Recl Trav Stn Mar Endoume Fac Sci Mars 16: 39-109.
Webster NS \& Blackall LL (2009) What do we really know about sponge-microbial symbioses? ISME J 3: 1-3.

Webster N \& Taylor M (2012) Marine sponges and their microbial symbionts: love and other relationships. Environ Microbiol 14: 335-346.

Webster NS, Cobb RE \& Negri AP (2008) Temperature thresholds for bacterial symbiosis with a sponge. ISME $J 2$ : 830-842.

Webster NS, Taylor MW, Behnam F et al. (2010) Deep sequencing reveals exceptional diversity and modes of transmission for bacterial sponge symbionts. Environ Microbiol 12: 2070-2082.

White JR, Patel J, Ottesen A, Arce G, Blackwelder P \& Lopez JV (2012) Pyrosequencing of bacterial symbionts within Axinella corrugata sponges: diversity and seasonal variability. PLoS One 7: e38204.

Yue JC \& Clayton MK (2005) A similarity measure based on species proportions. Commun Stat Theory Methods 34: 2123-2131.

\section{Supporting Information}

Additional Supporting Information may be found in the online version of this article:

Table S1. Pairwise comparisons of analyses of molecular variance (AMOVA) of bacterial communities in Ecionemia alata and Tethya bergquistae samples from different treatments.

Table S2. Relative abundance of each OTU per sample. 